\title{
Bird Diversity, Functions and Services across Indonesian Land-use Systems
}

\author{
Dissertation \\ for the award of the degree \\ "Doctor of Philosophy" \\ of the Georg-August Universität Göttingen, Faculty of Crop Sciences \\ within the International Ph.D. Program for Agricultural Sciences (IPAG)
}

submitted by

MSc. Kevin Felix Arno Darras

born in Ambilly, on the 21. Dezember 1986 
Table of contents

D 7

1. Referent:

Teja Tscharntke

2. Ko-referent:

Yann Clough

Date of oral examination: 4. Mai 2016

Date of thesis submission: 10. März 2016 
Table of contents

Thesis last updated: Wednesday, 18 May 2016

This thesis was printed $100 \%$ on recycling paper

\section{Table of contents}

\section{Abstract}

In tropical regions, rampant land-use conversion for agriculture threatens biodiversity hotspots. Forests are vanishing, and taxonomic diversity is severely affected by the transformation on a large scale. For mitigating the impacts of these land-use changes and reconciling human needs with biological conservation, we require effective and standardized biodiversity monitoring methods. Along with the biodiversity decline, functional diversity is also believed to suffer great losses, affecting ecosystem functions and their resilience. This also poses the question how ecosystem services will be affected.

Focusing on the province of Jambi in Sumatra, Indonesia, I present results from studies on aboveground biodiversity, concentrating on birds. I investigated four different land-use systems: lowland rainforest, jungle rubber, rubber monocultures, and oil palm monocultures. The performance of autonomous acoustic sampling of birds was compared with classical bird point counts using a systematic review and meta-analysis, as well as field data. For the first time, I present methods for measuring the sound detection space: the sampling area of acoustic recorders, an important pre-requisite of any diversity comparison. I then document the changes in diversity of birds associated with the conversion of forests to plantations, and show how bird communities and feeding guilds are affected. The functional dimension of these changes is expanded next, when we analyse the relationship between species richness and functional diversity, and subsequently analyse the change in ecological function of birds, arboreal ants, and leaf-litter invertebrates using single-trait and multi-trait indices. Finally I demonstrate the role of birds and bats, as well as ants, on ecosystem functions and yield in a long-term and large-scale full-factorial exclusion experiment situated in young oil palm plantations.

My results show that autonomous sound recordings systems are at least equal to traditional avian survey methods, generating datasets of indistinguishable completeness. However, acoustic sampling is superior to bird point counts in many other ways, not the least a lack of observer bias and guaranteed verifiability of results. Importantly, I show that the sound detection space of sound 
Abstract

recorders is measurable and has a strong impact on any measure of diversity obtained from acoustic data. Using traditional bird point counts, we also confirm previous research, presenting strong declines in bird diversity and large differences in their communities, which also impact feeding guilds differently in our two study regions. The more general study of bird, ant, and invertebrate function demonstrates that multi-trait indices can mask trends that are better assessed with single-trait indices. Nevertheless, species diversity was strongly correlated with functional diversity and their relationship indicated low functional redundancy, as well as a shift towards lower trophic levels for all taxa and towards more mobile species in birds and ants. Contrary to our expectations, these functional changes did not seem to affect ecosystem functions or oil palm yield in our exclusion experiment: we found that the bird and ant exclusion only affected arthropod predators, but left ecosystem functions and yield untouched.

I recommend promoting the use of autonomous acoustic sampling methods for their many advantages over traditional survey methods based on human observation. These methods still need to be developed and standardized, and I provide first elements of response by deriving sound detection spaces of acoustic recorders. However overall, acoustic sampling bears strong potential and could become a method of choice for assessing multiple animal taxa with one tool. In the discussion I further show that results from acoustic data are equivalent to those obtained from point counts, confirming that the taxonomic biodiversity losses we observed are robust and real. We can assert that land-use conversion detrimentally affects frugivores, possibly also insectivores, and positively affects omnivores. Also, the low functional redundancy we observed across all taxa predicts dire consequences of biodiversity loss for ecosystem functioning and resilience. Although we could not demonstrate a positive role of birds and ants on oil palm, we believe the observed trends to be specific to the region, which still experiences very low pest damage. However, we need to link animals to their function more directly with individual-based dietary data, and straightforward measurements of birds' ecosystem functions. We also call for examining animal movement more thoroughly to reveal the true picture of the functional transformation associated with land-use change. 
Introduction

\section{Introduction}

\section{General context}

Never before has Mankind exerted such pressure on the Earth's natural environments. We rely greatly on natural ecosystems for our own survival (Daily 1997) but environmental degradation is at an all-time high (Vitousek et al. 1997), and efforts to counter-act that development are so far ineffective (Butchart et al. 2010). Although our motivation to preserve biodiversity might stem from our own survival instinct, nature also has a value of its own and it is our obligation to protect it.

Biodiversity loss and environmental degradation must be comprehended as a first step before any action is taken. As ecologists we must use efficient means to recognise and study the mechanisms underlying what is more objectively called a transformation process. We must deliver sound science to guide decision-makers for mitigating the impact of human activities on the natural environment, while upholding or enhancing the services that it provides.

At present, tropical ecosystems are both the most threatened and the most species-rich (Myers et al. 2000). Threats comprise land-use and climate change, invasive species, pollution, and hunting among others. Meanwhile, focusing on terrestrial systems, agricultural expansion, along with goods collection, have the largest impact on terrestrial wildlife (The IUCN Species Survival Commission 2004; Geist and Lambin 2002).

\section{Biodiversity, ecosystem functions and services associated with aboveground biodiversity}

I focus on Southeast Asia, which as a whole constitutes a biodiversity hotspot (Myers et al. 2000) for its high biodiversity and endemism levels, as well as the alarming rate of conversion of forest to agricultural systems (Sodhi et al. 2004). Recently, oil palm (Elaeis guineensis) expansion has been identified as the greatest threat to biodiversity in Southeast Asia (Wilcove and Koh 2010). Biodiversity changes after forest conversion to oil palm plantations have already been reviewed, showing radically reduced biodiversity across several taxa (E.B. Fitzherbert et al. 2008) as well as drastic composition changes, although changes in abundance are more taxon-specific (Savilaakso et al. 2014, Foster et al. 2011, see Fig. 1). Another important cash crop of Southeast Asia is rubber (Hevea brasiliensis). The three main producers of rubber - Thailand, Indonesia, and Malaysia - are in Southeast Asia and provide two thirds of the globally produced natural rubber with strongly increasing shares (Food and Agriculture Organization 2013). In contrast, rubber plantations have not been reviewed yet, but several studies show strong reductions in richness and changes in composition of aboveground biodiversity in bats (Phommexay et al. 2011) and plants (Beukema et al. 
Introduction

2007), while most literature focuses on birds (Li et al. 2013, Thiollay 1995a, Aratrakorn, Thunhikorn, and Donald 2006, and Beukema et al. 2007). Arboreal ant communities however, change in composition but do not decrease in richness (Rubiana et al. 2015).

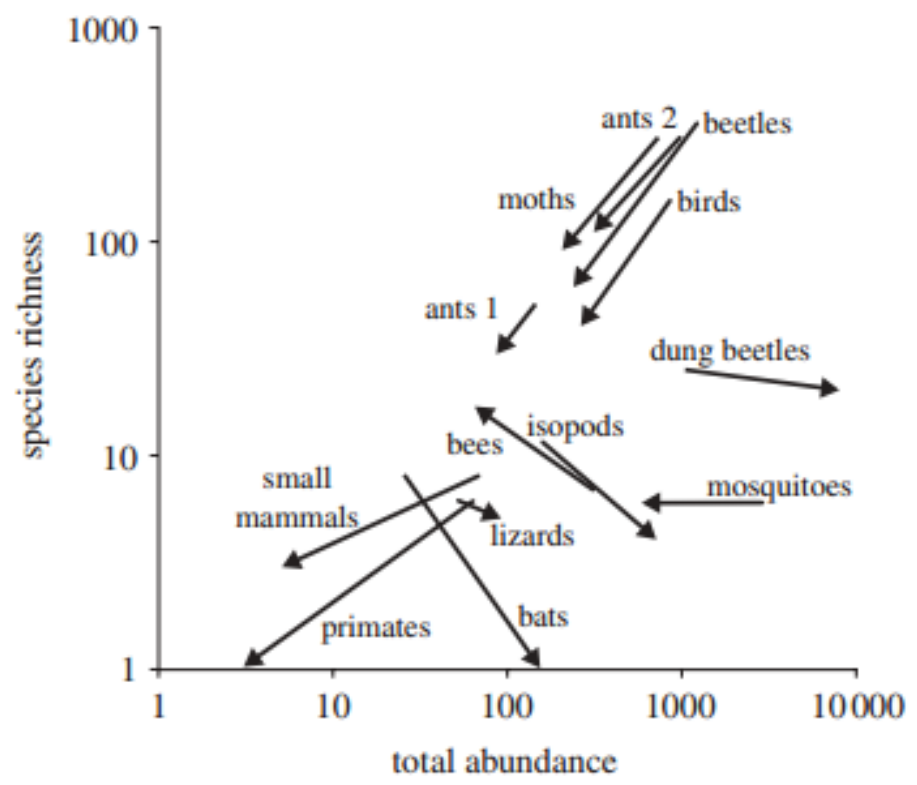

Figure 1: The impacts of converting primary rainforest into an oil palm plantation on the abundance and species richness of different taxa. Extracted from Foster et al. (2011)

Although biodiversity trends are quite clear, changes in ecosystem functions have received very little attention in oil palm (Savilaakso et al. 2014), and only disparate studies exist (Foster et al. 2011). Strikingly, I could not find any study linking ecosystem functions to aboveground biodiversity in rubber plantations. By classifying organisms into functional groups such as feeding guilds however, it becomes possible to infer functional changes with biodiversity loss as has been done with birds (C. H. Sekercioglu, Daily, and Ehrlich 2004). Along these lines, litter invertebrates have been shown to suffer greater losses of predators with land-use conversion to rubber and oil palm plantations (Barnes et al. 2014). Furthermore, frugivorous and insectivorous birds are negatively affected by conversion to rubber and oil palm (Thiollay 1995a, Aratrakorn, Thunhikorn, and Donald 2006). However, we should not directly infer loss of ecosystem functioning from biodiversity changes in functional groups (Swift, Izac, and van Noordwijk 2004). More importantly, the abundance, body mass and activity of the organisms are important determinants of ecosystem functioning (Barnes et al. 2014). So far, the actual ecosystem functions provided by aboveground biodiversity, such as pest control, litter decomposition, seed dispersal, and pollination, have not been measured directly in these different land-use systems, revealing a true knowledge gap.

Similarly, we lack research on ecosystem services, which are essentially a subset of all ecosystem functions that are beneficial from an anthropogenic point of view. One study showed that 
Introduction

birds may protect oil palms by controlling arthropod pests (L.P. Koh 2008), and more evidence suggests great potential of birds for bio-control of arthropod pests (De Chenon and Susanto 2006). Moreover, litter decomposition and oil palm pollination depend mainly on single species - the oil palm weevil Elaeidobius kamerunicus for pollination and the termite Macrotermes gilvas for decomposition (Foster et al. 2011). The role of pollinator and decomposer communities on these ecosystem services in oil palm are currently unknown, so that we cannot yet assert the role of aboveground biodiversity on ecosystem services.

\section{Location}

I carried out my research in tropical landscapes of the province of Jambi, on the island of Sumatra in Indonesia, Southeast Asia. Sumatra belongs to the Southeast Asian biodiversity hotspot and also undergoes very rapid, human-driven land-use change. Agricultural expansion has considerably reduced the forest cover (Margono et al. 2014) over the past decades in Indonesia, and Sumatra is a prime example of a process that is already advanced. Large swathes of land have been and are being converted to monoculture plantations of oil palm and rubber trees, but also to Acacia and Eucalyptus plantations, all of them cash crops, which currently constitute the main anthropic land use of the province of Jambi (Melati et al. in prep.).

This research is part of the Collaborative Research Centre 990 (EFForTS), and as such, most field work was carried out on the project's core plots established in forest, jungle rubber, and rubber and oil palm monocultures. The study sites are described in detail in Drescher et al. (2016) and presented in Figure 2. We additionally established additional experimental plots in young oil palm plantations, which are described more in detail in chapter 5. 


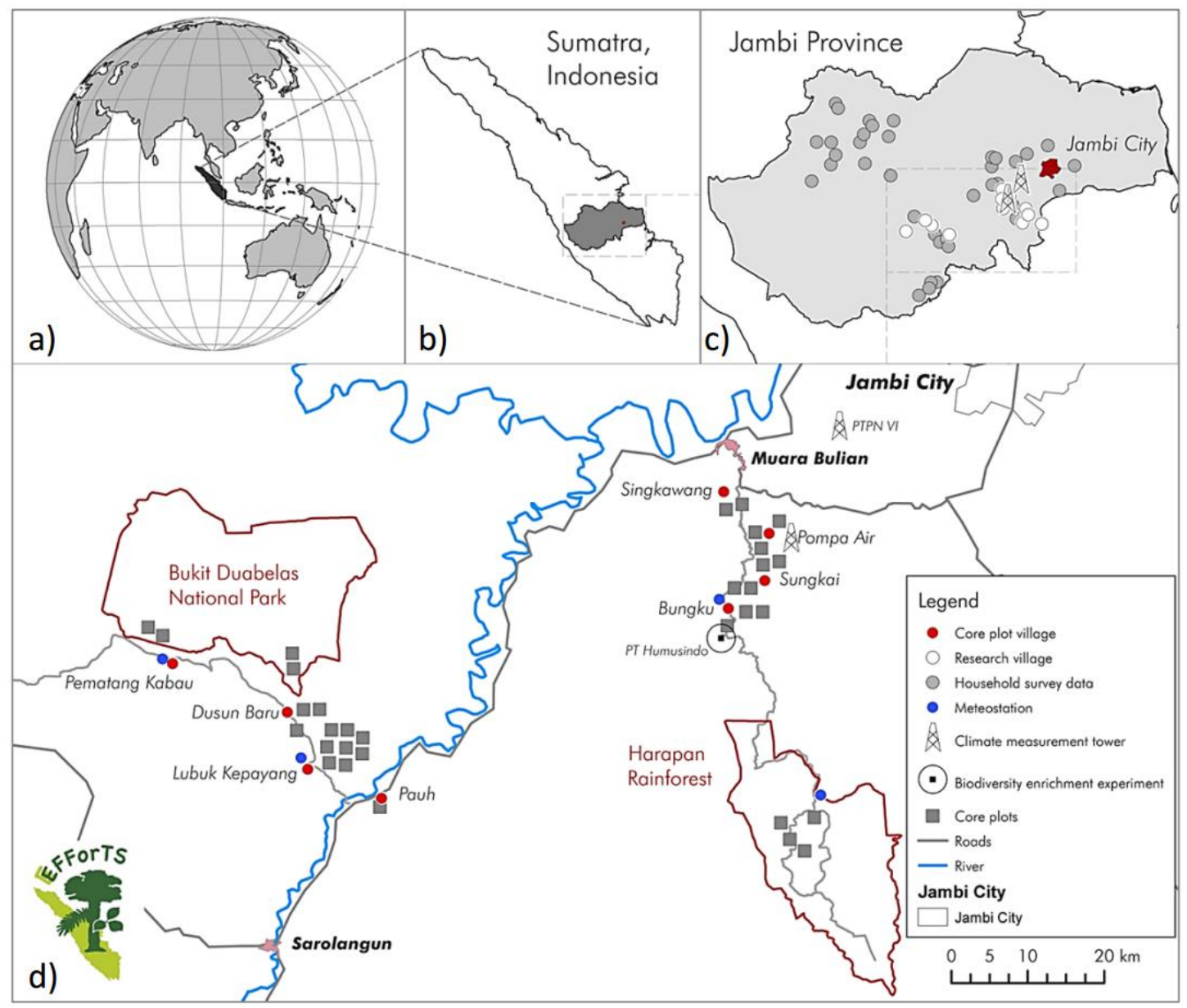

Figure 2: Overview of the CRC 990 study region, core plots, and research project infrastructure from Drescher et al. (2016)

\section{Study organisms and methods}

In the present study, I focus on birds because of their influential and varied roles in terrestrial ecosystems. By virtue of their diverse diets and great mobility, birds fulfil many functions as predators, seed dispersers and consumers, pollinators, and scavengers (Whelan, Wenny, and Marquis 2008). Birds are also one of the most species-rich taxa which experienced a fast radiation (Jetz et al. 2012). Thus, they constitute a taxon of choice for investigating the impact of agricultural expansion on biodiversity and ecosystem functioning.

We must aim for global, standard, and effective methods to assess biodiversity in the first place. Birds have been thoroughly studied for centuries using a variety of survey techniques and are therefore suitable for evaluating different assessment methods. Birds are surveyed on different spatial scales (points, transects, entire regions) with different detection methods (visual, acoustic, mist-netting, see Sutherland, Newton, and Green 2004). These survey techniques all rely on human observation but recently, autonomous recording units (ARUs) have emerged for carrying out 
Introduction

acoustic-only surveys. The effectiveness of these modern sampling methods has not been evaluated thoroughly yet.

\begin{abstract}
Aims
In the present thesis, I analyse traditional and modern avian survey techniques by comparing them and providing solutions for standardizing acoustic sampling methods. We then use these methods to assess taxonomic and functional diversity trends associated with the conversion of forest to rubber and oil palm agricultural systems in Southeast Asia, Indonesia. We finally elucidate bird functions and services using an experimental approach.

I evaluate autonomous sound recorders compared with the golden standard of bird surveys: traditional point counts, which rely on human observation, in chapter 2. Using a systematic review of studies comparing both methods, I carried out a meta-analysis with the available data and complemented the review with data from our own field survey, underlining fundamental differences between human-based and microphone-based detections. I conclude with a clear list of advantages for each method.
\end{abstract}

Acoustic survey methods have not existed for a long time and thus very few attempts have been made to standardize the methodology. Using simple equipment and protocols, in chapter $\mathbf{3}$ I show how to measure the detection space areas of acoustic recorders. By knowing the sampled area, we can infer the density of the sampled animals and make valid comparisons of biodiversity between sampling sites.

With these tools at hand, bird communities should be assessed in reference land-use systems and their agricultural derivatives. In chapter 4 I present the results of a point-count based survey to sample birds along a transformation gradient from forest habitats to oil palm plantations, while tracking the associated functional changes.

To unravel the birds' function, we use functional traits as proxies and investigate the functional response of arboreal ants, birds, and litter invertebrates in chapter $\mathbf{5}$. We contrast single trait values with multiple-traits indices and analyse the functional redundancy of the animal communities by relating species diversity to functional diversity.

Our ultimate goal is to expose the role of birds experimentally: in chapter 6, we manipulated ant and flying vertebrate (bird and bat) access to young oil palm plantations using exclosures for a whole year. We measured ecosystem functions such as decomposition, herbivory, pollination and predation alongside the crop yield to uncover the role of ants and flying vertebrates such as birds and bats. 
Chapter 1: Autonomous sound recording outperforms direct human observation in bird surveys: Synthesis and new evidence

\title{
Chapter 1: Autonomous sound recording outperforms direct human observation in bird surveys: Synthesis and new evidence
}

Kevin Darras ${ }^{1}$, Péter Batáry ${ }^{1}$, Irfan Fitriawan, Teja Tscharntke ${ }^{1}$

${ }^{1}$ Department of Crop Sciences, Agroecology, Georg-August-University, Grisebachstr. 6, 37077 Göttingen, Germany

\begin{abstract}
Autonomous acoustic sampling techniques are relatively new survey methods that are primarily used for birds, but also for anurans. Its rapidly increasing adoption faces an equally high scepticism as to whether such modern survey methods can match traditional, established methods based on human observation, primarily point and transect counts. Although several disparate studies have tested these modern sampling methods with the traditional ones, the overall conclusion is unclear.
\end{abstract}

We review the available evidence speaking for and against autonomous sound recording techniques and compare those systematically with avian point count surveys as a reference. We objectively compare alpha and gamma diversity levels of birds for both methods using a meta-analysis and complement the analysis with our own field survey data.

We found no significant difference between point counts and autonomous sound recordings in their efficiency of avian species sampling, although the sampled community composition differs in our own and several other studies. Although human hearing and microphones sample sound in a fundamentally different manner, results from both survey methods are comparable. We further discuss inherent pros and cons of either method and summarize our findings for guiding future study designs.

Modern acoustic sampling methods have come of age and effectively outperform traditional survey methods on grounds of sampling completeness, temporal and observer bias, data breadth, and practicality. Although we are certain of our results for birds, we are lacking similar studies to ascertain the efficiency of acoustic sampling methods for anurans and mammals. However in general our findings are generalizable to all sonant animal taxa and provide strong arguments for using autonomous sound sampling to monitor animal biodiversity. 
Chapter 1: Autonomous sound recording outperforms direct human observation in bird surveys: Synthesis and new evidence

\section{Introduction}

In the face of the current threats to global biodiversity, we urgently need to devise more efficient methods to survey vertebrate animals (Watson and United Nations Environment Programme 1995). We need a larger coverage on temporal and spatial scales, maximal return on financial investment and minimal bias to enable standardized, comparable, and repeatable results, but are facing massive challenges. Tropical regions in particular suffer from the disparate coverage of biodiversity assessments, as biodiversity is most intensively monitored in temperate regions, although species diversity is lower there (Collen et al. 2008). Although the importance of long-term biodiversity data is widely acknowledged, our temporal coverage of biodiversity is still low as such datasets are very rare (Magurran et al. 2010). Cost-effectiveness of survey methods, although it is a crucial factor in any ecological study design, has been explicitly considered only in a few studies, for example by recommending morpho-species identification in invertebrates (Oliver and Beattie 1996) and indicator taxa like birds for forest inventories (Gardner et al. 2008). Finally, considerations of global standardization and management of primary biodiversity data have only been theoretical so far (Soberón and Peterson 2004).

Most vertebrate taxa are usually surveyed by direct human observation. Human observers rely on aural and visual detection to count animals and identify species. However, any survey method based on human observation is prone to bias due to differences in experience and detection strength (eg. invasive plants (Fitzpatrick et al. 2009) and birds (Sauer, Peterjohn, and Link 1994)).

Furthermore, data are not verifiable since we can generally only rely on the expertise and memory of the surveyors for correct species identification, a shortcoming that is addressed in environmental DNA sampling approaches (Ji et al. 2013), although the method has its own drawbacks (Ficetola et al. 2015). Another alternative is to use photographic evidence to increase the standardisation of visual observations. Camera traps are specially designed for this and are used increasingly often, however, they can only practically sample animals of sufficient size (Rowcliffe and Carbone 2008).

Given that most terrestrial vertebrates (birds, bats, amphibians, mammals, but not reptiles) and some insects (e.g. cicadas and orthopterans) commonly use sound that can be recorded (Fletcher 2007), passive acoustic monitoring methods have recently gained more attention. Sound propagation is not impeded by obstacles such as vegetation as much as light waves are, so that animals are generally audible or detectable more often although they are rarely visible, especially in vegetated environments. For birds in particular, acoustic sampling methods have been studied in several studies by comparing them with traditional survey methods based on direct human observation (e.g. point counts and transects, for a simple overview see (Alquezar and Machado 2015)). Results are controversial in the sense that some studies show that acoustic surveys are more 
Chapter 1: Autonomous sound recording outperforms direct human observation in bird surveys: Synthesis and new evidence

effective than point counts, while other studies point to the opposite conclusion. Despite that extensive body of research, acoustic methods have not been used yet in community ecology to derive measures of species richness, abundance, or density. The existing literature focuses on single species or subsets of the bird community (eg. European nightjars (Zwart et al. 2014) or Water rails (Stermin, David, and Sevianu 2013).

First, we perform a meta-analysis of the current literature and compare the sampling completeness of acoustic monitoring methods with human observation surveys, using alpha and gamma richness as indicators. We also shed light on the performance of both methods with respect to species richness, abundance, community composition, and detection rate using data from a field survey. We discuss the inherent advantages of either method on the example of birds, focusing on a) temporal and sampling bias, b) sampling completeness and detection probability, c) data type and comparability, and d) practicality considerations. Results from our own survey are integrated into the meta-analysis and illustrate several points highlighted in the discussion.

\section{Methods}

\section{Systematic review and meta-analysis}

We retrieved scientific references from the Web of Science with the advanced search function, covering all years and databases, on the 29th of February, 2016. We used the following search string include any references dealing with birds, acoustic sampling methods, and point counts or transects:

$T S=(($ bird* OR avian OR avifaun*) AND ("sound record*" OR "acoustic record*" OR "automated record*" OR "acoustic monitor*" OR "recording system*") AND ("point count*" OR "bird count*" OR "point survey*" OR "point-count*" OR "point transect*"))

We read all abstracts to determine the relevance of each study: studies that compared acoustic and observational bird survey methods were included into our systematic review. Full texts were retrieved for all these studies and read entirely, and the references of these studies were further checked for additional potential studies. Studies that published data on mean bird species richness per site (alpha richness) or total species richness (gamma richness) recorded with both methods were used in the meta-analysis. The species richness between methods was compared with log response ratio (LRR) values (Hedges, Gurevitch, and Curtis 1999) using the following formula:

$$
L R R=\log \left(\frac{\text { species richness }}{\text { point counts }}\right)
$$


Chapter 1: Autonomous sound recording outperforms direct human observation in bird surveys: Synthesis and new evidence

Positive values indicate higher species richness in point counts, and negative values indicate higher species richness in sound recordings.

\section{Field study}

Twenty-six lowland rainforest plots were visited once in Jambi, Indonesia (Fig. 1), between April and June 2015, during the dry season, which corresponds to the breeding season for most birds in Indonesia. Some the forest plots had previously experienced selective logging, and hunting and bird trapping were reported in the area. We established a $200 \mathrm{~m}^{2}$ quadrant in the plots by spanning four $10 \mathrm{~m}$ ropes into each cardinal direction; all trees above a DBH (diameter at breast height) of 10 $\mathrm{cm}$ were counted and their DBH was measured. Forest plots had a closed canopy, an average basal area of $3111 \pm \mathrm{sd}: 1443 \mathrm{~m}^{2} \cdot \mathrm{ha}^{-1}$, and a tree density of $827 \pm \mathrm{sd}: 256 \mathrm{ha}^{-1}$. During the plot screening, we recorded a pure tone sequence $(0.5,2,4,8,12$ and $16 \mathrm{kHz}$, one second long at each step) emitted at distances of 2, 4, 8, 16 and 32 meters with portable loudspeakers (OnePe DZ-250, Dazumba, Indonesia) from our sound recorder (SM2Bat+ recorder fitted with one SMX-II and one SMX-US microphone). We call these recordings the sound transmission sequences; they were used to estimate the sound falloff with distance.

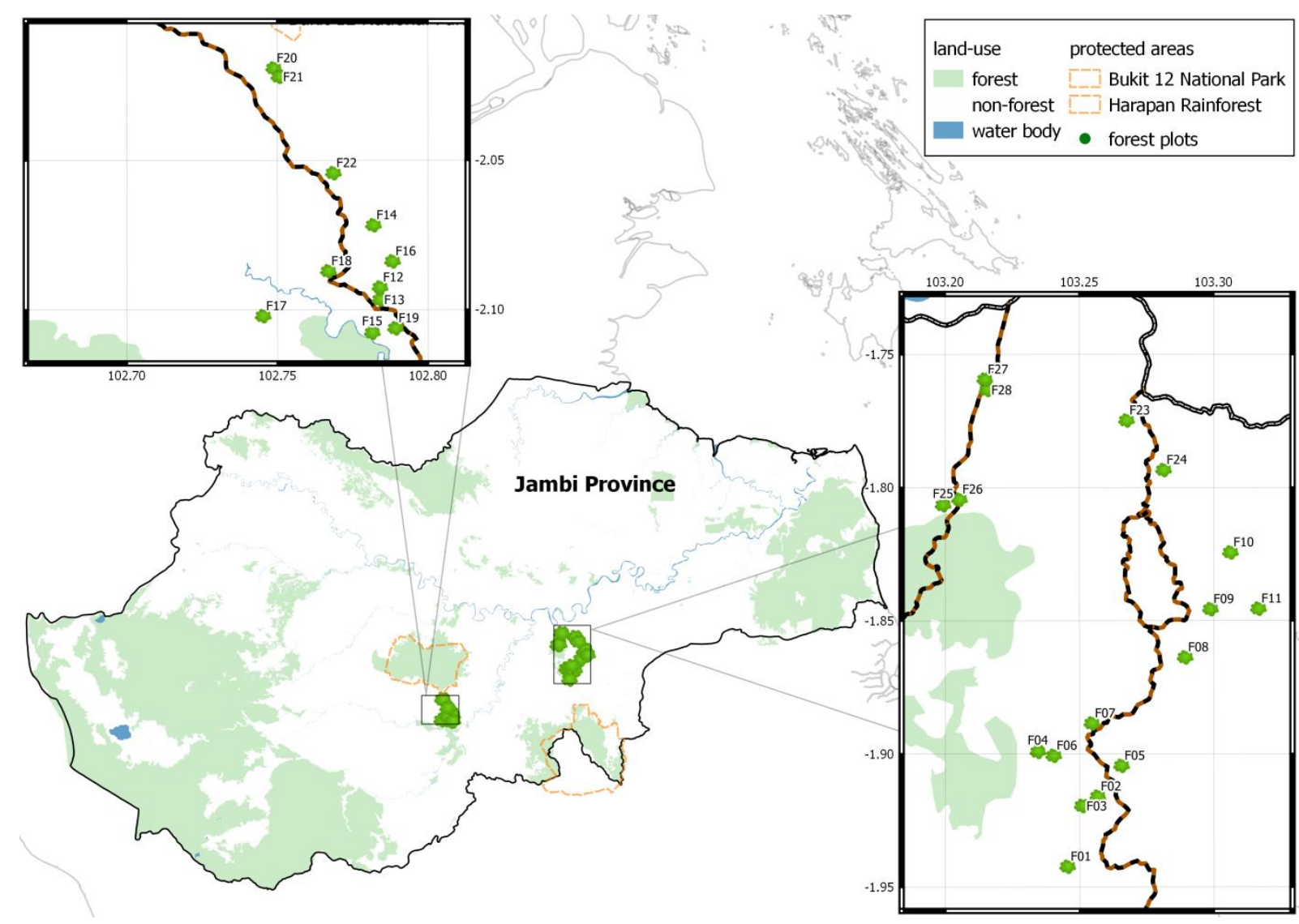

Figure 1: Map of the plots used in the survey. Forest cover is derived from Landsat data (used with permission from Dian Melati). 
Chapter 1: Autonomous sound recording outperforms direct human observation in bird surveys: Synthesis and new evidence

Sound recorders were installed one day before the bird survey and programmed to start recording at sunrise, and stopped at the end of the point counts. Twenty-minute point counts were carried out between 6:00 and 10:00, one minute after arriving on the plot, to avoid disturbing secretive bird species. The survey team comprised one ornithologist observer (IF) and one recordist without ornithological knowledge. The recordist notified the observer of bird calls that he did not detect and recorded all calls to aid in identification using a directional microphone (Sennheiser ME66 coupled to Olympus LS-3). All detected birds were recorded and identified following the MacKinnon field guide (MacKinnon and Phillipps 1993); their distance was measured with laser rangefinders (Nikon Laser 100 AS and Bushnell Fusion 1 Mile). The number of simultaneously detected individuals was counted for each species as a conservative measure of abundance.

The autonomous sound recordings were stopped manually at the end of the point count. Considering that autonomous sound recorders can collect data without human presence and start recording earlier in sites that are difficult to access, we used twenty minute sound recordings starting 30 minutes before the point count. Recordings and sound transmission sequences without information about their origin were uploaded to http://soundefforts.uni-goettingen.de/. The same observer (IF) listened to the recordings online while inspecting the spectrograms and tagged all bird calls with the species name, number of individuals, and estimated distance. The sound transmission sequence assisted the listener to estimate bird distances more accurately. An additional listener without ornithological knowledge listened to the same recordings to notify the observer of calls that he did not detect and check for general data consistency.

\section{Bird data analysis}

Using bird data from the point counts and sound recordings, we counted the number of species per plot (alpha richness) and the maximum number of simultaneously detected individuals of each species (abundance) per plot, to assess the survey method's sampling completeness. We used non-metric multidimensional scaling based on Bray-Curtis distance matrices to visualize the bird community composition. We standardized the community abundance matrix with a Hellinger transformation (Rao 1995) and performed a paired permutation test on a redundancy analysis of principal coordinates where the survey method was the explanatory variable. To investigate whether birds avoided human observers and assess how detection probability drops with distance, we plotted the distances to all bird detections for both survey methods. 
Chapter 1: Autonomous sound recording outperforms direct human observation in bird surveys: Synthesis and new evidence

\section{Results and Discussion}

\section{Meta-analysis}

We found nineteen studies with our search string (including the present one), of which fifteen were relevant, and twelve had usable data for the meta-analysis (Table S1). Alpha and gamma species richness recorded with both methods were not significantly different (Figure 1).

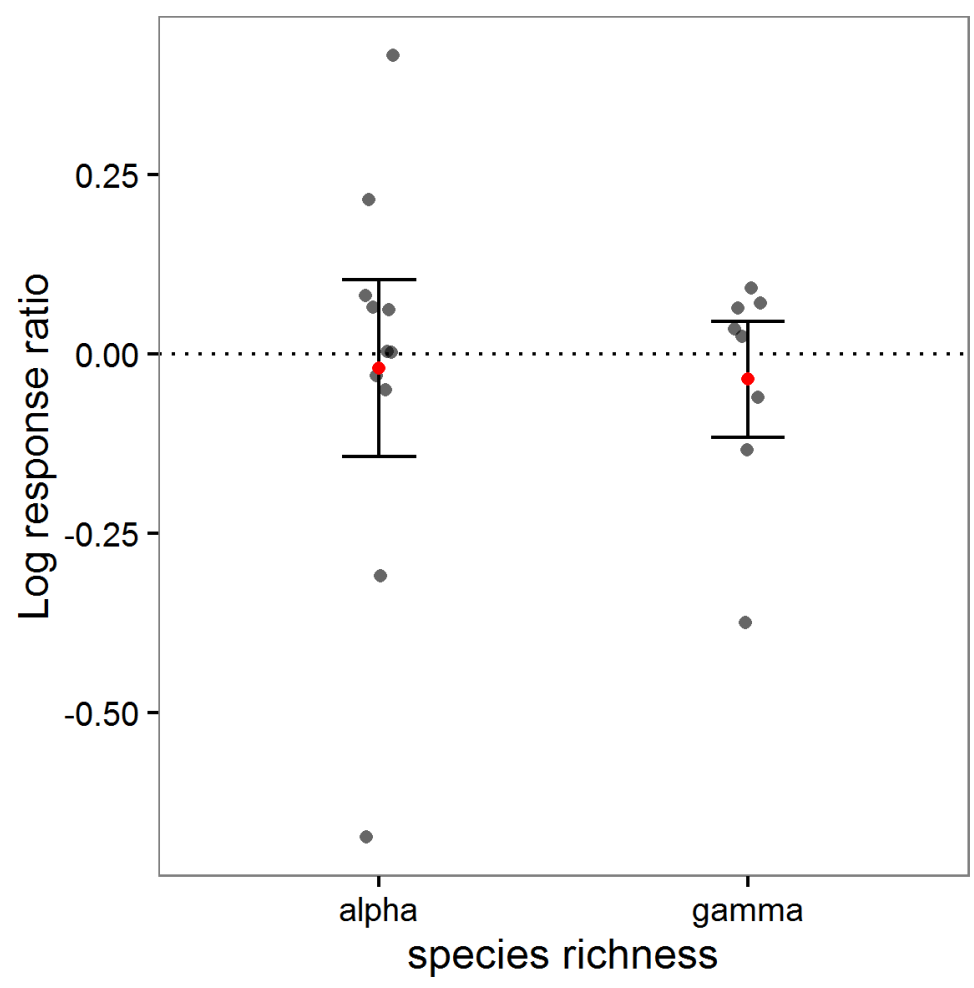

Figure 2: Log response ratios of bird richness sampled by point counts compared to automated sound recordings. Positive values indicate higher species richness in point counts, and negative values indicate higher species richness in sound recordings. The error bars display $83 \%$ confidence intervals, and indicate a significant $(\mathrm{p}<0.05)$ difference to the control (point counts) when they do not overlap the dotted line (Krzywinski and Altman 2013). The red dots represent the means.

\section{Avian abundance and richness comparison from the field survey}

The significance of all statistical tests was assessed at a level of $P<0.05$. Paired-sample Wilcoxon signed rank tests showed that the mean richness and abundance between sampling methods were not significantly different (richness: $P=0.32$; abundance: $P=0.16$, Figure 3 ). In total, 68 bird species were detected in point counts, versus 62 in sound recordings. 
Chapter 1: Autonomous sound recording outperforms direct human observation in bird surveys: Synthesis and new evidence

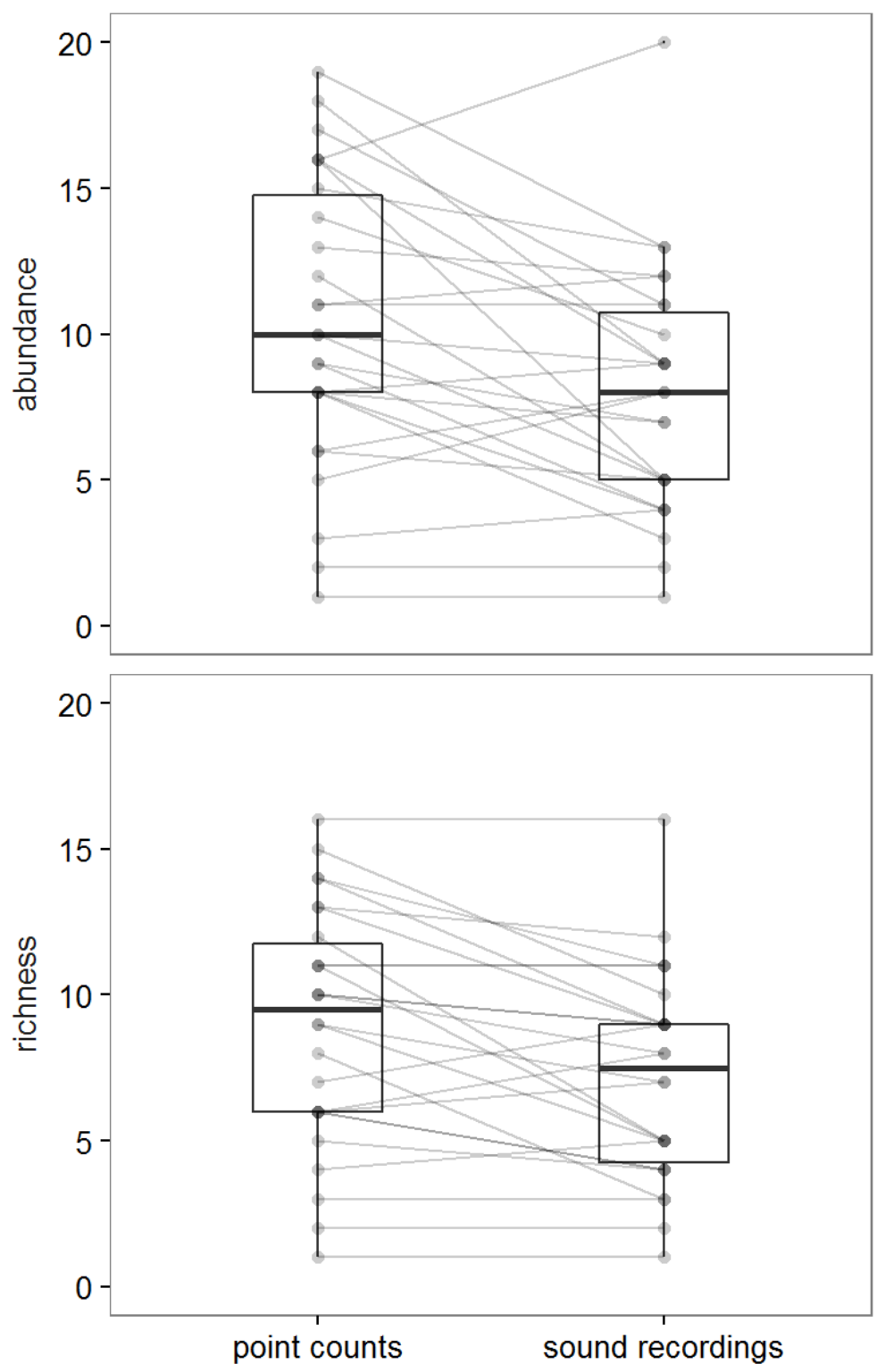

Figure 3: Boxplots and data points of bird species richness and abundance per plot, sampled in 26 forest plots with point counts and sound recordings. Measures from the same plot are connected with a line.

\section{Community composition differences}

The paired permutation test for redundancy analysis of principal coordinates to compare bird communities between methods was significant $(P=0.004)$, indicating that the sampled bird communities were different (Figure 4). Twenty-four species that were recorded by point counts were not recorded by autonomous recording units, while 18 species that were sampled by autonomous recording units were not sampled in point counts (Table S2). 
Chapter 1: Autonomous sound recording outperforms direct human observation in bird surveys: Synthesis and new evidence

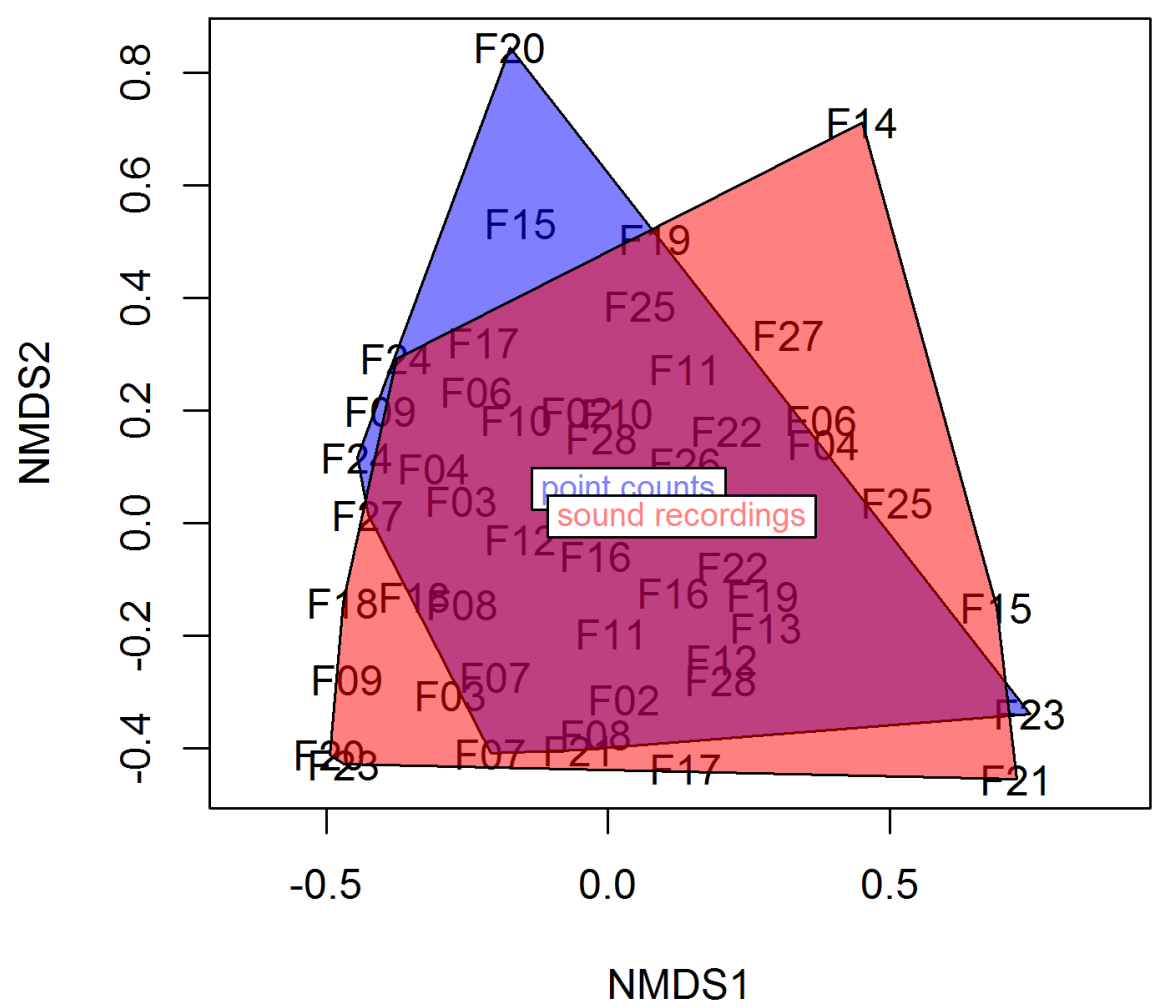

Figure 4: Non-metric multidimensional scaling of the bird communities sampled with different methods, the red polygon corresponds to sound recordings, the blue polygon corresponds to point count data.

\section{Frequency of detection with distance to sampler}

Detections were distributed differently along the distance to the sampler (human observer or sound recorder) for both methods (Figure 5). In point count data, detections were homogeneously distributed between 18 and 44 meters, with a distinct drop in detection number at close range $(<18$ $\mathrm{m}$ ) and long range (>44 m). For sound recording data, the frequency of detections followed a strong decline with distance; most detections were recorded at close and medium ranges ( $<25 \mathrm{~m})$. At close range $(<18 \mathrm{~m}), 15$ detections were found in point counts, versus 120 in sound recordings. 
Chapter 1: Autonomous sound recording outperforms direct human observation in bird surveys: Synthesis and new evidence

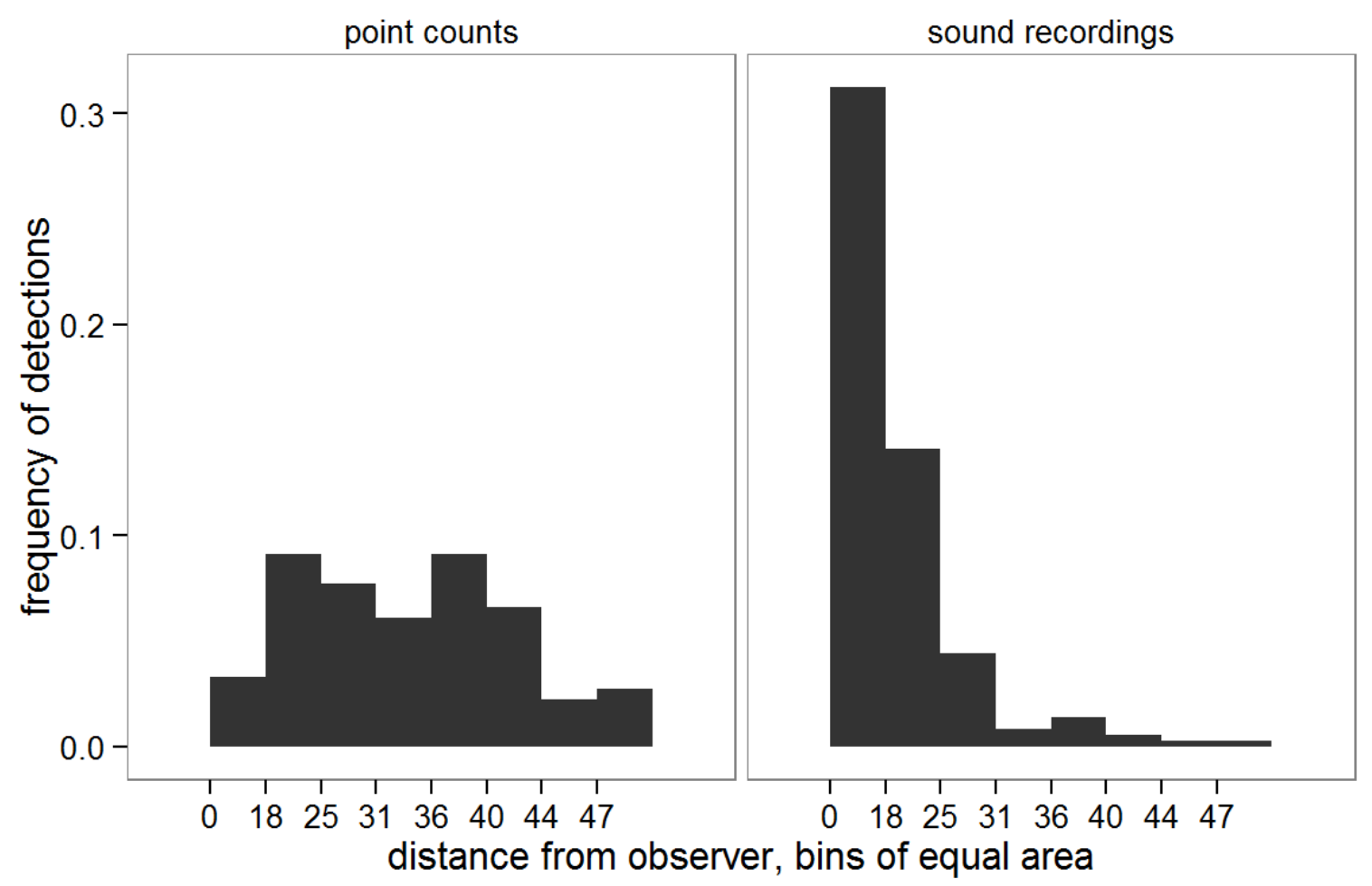

Figure 5: Frequency of bird detections in bins of equal area around the observer.

\section{Discussion}

\section{Temporal and sampler bias}

Point counts suffer from a trade-off between observation time and observer bias: the number of observers determines how many simultaneous (thus temporally unbiased) data points can be obtained, but it also dictates the number of observer-specific (thus observer biased) data points (Sauer, Peterjohn, and Link 1994). In contrast, sound recorders incur no sampler bias (or recorder bias), provided that microphones are calibrated. Microphones are manufactured under specific signal-to-noise ratio tolerances to start with, but signal-to-noise ratio can drift apart with time, depending on the environmental stress they have experienced (rainfall, temperature variations, shocks, pers. obs. KD). Thus, regular measurement of microphone signal-to-noise ratio at different frequencies is required to ensure that they can be calibrated, so that different recording units have the same detection efficiency.

When point count observations have corresponding photographic or audio evidence material, the bias between observers can be lessened by secondary verification, but these data are rarely available. To obtain such data, an additional worker is often needed, further raising the costs of the human-based survey. With sound recordings, audio material is essentially available at no additional cost, and it can be used for future identification checks. Even if sound recordings are 
Chapter 1: Autonomous sound recording outperforms direct human observation in bird surveys: Synthesis and new evidence

processed by people with little experience in call identification, as long as all calls are detected and reviewed by an expert ornithologist, the species identification will be standardized.

\section{Sampling completeness and detectability}

One clear and inherent advantage of human observation surveys is that they include visual detections, whereas sound recorders obviously don't. That advantage might be minor in dense forests - in our survey only $5 \%$ of observations were visual-only - but considerable in more open systems (e.g. (Diefenbach, Brauning, and Mattice 2003)). However, birds invariably vocalise, thus by using longer recording durations, even rarely singing species will eventually be detected.

Secretive species can be affected by the presence of human observers, especially when there is more than one. Indeed in our field survey, birds were less often detected close to human observers, whereas in sound recordings, birds are often heard near to the recorder (Figure 5). We attribute this drop in detection rate close to the observer to avoidance behaviour of birds. Interestingly, birds in disturbed systems might be less sensitive to human observer presence (see chapter 2, Fig S2). While timid birds might still be counted at greater distances in point counts, the detection probability would correspondingly be lower.

Species detectability in sound recordings is mainly a function of the microphone's signal-tonoise ratio. Sound can be amplified to any desired level after recording, but noise is amplified as well, so that bird call detection probability at long distances is affected by the noise level rather than the sensitivity. It is important to distinguish between the different types of noise: the ambient sound level - anthropogenic or biogenic - cannot be changed and equally affects humans and sound recorders; the equipment's noise level is determined by the microphone's signal-to-noise specification and by the noise floor of the recording device's electronics, which is usually negligible on all but the cheapest recorders. For acoustic sampling to be effective, the equipment noise floor should not exceed the ambient sound level. Our equipment - first released in January 2012 - used relatively cheap microphones (signal-to-noise ratio $>62 \mathrm{~dB}$ ), which currently retail at about 10 USD (Panasonic WM-61A). However, the more recent recorders released in 2015 by the same manufacturer use more sensitive elements (signal-to-noise ratio $>68 \mathrm{~dB}$ ). This shows that bird detection rates in sound recordings will improve along with technological progress.

In point counts of species-rich sites, birds can be missed when they occur simultaneously. One study showed a systematic underestimation of bird detections when calls are simultaneous (Bart and Schoultz 1984), which can also be worsened by human error (fatigue and lack of attention). In contrast, sound recorders will have unchainging performance until the batteries are depleted, and sound recordings can be played back repeatedly, so that birds can only be missed if the listening time 
Chapter 1: Autonomous sound recording outperforms direct human observation in bird surveys: Synthesis and new evidence

is deliberately constrained. Furthermore, spectrograms (eg. sonograms) can be routinely generated with open-source software and inspected while listening to audio recordings, allowing for both visual and aural detection of bird calls, further enhancing detection probability.

Finally, it is worth mentioning a fundamental difference between microphones and the human auditory system. While microphones respond linearly to sound pressure, humans have an approximately log-linear response to sound pressure, which explains the use of decibels (which is a logarithmic ratio) for describing loudness. In practice, this means that sounds that are much louder (in terms of sound pressure) are only perceived as being a little louder by humans. This characteristic is of advantage for humans but constraining for the design of microphones, where sensitivity needs to be balanced against the risk of saturation. In conclusion, humans have a much wider dynamic range for perceiving sounds, which explains the relatively flat frequency diagram in Figure 5, versus a sharp decline in detections with distance for sound recordings.

\section{Data type and comparability of methods}

Sound recordings provide a multitude of other data types that cannot be obtained from point counts. For instance, it is much easier to measure bird activity in time units or rates, even for different vocalizations types, which can be an interesting alternative to abundance measurements (see Figure 3 in the discussion). We can also analyse temporal dynamics throughout the day, between days, between seasons and years. Furthermore, we can generate sound diversity indices for large datasets automatically (Jérôme Sueur et al. 2014), at the only expense of coding and computation time. Acoustic indices can be used as a surrogate for species richness (Depraetere et al. 2012). Finally, all other sonant animal taxa are also available, allowing a more holistic biodiversity survey by sampling multiple organisms with the same equipment in a single survey.

When visual detections are numerous, observations can yield usable auxiliary data such as behaviour, food items, sometimes even the sex and age of the bird, although such data are rarely used in ornithological publications. To some degree, bird vocalizations convey similar information, since calls and songs have different functions: territorial advertisement, mate attraction, and alarm warnings are all indications about the bird's behaviour (Catchpole and Slater 2008). In some cases when the bird is moving and calling at the same time, movement direction can also be inferred. Depending on the position of the microphones, it is also possible to derive the source height of the calling bird and extract information about the stratum of occurrence like in point counts.

Abundance data tend to be more readily obtained from point counts, since it is more intuitive to track the movement of birds and infer whether they are different individuals. However in forests, bird individuals are rarely seen and thus hard to distinguish so that we can never really know 
Chapter 1: Autonomous sound recording outperforms direct human observation in bird surveys: Synthesis and new evidence

whether two different sightings correspond to the same or different individuals. Even in open areas, we cannot constantly track individual birds for ascertaining their identity in point counts. A more conservative estimate of abundance is obtained by summing the maximal number of simultaneously detected individuals over all species. This is the measure we used here, and it can be obtained from both survey methods.

The estimation of bird distance is also more straightforward to achieve in point counts since the distance to the estimated position of the animal can be measured with rangefinders. This forms the basis of distance sampling methods, which allow to compare diversity measures between different sites and to derive density estimates (Buckland et al. 2005). We must bear in mind, however, that these are also approximations, except when the animal can be seen and directly pointed at. In sound recordings, distances to birds can also be estimated, but they are probably more variable than distance measures from observers present on-site (for a similar study see Alldredge, Simons, and Pollock 2007). However, this should not introduce a bias between sampling sites when sound transmission recordings are used like in our study, so that animal diversity between sites can still be compared when filtering data above a common threshold distance. For another approach at standardizing detection spaces, see chapter 2.

\section{Practicality}

\section{Travel time}

Observers carrying out point counts usually need to reach the sampling site once before the survey to become familiar with the itinerary and surroundings. For every subsequent data collection, only one travel is necessary. In contrast, sound recorders need to be installed before they start recording and must be picked up or visited each time data collection or battery recharging is necessary. Typically, ARUs can record sound for several days in a row, or several days spread across a few months. Entirely autonomous recording systems have also been developed, which rely on solar panels for electricity, radio transmission for data transfer, and automated algorithms for species identification on a server (Aide et al. 2013), indicating that there is potential for improvement. Depending on the study design, either one of the survey methods could be more practical: if sampling periods are on consecutive days, at the same site, and the theft risk is low, sound recorders will prove advantageous. However if the number of sampling sites is high, either many recorders or frequent travels would be needed, making point counts more worthwhile.

\section{Scalability}

In point counts, the survey time at each site is traded off against the number of target sites that must be sampled in one day. Sound recorders however, if available in sufficient numbers, allow 
Chapter 1: Autonomous sound recording outperforms direct human observation in bird surveys: Synthesis and new evidence

for greater flexibility in scaling up sampling effort. It is effortless to program automated sound recorders to record for a few more hours, or even days, which only comes at the expense of data storage and processing time, as well as energy supply.

\section{Expert workforce}

It is often costly to hire taxonomic experts for traditional field surveys, which require their presence on site. Passive acoustic monitoring systems however can be installed and picked up by inexperienced staff, while the financial allocation for taxonomic experts can be minimized to use them only for the actual animal identification. Moreover, since their presence is not needed, data can be sent to them or provided online (Villanueva-Rivera and Pijanowski 2012), helping to keep travel and personnel costs low.

In the near future, automated species identification is also conceivable so that reliance on expert ornithologists will be even further diminished. Numerous studies have showed how calls of single species can be detected with a measureable probability and accuracy using computer algorithms (for a review see Swiston and Mennill 2009). It is only a matter of time until reference call collections are mature (but see Xeno-canto Foundation 2012) and complex song structures or entire song repertoires can be reliably assigned to species.

\section{Material costs}

Point counts usually require binoculars for birds, and field gear. However it is often the case that birders use their own, helping to keep the costs down. Autonomous sound recorders are relatively costly, although a multitude of hardware solutions exist (see Sousa-Lima et al. 2013 for an overview of marine recorders), spanning a price range between hundreds and thousands of U.S. dollars. An important consideration is also that in long-term studies, it is often difficult to employ the same people throughout. Sound recorders however are pieces of hardware that are purchased once and typically last for many years. They can be used over and over again, repaired and maintained, until they get broken or stolen, greatly facilitating long-term data compatibility.

\section{Site accessibility}

Some pristine habitats can be very difficult to reach. Especially when conducting morning point counts of birds, the observer should be present on site at dawn. This is often impossible in inaccessible areas where travel by night would be required and risky. When using sound recording platforms however, as long as the recorder is installed before the survey, it can be programmed to start any time to reliably meet the desired time point. 
Chapter 1: Autonomous sound recording outperforms direct human observation in bird surveys: Synthesis and new evidence

\section{Rapid assessments}

Sound recordings can be used to rapidly asses the avian diversity of a sampling site without requiring the elaborate and time-intensive process of identifying animals to species. Alternatively, bird vocalisation types could be counted as a proxy for morphospecies, and audio recordings are particularly amenable to rapid visual screening as they can be represented as spectrograms.

However, some birds have a large repertoire of songs so they might bias that measure. Still, on a more abstract level, sound diversity indices can be computed from soundscape recordings, providing an even faster measure of biodiversity (Jérôme Sueur et al. 2008).

\section{Conclusion}

We summarised the pros and cons of human observation surveys compared with acoustic surveys in Table 1 on a high level. Overall, we are convinced that automated sound recorders provide a convincing solution for gathering standardized and verifiable data over any time scale. Sound recorders do not disturb animals and record levels of biodiversity that are indistinguishable from the golden standard of avian survey methods. However, it is unknown how effective these sampling methods are for other animal taxa, although some evidence suggests that anurans might be equally well monitored (Acevedo and Villanueva-Rivera 2006). Beyond that, the technology is still new and enormous potential will be unlocked in the coming years.

Table 1: Pros and cons of human observation and automated acoustic methods for surveying birds. The more advantageous method is highlighted in bold.

\begin{tabular}{|c|c|c|}
\hline Criteria & Human observation survey & Automated acoustic survey \\
\hline Bird sampling completeness & (reference level) & indistinguishable from reference \\
\hline Bird distance data & measurable & estimable \\
\hline Behaviour observation & $\begin{array}{l}\text { possible for visual } \\
\text { detections }\end{array}$ & indications from vocalisation types \\
\hline $\begin{array}{l}\text { Observer bias and temporal } \\
\text { bias }\end{array}$ & negative trade-off & no bias between recorders \\
\hline $\begin{array}{l}\text { Sampling over long time } \\
\text { periods during the day }\end{array}$ & very difficult & possible for multiple days \\
\hline $\begin{array}{l}\text { Long-term surveys over } \\
\text { months and years }\end{array}$ & $\begin{array}{l}\text { difficult without contracted } \\
\text { ornithologists }\end{array}$ & possible during recorder lifespan \\
\hline upscaling sampling effort & difficult & easy \\
\hline Sampling time flexibility & limited & unlimited \\
\hline $\begin{array}{l}\text { Calculation of acoustic } \\
\text { diversity indices }\end{array}$ & impossible & possible \\
\hline $\begin{array}{l}\text { Measuring bird singing } \\
\text { activity }\end{array}$ & difficult & easy \\
\hline
\end{tabular}


Chapter 1: Autonomous sound recording outperforms direct human observation in bird surveys: Synthesis and new evidence

\begin{tabular}{l|ll}
\hline Identification validation & $\begin{array}{l}\text { only with evidence } \\
\text { material (audio or photo) }\end{array}$ & easy \\
$\begin{array}{l}\text { Detection of timid species } \\
\text { impaired at close range }\end{array}$ & $\begin{array}{l}\text { possible } \\
\text { Sampling in higher } \\
\text { vegetation strata }\end{array}$ & $\begin{array}{l}\text { possible } \\
\text { Travel time }\end{array}$ \\
Cost-effectiveness & $\begin{array}{l}\text { two travels per installation (except when } \\
\text { permanent stations are used) }\end{array}$ \\
\hline
\end{tabular}




\section{Supplementary data}

Table S1: Overview of studies retrieved using the search string in the Web of Science. Asterisks denote studies that were suitable for the systematic review, crosses indicate studies that yielded usable data for the meta-analysis. Note that the study by Venier et al. is mentioned twice as two types of equipment were tested.

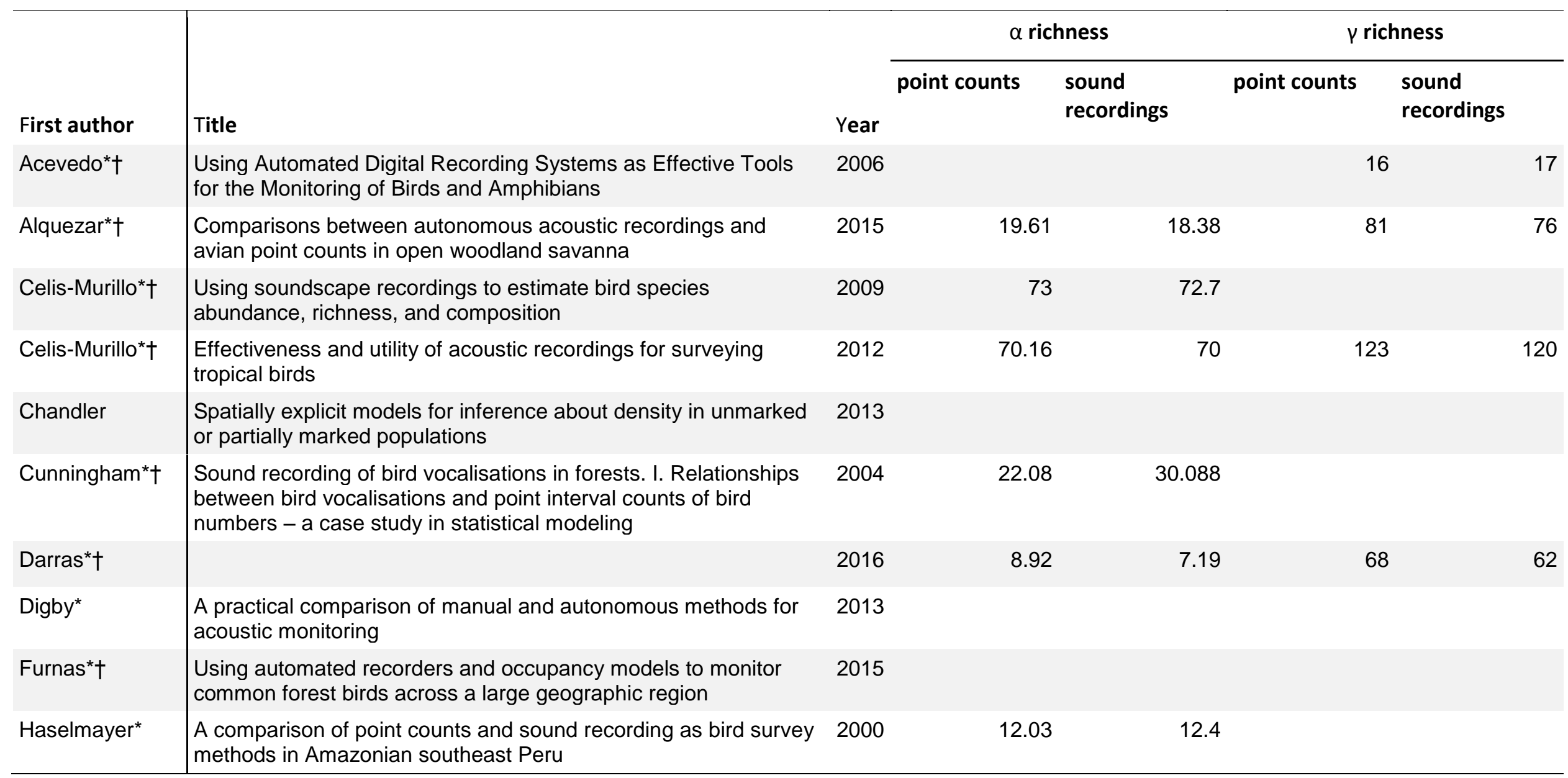




\begin{tabular}{|c|c|c|c|c|c|c|}
\hline Hobson* $†$ & $\begin{array}{l}\text { Acoustic Surveys of Birds Using Electronic Recordings: New } \\
\text { Potential from an Omnidirectional Microphone System }\end{array}$ & 2002 & & & 28 & 32 \\
\hline Hochachka & $\begin{array}{l}\text { Sources of Variation in Singing Probability of Florida Grasshopper } \\
\text { Sparrows, and Implications for Design and Analysis of Auditory } \\
\text { Surveys }\end{array}$ & 2009 & & & & \\
\hline Holmes* & $\begin{array}{l}\text { Using automated sound recording and analysis to detect bird } \\
\text { species-at-risk in southwestern Ontario woodlands }\end{array}$ & 2014 & & & & \\
\hline Hutto* $†$ & $\begin{array}{l}\text { Humans versus autonomous recording units: a comparison of } \\
\text { point-count results }\end{array}$ & 2009 & 13.8 & 9.1 & & \\
\hline Klingbeil ${ }^{*} \dagger$ & $\begin{array}{l}\text { Bird biodiversity assessments in temperate forest: the value of } \\
\text { point count versus acoustic monitoring protocols }\end{array}$ & 2015 & 8.35 & 7.85 & & \\
\hline Rempel* $^{*}$ & $\begin{array}{l}\text { Bioacoustic monitoring of forest songbirds: interpreter variability } \\
\text { and effects of configuration and digital processing methods in the } \\
\text { laboratory }\end{array}$ & 2005 & & & & \\
\hline Stermin & $\begin{array}{l}\text { An Evaluation of Acoustic Monitoring Methods for a Water Rail } \\
\text { (Rallus aquaticus) Population in a Large Reed Bed }\end{array}$ & 2013 & & & & \\
\hline Venier ${ }^{*} \dagger$ & $\begin{array}{l}\text { Evaluation of an automated recording device for monitoring forest } \\
\text { birds }\end{array}$ & 2012 & 9.71 & 8.95 & 58 & 54 \\
\hline Venier* $†$ & $\begin{array}{l}\text { Evaluation of an automated recording device for monitoring forest } \\
\text { birds }\end{array}$ & 2012 & 9.71 & 10.21 & 58 & 56 \\
\hline Wimmer* $†$ & $\begin{array}{l}\text { Sampling environmental acoustic recordings to determine bird } \\
\text { species richness }\end{array}$ & 2013 & 39.75 & 78 & 66 & 96 \\
\hline
\end{tabular}


Table S2: Species found only point counts or sound recordings. Birds detected only visually are indicated with an asterisk.

\section{Survey method}

\section{Point counts}

Sound recordings

\section{Species}

Cuculus micropterus, Corvus enca, Spilopelia chinensis, Prionochilus percussus, Pitta granatina, Chalcophaps indica, Calyptomena viridis, Terpsiphone paradisi, Psilopogon haemacephalus,

Orthotomus sericeus, Psittacula longicauda*, Pycnonotus aurigaster, Meiglyptes tukki, Chloropsis cochinchinensis, Stachyris rufifrons, Hypothymis azurea, Gracula religiosa*, Psittinus cyanurus,

Berenicornis comatus, Pelargopsis capensis, Rhinortha chlorophaea, Picoides moluccensis,

Pycnonotus melanicterus*, Eurystomus orientalis

Aethopyga siparaja, Alophoixus phaeocephalus, Arachnothera affinis, Cacomantis merulinus, Caprimulgus macrurus, Chrysophlegma miniaceum, Gallus gallus, Ketupa ketupu, Malacopteron cinereum, Nectarinia jugularis, Nyctyornis amictus, Oriolus xanthornus, Pellorneum capistratum, Pomatorhinus montanus, Prinia familiaris, Pycnonotus cyaniventris, Rhyticeros undulatus, Stachyris poliocephala 


\section{Chapter 2: Measuring sound detection spaces for acoustic animal sampling and monitoring}

Kevin Darras ${ }^{1}$, Peter Pütz ${ }^{2}$, Fahrurrozi ${ }^{3}$, Katja Rembold ${ }^{4}$, Teja Tscharntke ${ }^{1}$

${ }^{1}$ Agroecology Group, Department of Agriculture, Grisebachstr. 6, Georg-August University of Göttingen, 37077 Germany

${ }^{2}$ Chair of Statistics, Faculty of Economic Sciences, Georg-August University of Göttingen, 37073 Germany

${ }^{3}$ Agrobusiness Department, Faculty of Agriculture, University of Jambi, 36361 Indonesia

${ }^{4}$ Biodiversity, Macroecology \& Conservation Biogeography Group, Georg-August University of Göttingen, Büsgenweg 1, 37077 Göttingen, Germany

*Corresponding Author: kdarras@gwdg.de 
Chapter 2: Measuring sound detection spaces for acoustic animal sampling and monitoring

\begin{abstract}
Sound recordings obtained from passive acoustic monitoring systems are increasingly used to sample animal biodiversity. However, sound recorders sample variable detection spaces, so that data may not be comparable between sampling sites and recording setups.

Focusing on terrestrial systems, we measured understory vegetation, tree structure, sound transmission, ambient sound pressure level, and derived sound detection spaces of 38 plots in lowland rainforest, jungle rubber, and oil palm and rubber plantations, using different combinations of sound frequency ( 0.05 to $40 \mathrm{kHz}$ ) and source height ( 0 to $5 \mathrm{~m}$ ).

We show that simple vegetation structure measures poorly predict sound transmission, so that direct sound transmission measurements are indispensable. We depict highly variable sound detection spaces in different land-use types. Finally we estimated species richness of exemplary animal groups and found considerable differences between land-use types on the basis of variable detection space areas alone.

Sound detection spaces show complex responses but they need to be quantified in acoustic surveys to avoid substantial bias in biodiversity estimates between sampling sites. Detection spaces also determine species detection probabilities and allow comparing data between recording setups. We provide guidelines and computer scripts for measuring sound transmission and ambient sound level using consumer audio equipment and for computing detection spaces. Appreciating the effective sampling area of acoustic recorders closes a gap between acoustic and traditional animal survey methods. Species richness estimates can now be reported for measured sampling areas, and animal population variables such as abundance, density, and activity can be compared at equal areas.
\end{abstract}


Chapter 2: Measuring sound detection spaces for acoustic animal sampling and monitoring

\section{Introduction}

Passive acoustic monitoring systems are increasingly prevalent for surveying a wide range of soundemitting animals: ecologists use these systems to record birds (Celis-Murillo, Deppe, and Allen 2009), bats (Bader et al. 2015), amphibians (Aide et al. 2013), insects (Lehmann et al. 2014), terrestrial (Mielke and Zuberbühler 2013) and marine mammals (Wiggins and Hildebrand 2007), to construct general biodiversity indices (Jérôme Sueur et al. 2014), or to record soundscapes (Pijanowski et al. 2011). More complex systems using microphone arrays have been proposed for a wider audience of biologists to study a variety of other aspects such as anthropogenic noise, species interactions and social dynamics (Blumstein et al. 2011). Conservationists recognize the potential of passive acoustic monitoring techniques (Brandes 2008) and practitioners also increasingly embrace and implement acoustic monitoring programs on large scales (Fristrup 2009)). While challenges in automated signal recognition have been identified (e.g. (Swiston and Mennill 2009), there have been few attempts to standardize the sound recording methodology itself (Llusia, Márquez, and Bowker 2011); (Merchant et al. 2015).

Basic biodiversity estimates - such as species richness, activity, abundance and density - are derived from sampling methods that apply to defined areas or volumes, but when sampling sound, it is challenging to measure that space. In essence, biodiversity estimates derived from sound recordings in different sites may not be directly comparable due to site-specific acoustic characteristics: sound travels variable distances depending on the frequency, its sound pressure level, the background noise, the location of the sound source and also due to varying topography, climatic conditions and vegetation.

The determinants of sound transmission (or sound attenuation, hereafter "transmission") are well known. They have been described early for audible sound (Wiley and Richards 1978) and later also for higher frequencies reaching ultrasounds (Romer and Lewald 1992). The effect of vegetation has also been specifically addressed (Marten and Marler 1977; Marten, Quine, and Marler 1977); (Aylor 1972) and reviewed later (Forrest 1994). In most sound transmission studies, the focus has been on animal communication and rarely on the implications for acoustic biodiversity sampling (though see (Hobson et al. 2002) and (Patriquin et al. 2003)), a field which has expanded only relatively recently.

The area sampled by acoustic monitoring systems needs to be measured to identify the scale of a particular biodiversity estimate, as basic biodiversity estimates invariably increase with sampled area. Furthermore, it has been recognised that acoustic detectors vary in detection efficacy and range for different bat species (Adams et al. 2012), for aquatic organisms (Huveneers et al. 2015), and also for birds (Rempel et al. 2013). Furthermore birds have different detection probabilities (Sliwinski et al. 
Chapter 2: Measuring sound detection spaces for acoustic animal sampling and monitoring

2015), but the acoustic sampling area has not been considered yet to tackle these issues. The sampled area also depends on the ambient sound pressure level: distant sounds are more difficult to detect in noisy environments. Relatively early, (Morton 1975) calculated distances from the sound source over which sounds would reach the ambient sound level. More recently, a comprehensive analysis of acoustic communication distance determinants was made by (Ellinger and Hödl 2003) but it described only one study site and focused on implications for animal communication. We use the term "sound detection space" (hereafter "detection space"), which was introduced later by (Llusia, Márquez, and Bowker 2011), to define the space - in terms of area or volume - sampled by acoustic monitoring systems. Fortunately, the source sound pressure level and frequency - and to a certain degree, the source position - of animal sounds and vocalizations are generally characteristic and measurable for different species, and we assume here that variation between species is higher than within them. Thus, it is possible to compute detection spaces for different species across habitats, but as of today this has not been achieved.

We propose a method to measure sound transmission in various habitat types using consumer audio recording and playback equipment. We challenge the usefulness of our measurements by investigating whether vegetation structure data can predict sound transmission. Then, combining sound transmission values with calibrated ambient sound pressure level measures, we derive detection space areas of different land-use types. Finally, using exemplary species, we illustrate the impact that variable detection spaces can have on biodiversity measures derived from sound recordings.

\section{Materials and methods}

\section{Study region and vegetation structure measurements}

The study region is situated in the Batanghari and Sarolangun regencies of the province of Jambi, Sumatra, Indonesia. We recorded sound in 38 plots split into 5 land-use types. Core plots comprised 8 lowland rainforest plots, 8 jungle rubber plots, 8 rubber plantation plots, and 8 mature oil palm plantation (older than 8 years) plots. Six additional young oil palm plantation plots (younger than 4 years) were established to determine sound detection spaces in plantations without closed canopy. Our forest plots are located in an area of disturbed primary lowland rainforest that has been selectively logged in the past. Jungle rubber is an agroforestry system that is minimally managed, consisting of forest and rubber trees. The rubber (Hevea brasiliensis, Müll. Arg.) and oil palm (Elaeis guineensis, Jacq.) plantations are intensively managed monocultures. For more detailed information about the study area and the core plot design, see (Drescher et al. 2016). 
Chapter 2: Measuring sound detection spaces for acoustic animal sampling and monitoring

In the $50 \times 50 \mathrm{~m}$ core plots, all trees with a diameter at breast height (DBH) equal to or higher than 10 $\mathrm{cm}$ were counted to derive tree density per hectare, and their DBH was measured to derive total basal area per hectare (Kotowska et al. 2015b). Oil palm DBH was measured including the remaining leaf bases which stay attached to the trunk for many years after the leaf is cut, inflating its measure. The trunks in young oil palm plots did not yet reach breast height, therefore their DBH was null; their density was determined by measuring the area of a block containing 49 oil palms (a $7 \times 7$ block). Tree and mature oil palm height and crown base height were measured using a Vertex measuring device (IV-GS, Haglöf, Långsele, Sweden), and young oil palm height was measured using a meter. Tree height was measured until the tip of the highest branch and oil palm height was measured until the meristem. The crown base height was defined as the height of the lowest branch, or in the case of oil palm the lowest uncut frond. All vascular understory plant individuals ( $>1 \mathrm{~cm}$ height) growing within five randomly placed $5 \times 5$ meter subplots ( 3 subplots in young oil palm plots) were counted and their height measured. Understory plant density was expressed as the number of plants per hectare. In core plots, trees were counted and their DBH measured between August and September 2012 (Kotowska et al. 2015b); all other plant measurements were carried out between February 2013 and August 2014. In young oil palm plantations, all vegetation structure measurements were done in September 2015.

\section{Sound transmission measurement}

The sound transmission measurements were carried out in March 2014 in the core plots and January 2015 in the young oil palm plots, in good weather (no rain) and windless conditions, when insect noise was not prominent. We ruled out daily micro-climate variation effects by varying measurement times in the focal land-use types (Figure A1 in Appendix A), although time of day effects on sound transmission are known to be minor (Ellinger and Hödl 2003). We created a website to help researchers measure sound detection spaces which will be updated with new developments (Darras 2015).

In the middle of each plot, we attached autonomous sound recorders ("Song meters": SM2+ and SM2Bat+, default amplifier gain: 48dB, Wildlife Acoustics Inc., Massachusetts, USA) to a pole at a height of $2 \mathrm{~m}$. The SM2+ recorder was set to a sampling rate of 44.1 kilohertz $(\mathrm{kHz})$ with two acoustic omni-directional microphones for audible sound (SMX-II with Panasonic WM-61 unit), and the SM2Bat+ was set to $192 \mathrm{kHz}$ with two ultrasonic omni-directional microphones for ultrasound (SMXUS with Knowles SPM0404UD5 element). A rope with markings at 1, 2, 4, 8, 16, 32 and 64m was stretched from the recorder front face to the plot border to position the sound emitters at logarithmically increasing distances. The sound emitters' polar axes were always at $90^{\circ}$ from the 
Chapter 2: Measuring sound detection spaces for acoustic animal sampling and monitoring

microphones' polar axes, thus ruling out variation in recorded sound level due to the microphone's polar pattern.

At each marked distance step, we used portable loudspeakers (OnePe DZ-250, Dazumba, Indonesia) and an ultrasound emitter in "chirp" mode (US calibrator Wildlife Acoustics Inc., Massachusetts, USA), to emit audible and ultrasonic test sounds. The audible test sound consisted of a pure tone sequence at $0.5,2,4,8,12$ and $16 \mathrm{kHz}$, one second long at each step, repeated 3 times (Appendix B). The ultrasound test sound was not adjustable and consisted of pure tones at $40 \mathrm{kHz}$, emitted approximately every 0.25 seconds for 10 seconds. The loudspeaker and calibrator were attached to a squeegee with rubber strips to minimize vibration. We emitted test sounds from ground level (10 $\mathrm{cm}$ ) and then fitted the squeegee onto a telescopic cleaning pole to reach heights of 2 and 5 meters. After recording all test sounds from 1 to 64 meters (only until 32 meters for ultrasound) at all heights, we stretched the rope from the back side of the recorder to the opposite direction and repeated the measurements.

\section{Ambient sound level measurement}

We recorded ambient audible sound and ultrasound in all plots using the same autonomous sound recorders, from the same position. From late June to late July 2014, we sampled audible sound (0-20 $\mathrm{kHz}$ ) in the core plots over a total period of 12 days; at any day 2 plots in each land-use type ( 8 plots in total) were recorded simultaneously with $\mathrm{SM} 2+$ units set to $44.1 \mathrm{kHz}$ and fitted with two SMX-II microphones. In December 2014, we sampled ultrasound $(20-80 \mathrm{kHz})$ in the core plots over a total period of 8 days; at any day one plot in each land-use ( 4 in total) were recorded simultaneously with SM2Bat+ units set to $192 \mathrm{kHz}$ and fitted with two SMX-US microphones. Audible sound and ultrasound from the additional young oil palm plots were sampled in the beginning of July 2014 over 4 days using SM2Bat+ units fitted with one SMX-II and one SMX-US microphone. Ambient audible sound recordings were extracted from 20 minutes of sound after sunrise on two consecutive days for each plot (three recordings were unusable due to rain). Ambient ultrasound recordings were extracted from 20 minutes of sound between sunset (around 18:00) and 21:00 for each plot, depending on the timing of rain. We listened to the recordings to identify the sources of sound at different frequency bands.

We produced calibrated sound pressure level measures using the method presented by (Merchant et al. 2015) for each recording channel. The base frequency response of the acoustic SMX-II microphone (flat from $50 \mathrm{~Hz}$ to $15 \mathrm{kHz}$ ) and ultrasonic SMX-US microphones (measured by Wildlife Acoustics Inc. from 20 to $90 \mathrm{kHz}$ ), as well as the SM2+ and SM2Bat+ gain and analog-to-digital converter voltage were extracted from the manufacturer's technical documentation to determine the sensitivity of our recording setup. We additionally measured the frequency response of all our microphones relative to 
Chapter 2: Measuring sound detection spaces for acoustic animal sampling and monitoring

each other at each test sound frequency (audible frequencies for SMX-II microphones and $40 \mathrm{kHz}$ for the SMX-US microphone) to account for the differences between individual microphones. Microphone sensitivities in-between the frequencies of the test sounds were interpolated. Finally, we additionally determined the noise floor of our recorder and the directivity of our sound emitters (Appendix C).

\section{Calculation of sound transmission, ambient sound level, and detection spaces}

We calculated sound transmission, ambient sound pressure level and detection space values for each land-use type against all sound frequencies (hereafter "frequency") and sound source heights (hereafter "height") to detect trends between land-use types at different frequencies and heights. The audio data were analysed in R 3.10 (R Foundation for Statistical Computing 2014) with the package seewave 1.7.6 (J. Sueur, Aubin, and Simonis 2008) and graphs were generated with the package ggplot2 1.0.1 (Wickham 2009). All R scripts and data are available in Appendix D.

For sound transmission measurements, we extracted the sound pressure level from spectrograms with a Hanning window and a window length of $512 \mathrm{~ms}$. We used all pure tones and their background ambient level (one second from the pure tone for audible frequencies and in-between test sounds for ultrasound tones) at all combinations of frequency, distance, height, direction and plot. We used 2 seconds for the pure audible tones at their base frequency $( \pm 0.1 \mathrm{~Hz})$ and 2 seconds for the ultrasound pure tones $(40 \mathrm{kHz} \pm 0.4 \mathrm{~Hz}$ ) at each combination. Ultrasound test signals were emitted as pure tones with irregular timings, so the amplitude peaks were detected automatically and confirmed manually. We obtained a total of 44954 sound measures. Clipped signals were detected automatically and rejected. Pure tone sound pressure level values that were less than $4 \mathrm{~dB}$ higher than their corresponding ambient level were rejected too. Estimated distances to the sound source were computed using the Pythagorean Theorem. We used linear regression models to calculate sound transmission: we defined it as the slope of the sound level linear decay with the logarithm of distance and expressed it in decibel $(\mathrm{dB})$ loss per doubling of distance.

Ambient sound pressure level was measured from the median frequency spectrum of the ambient sound recordings at a reference level of $20 \mu \mathrm{Pa}$ using a modified version of the meanspec ( $\mathrm{R}$ package seewave) function (Appendix D). The ambient sound level and detection spaces of one young oil palm plot were excluded as we used an uncalibrated microphone.

To derive detection spaces, we determine the sound extinction distance: we defined it as the distance at which the source's sound pressure level reaches the ambient sound pressure level, similarly to (Morton 1975). It is also defined as the "communication distance" in research focusing on the implications for animal communication. First, we standardized the loudspeaker's and calibrator's 
Chapter 2: Measuring sound detection spaces for acoustic animal sampling and monitoring

sound pressure level to a reference value of $80 \mathrm{~dB}$ at 1 meter from the source by subtraction. Then, we obtained the extinction distance at the intersection of the linear sound decay line with the ambient sound level threshold (Figure A2 in Appendix A). Thus, the sound extinction distance corresponds to the radius of the detection space, when approximated by a circle, and sound detection spaces were defined as the area of that circle. Data consistency was checked using plots of sound falloff against logarithmic distance to the source at different heights and frequencies at all sites (Appendix E).

\section{Statistical analysis of sound transmission, sound extinction distance, and vegetation structure}

We analysed the contribution of land-use type to sound transmission and sound extinction distance in analyses of variance. We constructed separate linear mixed-effects models to explain sound transmission and the logarithm of sound extinction distance with land-use type, frequency and height (including all interactions) as predictors, using plot as a random effect. We conducted a stepwise model selection (stepAIC function from R package MASS) for each model to determine the best model.

We compared models using vegetation structure, plot, and land-use type variables to find the best predictors of sound transmission. Accounting for heteroscedasticity, we constructed separate feasible generalized least squares models for each ecological predictor (plot, land-use, tree height, tree density, basal area, crown base height, understory plant density and height), together with physical variables (height, frequency) to explain sound transmission. A simple model including only the physical variables was also constructed for comparison purposes. Since tree density information would be available whenever trees are measured, we also included tree density as an additional predictor in the basal area, tree height, and crown base height models to improve their predictive power. We used dummy variables for each height and frequency in the feasible generalized least squares models, as they had complex non-linear relationships with sound transmission. We included all two-way interactions between predictors. We conducted a stepwise model selection for each model. The resulting models, each containing its respective ecological predictor, were compared by Akaike's Information Criterion (AIC) scores, which can be seen as a means of comparing models in terms of predictive ability (Konishi and Kitagawa 2008).

\section{Simulation of detected species richness}

We chose four species from representative animal taxa (frogs, bats, cicadas and birds) whose calls were heard in our recordings to calculate exemplary detection spaces with frequencies, call sound levels, and heights that are typical for each animal group (recordings in Appendix B). For the bat and the bird species, we calculated the call sound level directly from our recordings (method in Appendix 
Chapter 2: Measuring sound detection spaces for acoustic animal sampling and monitoring

C) as we had the distance of the animal at our disposal. For the frog and the cicada, we chose sound source levels of similar species found in the literature. All call sound levels were expressed at a reference distance of one meter, relative to $20 \mu \mathrm{Pa}$. The birds were represented by the short-tailed babbler (Malacocincla malaccensis, Hartlaub), which calls at $71 \mathrm{~dB}$ around $3 \mathrm{kHz}$ and is active close to the ground. We chose a vesper bat (Tylonycteris robustula, Thomas), which is an aerial forager emitting ultrasound mostly around $40 \mathrm{kHz}$, to represent bats, and determined a call level of $59 \mathrm{~dB}$. Further, we use a cicada song (family Cicadidae, undetermined species) that can be found on tree trunks, predominantly heard at $14 \mathrm{kHz}$ (sound recordings in SI). We assumed that it can attain a source sound level of $97 \mathrm{~dB}$, which is the mean sound level of 30 cicada species analysed by (Sanborn and Phillips 1995). Finally we chose frog calls (undetermined species) calling out from the ground, and determined that it had a typical sound source level of $100 \mathrm{~dB}$ (Penna and Solís 1998).

We illustrated how the differing detection space areas would translate to different numbers of detected species based on documented species-area relationships. We used the most relevant and best-fitting power-law models describing species-area relationships as reviewed by (Drakare, Lennon, and Hillebrand 2006): an amphibian model from the West Indies for the frog (MacLean, Kellner, and Dennis 1977), a butterfly model from the West Indies for the cicada (Davies and Spencer Smith 1998), a model for birds of South-East Asia (Brooks et al. 1999) and a model for fruit bats from the Philippines (Heaney 1991).

We compared the detected species richness between land-use systems for each animal taxon. First we computed the sound extinction distance of each representative species based on its call source level, height and frequency. We computed the detection space area from the extinction distance and transformed it to a theoretical detected species richness number using the corresponding speciesarea models. We used a linear mixed-effects model with the logarithm of the extinction distance of each species, accounting for heteroscedasticity, to test for differences between forest and the other land-use types with Tukey post-hoc tests (R package multcomp). The Tukey post-hoc tests reveal the significance of the expected species richness differences between land-use types, as the extinction distance is only a transformed measure for the expected number of species. We visualized the relative detected species richness and calculated it by dividing the detected species richness by the mean detected species richness among all land-use systems for easier comparison and visualization. 
Chapter 2: Measuring sound detection spaces for acoustic animal sampling and monitoring

\section{Results}

\section{Vegetation structure proxies for sound transmission}

We found that the best predictor of sound transmission was the plot identity, despite the loss of degrees of freedom (Table 1). Land use type also predicted transmission better than any of the simple or combined vegetation structure variables.

Table 1: Comparison of generalized least squares models $(n=756)$ explaining variation in sound transmission, accounting for heteroscedasticity. Akaike Information Criterion scores are shown for the resulting models after stepwise model selection from models including all two-way interactions.

\begin{tabular}{l|lll}
\hline $\begin{array}{l}\text { Physical } \\
\text { explanatory } \\
\text { variables }\end{array}$ & $\begin{array}{l}\text { Ecological explanatory } \\
\text { variable }\end{array}$ & $\begin{array}{l}\text { AIC score of LME } \\
\text { model }\end{array}$ & $\begin{array}{l}\text { degrees of } \\
\text { freedom }\end{array}$ \\
\hline height, frequency & (none) & 2633 & 21 \\
& plot & 2392 & 336 \\
& land use & 2496 & 57 \\
& tree density & 2579 & 30 \\
& basal area + tree density & 2555 & 44 \\
& tree height + tree density & 2527 & 58 \\
& crown base height + tree & 2522 & 56 \\
& density & & 24 \\
& understory density & 2625 & 30 \\
\hline
\end{tabular}


Chapter 2: Measuring sound detection spaces for acoustic animal sampling and monitoring

It was not possible to separate the effects of $\mathrm{DBH}$, tree height, tree crown base height and - to a lesser degree - tree density from the effect of land-use, as the tree variables were characteristic for each land-use. However, we show the relationship between all vegetation structure variables and sound transmission in Figures A3-5 in Appendix $A$ as there is often significant $(p<0.05)$ positive correlation with tree height, tree density, and crown base height at frequencies above $12 \mathrm{kHz}$ and heights of $2 \mathrm{~m}$, and especially $5 \mathrm{~m}$. Basal area contrasts with the other tree variables, as it does not scale with height in oil palm plantations.

For understory density and height, which show some overlap between land-use types, we found significant correlations with sound transmission (Figures A3-5 in Appendix A). For instance, understory height is negatively associated with ultrasound transmission at $0 \mathrm{~m}$, indicating that tall vegetation blocks sound for ground-based sources. However understory height has a positive effect at higher source heights ( 2 and $5 \mathrm{~m}$ ). Understory density negatively affects frequencies above $12 \mathrm{kHz}$ for sound sources at $5 \mathrm{~m}$, indicating that it absorbs and scatters sound that would otherwise be reflected from the ground.

\section{Sound transmission patterns}

Frequency and height are the main determinants of sound transmission, but land use still has an impact ( $p=0.0065$, see Table A1). The effects of height and frequency were different in each land-use type since their interactions with land-use showed a distinct effect (all $p<<0.05$ ). Absolute transmission values cannot be compared between frequencies as they depend on our sound source's directivity, which increases with frequency (Figure A6 in Appendix A), meaning that sound waves become more focused and suffer less loss with distance. However for given frequencies, transmission values can be compared across land-use types and heights.

Generally, the higher the source, the higher the transmission values, but trends vary between landuse types (Figure 1). At low frequencies $(0.5 \mathrm{kHz})$, plantations have high ground-level sound transmission, probably because they largely lack a scattering leaf-litter layer. In mature rubber and oil palm plantations, at 8 and $12 \mathrm{kHz}$, sound transmission at medium level $(2 \mathrm{~m})$ often surpasses sound transmission at high levels $(5 \mathrm{~m})$, presumably because of a wave guide effect (Appendix C). 


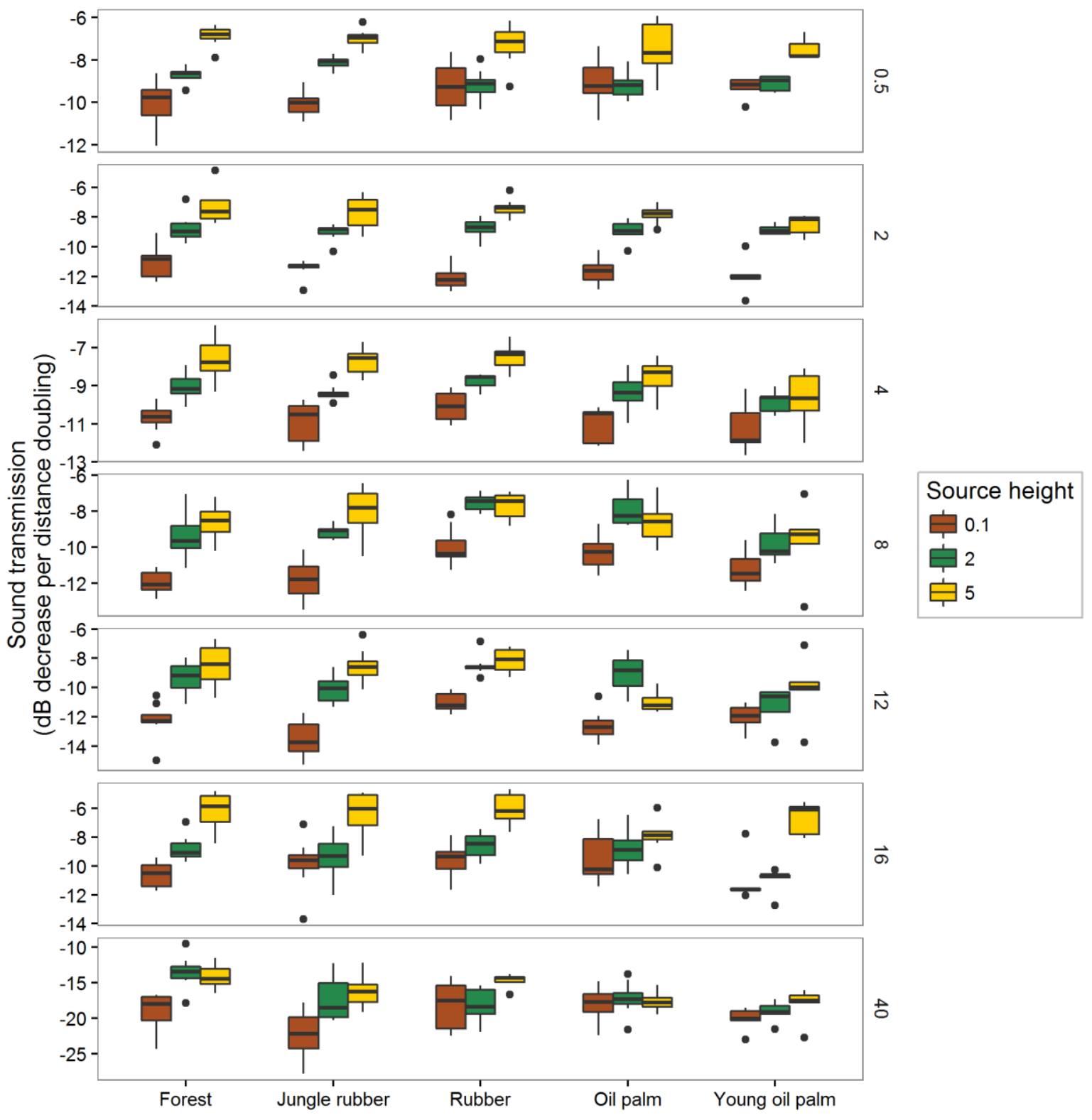

Figure 1: Boxplots of sound transmission values for different sound frequencies, source heights, and land-use systems.

\section{Ambient sound pressure levels}

In sunrise recordings, forest is generally louder than the other land-use types (Figure 2). Plantations are noisier at low frequencies (below $0.5 \mathrm{kHz}$ ) due to engine noise (motorbikes and cars). At approximately $3.6 \mathrm{kHz}$, all land-use types exhibit a peak due to bird activity. Plantations and forest experience a peak in ambient sound at $5 \mathrm{kHz}$ due to insect noise. At high audible frequencies (above $10 \mathrm{kHz}$ ), forest and jungle rubber have distinctly higher sound levels, with a peak at $15 \mathrm{kHz}$, due to cicadas (mostly one species). 
Chapter 2: Measuring sound detection spaces for acoustic animal sampling and monitoring

In night recordings, jungle rubber and forest are distinctly noisier than plantations (up to $20 \mathrm{~dB}$ more) but all land-use types follow a similar pattern. There are ambient level peaks from 3 to $6 \mathrm{kHz}$ due to insect noise and at $70 \mathrm{kHz}$ (probably of insect origin). The origins of the peaks in young oil palm plantations at 60 and $70 \mathrm{kHz}$ were unrecognizable. Similarly as in sunrise recordings, low frequencies ( $50 \mathrm{~Hz}$ to $1 \mathrm{kHz}$ ) are louder than all other frequencies, which is also due to the higher noise floor of the recorder at low frequencies.

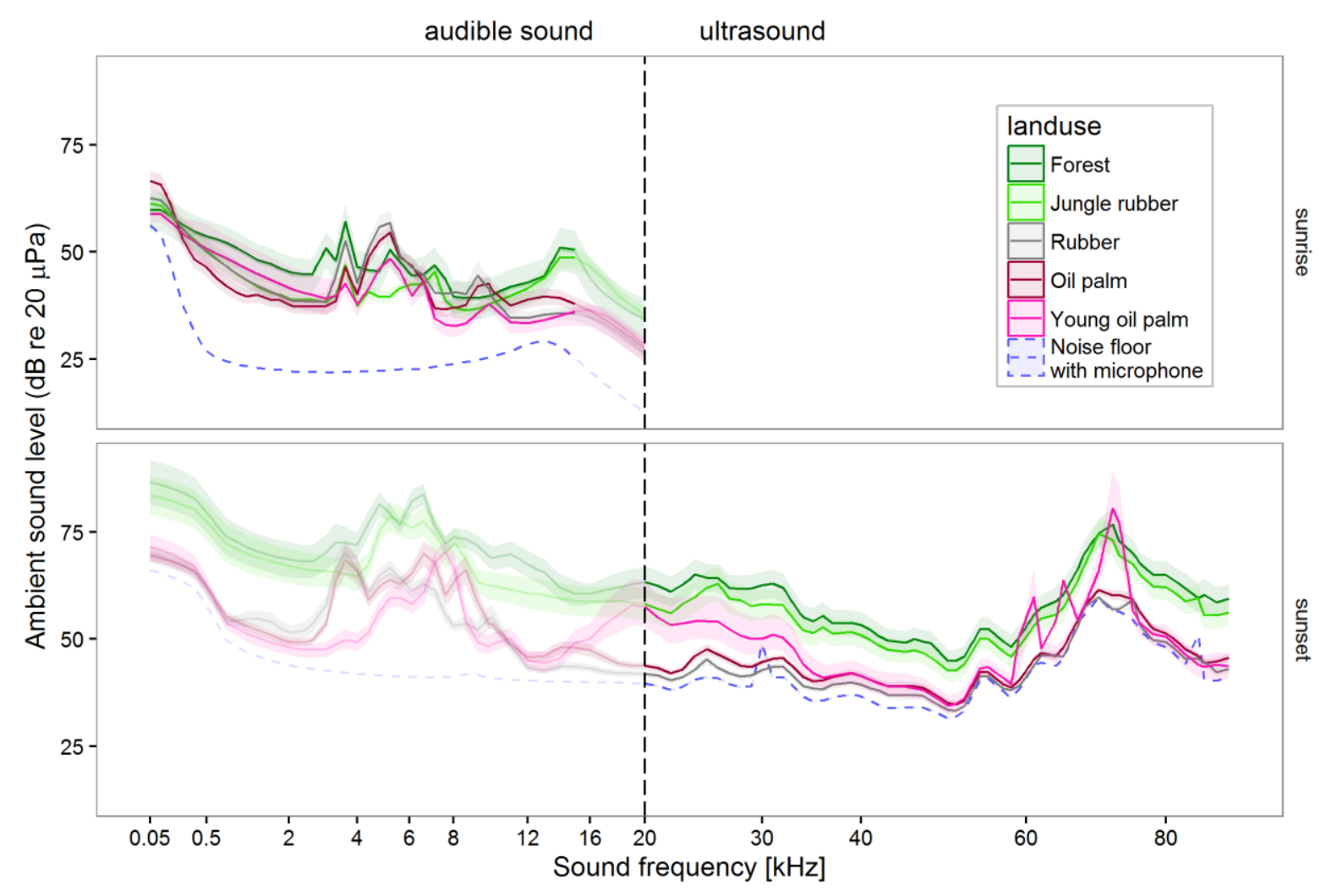

Figure 2: Means of the ambient sound median frequency spectrum (window length: 512) for different land-use systems. Acoustic and ultrasound levels were respectively extracted from 20 minutes of dawn recordings on two consecutive days and 20 minutes of night recordings. Error bands represent standard errors of the mean.

\section{Detection spaces}

Sound extinction distances directly determine sound detection spaces, and the former were mainly determined by sound source frequency and height (see interactive plot), but land-use type still had a minor effect (Table A2). Detection spaces are smallest in forest sites, and generally increase with sound source heights (Figure 3). Compared with forest and jungle rubber, plantations have greater detection spaces at audible and ultrasound frequencies, except between 4 and $6 \mathrm{kHz}$, where their ambient sound level is high (Figure 2). However, detection spaces in oil palm are distinctly smaller than the other plantations at $5 \mathrm{~m}$, as the sound source would often be masked by the fronds. Only for 
sound sources at two meters height at $40 \mathrm{kHz}$ (night time) and also at $50 \mathrm{~Hz}$ (at sunrise) do forest habitats have markedly bigger detection spaces than the other land-use types. Forest detection spaces reach their minima at 15 and $3.6 \mathrm{kHz}$, where their ambient sound levels are high.

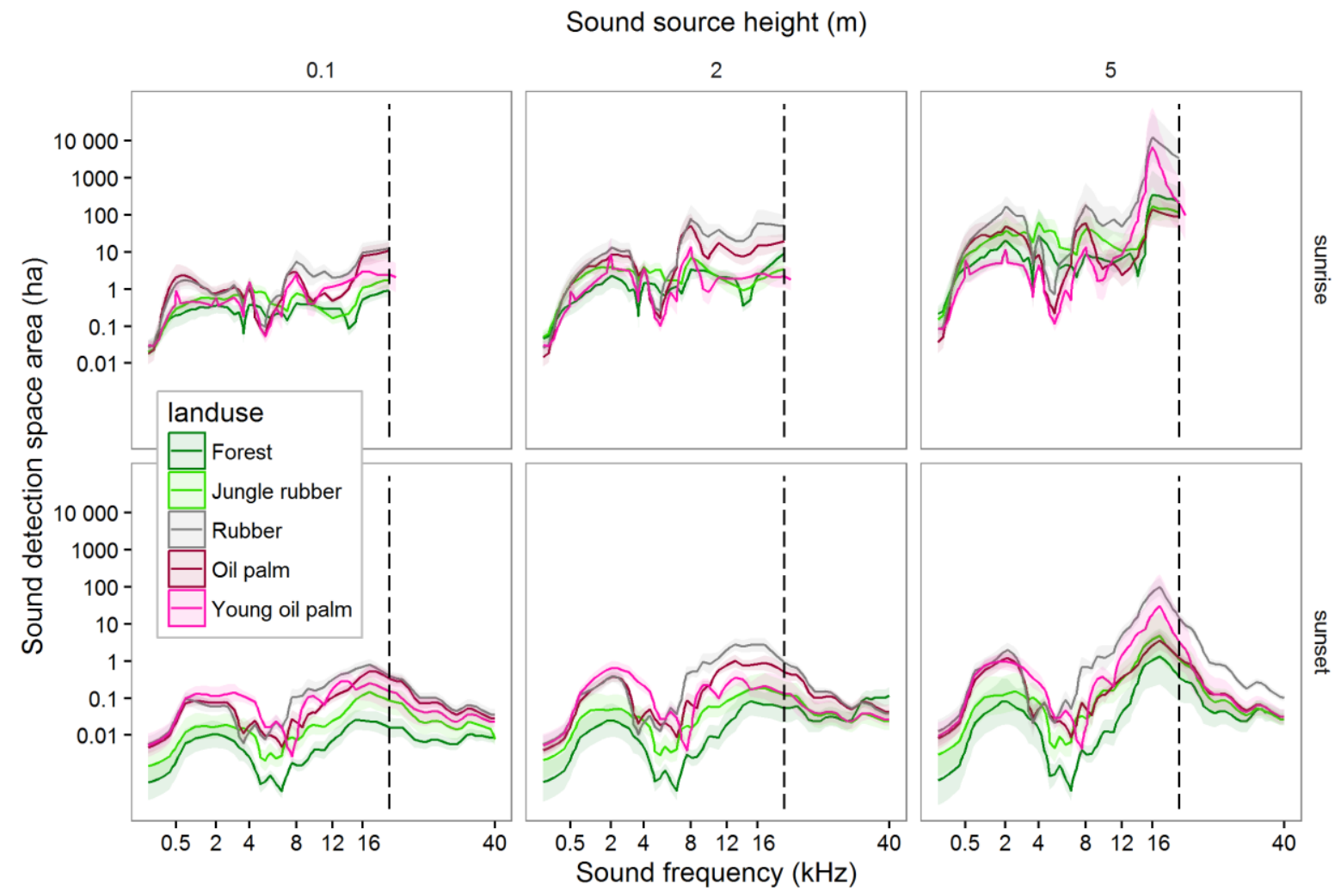

Figure 3: Geometric mean of sound detection space areas for different frequencies and sound source heights in different land-use types, error bands represent standard errors of the mean. Our sound source had increasing directivity with frequency and a source level of $80 \mathrm{~dB}$. See the iPlot for an interactive version.

\section{Detected species richness}

Figure 4 demonstrates that depending on the strength of the call, the sound frequency used by animals, and the stratum in which they vocalize, different trends in detected species richness could be observed on the basis of sampling area alone. We depict $p$-values under the assumption that there is no difference between the relative species richness of forest and the respective land-use. Generally, forest sites have the lowest relative detected species richness except for bats. Rubber plantations consistently reached relatively high values. 


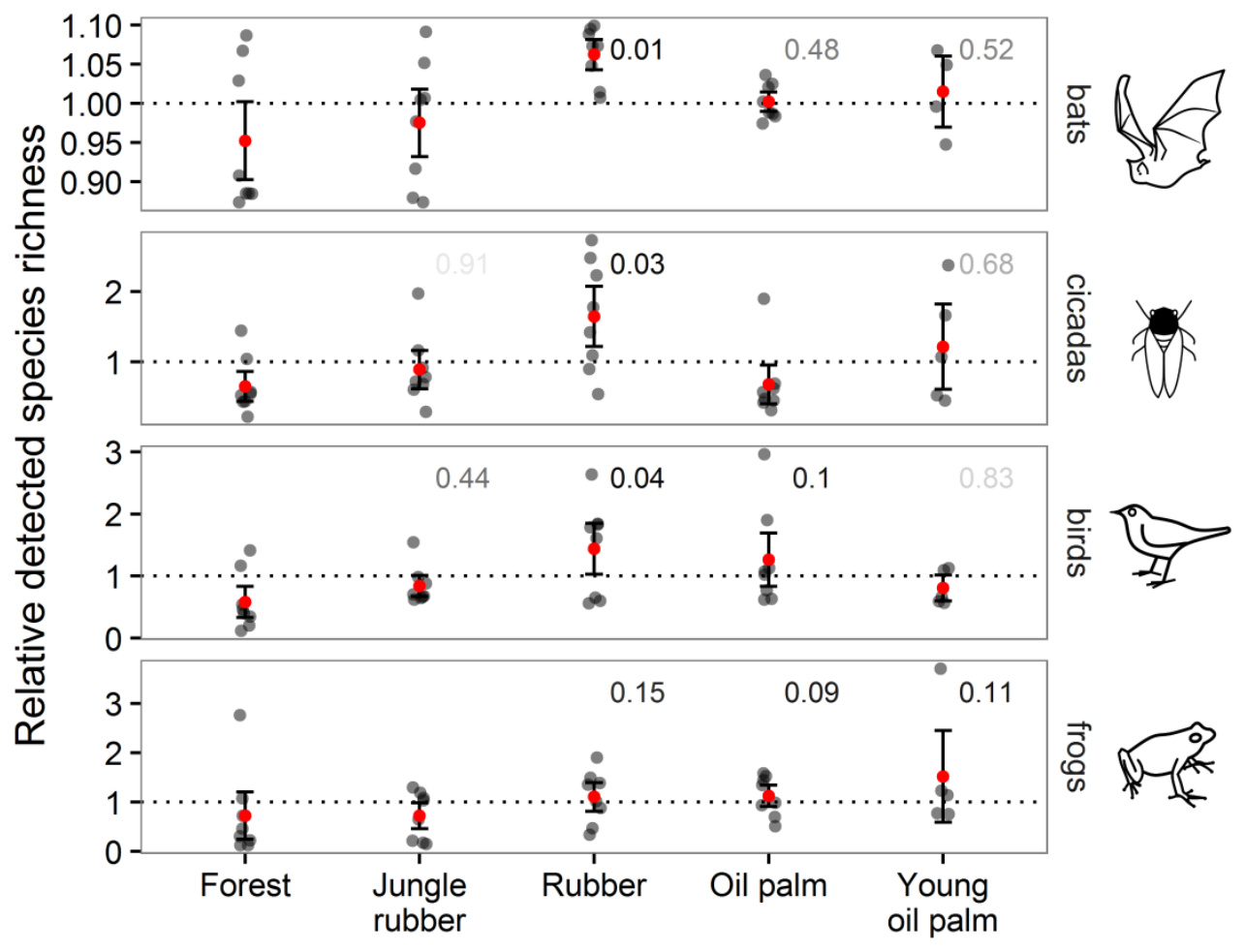

Figure 4: Detected species richness relative to the mean detected species richness across all land-use types. Detected richness describes the number of species that would be found based on the detection space area alone. Mean richness for each land-use type is indicated by red points with standard error of the mean error bars. P-values (rounded to 2 decimals) under the hypothesis of equal species richness to the forest are depicted and derived from a post-hoc test based on a linear mixed-effects model of sound extinction distance with plot as random effect.

\section{Discussion}

\section{The need to measure sound transmission and detection spaces directly}

No simple vegetation structure proxy can be used to determine the sound transmission of a particular habitat or location. Alternatively, more complex combinations of vegetation structure measures could be used to predict sound transmission more accurately (Embleton 1963). However, any such calculations would involve more effort than measuring sound transmission directly. Furthermore, we already tested some combined tree variables (eg. DBH with tree density data), but none of these were satisfying predictors. It is possible that understory measures, which were measured over the course of more than one year, did not exactly represent the plot's understory condition at the time of the sound measurements, but they were still representative of each land-use type.

Land-use type does not predict sound transmission precisely enough either. Similarly, earlier work on sound transmission (Marten and Marler 1977)(Marten, Quine, and Marler 1977) suggested that habitat affects sound transmission only slightly. Climatic conditions, which also affect transmission, 
Chapter 2: Measuring sound detection spaces for acoustic animal sampling and monitoring

are typical for each land-use type but they differ only little between land-use types (Drescher and et al., n.d.). Sound transmission differences would have been greater if we had compared open and wooded systems - young oil palm plantations did not have a closed canopy but the palm fronds were as high as 5 meters.

Presumably, the large unexplained variation in sound transmission within land-use types was due to site-specific differences in plant composition, leaf morphology, and topography. Indeed, plot-level data predicted sound transmission best, solidly supporting our recommendation to measure sound transmission directly in each sampling site. The underlying sources of variation leading to the observed patterns in sound transmission are manifold. Our study was not designed to address these, but they are discussed elsewhere (Appendix C).

\section{Variation in ambient sound}

Ambient sound levels varied considerably with frequency, but they were also distinct between landuse types (Figure 2). They are variable throughout the day and across seasons too, but minor day-today variation was averaged out with our replicates. Similarly, (Ellinger and Hödl 2003) show that ambient noise varies tremendously with the time of the day and the frequency. Thus to fully account for the variability in ambient sound level, multiple time periods should be sampled. However, here we refrained from analysing temporal patterns and focused on dawn levels corresponding to peak bird calling times, and nightly ultrasound levels corresponding to bat and frog calling times. Correspondingly, we advise to match ambient sound recordings with the typical daily activity time of the monitored animals, while also measuring ambient sound during the different sampling seasons. Furthermore, (Ellinger and Hödl 2003) emphasized that ambient noise affects communication distances - thus detection spaces - more than sound transmission. We confirm their findings because the differences in ambient sound level between land-use types were more pronounced than those in sound transmission.

\section{Variation in detection spaces}

We saw that detection space areas also vary tremendously: analogously to ambient sound level, detection spaces are affected by land-use (Table A2), as well as frequency and time of the day (Figure 2), but also height (Figure 3), like (Ellinger and Hödl 2003) showed. Thus, the vocalizing organism is an important determinant due to its choice of stratum within the vegetation. Moreover, the sound level of the vocalization affects detection spaces greatly as they increase with the square of the sound extinction distance. In addition, the latter increase exponentially with higher transmission values, which might result from calls that are lower-pitched or more directive (Patricelli, Dantzker, and Bradbury 2007). Variation in detection spaces becomes even higher when considering species with multiple songs in their repertoires, which might be emitted from different heights. Likewise, complex 
Chapter 2: Measuring sound detection spaces for acoustic animal sampling and monitoring

songs spanning a wide frequency range would not have a unique sound detection space value but rather different detection spaces at each combination of frequency and source level. Hence, out of simplicity and feasibility, we recommend referring to the maximal sound detection space area attained by animals at their highest sound level with their best-transmitting call frequency.

\section{Implications for ecoacoustic studies}

Here we derived estimated species richness values for different exemplary animal groups. We demonstrated how the differences in sound detection space areas would translate into flawed estimates of species richness between land-use types, even though they are relatively similar in our case (all systems contain trees providing a more or less closed canopy). Our results are different for each animal group and identify the multitude of factors which determine the detection space of the species: mainly the sound source amplitude, the stratum it vocalizes in, the sound frequency it uses, the background noise it experiences, and the land-use in which it is emitting sound. Fortunately, our results allow quantifying the sampling area in different sampling sites. We elaborate on technical recommendations separately (Appendix C).

Methodological studies are particularly affected by sound detection space theory. It has been shown previously that acoustic recorders differ in their detection efficacy for different animal groups (Adams et al. 2012) (Huveneers et al. 2015); (Rempel et al. 2013). Indeed, quantifying the detection spaces of these recorders would allow us to compare data from different recording systems and sites. It should be noted that although their ranges would not simply depend on the polar pattern and sensitivity of the microphones used but also on the recorder noise floor and microphone signalto-noise ratio, and these specifications are implicitly taken into account when measuring detection spaces. The different detection areas sampled by different survey methods also have not been taken into account in several studies reporting the efficacy of point counts versus acoustic recordings (Acevedo and Villanueva-Rivera 2006); (Alquezar and Machado 2015); (Celis-Murillo, Deppe, and Ward 2012): clearly, survey methods with larger detection spaces should yield more detections. Similarly, quantifying detection spaces of single species has high relevance for calculating species detection probability and their measured occurrence. It was already suggested by (de Solla et al. 2005) on the example of anuran surveys, that species detectability is driven by specific calling strategies. Indeed detection spaces, when multiplicatively coupled with calling frequencies and population densities - which are respectively probabilities of calling and presence - should be the main determinants of acoustic detection probability. Detection spaces offer an alternative for calculating species occupancy models.

Biodiversity surveys would generally also benefit from quantifying detection spaces. In our study, we observed high correlations between vegetation structure and ultrasound transmission, suggesting 
Chapter 2: Measuring sound detection spaces for acoustic animal sampling and monitoring

that habitats with contrasting vegetation will affect bat detection differently. Indeed, it was shown that vegetation measures correlate with bat activity (Ford et al. 2005), and they have been taken into account in occupancy models recently (Bader et al. 2015). Although it was recognized early that ultrasound transmission differs across habitat types (Patriquin et al. 2003), and it has been observed to affect sampling of bats directly (Kalcounis et al. 1999), such considerations are not systematically taken into account (see for example (Frey-Ehrenbold et al. 2013); (Jung et al. 2012); (Newson, Evans, and Gillings 2015). We argue that instead of measuring vegetation variables, direct quantification of detection spaces would be more useful. Along the same line, variable detection spaces affect the results obtained from sampling birds in different habitat types (Wimmer et al. 2013)(SebastiánGonzález et al. 2015), and they could even influence acoustic diversity indices in relation to vegetation structure (Pekin et al. 2012), since sites with higher sound transmission would have a higher chance of yielding a higher acoustic diversity.

Interestingly, call transmission measurements have been used in a few cases for calculating detection ranges of single cryptic bird species (K. T. A. Lambert and McDonald 2014) and temperate song birds (Furnas and Callas 2015), although in the latter case it is unknown how much they varied between species. The authors could make valid comparisons of abundances between habitats on the basis of an identical acoustic sampling area, taking into account the bird call's source level and height.

\section{Applications for acoustic animal sampling}

Obtaining species richness estimates from acoustic data that are comparable between sampling sites is challenging, as the relationship between area and species richness is not linear. Moreover, each land-use type actually follows its own species-area relationship. On one hand, detection spaces can be larger in some habitats, but they can have shallower species-area curves (e.g. in plantations for birds), which counteract the depicted differences in relative richness. On the other hand, habitats with greater detection spaces do not necessarily have shallower species-area curves (e.g. forest for bats), so the effect can be reversed and is entirely dependent on the organism and its stratum. Hence, calculating expected species richness for a common reference area requires considerable knowledge: comprehensive studies are needed to estimate accurate species-area model parameters and derive absolute species numbers.

Alternative methods still need to be devised to compare species richness without bias in the field of ecoacoustics, especially because richness is the measure of choice for appreciating biodiversity and its conservation value. As we alluded here, for a simple correction, relative detected species richness could be used as a multiplicative term to correct for the total species numbers. Otherwise, when transmission values are known for sampling sites, noise could be artificially added to sound recordings to cap the detection spaces to a common, equal area. However, all approaches would 
Chapter 2: Measuring sound detection spaces for acoustic animal sampling and monitoring

require individual calculations for each species, so that the task is daunting for anyone sampling entire communities. While detection spaces of some species might be used to represent others, some of the variation would be swept under the rug. Overall, easy solutions are not available yet for quantifying detection spaces of each species in entire animal communities, but our study reveals the complexity of acoustic detection space matters and cautions strongly against ignoring them.

Estimating distances to each animal call is a tempting and simple method since all detections below a certain threshold could be filtered to yield a dataset that enables unbiased species richness comparisons while avoiding dealing with the complex, multiple factors affecting detection spaces. Listeners could estimate distances to each animal call in the sound recordings, although the uncertainty might be substantial (Alldredge, Simons, and Pollock 2007). Additionally including sound recordings of test sounds from increasing distances could allow them to appreciate the sound transmission and assist them to estimate call distance. However, it is unknown how accurate human distance estimates from unattended sound recordings would be. Provided animal sound source levels are known, measuring the sound level, and ideally the directivity of animal calls in sound recordings and gauging them with measured transmission values could yield more trustworthy extinction distance estimates and detection spaces.

Other animal population variables like abundance and activity are more straightforward to compare. For instance in one sampling site, animal calling activity and abundance probably increase linearly with the sampling area and thus become quantifiable with known detection space areas. With these measures, comparison at a common denominator area is easier, since we only need to divide them by the sampled area or interpolate to the lowest sampled area. In that sense, detection spaces can be used further to calculate population densities too, simply by dividing the number of detections by the sampled area, addressing a shortcoming of acoustic sampling systems underlined by (Acevedo and Villanueva-Rivera 2006). With bird recordings, listeners can even distinguish between individuals and estimate true abundances by using known call repetition rates and localizing the sound source in stereo recordings. Previously, to calculate population densities with acoustic data, uncalibrated microphone arrays were used (Dawson and Efford 2009), making the analysis and survey setup inherently more complicated. In contrast in marine systems, the theory behind terrestrial animal density estimation using acoustic data is more advanced and has been reviewed by Marques et al. (Marques et al. 2013), although the necessity for measuring detection spaces also prevails.

To some degree, the challenges we underlined for acoustic monitoring also apply to traditional survey methods like point counts. We argue that gauging sound detection spaces allows animal ecologists to obtain comparable data from acoustic surveys as they would obtain from traditional surveys, thereby closing a knowledge gap between these two methods. Although we have exposed 
Chapter 2: Measuring sound detection spaces for acoustic animal sampling and monitoring

the complexity of measuring sound detections spaces and accounting for them in animal acoustic biodiversity surveys, we believe this is a necessary evil to take advantage of the compelling potential offered by passive acoustic monitoring systems as a tool for conservation science.

\section{Glossary}

Sound transmission: coefficient of the linear decay of the sound pressure level with the logarithm of distance to the source level.

Sound extinction distance: the distance at which a source's sound pressure level reaches the ambient sound pressure level

Ambient sound level: Sound pressure level of all surrounding sound, usually sampled with omnidirectional microphones

Species-area curves: Curves describing the relationship between total number of species and the area of the sampled area, both of which might be log-transformed

\section{Role of the Funding Source}

The study sponsors had no influence on the study design; the collection, analysis, and interpretation of data; the writing of the report; and the decision to submit the paper for publication. The first author was granted a research permit from the Forestry authorities (211/SIP/FRP/SM/VI/2012). This study was financed by the Deutsche Forschungsgemeinschaft (DFG, grant number SFB 990/1) in the framework of the collaborative German -Indonesian research project EFForTS (CRC 990).

\section{Acknowledgements}

We declare that there are no conflicts of interest. We thank Edi Djismin, Happy and Patrick Mauritz Diaz for carrying out part of the fieldwork. We thank the following persons and organizations for granting us access to and use of their properties: village leaders, local plot owners, PT REKI, Bukit Duabelas National Park. We also want to thank our Indonesian counterpart Yeni Mulyani for her support, two anonymous referees who greatly improved the manuscript, the Akustikbüro Göttingen for inspiring input in the early stages of the project, and Tobias Weege for valuable advice on acoustic matters. 


\section{Appendix A: Supplementary Tables and Figures}

Table A.1 Analysis of variance of a linear mixed-effects model $(n=777)$ explaining sound transmission with frequency, height, land-use and all interactions. We accounted for heteroscedasticity and used plot as random variable.

\begin{tabular}{l|ll}
\hline Explanatory variables & F-value & p-value \\
\hline frequency & 377 & $<0.0001$ \\
height & 537 & $<0.0001$ \\
land-use & 4 & 0.0065 \\
frequency:height & 11 & $<0.0001$ \\
frequency:land-use & 4 & $<0.0001$ \\
land-use:height & 7 & $<0.0001$ \\
frequency:land-use:height & 2 & $<0.0001$ \\
\hline
\end{tabular}


Chapter 2: Measuring sound detection spaces for acoustic animal sampling and monitoring

Table A.2 Analysis of variance of a linear mixed-effects model $(n=773)$ explaining the logarithmic sound extinction distance (the radius of detection spaces) with frequency, height and land-use data. We accounted for heteroscedasticity and used plot as random variable. The three-way interaction was removed after stepwise selection.

\begin{tabular}{l|ll}
\hline Explanatory Variables & F-value & p-value \\
\hline frequency & 166 & $<0.0001$ \\
height & 228 & $<0.0001$ \\
land-use & 4 & 0.013 \\
frequency:height & 12 & $<0.0001$ \\
frequency:land-use & 2 & 0.0001 \\
land-use:height & 3 & 0.0041 \\
\hline
\end{tabular}




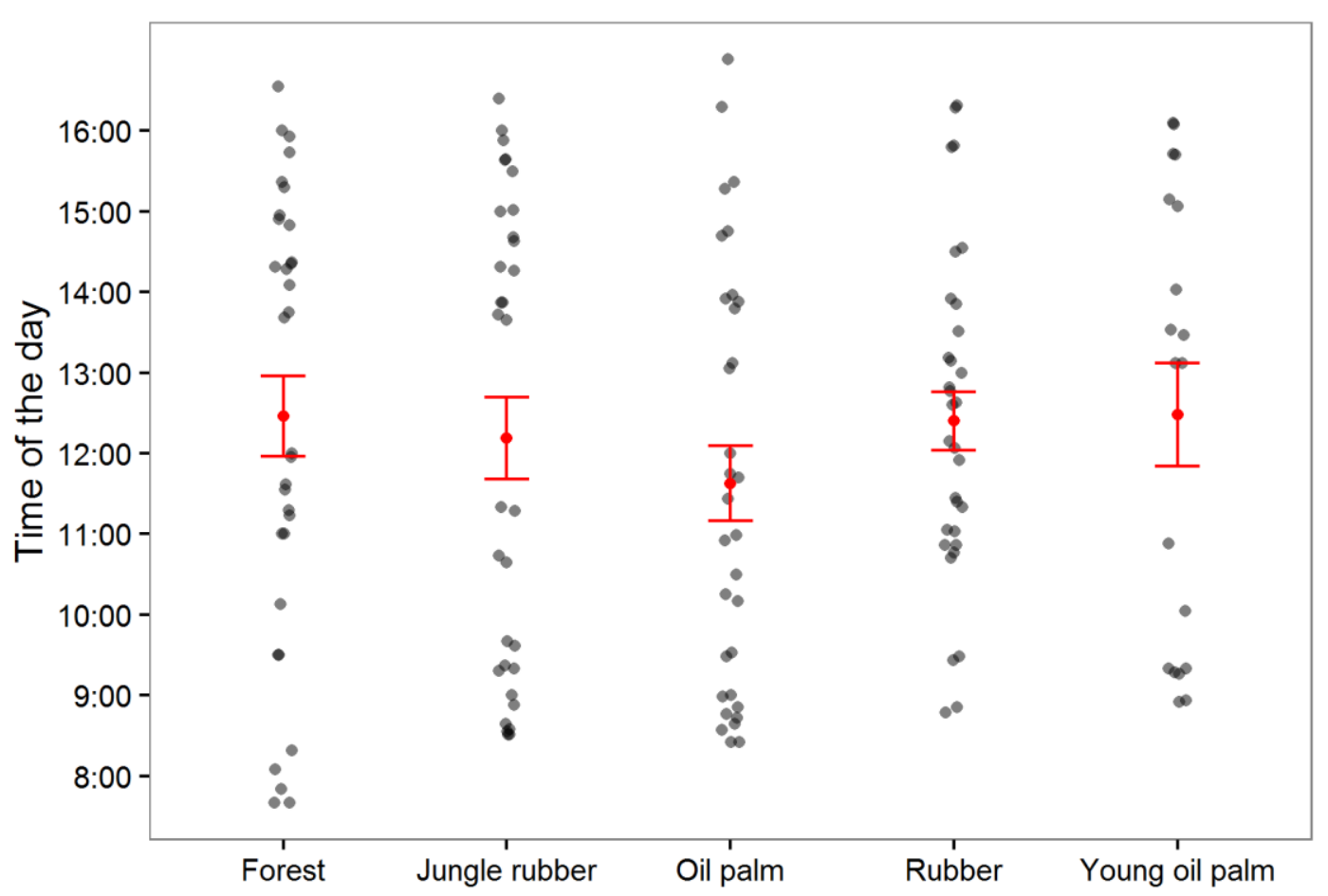

Figure A.1 Time of the day of the sound transmission measurements in each land-use. Grey semitransparent dots represent the measurements (both for front and back directions) and we used jitter to avoid overplotting, red dots represent the means and the error bars represent standard errors of the mean.

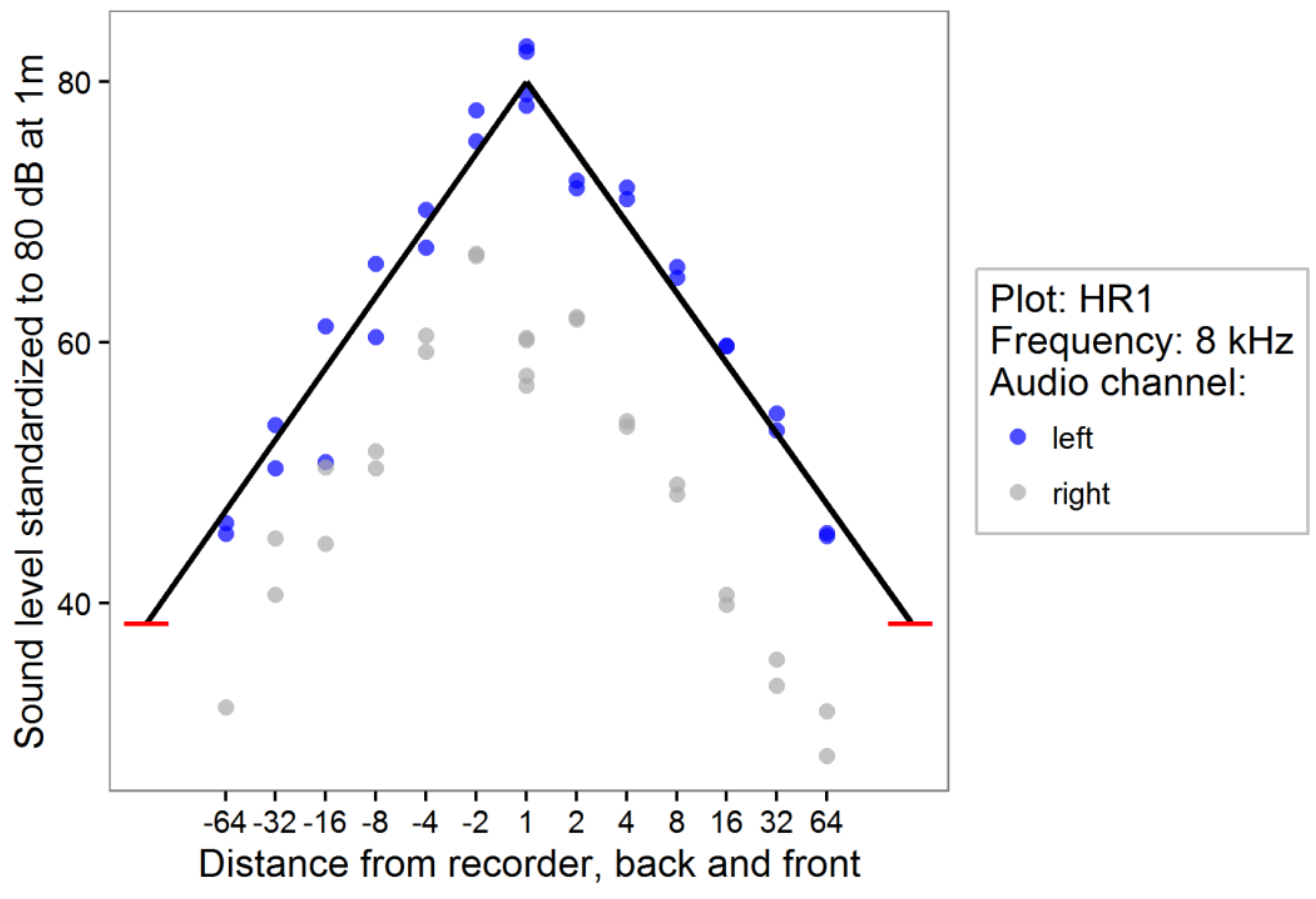

Figure A.2 Typical sound profile for a rubber plantation plot. The red line caps the sound transmission slopes at the corresponding ambient sound level. The microphones have different sensitivities which were coded as a dummy variable in the linear model and thus affect only the regression's intercept. The sound source reference sound pressure level is at one meter from the microphone. Negative distances correspond to the direction to the back of the recorder. 


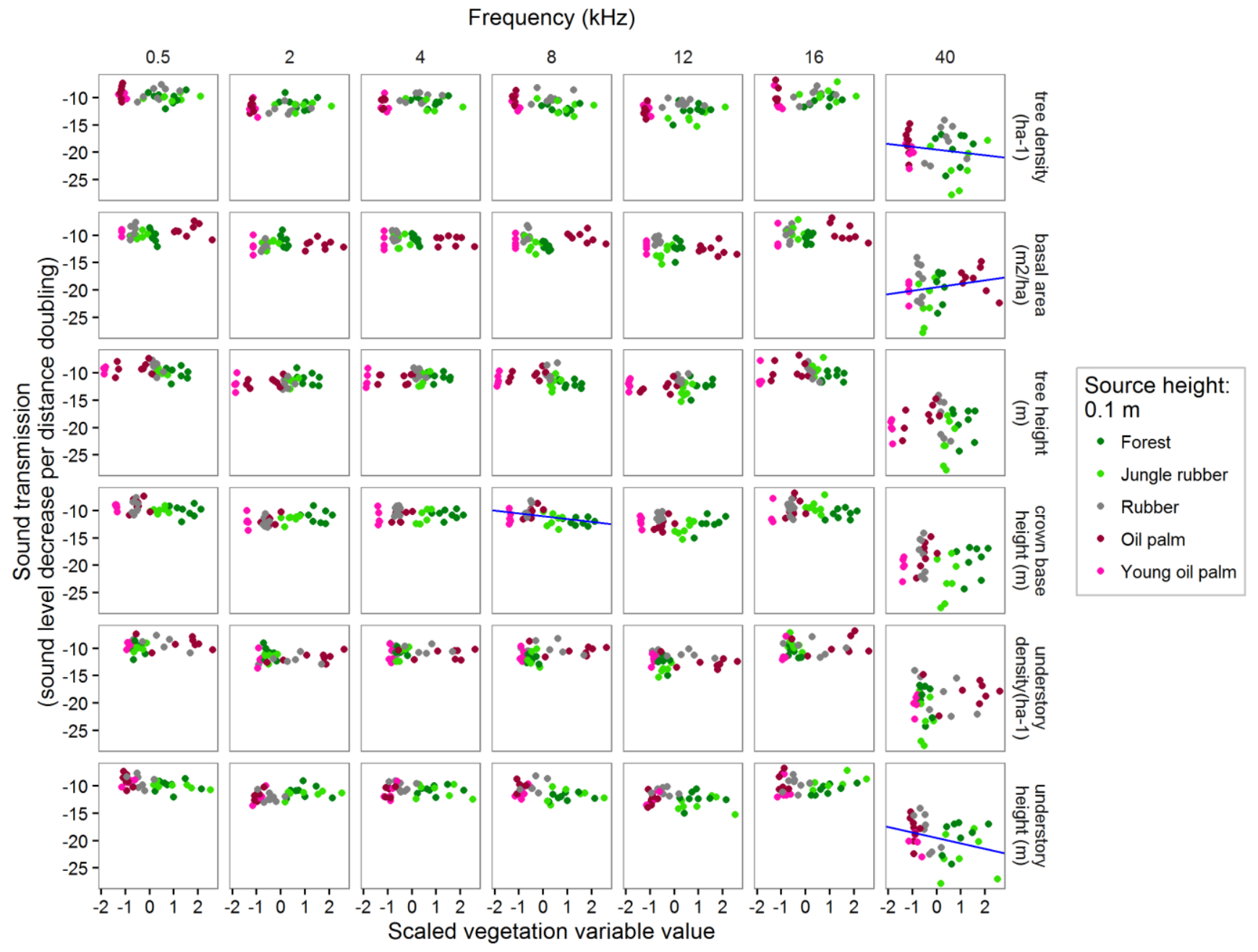

Figure A.3 Correlations between sound transmission and scaled vegetation variables at a sound source height of $0.1 \mathrm{~m}$. Slopes indicate significant $(p<0.05)$ correlations based on a t-test in the simple linear regression model. 


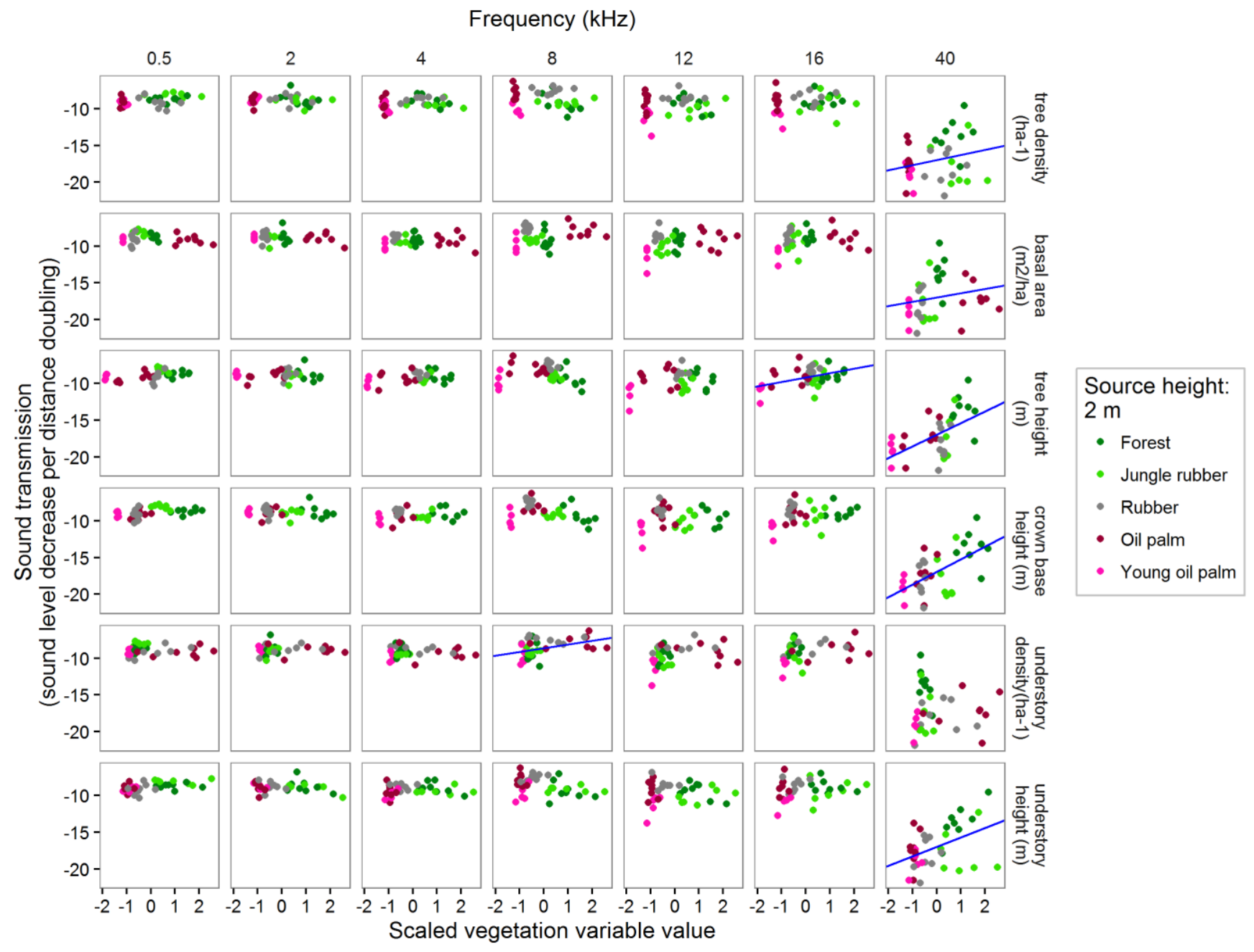

Figure A.4 Correlations between sound transmission and scaled vegetation variables at a sound source height of $2 \mathrm{~m}$. Slopes indicate significant $(p<0.05)$ correlations based on a t-test in the simple linear regression model. 


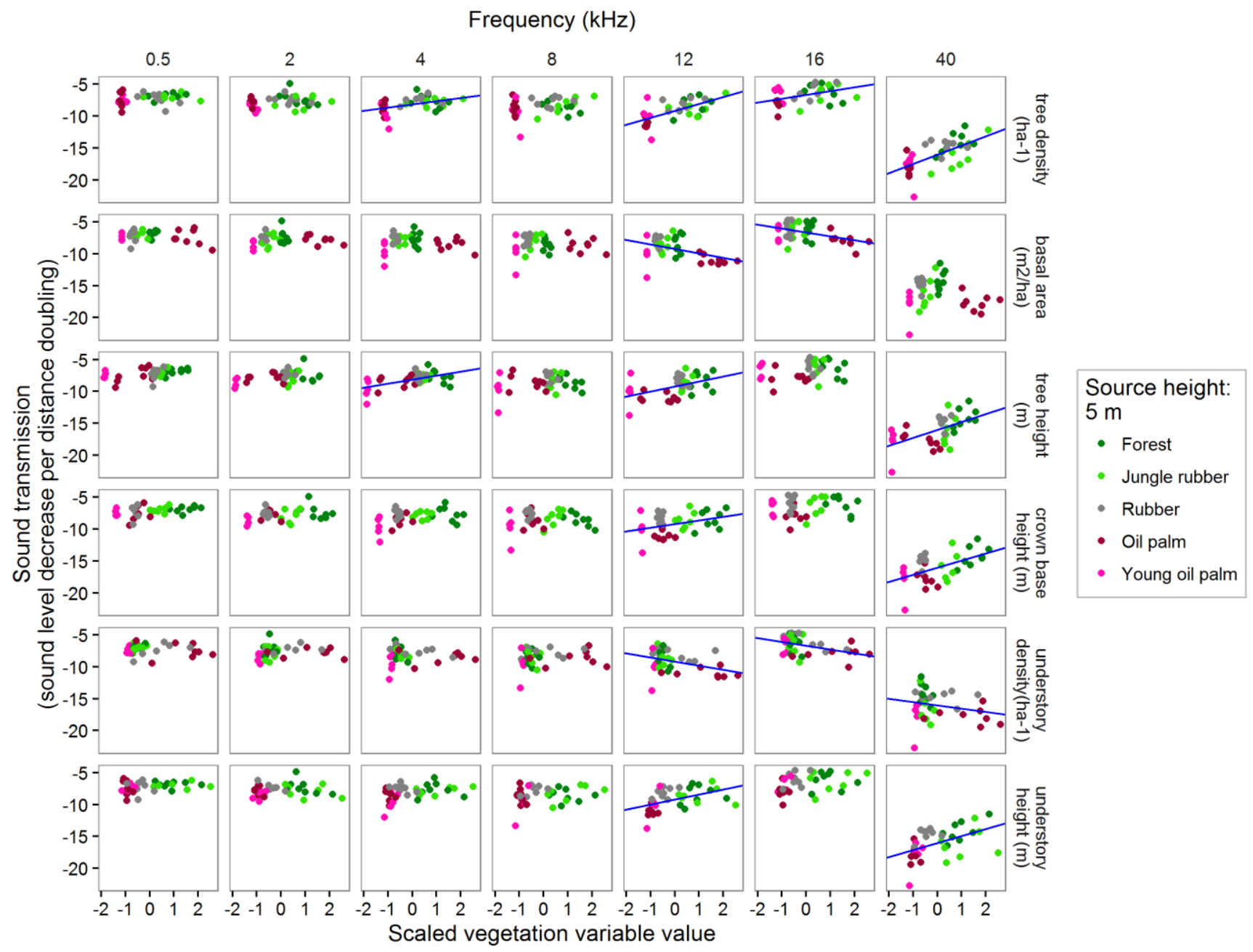

Figure A.5 Correlations between sound transmission and scaled vegetation variables at a sound source height of $5 \mathrm{~m}$. Slopes indicate significant $(\mathrm{p}<0.05)$ correlations based on a t-test in the simple linear regression model. 
Frequency $[\mathrm{kHz}]$

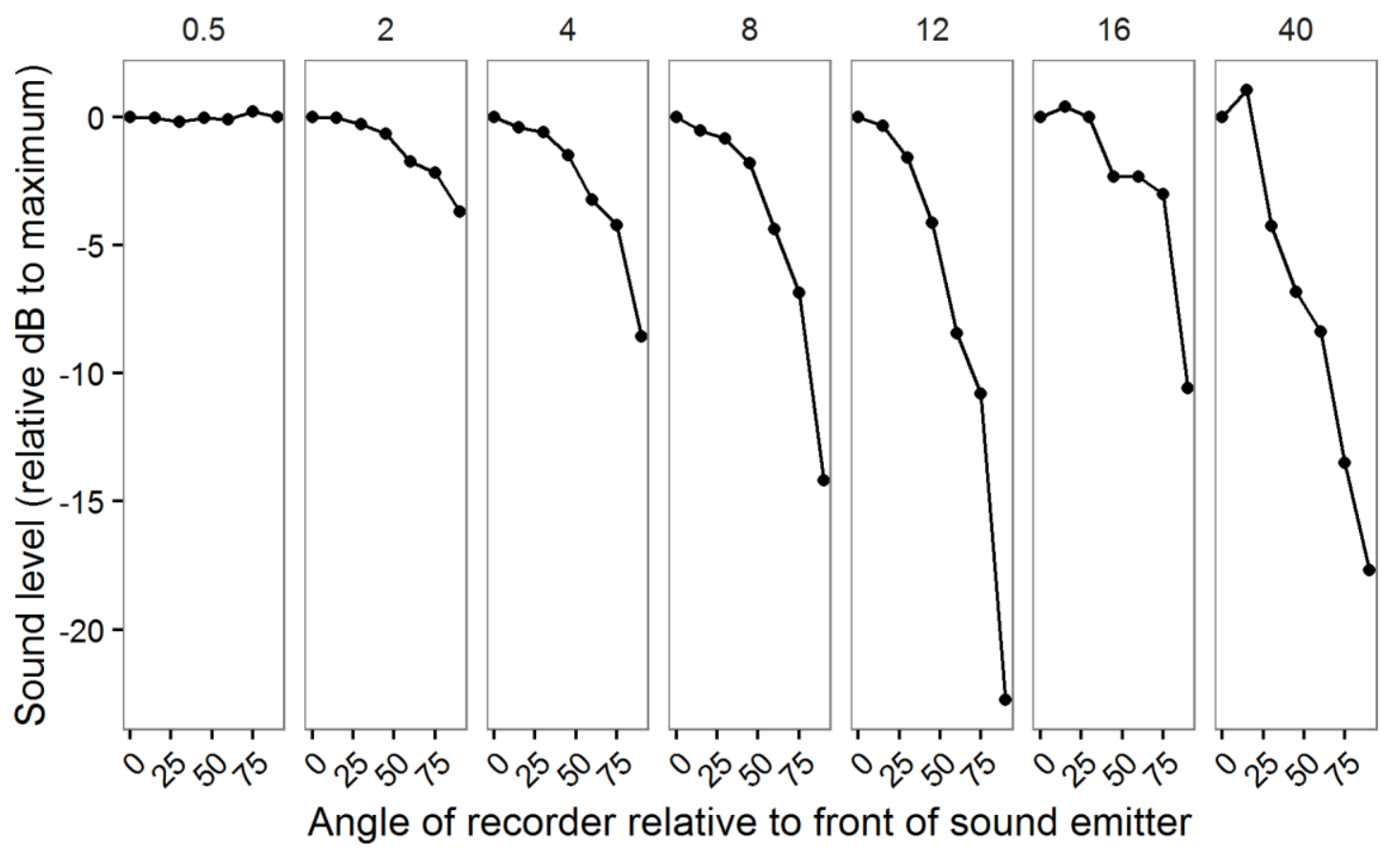

Figure A.6 Directivity of our acoustic loudspeaker ( 0.5 until $40 \mathrm{kHz}$ ) and ultrasound calibrator (40 $\mathrm{kHz})$, measured as the sound falloff with increasing angle from the front of the emitter to the microphone. 


\section{Appendix C: Additional measurements and discussion}

\section{Noise floor measurement}

An anechoic chamber was not available, so we recorded sound for 3 minutes at night in cottonstuffed cool boxes with both types of sound recorders (SM2+ and SM2Bat+) and fitted microphones to determine the noise floor of our recorders. This allows us to compare sound level measures between frequencies to discern when higher values are due to a higher noise floor or to a higher recorded sound level.

\section{Loudspeaker and ultrasound calibrator directivity measurement}

At heights of 0 and $5 \mathrm{~m}$, the sound emitters could not be exactly directed to the sound recorders so we corrected for the diminished sound level by measuring sound emitter directivity at angles of 0 , $15,30,45,70$, and 90 degrees from the front of the sound emitter, at a height of 2 meters above the ground, in a bare land site. The loudspeaker was positioned 2 meters from an acoustic microphone (SMX-II) and the ultrasonic calibrator at 4 meters from an ultrasonic microphone (SMX-US). We achieved the measurements at the different angles by tilting the sound emitter upwards at each angle increment, and repeated the measurements with the sound emitter upside down. We took the mean of the values to find the directivity of our sound emitters at each angle and frequency (Fig A6).

\section{Determining bird and bat call sound pressure levels}

Using the distance to the animal and the microphone sensitivity, we computed the sound pressure level from the mean frequency spectrum (window length of 512 meanspec function in R package seewave) of four different calls for each animal. We calibrated the sound pressure level using (Merchant et al. 2015) and extracted the maximum SPL to characterize the peak sound pressure level of the bird and the bat. For the bird Malacocincla malaccensis, we used the average of two estimates of its distance to the sound recorder from two human listeners. The sound pressure level at one meter was calculated using the inverse square law for sound loss with distance. For the bat Tylonycteris robustula, we used a recording of a captured individual situated exactly at one meter from the microphone. 
Chapter 2: Measuring sound detection spaces for acoustic animal sampling and monitoring

\section{Discussion of sound transmission sources of variation}

Many variables affect sound transmission, but our study was not designed for pinpointing its determinants. It was shown before that sound from higher up usually transmits better within vegetation strata (Marten and Marler 1977). Indeed, low sound sources lose a greater proportion of their energy as it is reflected off (or absorbed by) the ground and cannot reach the recorder, which is worsened by the presence of temperature gradients at the ground, leading to a "sound shadow" effect (Wiley and Richards 1978). Our design differs from previous studies in that we recorded sound from the listener's perspective, so that sound from higher strata has to cross the tree crowns to reach the recorder. Nevertheless, sound transmission generally improved with height (Figure A7).

Under specific circumstances however, sound transmission from low and medium levels can be higher than expected. At higher frequencies, sound reaches wave lengths that allows it to interact with leaves: at $8 \mathrm{kHz}$, the wavelength attains $4 \mathrm{~cm}$ and matches the size of small tree leaves in our sites. In plantations, rubber leaflets have entire leaflets, elliptical to ovate, with dimensions of 4 to 50 $\mathrm{cm}$ times 1.5 to $15 \mathrm{~cm}$ (Boer 2000) and oil palm leaflets are 35 to $65 \mathrm{~cm}$ times 2 to $4 \mathrm{~cm}$ large (R. H. V. Corley and Tinker 2008). Indeed, live plants act as a low-pass filter (Martens et al. 1985), so that higher frequencies can interact with them. Note that we carried out our measurements inside a mature vegetation structure with a canopy (except in young oil palm sites): at two meters height, the sound path from the emitter to the recorder was relatively unobstructed (especially in plantations). We suggest that at these heights, our wooded habitats enhance sound transmission of high frequencies: sound emitted between the ground and canopy might be channelled, thus confirming the "wave-guide effect" mentioned by (Wiley and Richards 1978). As (Morton 1975) also postulated, the canopy acts as the ceiling and we might add that the ground acts as the floor. Further, leaves are mostly horizontal in the lower crown parts (pers. obs.) and sound reflection coefficients of plant leaves increase strongly with sound frequency (Martens et al. 1985). Leaves could reflect sound like a myriad of mirrors.

Other sources of sound transmission variation include climatic variables, such as atmospheric temperature gradients and turbulences, as reviewed by (Ingård 1953). Our test signals were repeated at multiple distances, typically over 30 to 45 minutes. The daily variations of climatic variables (temperature, humidity, etc.) were implicitly averaged over the course of the day in our measurements and thus should not introduce a bias in our comparisons between land-uses. (Ellinger and Hödl 2003) also showed that the time of the day played only a minor role compared to height and frequency thus sound transmission measurements need not to be replicated at several times of the day. Nevertheless, it is possible that systematic climatic differences contributed to our observed trends, but then again they would be inherent to each land-use. Interestingly, it is possible that in the 
Chapter 2: Measuring sound detection spaces for acoustic animal sampling and monitoring

core plots, sound waves could meet a temperature gradient in the tree crown, thus refracting down instead of being lost in the upper levels (Wiley and Richards 1978), further enhancing the sound channelling effect hypothesized before.

\section{Technical aspects and recommendations}

Sound source directivity has a considerable impact on sound transmission measurements (Wiley and Richards 1978), and therefore, sound detection spaces. Common commercial loudspeakers such as the one we used have a directivity that is physically determined by the sound source size: generally the larger the source, the more directed the sound is for increasingly lower frequencies.

In that sense, they are representative of animal sound sources, which are also directional and we might add that moderately-sized birds probably have sound-emitting organs of similar size as our loudspeakers (membrane diameter: $25 \mathrm{~mm}$ ). Thus the varying directivity precludes the comparison of transmission values across the frequency range. While loudspeakers that are omni-directional across a part of our frequency range such as these employed in architectural acoustics would allow designing experiments describing transmission trends along the frequency axis, their price is prohibitive for field ecologists and such systems are not portable. These systems should be used for quantifying sound transmission in general terms irrespective of directivity and without reference to animal calls, which are generally directional. Preferably, in biodiversity surveys, sound transmission of every animal call should be measured separately. (Llusia, Márquez, and Bowker 2011) provided a short protocol for measuring sound detection spaces of single species using loudspeakers calibrated to the source's sound level, but did not take into account the directivity of the loudspeakers nor the variations in ambient noise. Ideally, sound detection spaces should be measured using live animals, which could be feasible for studies focusing on single species but daunting for general biodiversity studies dedicated to entire communities.

We recommend using pure tones for measuring sound transmission and demonstrated that simple portable loudspeakers can be used. Sound transmission measurements traditionally rely on a system of specialized equipment (Ellinger and Hödl 2003) to calculate sound transmission. In contrast, we leverage freely available computational technology to obtain the same results. Likewise, white noise is usually used to characterize multiple frequencies in one go (Morton 1975). We could also achieve this with our loudspeakers, however our results were more variable than with pure tones, whose intensities can be adapted singly to compensate for the irregular frequency response of low-end loudspeakers. Besides, for sound transmission measurements, the absolute sound level of the loudspeakers needs not to be known or calibrated: since sound transmission is described by the slope of the sound fall-off, thus it is not affected by the absolute source level (the intercept, which is affected by the microphone sensitivity). 
Chapter 2: Measuring sound detection spaces for acoustic animal sampling and monitoring

We also advocate using logarithmically increasing source distances instead of recording sound in two points only: a wider frequency range can be covered (Marten et al. had difficulties to record the higher frequencies at a distance of $100 \mathrm{~m}$ in some habitats) as different frequencies have different a priori unknown - extinction distances. Moreover, low-cost loudspeakers typically do not have flat frequency responses, thus some frequencies clip at one or two meters from the recorder while others do not, thus multiple sampling distances are required. Having more data points also allows estimating the transmission more accurately and to sample a whole transect in the habitat, as transmission will vary with the exact position of the emitter in the vegetation, especially at higher frequencies which are affected more strongly by vegetation.

We argue that total sound transmission values are more practical for ecologists than excess transmission values, commonly used by acousticians. Excess transmission expresses the difference of the measured sound level to the theoretical sound level that would have been attained by a point source of sound in free space (Marten and Marler 1977). However, terrestrial systems of interest to ecologists invariably have a ground and often vegetation, and animal sound sources are directional, so that substantial departures from the theory are the rule.

There are several possibilities to measure ambient sound pressure levels. We used median instead of mean ambient sound levels to account for the fact that birds and mammals usually vocalize when conspecifics are quiet: median values are less influenced by extreme values and would thus be more representative of the constant background sound level that vocalizing animals must exceed. Note that this consideration may not apply for some insects and amphibians which vocalize in chorus (Greenfield 1994) or irrespective of conspecific calls, but these sounds are generally continuous and thus median sound levels would yield similar results. Better still, it would be even more accurate to devise methods that measure the sound pressure level of background noise, filtering out impulsive sounds to measure only the continuous sound that vocalizing animals must exceed. 
Chapter 3: Bird Responses to Lowland Rainforest Conversion in Sumatran Smallholder Landscapes, Indonesia

\section{Chapter 3: Bird Responses to Lowland Rainforest Conversion in Sumatran Smallholder Landscapes, Indonesia}

In press in:

Prabowo, E.W., Darras, K., Clough, Y., Toledo-Hernandez, M., Arlettaz, R., Tscharntke, T., (accepted).

Bird Responses to Lowland Rainforest Conversion in Sumatran Smallholder Landscapes, Indonesia.

Plos ONE. doi:10.1371/journal.pone.0154876

Walesa Edho Prabowo $\rrbracket^{1}$, Kevin Darras $\rrbracket^{* 2}$, Yann Clough ${ }^{2}$, Manuel Toledo-Hernandez ${ }^{2}$, Raphael

Arlettaz ${ }^{1}$, Yeni A. Mulyani ${ }^{3}$, Teja Tscharntke ${ }^{2}$

ๆ These authors contributed equally to this work

* corresponding author email: kdarras@gwdg.de (KD)

${ }^{1}$ Division of Conservation Biology, Institute of Ecology and Evolution, University of Bern, Bern, Switzerland

${ }^{2}$ Division of Agroecology, Department of Crop Sciences, Georg-August University of Göttingen, Göttingen, Germany

${ }^{3}$ Department of Forest Resources Conservation and Ecotourism, Faculty of Forestry, Bogor Agricultural University, Bogor, Indonesia 
Chapter 3: Bird Responses to Lowland Rainforest Conversion in Sumatran Smallholder Landscapes, Indonesia

\begin{abstract}
Rapid land-use change in the tropics causes dramatic losses in biodiversity and associated functions. In Sumatra, Indonesia, lowland rainforest has mainly been transformed by smallholders into oil palm (Elaeis guineensis) and rubber (Hevea brasiliensis) monocultures, interspersed with jungle rubber (rubber agroforests) and a few forest remnants. In two regions of the Jambi province, we conducted point counts in 32 plots of four different land-use types (lowland rainforest, jungle rubber, rubber plantation and oil palm plantation) as well as in 16 nearby homegardens, representing a small-scale, traditional agricultural system. We analysed total bird abundance and bird abundance in feeding guilds, as well as species richness per point count visit, per plot, and per land-use system, to unveil the conservation importance and functional responses of birds in the different land-use types. In total, we identified 71 species from 24 families. Across the different land-use types, abundance did not significantly differ, but both alpha and gamma species richness were reduced in plantations. Feeding guild abundances between land-use types were variable, but homegardens were dominated by omnivores and granivores, and frugivorous birds were absent from monoculture rubber and oil palm. Jungle rubber played an important role in harbouring forest bird species and frugivores. Homegardens turned out to be of minor importance for conserving birds due to their low sizes, although collectively, they are used by many bird species. Changes in functional composition with land-use conversion may affect important ecosystem functions such as biological pest control, pollination, and seed dispersal. In conclusion, maintaining forest cover, including degraded forest and jungle rubber, is of utmost importance to the conservation of functional and taxonomic bird diversity.
\end{abstract}


Chapter 3: Bird Responses to Lowland Rainforest Conversion in Sumatran Smallholder Landscapes, Indonesia

\section{Introduction}

Land-use change is inevitable: the growing human population, increasing wealth, and development of global markets lead to increasing demands for natural products, and as a response, natural ecosystems continue to be converted to agriculture (Schroth et al. 2013). This expansion endangers wildlife biodiversity as well as the capacity of the ecosystem to continue delivering services (Jonathan A. Foley et al. 2005a). The quest for more cropland has put more pressure on tropical regions, which often offer lower production costs and less environmental regulation (H. K. Gibbs et al. 2010). Tropical lowland forest is one of the most biodiversity-rich terrestrial ecosystems, but with the continuing expansion of agricultural land, that biodiversity is in a fragile state, in particular in Southeast Asia (Sodhi et al. 2004).

The island of Sumatra has experienced rapid land-use change. Indonesia's annual forest cover loss is now estimated to be the highest in the world (Margono et al. 2014), and by $201070 \%$ of Sumatra's forested area had been converted (Margono et al. 2012). In Jambi, rubber agroforestry and oil palm agroforestry respectively covered 1284003 and 941565 ha, summing up to 45\% of anthropogenic land-use cover (Dinas Komunikasi dan Informatika Prov. Jambi 2013). Plans by the Indonesian government to double its palm oil production by 2020 suggest this trend will continue (L. P. Koh and Ghazoul 2010). In the face of dwindling forest cover, the question arises as how to compensate for the natural habitat losses and their impact on functional and taxonomic biodiversity.

In Southeast Asia, the response of bird communities to forest conversion has been documented before. In Thailand, bird diversity is lower in commercial rubber and oil palm plantations than in forest, and frugivorous-nectarivorous, insectivorous, and forest species are most affected (Aratrakorn, Thunhikorn, and Donald 2006). Similar findings were reported by Thiollay for agroforests (including rubber) situated in separate regions of Sumatra (Thiollay 1995a). While monoculture agro-forests are also omni-present in our study region, agricultural systems with a more complex structure and plant composition might serve as refuges for plants and animals. Two such land-use systems are commonly found in our study region in the form of jungle rubber - a forest-like rubber plantation - and homegardens - defined here as a multistory combination of trees and crops around the homestead (B. M. Kumar and Nair 2006). Despite that, jungle rubber is not equivalent to forest in conservation terms, but it can harbor more birds than rubber monocultures (Beukema et al. 2007). Homegardens are another diverse land-use system but on a smaller scale, and they are widely adopted by Indonesian households as they can support households in times of food shortage or generate additional income (Marsh 1998). They are traditional agricultural systems characterized by low intensity management and high plant biodiversity, sometimes resembling natural forest (Mohri et al. 2013). However plant species richness and structure are variable and determined by social and 
Chapter 3: Bird Responses to Lowland Rainforest Conversion in Sumatran Smallholder Landscapes, Indonesia

geographic factors (B. Mohan Kumar and Nair 2004). Jungle rubber and homegardens are traditional agricultural systems with potential for conservation due to their high plant species richness and structural heterogeneity. Jungle rubber however may be threatened, as it was once prevalent in the province of Jambi but it is being replaced by monospecific plantations (Feintrenie and Levang 2009).

The effect of land-use change on birds in the relatively small-scale mosaics of smallholder rubber plantations, oil palm plantations, jungle rubber, remnant forest blocks and homegardens, have never been jointly investigated. Existing studies sampling birds in rubber habitats usually come either from large-scale commercial plantations (Aratrakorn, Thunhikorn, and Donald 2006), or from older, intensive single-site transect studies on a subset of these systems (Beukema et al. 2007). Oil palm plantations have been more intensively studied by Azhar et al. in peninsular Malaysia (Azhar et al. 2015), (Azhar et al. 2011), but without comparison to other agricultural land-use systems. In Indonesia, smallholder oil palm plantations cover an equally large area as commercial plantations (USDA 2007) but they have lower intensity management and yields, thus having greater potential for biodiversity conservation (Azhar et al. 2013), (Azhar et al. 2011), although some evidence suggests that the difference may be negligible (Asrulsani Jambari et al. 2012). The bulk of the rubber production in Indonesia is also coming from smallholder plantations (Kopp and Brümmer 2015) with low management intensity. Valorising these small-scale agricultural habitats could not only help to meet conservation targets by maintaining a more heterogeneous landscape for bird communities; it could also enhance their own ecological functions, since birds can control arthropods pests (Maas, Karp, Bumrungsri, Darras, Gonthier, Huang, Lindell, Maine, Mestre, Michel, Morrison, et al. 2015), disperse seeds, and pollinate plants (Whelan, Wenny, and Marquis 2008).

Here we use lowland rainforest as a reference to investigate the effect of conversion to different land-use types on the total bird abundance, the abundance within feeding guilds, different measures of species richness, and species composition of bird communities, and evaluate the conservation value of these habitats. We conducted bird point counts in 32 plots of 4 different systems: lowland rainforest, jungle rubber, rubber plantations and oil palm plantations, which are the main land-use systems in the landscape mosaic in Jambi. We additionally sampled birds in 16 homegardens that represent small-scale traditional systems, situated in the same study region to evaluate their contribution to conservation. We expect that bird species richness is highest in forest due to the more diverse food resources and structural complexity, and lowest in the monocultures. Homegardens and jungle rubber may have intermediary biodiversity levels and thus act as refuges for forest species because of their high plant species diversity and structural heterogeneity. We also expect that some groups, such as feeding generalists (omnivores), reach higher abundances in the 
Chapter 3: Bird Responses to Lowland Rainforest Conversion in Sumatran Smallholder Landscapes, Indonesia

monocultures because these species are more flexible in their diets and can thus take advantage of disturbed systems' food resources.

\section{Materials and methods}

Data are publicly available on Dryad (doi:10.5061/dryad.g77m8). The study plots are privately owned except for the forest sites, which are situated in the protected forests Harapan Rainforest (PT. Restorasi Ekosistem Indonesia) and the Bukit Duabelas National Park.

Bird field sampling was observational and carried out by the first author, who is Indonesian, so no research or collection permit was required. The joint co-authors' research permit (number 211/SIP/FRP/SM/VI/2012) was recommended by the Indonesian Institute of Sciences (LIPI) and issued by the Ministry of Forestry.

This research involved human participants from 16 households for the homegarden survey. No institutional review board or ethics committee was available in our project region. Instead, the survey was approved by the Unit Management office of the CRC 990 at the local University of Jambi and by the project's Indonesian counterparts. Local authorities (village leaders) were informed of the survey with official letters from the Unit Management office. Complying with Indonesian customs, simple verbal consent was obtained from each household head for sampling in their homegardens and participating in the interview. Participants signed receipts for obtaining monetary compensation after the interview. Personal data were first recorded in the field for identification purposes and later removed for the statistical analysis and deposition on Dryad.

\section{Study sites}

The study sites are situated near two protected forests in Jambi Province, Sumatra, Indonesia (Fig 1). Thirty-two plots, 50×50m in size, with 16 plots per region, were established on lowland rainforest and 3 transformed habitats: jungle rubber, rubber (Hevea brasiliensis) plantation and oil palm (Elaeis guineensis) plantation in the frame of the CRC 990 (EFForTS) project. Our lowland rainforest sites are natural forests that have experienced some disturbance such as clearing and logging. Jungle rubber is planted rubber with secondary forest re-growth and minimum management practices (Feintrenie and Levang 2009). Rubber plantations and oil palm plantations are intensively managed monoculture plantations covering an extensive area of the province. The study design and region is described in detail by Drescher at al. (Drescher et al. 2016). The mean pair-wise distance between sites was 11.5 $\mathrm{km}$ and $18.2 \mathrm{~km}$ for the Bukit Duabelas and Harapan regions, respectively. 
Chapter 3: Bird Responses to Lowland Rainforest Conversion in Sumatran Smallholder Landscapes, Indonesia

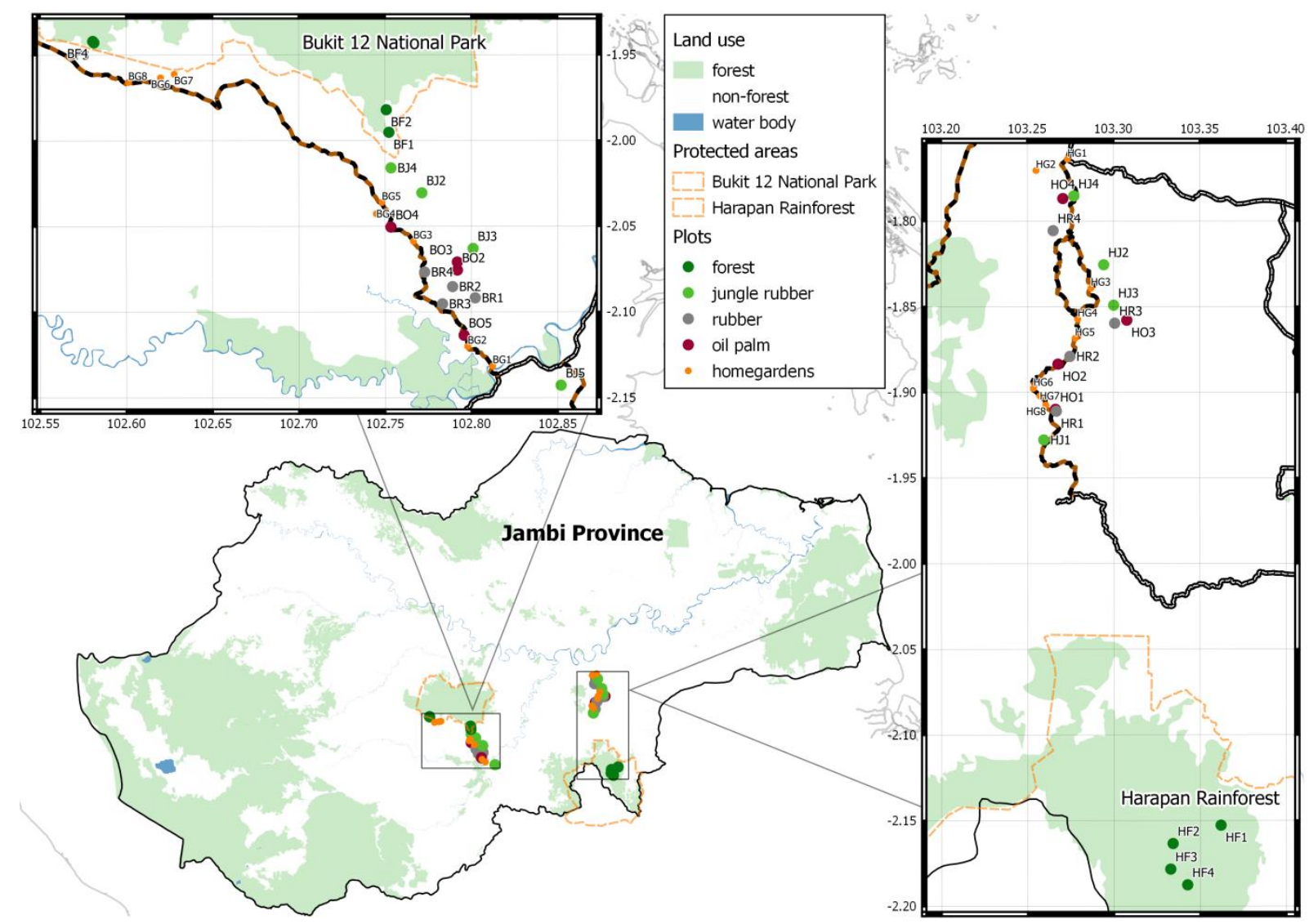

Fig 1. Map of the plots and homegardens in Jambi Province, Sumatra, Indonesia. The first letter of plot and homegarden codes indicates the region (H: Harapan, B: Bukit Duabelas), the second letter the land-use type (F: forest, J: jungle rubber, R: rubber, O: oil palm, G: homegarden). Forest cover is derived from Landsat 2013 (data from USGS/NASA Landsat, imagery interpretation courtesy of Dian Melati).

We additionally selected 8 homegardens, which were not part of the core study sites of the CRC 990, in each region. Homegardens were separated by a minimum distance of $100 \mathrm{~m}$ and it was not possible to have larger separation between them since they are invariably tied to human settlements along roads. The selected homegarden areas ranged between between 100 to $300 \mathrm{~m}^{2}$, smaller or larger homegardens (observed range $50-800 \mathrm{~m}^{2}$ ) were either too small for meaningful bird surveys, or, for the larger ones, too rare and unrepresentative to include in our sample. The typically small size of homegardens compared to plots prompted us to double the amount of homegardens (16 homegardens vs. 8 plots per land-use type).

\section{Bird survey}

We conducted point count surveys in the centre of the plots in forest, jungle rubber, and rubber and oil palm plantations. Each plot was visited four times, except five plots (BF1, BF2, BJ2, BJ4, and BO1, see Fig 1 ) which could only be visited three times due to time constraints. Each homegarden was also 
Chapter 3: Bird Responses to Lowland Rainforest Conversion in Sumatran Smallholder Landscapes, Indonesia

visited four times, except two homegardens (BG1 and BG2) which could only be visited three times due to time constraints. Each point count visit lasted 20 minutes. In the homegardens, birds were observed from the best possible vantage point. Individuals flying through or above the plot or homegarden were excluded. Each site was surveyed from June until July 2013, during non-rainy days. Cloud cover during the visit was estimated by eye and expressed in percent as clouded weather can possibly affect bird activity (Robbins 1981).

Birds were surveyed by sound and sight between $6: 00$ and $10: 00$ by the first author using $7 \times 42 \mathrm{~mm}$ binoculars (Nikon Monarch). Species identity, number of individuals, used vegetation layer (only for plots: ground, understory, middlestory, canopy, emergent trees) or used plant species (only for homegardens), horizontal distance from the observer (measured by a digital rangefinder Nikon Laser $1000 \mathrm{AS})$ were recorded. The timing of bird data collection randomly alternated between early to late morning to minimize a bias due to the observation time (Ralph, Droege, and Sauer 1995), (Sutherland, Newton, and Green 2004). Unfamiliar bird calls were recorded using a directional microphone (Sennheiser ME-66/K6) coupled to a digital sound recorder (Olympus LS-3). The recordings were later compared with online databases: the public bird call database Xeno Canto (www.xeno-canto.org) and our own database SoundEFForTS (http://soundefforts.uni-

goettingen.de/). Bird species identification in the field followed Mackinnon, Phillips \& van Balen (MacKinnon and Phillipps 1993), but we used Birdlife international (BirdLife International 2015) taxonomy in the analysis.

\section{Homegarden survey}

Semi-structured interviews (S1 Questionnaire) with the homegarden owners showed they were tended by people aged 21 to 71 years, and mostly by women or both genders (13 out of 16 homegardens). Homegarden products were used for personal consumption and only occasionally sold ( 3 households). Fertilizer and herbicides were used in 13 homegardens, with insecticides used in 8 homegardens. On average, the ground cover consisted of $65 \%$ of vegetation and litter, while the rest was mostly bare ground. We could identify a total of 109 cultivated plant species, of which 42 were tree species. An average of $18(\mathrm{sd}: \pm 7)$ identified cultivated plant species per homegarden was found, of which an average of 7 (sd: \pm 4 ) species were trees. The most common plants (found in more than half of the plots) were chili pepper (Capsicum frutescens), papaya (Carica papaya), coconut trees (Cocos nucifera), turmeric (Curcuma longa), lemongrass (Cymbopogon sp.), sweet potato (Ipomea batatas), mango (Mangifera indica), cassava (Manihot esculenta), banana (Musa sp.), sugarcane (Saccarum officinarum), katuk (Sauropus androgynus), and ginger (Zingiber sp.). Generally, homegardens had few tall trees and they were never integrated in remnant forest habitat (for an example see S1 Fig), 
Chapter 3: Bird Responses to Lowland Rainforest Conversion in Sumatran Smallholder Landscapes, Indonesia

Due to their inevitably smaller areas (mean $\pm s d=220 \pm 51 \mathrm{~m}^{2}$ ), the 16 homegardens' bird abundance, richness, feeding guilds, and communities were not comparable statistically to those from the plots (area: $2500 \mathrm{~m}^{2}$ ). In one homegarden (HG8), the owner "cleaned" all vegetation so that the bird survey could not be conducted.

\section{Data analysis}

\section{Diet, stratum, habitat and Red List status}

All birds were classified into feeding guilds (insectivores, frugivores, granivores, omnivores, and nectarivores) based on their primary diet. The classification is mainly based on Thiollay (Thiollay 1995a) and was completed with data from the Handbook of the Birds of the World (del Hoyo, Elliott, et al. 2015). We used the same sources, as well as Beukema et al. (Beukema et al. 2007), to complement the data with the birds' preferred habitat use as defined by Thiollay (Thiollay 1995a) (primary and old secondary forest interior; forest gaps, edges, or upper canopy; little wooded and cultivated areas). Data about the foraging strata were extracted from Wilman et al. (Wilman et al. 2014a) (tree crown; bark and wood at any height; understory, mostly foliage and epiphyte; grass shrubs in open areas). We plotted the abundance per feeding guild, habitat type, or foraging strata in each land-use type and region and only used the data from the first three visits to avoid a bias due to several sites missing the fourth visit. We supplemented the bird data with information from the IUCN Red List (The IUCN Species Survival Commission 2004) to show the number of species of conservation importance.

\section{Response variables}

We used the sum of the maximum of simultaneously detected individuals per species as a conservative measure of abundance. Abundance was computed per point count visit to be comparable with our measure of species richness per point count visit. We also analysed the abundance in each feeding guild and the rarefied richness per plot after 3 visits, and the total richness per land-use type after 3 visits was visualised. For the per-visit richness and abundance, we also counted birds that were only identified to genus level if they differed from the genera of the other observed birds during the same visit.

For homegardens, we computed the average number of species and abundance of birds, counted after three visits. We also pooled data from all 16 homegardens, obtaining a total area of $3297 \mathrm{~m}^{2}$, which is more similar to the area covered by our point counts in core plots, to count the total species richness. 
Chapter 3: Bird Responses to Lowland Rainforest Conversion in Sumatran Smallholder Landscapes, Indonesia

\section{Statistical models}

All analyses were carried out using R software version 3.2.1 (R Core Team 2015a) and graphs were made using the ggplot2 R package (Wickham 2009).

For all per-visit count data (abundance and richness), we fitted generalized linear mixed-effects models (GLMER, glmer function from R package Ime4) with plot as a random effect and Poisson family. Rarefied species richness yielded one data point per plot and as a consequence, it was modelled using a generalized linear model (GLM) with Poisson family (without random effects). For all models, we started with the full set of explanatory variables, including land-use type and region (categorical variables) as well as their interaction, and scaled cloud cover (z-transformed to avoid convergence issues in GLMERs). The full model's overdispersion, homoscedasticity and residual normality assumptions, as well as outliers, were checked using diagnostic plots. We generated all possible models based on all combinations of predictors included in the full model and ranked them by AICc (Burnham and Anderson 2004) (dredge function from R package MuMIn). All variables that were included in the best models (models within $2 \triangle \mathrm{AICC}$ scores from the best model) were used to construct a model which served in a subsequent post-hoc pairwise comparison of land-use types with forest (glht function from R package multcomp (Hothorn, Bretz, and Westfall 2008a)), and we report the results whenever a global Chi-square-test was significant $(P<0.05)$. Total richness per land-use type was not analysed statistically since it is an aggregated measure.

\section{Community composition}

We visualized the bird community composition using non-metric multidimensional scaling (NMDS) based on Bray-Curtis distances derived from an abundance community matrix ( $R$ package vegan (Oksanen et al. 2015)). We performed permutational multivariate analysis of variance tests (adonis function from $\mathrm{R}$ package vegan) to detect the difference of each transformed land-use's community with forest. 
Chapter 3: Bird Responses to Lowland Rainforest Conversion in Sumatran Smallholder Landscapes, Indonesia

\section{Results}

Based on our point counts, we detected 451 birds representing 71 species and 24 families, as well as 74 birds from 13 species and 7 families, respectively in core plots and in homegardens. Sampling intensity was comparable between land-use types, and rarefaction analysis supports our finding (S2 Fig), although forest appears to have been under-sampled. Among all detections, 25 were only identified to genus level and 9 detections remained wholly unidentified. Twenty genera were only found in forest, 4 only in jungle rubber, 6 only in rubber, and 5 only in oil palm. Birds were usually recorded more often close to and also far away from the observer in the plantations (S3 Fig). The estimated cloud cover was highest in forest and lowest in rubber (S4 Fig), but we did not test for statistical significance.

\section{Total bird abundance and species richness}

The best model for bird abundance per visit was the null model, and there were no other models within $2 \triangle \mathrm{AICC}$, so no global test was needed. The bird abundance per visit followed different trends among regions (Fig 2). The best models (within $2 \triangle \mathrm{AICC}$ ) for bird abundance per feeding guild (using only insectivores and omnivores for which we had enough detections) did not contain land-use type or region as predictors, so no global test for assessing differences between land-use type and region was conducted. The best models for species richness per visit contained land-use type and region predictors. The global Chi-square test for the contrasts between land-use types was significant $(P<0.05)$ and the multiple comparison showed significantly $(P<0.05)$ higher values in forest than in the rubber and oil palm plantations for the Harapan region. The best model for rarefied species richness contained only land-use type as a predictor: there were no other models within $2 \triangle \mathrm{AICc}$. The global test for the contrasts between land-use types was significant $(P=0.01)$ and showed significantly $(P<0.05)$ higher values in forest than in the rubber and oil palm plantations (Fig. 3). For all responses, cloud cover was dropped from the predictors as it was never contained in the best models within 2 $\triangle \mathrm{AIC}$. 
Chapter 3: Bird Responses to Lowland Rainforest Conversion in Sumatran Smallholder Landscapes, Indonesia
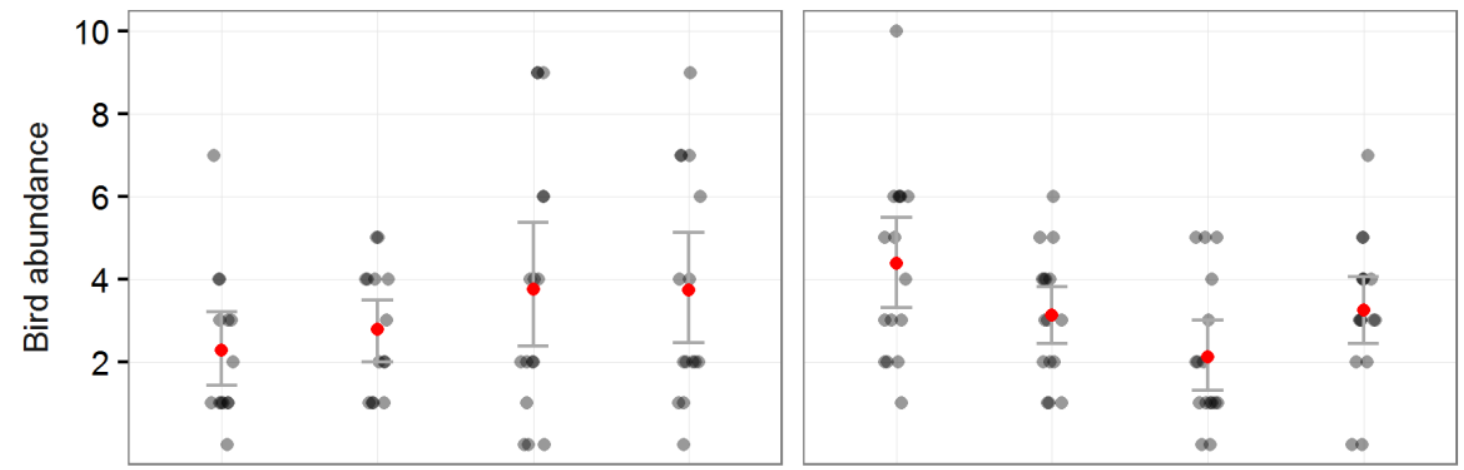

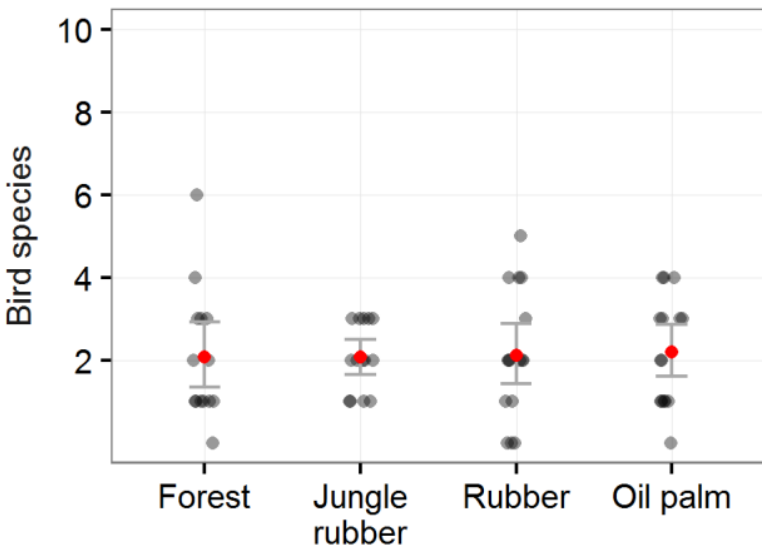

Bukit 12

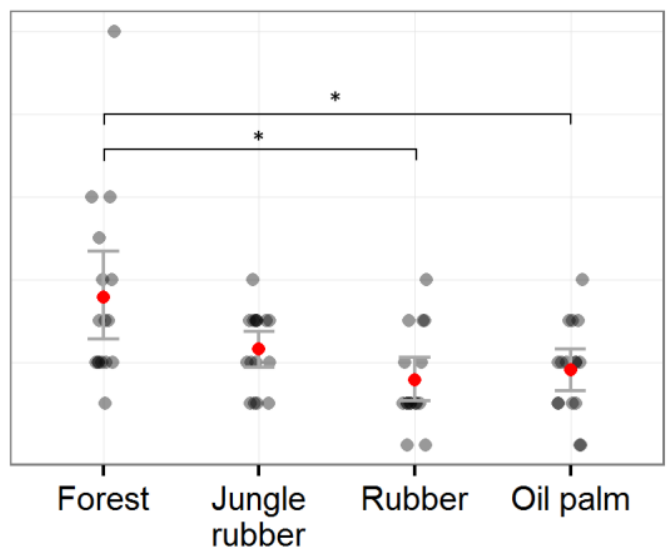

Harapan

Fig 2. Bird abundance and species richness per 20 minute visit, split up by land-use type for two regions in the province of Jambi, Sumatra. Black dots represent visits, red dots represent mean values per land-use type, error bars represent the mean standard error, asterisks denote statistical significance in post-hoc multiple comparisons with forest. 
Chapter 3: Bird Responses to Lowland Rainforest Conversion in Sumatran Smallholder Landscapes, Indonesia

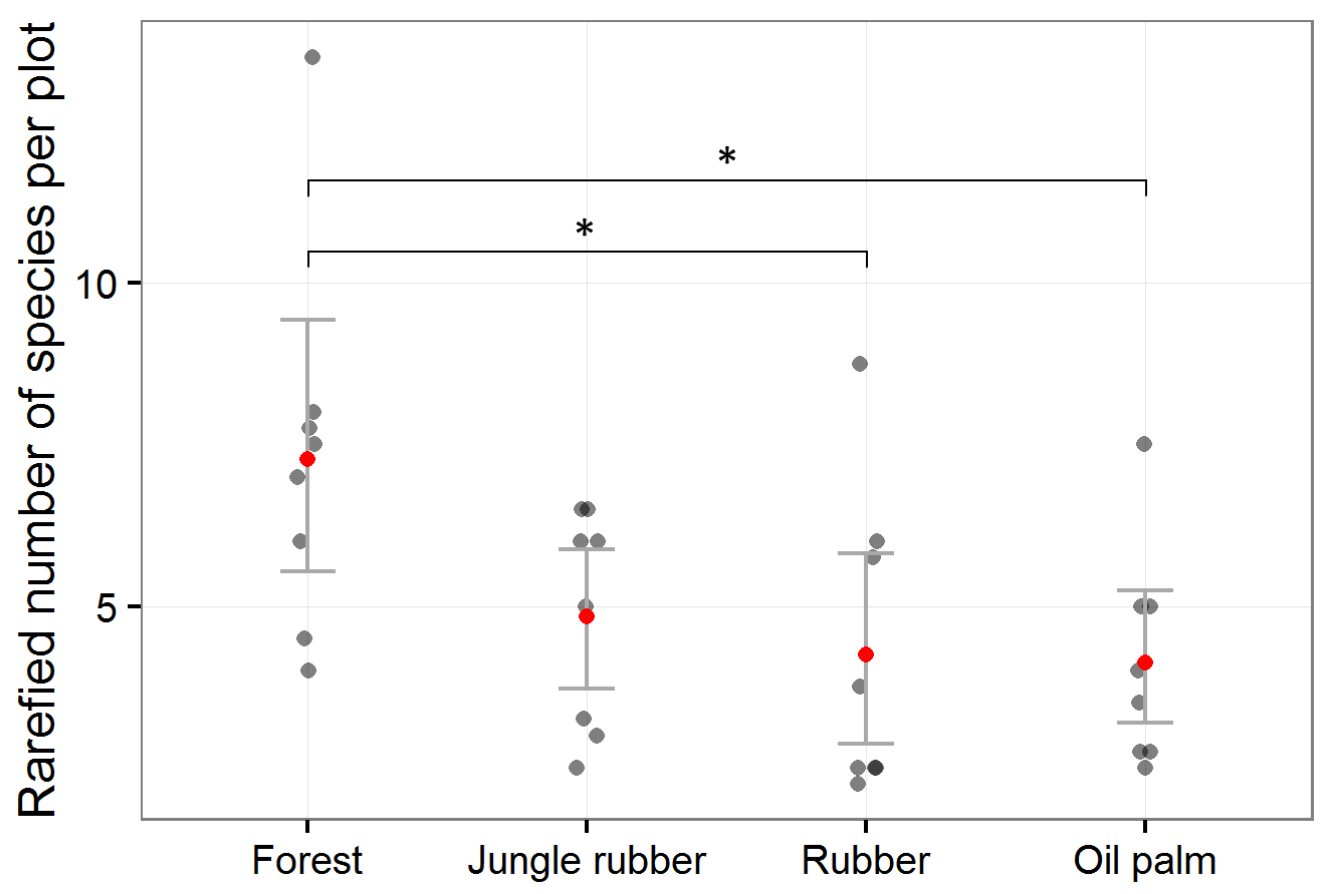

Fig 3. Rarefied species richness after three 20 minute visits, split up by land-use type for both regions combined in the province of Jambi, Sumatra. Grey dots represent plots, red dots represent mean values per land-use type, error bars represent the mean standard error, asterisks denote statistical significance in post-hoc multiple comparisons with forest.

In both regions, the total species richness per land-use type was highest in forest (see Fig 4). The species richness in rubber sites of Bukit Duabelas was relatively high, even surpassing the species richness in jungle rubber. In both regions, species of conservation concern ("near threatened" category according to IUCN Red List) were increasingly rare along the land-use conversion gradient and mostly absent in plantations. 
Chapter 3: Bird Responses to Lowland Rainforest Conversion in Sumatran Smallholder Landscapes, Indonesia

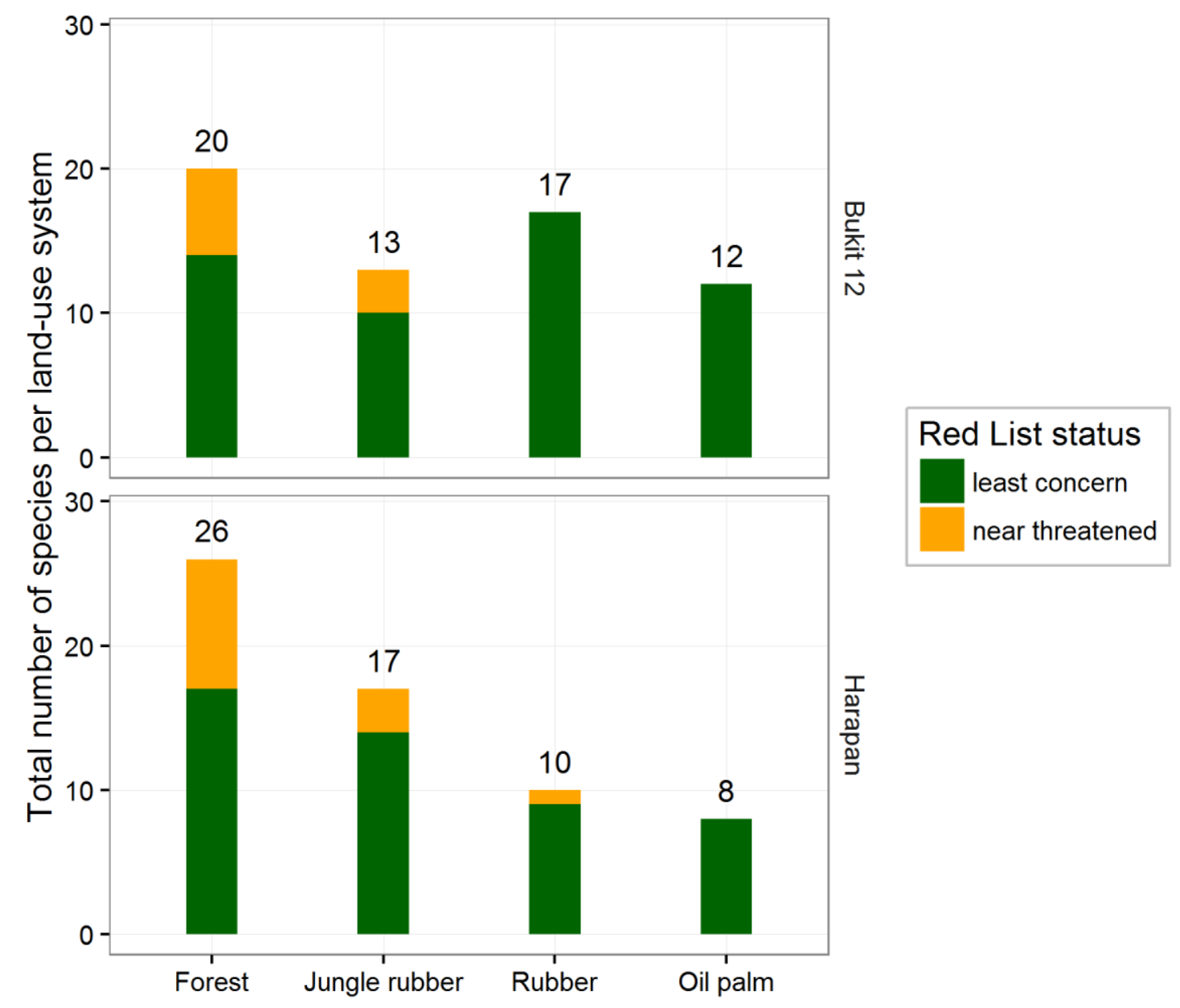

Fig 4. Total bird richness after three 20 minute visits in each land-use type and IUCN Red List threat status for two regions in the province of Jambi, Sumatra. For some unidentified birds, the threat status was not available (NA).

In 4 of the 15 homegardens, we did not find any bird even after four visits. After 3 visits, the average total species richness per homegarden was $1.6(\mathrm{sd}: \pm 1.4)$ with a maximum of 5 species, and the mean number of detections per visit was of 1.15 individuals. All 15 homegardens pooled together had a species count of 11 after three visits.

\section{Feeding guild abundances}

Insectivores declined in converted land-use types in the Harapan region, and the trend was reversed in the Bukit Duabelas region (Fig 5); the highest omnivore abundances were observed in plantations, but both trends were not significant (global Chi-square test $P=0.18$ ), so we refrain from a more detailed description of these results. Frugivores were absent from plantations in both regions, while nectarivores were only present in plantations at Bukit Duabelas, and in forest and jungle rubber at Harapan. Granivores made up a minor proportion of detections and were mostly found in oil palm. 
Chapter 3: Bird Responses to Lowland Rainforest Conversion in Sumatran Smallholder Landscapes, Indonesia

In homegardens, we predominantly found granivores (22 individuals) and omnivores (17 individuals). Nectarivores were still common (10 individuals), while insectivores were rare (3 individuals).

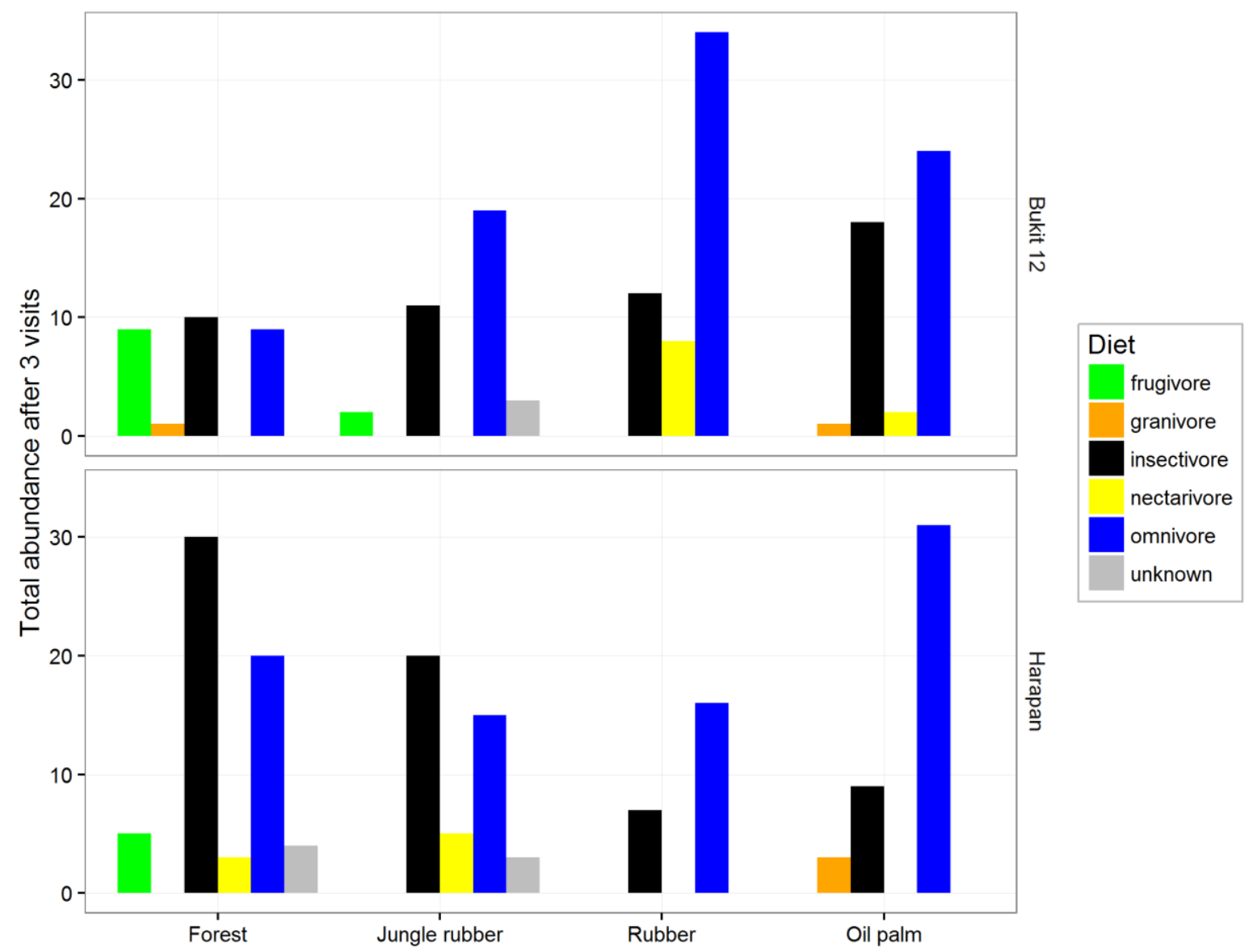

Fig 5. Bird abundance after three 20 minute visits in each feeding guild per land-use type for the two different regions of the province of Jambi, Sumatra. Feeding guild categories were based on Thiollay et al. (1995).

\section{Community composition}

Two dimensional ordination visualization of bird communities based on abundance data showed that the forest community was different from the other communities in the converted land-use systems (Fig 6). Clear overlap was visible between jungle rubber and rubber plantations, and to a lesser extent between rubber and oil palm plantations. The ADONIS analyses revealed that land-use type was significant in partitioning the bird communities, and that forest communities were significantly different from each of the other communities in converted land-use types (all $p<0.001$ ). 
Chapter 3: Bird Responses to Lowland Rainforest Conversion in Sumatran Smallholder Landscapes, Indonesia

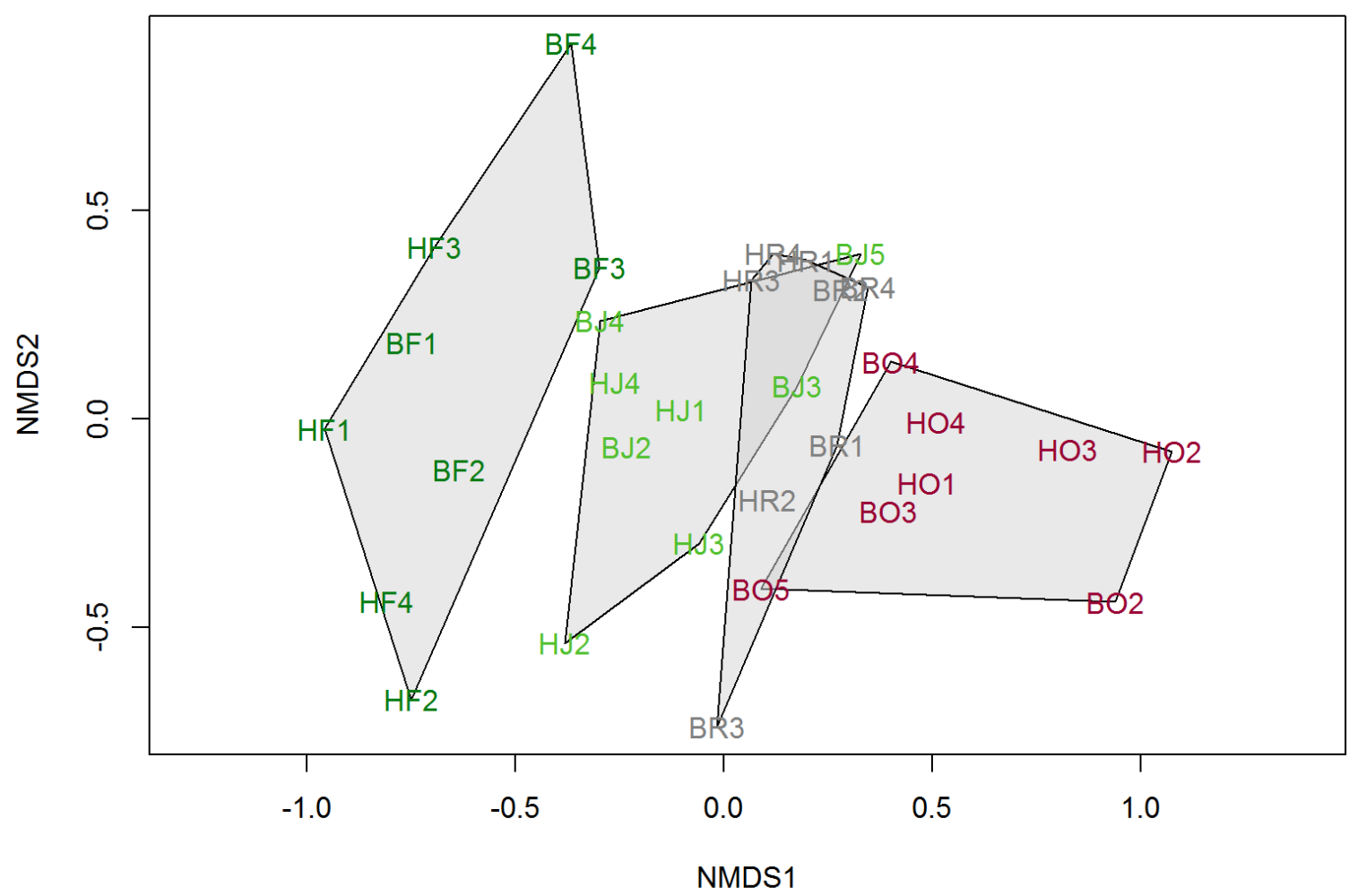

Fig 6. Non-metric Multidimensional Scaling of bird communities in different land-use types of Jambi, Sumatra. Graph based on abundance data from both regions.

\section{Discussion}

We found no differences in terms of abundance between the land-use types, but both richness per visit and rarefied richness per plot were significantly lower in plantations compared with forest. Frugivores were absent from monocultures; the trends in abundance of insectivores and omnivores are statistically not significant, so we do not interpret them further. Richness per land-use type decreased along the transformation gradient, with almost no bird species of conservation concern present in monocultures. Bird communities in jungle rubber, rubber and oil palm monocultures were significantly different from forest communities.

\section{Diversity along the land-use conversion gradient}

Overall, species richness decreased from forest to plantations. In our region, forest harboured more than twice the number of species compared to oil palm plantations, and many more genera were restricted to forest habitats than to plantations. However the species richness decline was not as sharp as the one observed by Aratrakorn et al. in commercial plantations (Aratrakorn, Thunhikorn, and Donald 2006), where losses of at least $60 \%$ bird species were reported: we documented losses of 
Chapter 3: Bird Responses to Lowland Rainforest Conversion in Sumatran Smallholder Landscapes, Indonesia

$43-45 \%$ in rarefied richness in plantations compared to forest. It suggests that smallholder agricultural plantations might be less detrimental for birds, due to their inherently smaller sizes contributing to a higher diversity of habitats in the landscape mosaic. Species groups that went missing after conversion of forest are hornbills, trogons, barbets, woodpeckers, flycatchers, and some babblers. The lack of large canopy trees (for hornbills), standing dead trees (for woodpeckers), woody understory growth (for babblers and understory foragers), might have greatly affected these forest species (Thiollay 1995a)(Sodhi et al. 2010).

We expected that monoculture rubber would be more hospitable to birds than oil palm plantations: the branched rubber tree structure may provide more space for foraging, perching, or nesting. Even though rubber is harvested more frequently, tapping takes place at the trunk base, while harvesting in oil palm occurs in the middle of the canopy, which is potentially more disturbing. Although several bird species are able to shift their foraging height in response to disturbance (F. R. Lambert 1992), oil palm plantations clearly cannot harbour tree crown species, integrating open-land species instead (S5 Fig). However all in all, we could not detect differences in abundance or richness between the rubber and oil palm plantations, and their communities were relatively similar (Fig 6), which was also found by Aratrakorn et al. (Aratrakorn, Thunhikorn, and Donald 2006). Both plantation types are novel, simplified monocultures with a high disturbance regime due to human management activities, explaining the high prevalence of similar generalist species in both systems.

\section{Differences in feeding guild responses}

In our study, frugivores were seldom found in jungle rubber compared to forest, and were entirely absent in the monoculture plantations. Therefore we deduce that bird seed dispersal may be severely decreased in transformed systems. This result was consistent with other findings in Sumatran agroforest (Thiollay 1995a), in Hainan rubber plantations (Li et al. 2013), and in Thai commercial rubber and oil palm plantations (Aratrakorn, Thunhikorn, and Donald 2006). Availability of fruits, which fluctuates strongly between seasons and years even in natural forests (Terborgh 1986), is crucial for maintaining frugivores, and the presence of fruiting remnant forest trees in jungle rubber could make a decisive difference (Abrahamczyk et al. 2008).

In Bukit Duabelas, we found nectarivores only in plantations, while they only occurred in jungle rubber and forest in Harapan. Although agroforestry systems, when adjacent to open areas, may result in spillover of nectarivore species (Cagan H. Sekercioglu 2012), we suggest this increase is mainly due to the Hevea blooming during the bird survey in Bukit 12. Rubber provides large extrafloral nectar resources during the blooming period, and Li et al. (Li et al. 2013) suggest that birds utilize them, as they also observed similar temporal trend of nectarivores. We hypothesize that nectarivorous sunbirds (which are facultative insectivores) might also be attracted by the insect 
Chapter 3: Bird Responses to Lowland Rainforest Conversion in Sumatran Smallholder Landscapes, Indonesia

pollinators of rubber (thrips and midges, pers. obs. YC). Flowerpeckers (Dicaeum trigonostigma) might use rubber as well, as they were reported to consume rubber flowers directly (Cheke and Mann 2016). Bird pollination thus seems to be decreased in plantations and only temporarily upheld in rubber plantations during the blooming time, when bird pollinators are attracted.

Especially in Harapan, insectivore abundances decreased from forest to jungle rubber and then to rubber. In Bukit 12 however, insectivore abundance increased in plantations. Almost all insectivores found in oil palm are open land and common species such as Prinia and Orthotomus. Forestdependent insectivores, such as Grey-chested Jungle-flycatcher Rhinomyias umbratilis, Scarletrumped Trogon Harpactes duvaucelli, and Banded broadbill Eurylaimus javanicus were never found outside the forest sites. At the same time, a large portion of understory insectivores, such as babblers, were found almost exclusively in forest and jungle rubber, as they are sensitive to habitat degradation (Powell, Cordeiro, and Stratford 2015). They could not be found entering deep into the plantations, even when observed in nearby jungle rubber fragments (pers. obs. WEP). The absence of undergrowth vegetation on plantation plots seems to be affecting this group greatly (Aratrakorn, Thunhikorn, and Donald 2006). Bark gleaning insectivores like woodpeckers and nuthatch were entirely missing in oil palm. Under these circumstances, we are unsure whether pest predation services - which might be relevant for oil palms (L.P. Koh 2008) - are hampered or enhanced in plantations. There are indications that common species (like Pycnonotus, Orthotomus and Prinia species) comsume a broad variety of insects in oil palm, but not specifically pests (De Chenon and Susanto 2006). Consequently biocontrol effects could be positive or negative, as birds may affect pests as well as their natural enemies. Note that overall, the diversity of the insectivorous feeding guild is strongly reduced (S6 Fig, 16 species in plantations combined versus 29 in forest and jungle rubber combined).

In rubber and oil palm plantations, we generally observed similar species compositions with omnivores such as Pycnonotus goiavier and Dicaeum trigonostigma dominating. Overall, omnivores were more than twice as abundant in the plantations compared to the forest, but they had only slightly lower observed richness (13 species in plantations combined versus 16 in forest and jungle rubber combined). Forest omnivores such as leafbirds, fulvettas, and scimitar-babblers, were replaced by other species that have adapted well to anthropogenic habitats, such as bulbuls (Pycnonotus spp.). In summary, our results show that there is a feeding guild composition change towards less specialized birds in the simpler habitat types such as plantations (Abrahamczyk et al. 2008),(Cagan H. Sekercioglu 2012) (Maas, Clough, and Tscharntke 2013b). It is uncertain whether the omnivorous birds can still fulfil the seed dispersal function of the missing frugivores in plantations, as only dietary analyses could reveal that. 
Chapter 3: Bird Responses to Lowland Rainforest Conversion in Sumatran Smallholder Landscapes, Indonesia

\section{Confounding factors and recommendations}

Differences in bird detectability between land-use types should hardly bias our results since we only recorded birds that are within the plot (maximum distance $35 \mathrm{~m}$ ). However we found that birds in forest and jungle rubber were rarely detected in the close vicinity of the observer, suggesting in these natural systems birds are usually more secretive. We could not correct for this minor bias so our estimates are conservative for forest sites. Moreover, the weather conditions were usually worse in forest than in the other systems, while the skies were clear during the rubber plot visits. While we could account for that in our models, the weather covariate was always dropped, suggesting that it may not affect our outcomes significantly (see also (Bas et al. 2008)).

Both regions showed strikingly different trends in the abundance, species richness and number of conservation-relevant species for forests and rubber plantations, suggesting that regional effects are of major importance. While we cannot test or quantify the regional effect with only two studied regions, we know that especially the forests were dissimilar: in Bukit Duabelas, law enforcement was ineffective as bird trapping and rubber tapping were still ongoing in the vicinity of our plots. The Harapan forest sites were better protected and could also benefit from ongoing restoration efforts.

Other factors may influence the observed abundance and richness trends. Indeed several studies (Aratrakorn, Thunhikorn, and Donald 2006), (Azhar et al. 2015) (Asrulsani Jambari et al. 2012) showed that understory presence could positively affect bird species richness. We did not test for such an effect, but our highest abundance and richness values were in plots with dense and tall undergrowth (pers. obs. WEP). The importance of rubber blooming was mentioned above and indeed, we observed higher nectarivore abundances in the Bukit 12 survey when rubber was blooming. Another possible influencing factor is the distance from the forest fragments. Aratrakorn et al. (Aratrakorn, Thunhikorn, and Donald 2006) did not find any evidence for this in their commercial plantations, but Azhar et al. found effects for arboreal omnivores and terrestrial frugivores (Azhar et al. 2013). In our Bukit 12 region however, plots from converted land-uses were closer to the forest border than in Harapan (on average $3.2 \mathrm{~km}$ versus $6.0 \mathrm{~km}$ for Harapan, Fig 1). We suggest that the proximity to forest could explain the relatively high species richness and abundances in the Bukit 12 converted land-use plots. . All things considered, we recommend that during bird surveys in rubber plantations, blooming events should be noted, and in plantations, understory density should be quantified. A designed gradient in distance from the transformed plots to the forest (as a reference system), combined with a more sophisticated land-use cover analysis, could impart the influence of forest proximity on bird communities, which should ideally be tested in different regions. 
Chapter 3: Bird Responses to Lowland Rainforest Conversion in Sumatran Smallholder Landscapes, Indonesia

\section{Conservation Implications}

Despite being perennial habitats, monospecific plantations are too simplified to harbour as many species as forests. Our results show that among the transformed habitats on the study site, jungle rubber still plays an important role in harbouring bird species, particularly forest species that cannot survive in structurally much simpler habitat (S7 Fig): jungle rubber in both regions harboured 14 forest species, which was more than twice the number in both monoculture plantations combined (6 species). Strikingly, the entire feeding guild of frugivores was missing from the moncultures. Jungle rubber communities were intermediate in composition between forest and plantation communities (Fig 6), and almost half of the 15 near threatened species from the forest were found in jungle rubber. As a buffer (Beukema et al. 2007), jungle rubber favours forest bird species due to its vegetation structural complexity and plant diversity (including fruiting trees), as it resembles secondary forest more than the other types of land-use (Gouyon, de Foresta, and Levang 1993).

Despite encouraging evidence from other parts of the world that homegardens can sustain bird communities and thus support conservation targets (Goulart et al. 2011), we found that single homegardens in our region were quite irrelevant for conserving bird communities. The gardens were irregular in shape, leading to possibly stronger edge effects, markedly smaller in size than the study plots, and located near to roads and households, which are a source of disturbance. Homegardens may be attractive to birds for its food-resources. Therefore, owners may perceive them as a threaten to the crops, and in some cases use visual methods such as birds-scarers to dissuade birds from entering into the homegardens (pers. obs. MTH). Additionally we found a low plant species richness and structure and full-grown trees were rare (pers. obs. MTH). In contrast, homegarden studies in Sulawesi and Java respectively recorded from 28 to 37 and from 42 to 58 plant species per homegarden (Kehlenbeck and Maass 2004), (Yamamoto et al. 1991). In contrast however, when pooling homegarden data for a fairer comparison of species richness with core plots at similar areas, we found a high number of species (11). Although this number is inflated due to the geographical separation between homegardens (high beta-diversity) it comes second after the highest species richness recorded in plots. Therefore, although homegardens certainly do not provide breeding habitat for birds due to their high disturbance regime, they can apparently provide resources that are used by many bird species.

Bird communities can be preserved with several management practices. Favouring a more diverse tree structure and habitat in plantations can be achieved by planting trees in cohorts of varying ages, with intercropping of rubber (Snoeck et al. 2013) and oil palm (Amoah et al. 1995), keeping remnant forest trees - especially fruiting trees for the missing frugivorous trees (Harvey and Haber 1998) and standing dead trees ("snags") (J. P. Gibbs, Hunter, and Melvin 1993), and by maintaining a denser 
Chapter 3: Bird Responses to Lowland Rainforest Conversion in Sumatran Smallholder Landscapes, Indonesia

undergrowth (Aratrakorn, Thunhikorn, and Donald 2006), (Azhar et al. 2015) (Asrulsani Jambari et al. 2012). Interestingly, some findings by Azhar et al. suggest that polyculture may not necessarily be beneficial for the overall bird species richness (Azhar et al. 2014). Finally at the regional scale, the matrix between the forested natural habitat and transformed habitat can be improved by keeping plantations small and forested systems connected (Tscharntke et al. 2008).

Previously, the predicted land use development in Jambi incorporated a combination of jungle rubber along with monoculture plantations (Feintrenie and Levang 2009). However recent changes show a shift to more profitable monoculture plantations(Clough (in revision)). Smallholders could maintain their jungle rubber agroforestry due to the minimal management costs and limited capital, but oil palm offers short term profits (Feintrenie and Levang 2009), (Lee et al. 2014). The immediate challenge for conservation in the study area is the change of forest and jungle rubber towards a homogenized region dominated by large scale monoculture plantations.

Policies which support smallholders in maintaining the heterogeneity within the landscape mosaic are required. With the growing eco-sensitive market, smallholder rubber certification - despite its complexity - should be developed further (Gouyon 2003). A multi-stakeholder approach providing incentives for smallholders to maintain their jungle rubber is feasible as has already been implemented in the Bungo regency (Leimona et al. 2015). Favouring jungle rubber and mixed crop plantations, along with practices which maintain structural complexity of the plantation will benefit the environment and biodiversity more. Meanwhile, it is of utmost importance to protect and maintain the remaining forest cover.

\section{Acknowledgements}

We would like to thank the field team of B09 sub-group, B.P.H. Hamonangan and Patrick M. Diaz, for the kind field assistance. We thank the following persons and organizations for granting us access to and use of their properties: village leaders, local plot owners, PT Humusindo, PT REKI, PT Perkebunan Nusantara VI, Bukit Duabelas National Park. We are grateful to Louis-Felix Bersier, Paméla Lagrange, and an anonymous reviewer for stimulating us to improve our manuscript. We acknowledge support by the German research foundation and the open access publication funds of the Georg-August University of Göttingen. 
Chapter 3: Bird Responses to Lowland Rainforest Conversion in Sumatran Smallholder Landscapes, Indonesia

\section{Supporting Information}

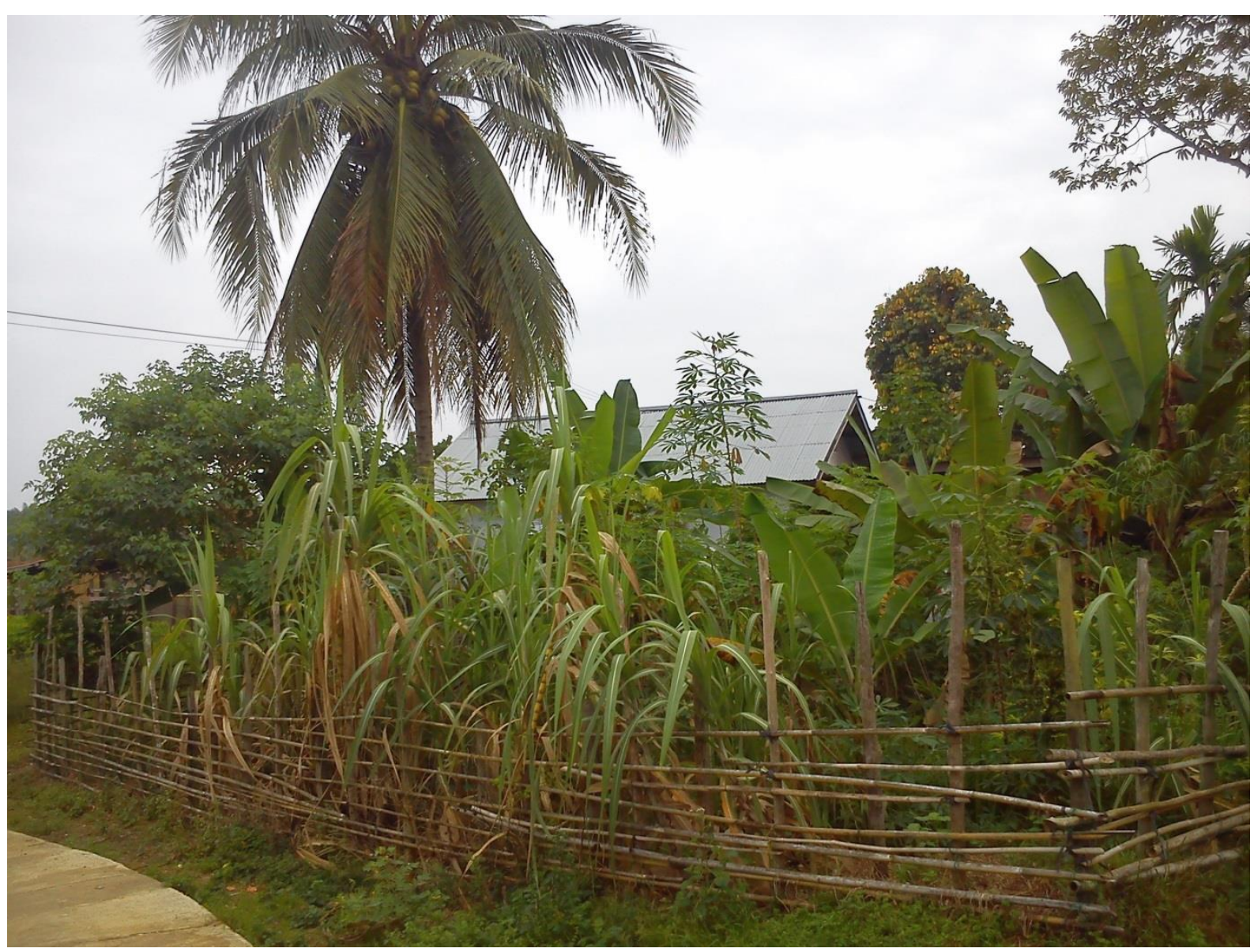

S1 Fig. An example of homegarden (BG1) sampled in our study. 
Chapter 3: Bird Responses to Lowland Rainforest Conversion in Sumatran Smallholder Landscapes, Indonesia

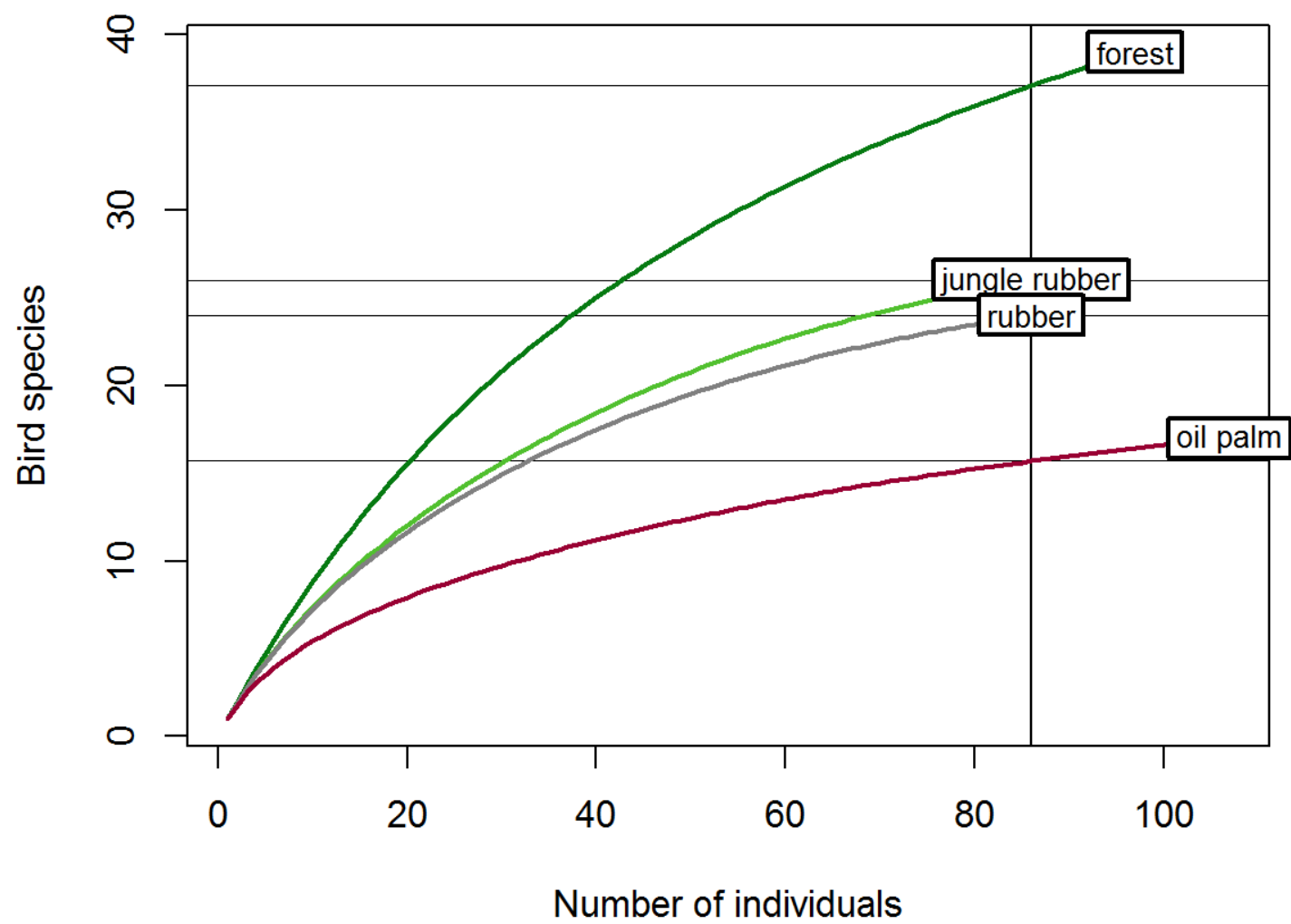

S2 Fig. Rarefaction curves for each land-use type. Total species richness was rarefied to the lowest sample size occurring in jungle rubber, where 88 birds were observed. Total rarefied richness forest: 38; jungle rubber: 27; rubber: 25, oil palm: 16 . 
Chapter 3: Bird Responses to Lowland Rainforest Conversion in Sumatran Smallholder Landscapes, Indonesia

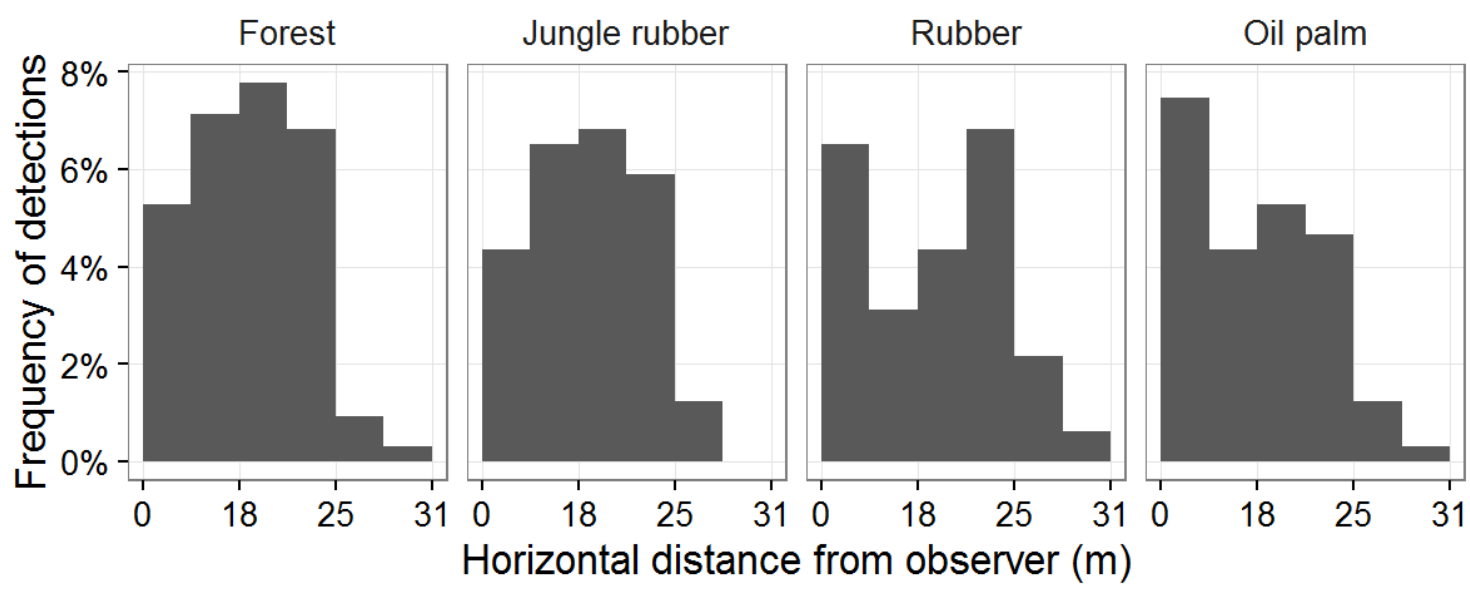

S3 Fig. Histograms of bird detections in each land-use type depending on the distance from the observer, divided in bins of equal area

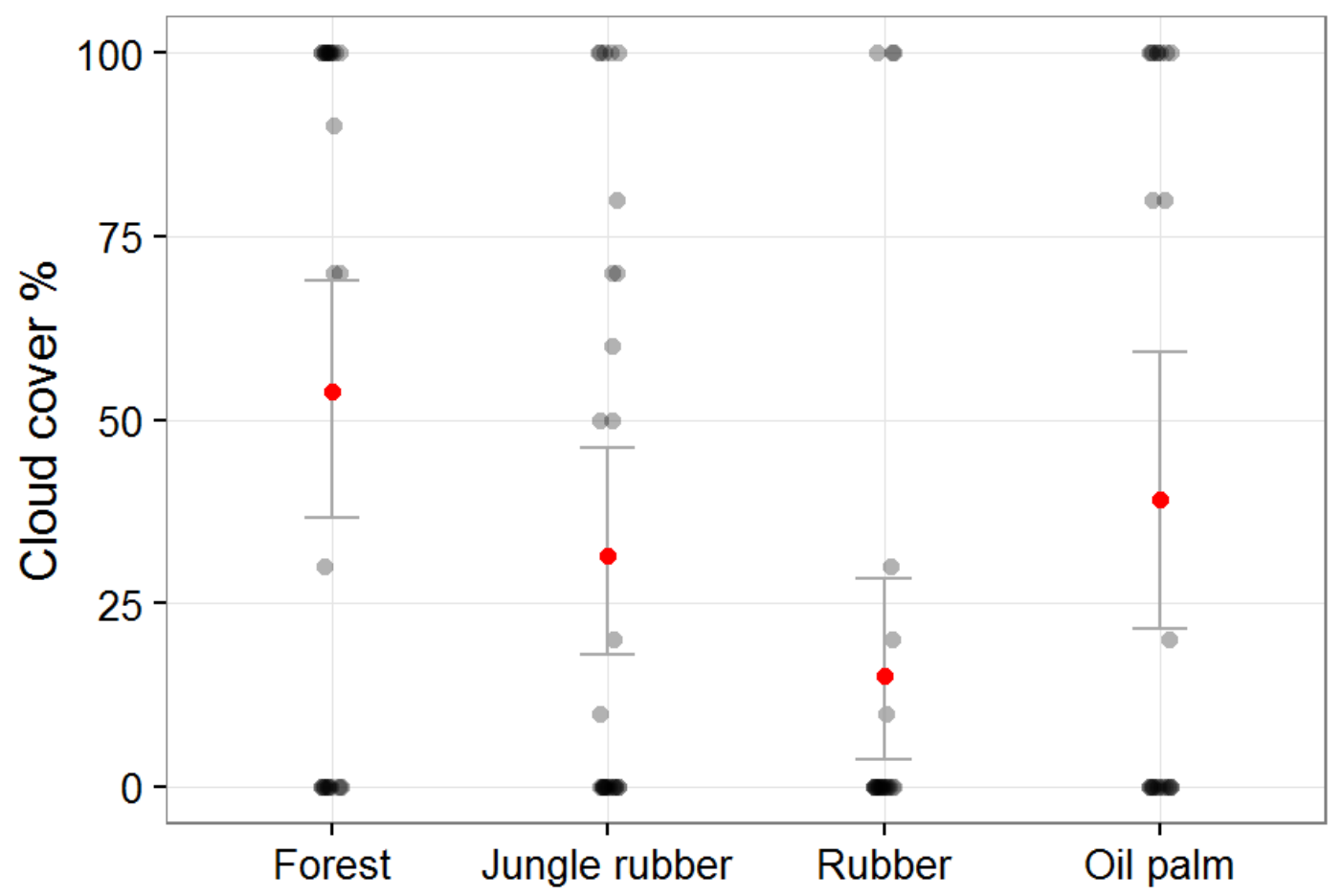

S4 Fig. Estimated percent cloud cover during each core plot visit in each land-use type. Means are indicated in red, error bars represent the standard error of the mean. 
Chapter 3: Bird Responses to Lowland Rainforest Conversion in Sumatran Smallholder Landscapes, Indonesia

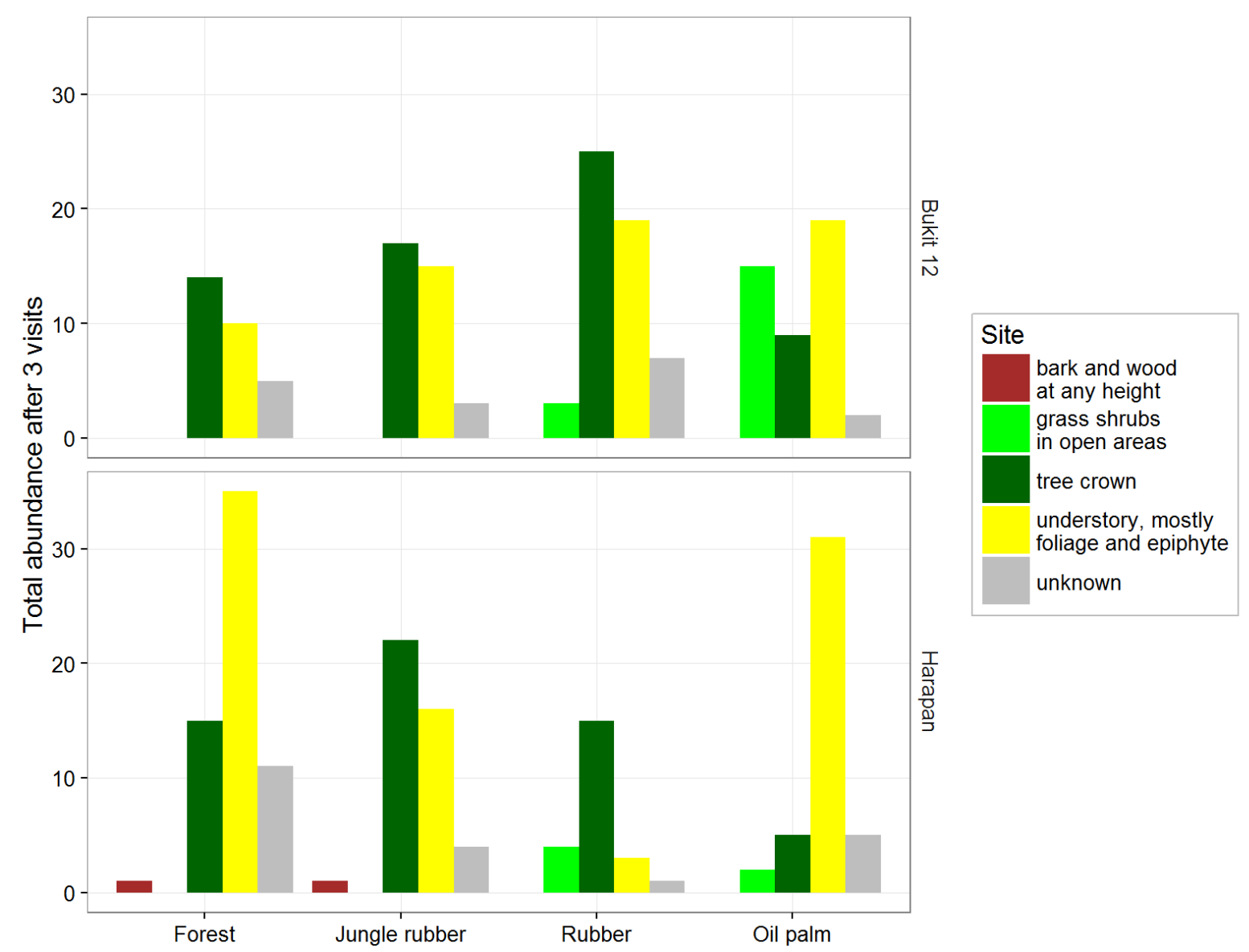

S5 Fig. Bird abundanceafter three 20 minute visits in each stratum preference group per landuse type for two regions of the province of Jambi, Sumatra. Strata preferences were obtained from Wilman et al. (2014) 
Chapter 3: Bird Responses to Lowland Rainforest Conversion in Sumatran Smallholder Landscapes, Indonesia

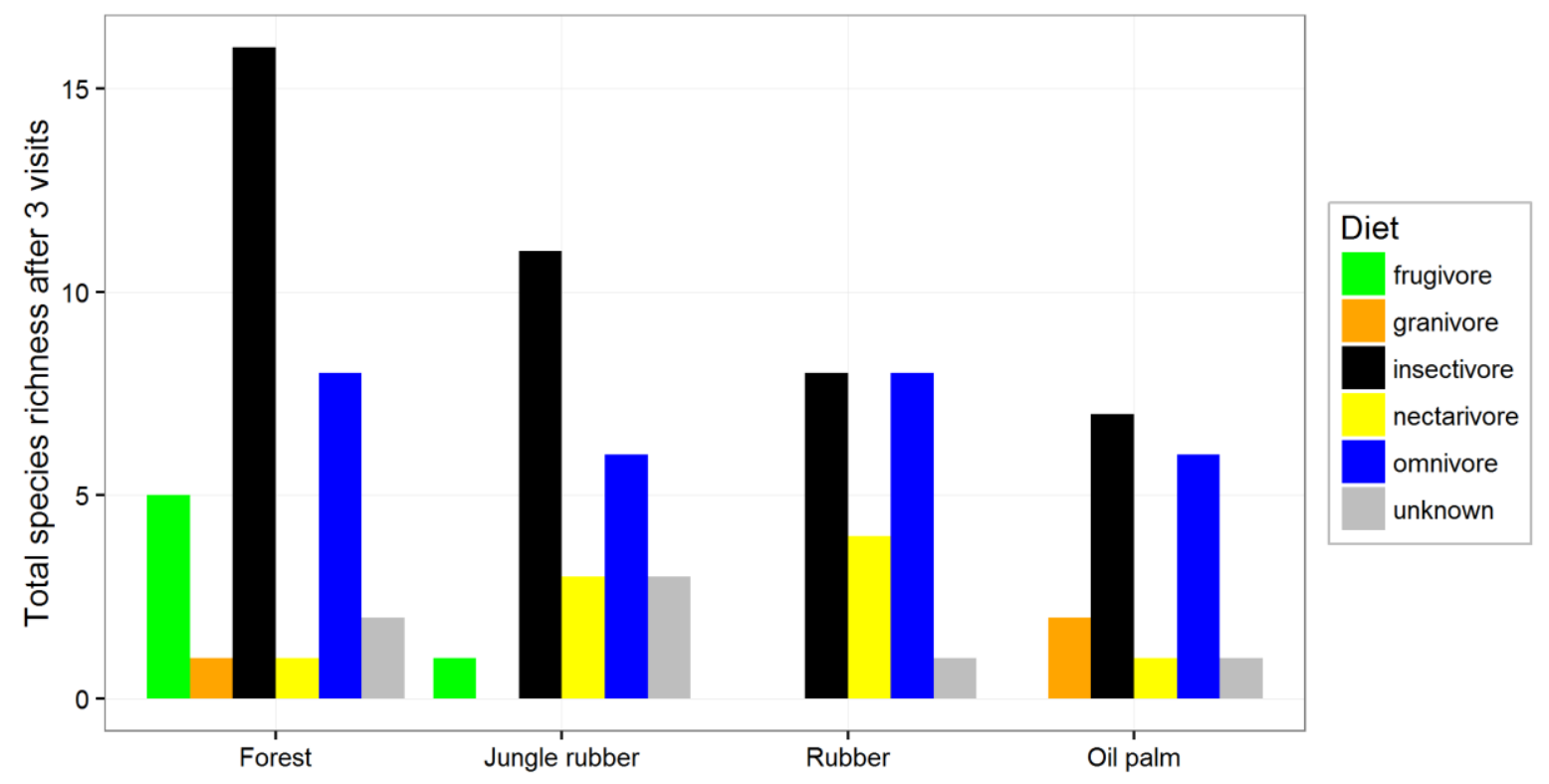

S6 Fig. Total bird species richness after three 20 minute visits in each feeding guild per land-use type. Feeding guild categories were based on Thiollay et al. (1995) 
Chapter 3: Bird Responses to Lowland Rainforest Conversion in Sumatran Smallholder Landscapes, Indonesia

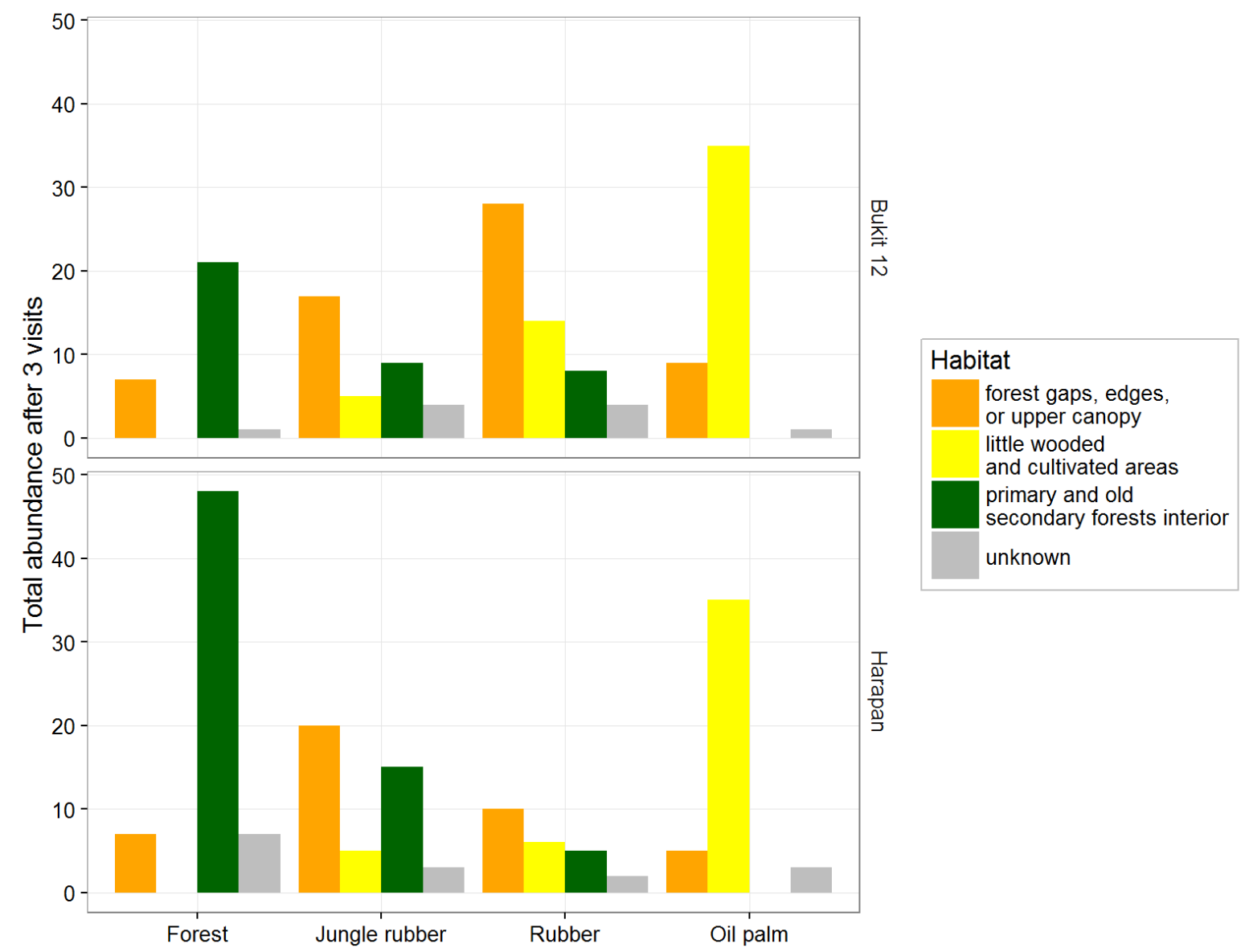

S7 Fig. Bird abundance after three 20 minute visits in each habitat preference group per landuse type for two regions of the province of Jambi, Sumatra. Habitat preferences were mainly obtained from Thiollay et al. (1995). 
Chapter 4: Single- and multi-trait measures reveal widespread functional diversity loss in humanmodified tropical landscapes

\section{Chapter 4: Single- and multi-trait measures reveal widespread functional diversity loss in human-modified tropical landscapes}

Lisa H. Denmead ${ }^{1,} \uparrow$, Kevin Darras $^{1}$, Yann Clough ${ }^{1,2}$, Ingo Grass ${ }^{1}$, Andrew D. Barnes ${ }^{3}$, Ulrich Brose ${ }^{3,4,5}$, Damayanti Buchori ${ }^{6}$, Malte Jochum ${ }^{3}$, Holger Kreft ${ }^{7}$, Steffen Mumme ${ }^{3}$, Walesa Edho Prabowo ${ }^{8}$, Akhmad Rizali ${ }^{9}$, and Teja Tscharntke ${ }^{1}$

${ }^{1}$ Agroecology, University of Goettingen, Goettingen 37077, Germany

${ }^{2}$ Centre for Environmental and Climate Research, Lund University, Lund S-223 62, Sweden

${ }^{3}$ Systemic Conservation Biology, J.F. Blumenbach Institute of Zoology and Anthropology, University of Goettingen, Goettingen 37073, Germany

${ }^{4}$ German Centre for Integrative Biodiversity Research (iDiv), Halle-Jena-Leipzig, Leipzig 04103, Germany.

${ }^{5}$ Institute of Ecology, Friedrich Schiller University Jena, Jena 07737, Germany

${ }^{6}$ Department of Plant Protection, Bogor Agricultural University, Kampus IPB Dramaga, Bogor 16680, Indonesia

${ }^{7}$ Biodiversity, Macroecology and Conservation Biogeography, University of Goettingen, Goettingen 37077, Germany

${ }^{8}$ Division of Conservation Biology, Institute of Ecology and Evolution, University of Bern, Bern 3012, Switzerland.

${ }^{9}$ Department of Plant Pests and Diseases, Faculty of Agriculture, University of Brawijaya, Malang 65145 , Indonesia

† Email: Idenmea@gwdg.de 
Chapter 4: Single- and multi-trait measures reveal widespread functional diversity loss in humanmodified tropical landscapes

\begin{abstract}
In the tropics, land-use transformation from rainforest to monoculture agriculture such as oil palm and rubber plantations is happening at a rapid rate causing considerable species loss. Patterns of species loss with land-use change are comparatively well studied, but this is in contrast to the building evidence that functional diversity, and not species richness per se, is the main driver of ecosystem functioning and stability. To comprehensively investigate the effects of land-use change on species richness and functional diversity, as well as the relationship between the two, we surveyed birds, arboreal ants and leaf-litter invertebrates across 32 lowland rainforest, jungle rubber, monoculture rubber and oil palm plantation sites in Sumatra, Indonesia. We quantified species richness, functional diversity and single- and multi-trait functional indices (community-weighted mean and variance, functional dispersion, functional evenness and functional divergence) for each taxonomic group using feeding guild, dispersal and biomass traits. We found linear relationships between species richness and functional diversity across all taxa, indicating low functional redundancy in these systems. Also, species richness and functional diversity declined from forest to oil palm for birds and leaf-litter invertebrates, with intermediate responses in the rubber systems. Ants however, had higher diversity in oil palm compared with forest and jungle rubber. There were few significant responses to land-use change for multi-trait indices, but noteworthy responses for single-trait indices. In particular, for all taxa species from higher trophic guilds decreased from forest to oil palm. The observed decrease in species richness from rainforest to monoculture plantations across multiple taxa, along with the tightly coupled decreases in functional diversity and low functional redundancy, could threaten long-term ecosystem stability through potential consequences for ecosystem processes. The complementary results from using multiple functional indices emphasizes the need to combine different multi-trait and single-trait measures to better understand the effects of land-use change on communities and associated functions.
\end{abstract}


Chapter 4: Single- and multi-trait measures reveal widespread functional diversity loss in humanmodified tropical landscapes

\section{Introduction}

Land-use change due to agricultural expansion is causing considerable species loss worldwide (Jonathan A. Foley et al. 2005b; Newbold et al. 2015). In tropical regions in particular, conversion of forest and agroforests into monoculture agriculture such as oil palm is happening at an extremely rapid rate, leading to highly simplified landscapes (Emily B. Fitzherbert et al. 2008). In Indonesia, currently the world's leading palm oil producer, oil palm plantation crop cover was nine million hectares in 2010 with a projected increase to 18 million hectares by 2020 (Lian Pin Koh and Ghazoul 2010). The predicted further large-scale expansion of oil palm plantations and other high-intensity agricultural systems has extensive implications for species loss and subsequent alteration of ecosystem functions and services (Emily B. Fitzherbert et al. 2008).

Although patterns of species loss with land-use change are relatively well studied (Emily B. Fitzherbert et al. 2008), it is now widely understood that functional diversity, and not species richness per se, is the main driver of ecosystem functioning and stability (Tilman et al. 1997; Lefcheck and Duffy 2015; Gagic et al. 2015). Functional diversity refers to a component of biodiversity that measures the variation in the functionally relevant traits present in a community (Petchey and Gaston 2006). Trait-based diversity indices provided higher explanatory power than species-based diversity indices (e.g. species richness and Shannon diversity) for predicting seven ecosystem functions' responses in a recent study by Gagic et al. (2015). Also, multifunctionality of ecosystems (rates of multiple processes) was only directly affected by variation in functional diversity measures rather than taxonomic diversity in a grassland biodiversity experiment (Mouillot et al. 2011). Understanding the response of functional diversity to land-use change will be extremely important if we are to fully grasp the long-term consequences on ecosystem functioning (Senior et al. 2013).

Quantifying functional diversity also enables the investigation of the relationship between species richness and functional diversity. Functional diversity and species richness are often correlated (Flynn et al. 2009; Bihn, Gebauer, and Brandl 2010), but the relationship between the two is not necessarily linear. Its shape has important implications for functional redundancy and complementarity (Flynn et al. 2009). For example, species may be lost without an equivalent loss in functional diversity if a number of species have similar traits within the community, indicating functional redundancy and the possibility of community resilience to disturbance. Alternatively, if functionally unique species are lost there could first be a sharp decline in functional diversity with only a small reduction in species richness. For example, species with large body sizes, small geographic ranges and high trophic position are often more sensitive to disturbance and are therefore lost first in disturbed ecosystems with potential serious consequences for the ecosystem functions they perform (Henle et al. 2004; Larsen, Williams, and Kremen 2005). 
Chapter 4: Single- and multi-trait measures reveal widespread functional diversity loss in humanmodified tropical landscapes

Functional responses can be assessed using indices based on single-traits (e.g. community-weighted mean (CWM), Sonnier, Shipley, and Navas 2010) or multiple traits (e.g. functional dispersion, the mean distance of each species trait values to the community trait space centroid, Etienne Laliberté and Legendre 2010). Recently, there has been a growing body of research investigating the relative benefit of different functional indices and which best predict ecosystem functioning (e.g. Mouillot et al. 2011; Butterfield and Suding 2013; Gagic et al. 2015). However, it is still unclear if single-trait, multi-trait or combinations of both provide the most appropriate or informative data for understanding changes in functional diversity or the consequences of those changes. A number of studies investigating both single-trait and multi-trait functional indices in plants have found that a single-trait index (CWM) better predicts measured ecosystem functions (e.g. Butterfield and Suding 2013). Correspondingly, Gagic et al. (2015) found that, of the reviewed studies that considered both single- and multi-trait indices, $73 \%$ demonstrated certain single-trait indices were better at predicting ecosystem functioning than multi-trait indices. However, others claim that only considering one type of index is insufficient, and that both are needed to gain a comprehensive understanding of community functional diversity (Gagic et al. 2015).

Although there is an increasing amount of research that investigates both taxonomic and functional diversity in the context of land-use change, studies across multiple taxa and in different land-use systems are still rare (but see Flynn et al. 2009; Senior et al. 2013; Gagic et al. 2015). In the present study, we use community and trait data from arboreal ants, leaf-litter macro-invertebrates and birds to study functional diversity responses to land-use change in Sumatra, Indonesia. We assess four land-use systems important to the study region, lowland rainforest, jungle rubber, rubber and oil palm. To comprehensively assess changes in functional diversity, we estimate the relationships between taxonomic and functional diversity and the responses of multiple single and multi-trait functional indices to land-use change, and compare the relative value of single or multi-trait indices. Understanding functional diversity loss in these systems is important for predicting effects on ecosystem functioning and for understanding the overall consequences of land-use change. 
Chapter 4: Single- and multi-trait measures reveal widespread functional diversity loss in humanmodified tropical landscapes

\section{Materials and Methods}

\section{Study Area}

Our study was carried out within two lowland regions in the Batanghari and Sarolangun Regencies of Jambi Province, Sumatra, Indonesia at elevations of 40-100 m a.s.l. These regions were adjacent to two protected areas, the Bukit Duabelas National Park and the Harapan Rainforest (Fig. S3.1). This area is typical of lowland Sumatra in that it has undergone extensive selective logging and deforestation, especially over the past 50 years as a result of the increasing expansion of agricultural land (Laumonier et al. 2010). In particular, rubber is the most dominant crop in the province with a land cover of 650,000 ha in 2011 . However, over the past 20 years oil palm has become increasingly dominant, increasing almost 4-fold from 150,000 ha to 550,000 ha in the period from 1996 to 2011 (Gatto, Wollni, and Qaim 2015).

\section{Study design}

Between October 2012 and August 2014 sampling was conducted across four land-use systems: degraded lowland rainforest, jungle rubber, rubber plantation and oil palm plantation. In the two study regions, each land-use system was replicated four times ( $n=32)$. At each of the 32 study sites, a $50 \mathrm{~m} \times 50 \mathrm{~m}$ sampling plot was defined, which included five randomly assigned $5 \mathrm{~m} \times 5 \mathrm{~m}$ subplots.

All sites were on little or no slope, had comparable soil and mircoclimate conditions within a region, and the plantations were of similar age. The mean pair-wise distance between sites was $11.5 \mathrm{~km}$ and $18.2 \mathrm{~km}$ for Bukit Duabelas and Harapan regions, respectively). The rainforest sites were within Bukit Duabelas National Park and Harapan Rainforest and, although protected, have been selectively logged in the past. Jungle rubber represents an agroforestry system consisting of degraded forest with rubber trees between the native vegetation and minimal management (e.g. minimal mechanical weeding but typically no fertilizer application). The rubber and oil palm plantations, in contrast, were intensively managed monoculture systems. For a detailed description of the study site management practices see Allen et al. (2015).

\section{Sampling methods and trait determination}

\section{Arboreal ants}

We used plastic observation plates with two baits of $2 \mathrm{~cm}^{3}$ of tuna in oil and two sponges saturated with $70 \%$ sucrose solution attached to sample arboreal ant species (hereafter, "ants") (Wielgoss et al. 2010). One plate was tied at breast height on each of two randomly selected trees in all five subplots at each site (total of 10 trees per site). If there were not two trees in a subplot (often the case in oil palm plantations), the closest trees to the subplot were chosen. At 15, 30, 45 and 60 minutes after placing the plates on the trees, the abundance of each ant species present on the plate (separately 
Chapter 4: Single- and multi-trait measures reveal widespread functional diversity loss in humanmodified tropical landscapes

for ants feeding on sugar or tuna) was recorded. Specimens were collected from each ant species present where possible without disrupting recruitment. Surveys were conducted at each site four times during the study period (first: October 2012, second: February-March 2013, third: SeptemberOctober 2013, fourth: February 2014), between 9:00 am and 11:00 am. No sampling was conducted during or immediately after rain due to a reduction in ant activity under wet conditions. All ants collected were identified to genus level (Fayle, Yusah, and Hashimoto 2014). We identified specimens to species level where possible and assigned the remainder to morphospecies. Ant abundance per species at a given site was defined as the mean of the maximum number of each species on each plate (at any time measurement) used at a site (over the whole survey). By taking the mean abundance from the maximum at any given time during the surveys we took into account the possibility of competition that could disadvantage subdominant species if only looking at the abundance after 60 minutes.

Three traits were defined for each ant species present: head length (as an indicator of body mass), protein/carbohydrate preference ratio (feeding type) and relative leg length (dispersal) (Bihn, Gebauer, and Brandl 2010). Head and leg length (combined tibia and femur) were measured to the nearest $0.01 \mathrm{~mm}$ on between one and five individuals from each species at each site and a mean was used for analysis. Relative leg length was calculated by dividing by head length. The protein/carbohydrate preference ratio for each species was determined by dividing the total abundance of the species counted at the protein baits (tuna) by the total abundance of the species at both baits (higher ratio indicates increased predator abundance).

\section{Leaf-litter macro-invertebrates}

In each of three (out of the possible five) randomly chosen subplots at each site we sieved 1 $\mathrm{m}^{2}$ of leaf-litter over a coarse sieve (mesh width of $2 \mathrm{~cm}$ ). Macro-invertebrates were then handcollected from the sieved litter. Samples were collected in October and November 2012. Specimens were identified to morphospecies based on consistent morphological characteristics.

Three traits were defined for each morphospecies of leaf-litter macro-invertebrate (hereafter, "invertebrates"): body mass, feeding guild and dispersal capacity (Mumme 2014). Body mass was calculated from individual body lengths using length-mass regressions from the literature (for details see Mumme 2014). Each morphospecies was assigned to one of three feeding guilds: primary consumers (herbivores and detritivores), omnivores and predators, based on a combination of literature, taxonomy and morphology. To enable the analysis of categorical traits, each feeding guild was given a score between 0 and 1 for analysis; primary consumers were scored as 0 , omnivores as 0.5 and predators as 1 . Dispersal capacity was assessed by allocating morphospecies into two groups according to whether they were winged (scored as 1 for analysis) or wingless (0). 
Chapter 4: Single- and multi-trait measures reveal widespread functional diversity loss in humanmodified tropical landscapes

\section{Birds}

Bird data were collected using standardized point counts and passive acoustic monitoring stations. The point counts were completed at the center of each plot and all birds within the plot were observed (using 7 × $40 \mathrm{~mm}$ Nikon Monarch binoculars) and recorded for 20 minutes between 6:00 and 10:00 from June-July 2013. The timing of bird data collection alternated between early and late morning and all plots were visited 3 times (60 min sampling per plot in total). Individuals flying above the canopy were excluded, and unfamiliar bird calls were recorded using a directional microphone (Sennheiser ME-66/K6). The recordings were compared with an online bird call database (XenoCanto) for confirmation. Bird species identification follows Birdlife International (BirdLife International 2015) (97.4\% of observed birds were identified to species level). Additionally, we recorded sound for 20 minutes after sunset at $44100 \mathrm{~Hz}$ on two channels using sound recorders (SM2+ recorder with 2 SMX-II microphones, Wildlife acoustics $\left.{ }^{\circledR}\right)$ which were attached to a tree at the center of the plot at $2-2.5 \mathrm{~m}$. Eight plots could be sampled simultaneously, so sampling all 32 plots took 4 days (10th and 13th of May for Harapan region, and the 3rd and 7th of June 2013 for Bukit Duabelas). Recordings were uploaded to a website (http://soundefforts.uni-goettingen.de/) where two independent ornithologists tagged all audible bird calls within an estimated $35 \mathrm{~m}$ radius with the corresponding species name. A third ornithologist reviewed all identifications. Bird data from sound recordings and point counts were subsequently merged.

Three traits were defined for each bird species present: body mass, feeding guild and relative wing length (dispersal). Body mass and feeding guild were obtained from Wilman et al. (2014b) and wing length data from Robinson \& Chasen (1927). The bird species were assigned to one of three feeding guilds: herbivores (frugivore, nectivore, granivore, scored as 1 ), omnivores (0.5) and predators (mostly insectivores, 0 ). Relative wing length was calculated by dividing wing length by body mass.

\section{Functional diversity indices}

We calculated functional diversity (FD) in each site for each taxonomic group (community) to directly compare it with species richness (SR) and determine the relationship between the two (Flynn et al. 2009). FD is a dendrogram-based index calculated as the total branch length of the community functional dendrogram following Petchey \& Gaston (2002). FD is one of the most commonly used trait-based measures of functional diversity and, as suggested by Flynn et al. (2009), can be related to species richness to assess the functional redundancy within a system (Flynn et al. 2009; Brown et al. 2011). FD calculations were computed based on presence/absence data and standardized trait values in R 3.2.0 (R Core Team 2015b). 
Chapter 4: Single- and multi-trait measures reveal widespread functional diversity loss in humanmodified tropical landscapes

To compare community trait composition across land-use systems, we calculated three multi-trait functional indices that are based on how species are distributed within a multidimensional functional trait space (trait-space based indices): functional evenness (FEve), functional divergence (FDiv) and functional dispersion (FDis) (Villéger, Mason, and Mouillot 2008; Etienne Laliberté and Legendre 2010). FEve measures the evenness of abundance distributions within the total trait space. FDiv describes the proportion of the total abundance that includes species with extreme traits. Finally, FDis is the abundance-weighted mean distance of each species trait values to the community trait space centroid. We calculated the three indices with abundance data and standardized trait values using the dbFD function in the FD package in R 3.2.0 (Etienne Laliberté and Legendre 2010; E. Laliberté and Shipley 2014; R Core Team 2015b).

To determine if important functional responses are lost when combining traits into multitrait indices of functional diversity, we also calculated two single-trait indices for each trait studied; community weighted mean (CWM) and community weighted variance (CWV) (Sonnier, Shipley, and Navas 2010; Butterfield and Suding 2013). CWM is the abundance-weighted mean trait values for a community, whereas CWV is the variability of the trait values around the mean community value.

\section{Statistical analysis}

\section{Relationship between species richness and functional diversity}

Under the assumption that land-use system is driving both SR and FD, we tested for differences between the SR and FD response to land-use system (and therefore a presumed nonlinear relationship between the two) by directly testing for the presence of an interaction between the type of diversity measure used (SR or FD) and land-use system. For each taxonomic group, we therefore compared two linear mixed-effects models (LMEs) (fitted by maximum likelihood) testing for the effect of land-use system on diversity (including both diversity types in the data); one with diversity type included as a predictor with an interaction term, and one without. Study site nested within region was included as a random effect in both models. The statistical notation of the models thus read as

(1) Diversity land-use type $\times$ diversity type + random $=\sim 1 \mid$ region $/$ site

(2) Diversity $\sim$ land-use type + random $=\sim 1$ region/site

where diversity is the standardized $S R$ and FD values and diversity type is either $S R$ or FD. If $\triangle A I C C \geq 2$, the model with the lowest AICc (small sample size corrected Akaike information criterion's scores) was considered the best supported model. We also considered Akaike weight when determining the best supported model. If the best supported model did not include the interaction term then a linear relationship between species richness and functional diversity was assumed. The best-fit model, refitted using restricted maximum likelihood, was then used to determine the effect of land-use 
Chapter 4: Single- and multi-trait measures reveal widespread functional diversity loss in humanmodified tropical landscapes

system on overall diversity (both SR and FD). Tukey post-hoc tests with Bonferroni correction were used to test for significant differences among the systems. Apart from FD, FDis has also been used to investigate relationships between species richness and functional diversity (Luck, Carter, and Smallbone 2013; Grass, Berens, and Farwig 2014b). To corroborate our findings based on FD, we also tested for differences between SR and FDis responses to land-use system, using the same modelling framework as with FD. LMEs, AICC score calculations and post-hoc tests were conducted using the nlme (Pinheiro et al. 2015), AlCcmodavg (Mazerolle 2015) and multcomp (Hothorn, Bretz, and Westfall 2008b) packages in R 3.2.0 (R Core Team 2015b).

\section{Responses of functional diversity indices to land-use change}

We used LMEs to determine the effect of land-use system on FEve, FDiv, FDis, CWM and CWV, with region specified as a random effect. When LMEs contained a significant effect of land-use system on the response variable, we performed a Tukey post-hoc test (with Bonferroni correction) to test for significant pair-wise differences among land-use systems. To meet assumptions of normality all biomass CWM and CWV values were log transformed prior to analysis. 
Chapter 4: Single- and multi-trait measures reveal widespread functional diversity loss in humanmodified tropical landscapes

\section{Results}

\section{Relationships between taxonomic and functional diversity}

For all taxonomic groups (ants, invertebrates, birds), the model testing the response of SR and FD to land-use change without an interaction with diversity type included as a predictor was the bestsupported model based on AICc (Fig. 3.1, Table S3.1). The supplementary analyses comparing species richness with FDis showed similar results (Table B1).

When testing the response of overall diversity (SR and FD) to land-use system using the bestsupported model, we found that all taxonomic groups responded significantly to land-use change, although directions of the effect varied (Fig. 3.1, Table S3.2). Both birds and invertebrates showed a significant decline in both taxonomic and functional diversity across the land-use gradient (Fig. 3.1, Table S3.3). Ants conversely had significantly lower SR and FD values in forest and jungle rubber compared with oil palm and significantly lower values in rubber compared with jungle rubber (Fig. 3.1, Table S3.3). SR and FD of invertebrates were significantly lower in oil palm, compared with all the other land-use systems, which had similar values except for a marginally significantly higher diversity in forest than jungle rubber (Fig. 3.1, Table S3.3). SR and FD were significantly higher in forest than oil palm for birds, with the rubber systems having intermediate values (Fig. 3.1, Table S3.3). 
Chapter 4: Single- and multi-trait measures reveal widespread functional diversity loss in humanmodified tropical landscapes
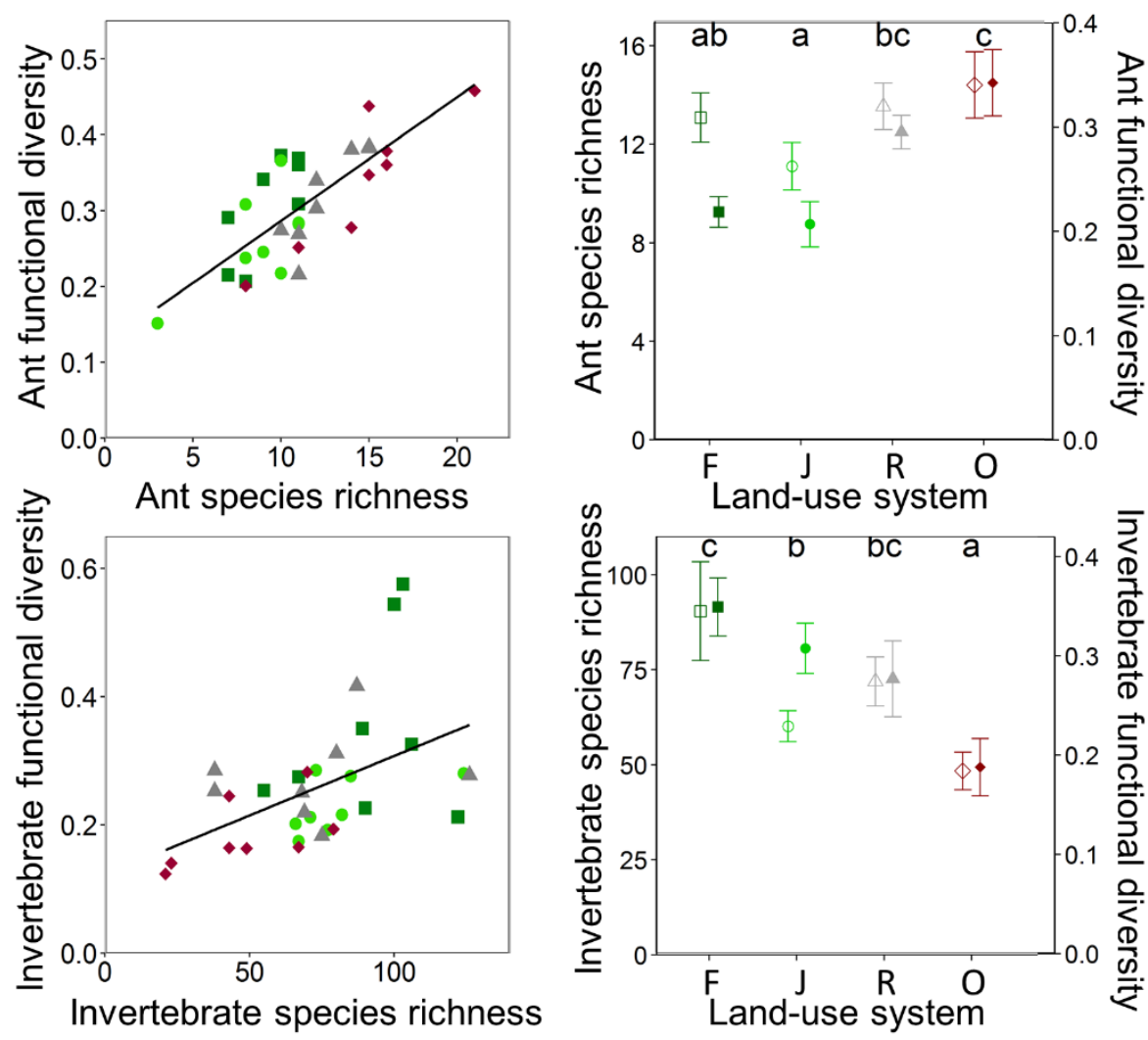

Forest

- Jungle rubber

Rubber

- Oil palm

Species richness

ф Functional diversity
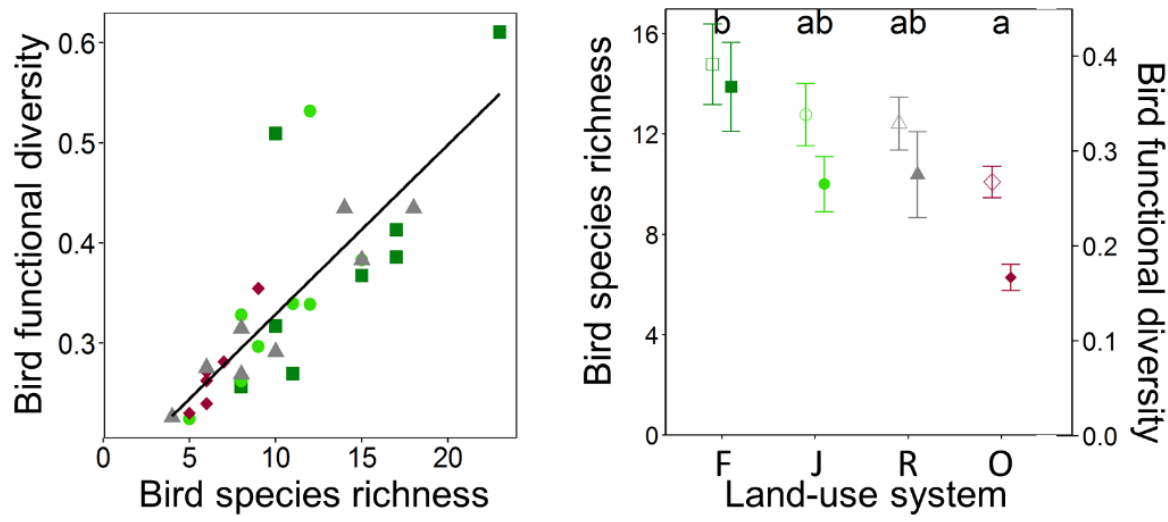

Figure 3.1. The relationship between species richness and functional diversity (left column) and response of species richness and functional diversity to land-use system (right column) for ants, leaf-litter macro-invertebrates and birds. Means (SR and FD) with different letters are significantly different (Tukey's HSD, $\mathrm{p} \leq 0.05$ ). Error bars indicate standard error. $\mathrm{F}=$ forest, $\mathrm{J}=$ jungle rubber, $\mathrm{R}=$ rubber, $\mathrm{O}=$ oil palm. $\mathrm{SR}=$ Species richness, $\mathrm{FD}=$ Functional diversity .

\section{Functional diversity responses to land-use change}

\section{Multi-trait functional indices}

FDiv and FDis did not respond significantly to land-use change for both birds and invertebrates, however, for ants there significant differences between land-use systems for FDiv and FDis (Table S3.4). More specifically, ant FDiv was significantly higher in jungle rubber and oil palm compared with forest (Fig. 3.2, Table S3.5) and ants had significantly higher FDis values in oil palm than in forest with intermediate values for the rubber systems (Fig. 3.2, Table S3.5). FEve was only significantly different 
Chapter 4: Single- and multi-trait measures reveal widespread functional diversity loss in humanmodified tropical landscapes

between land-uses for birds (Table S3.4), with oil palm having significantly lower FEve values than the other three land-uses which had similar values (Fig. 3.2, Table S3.5).

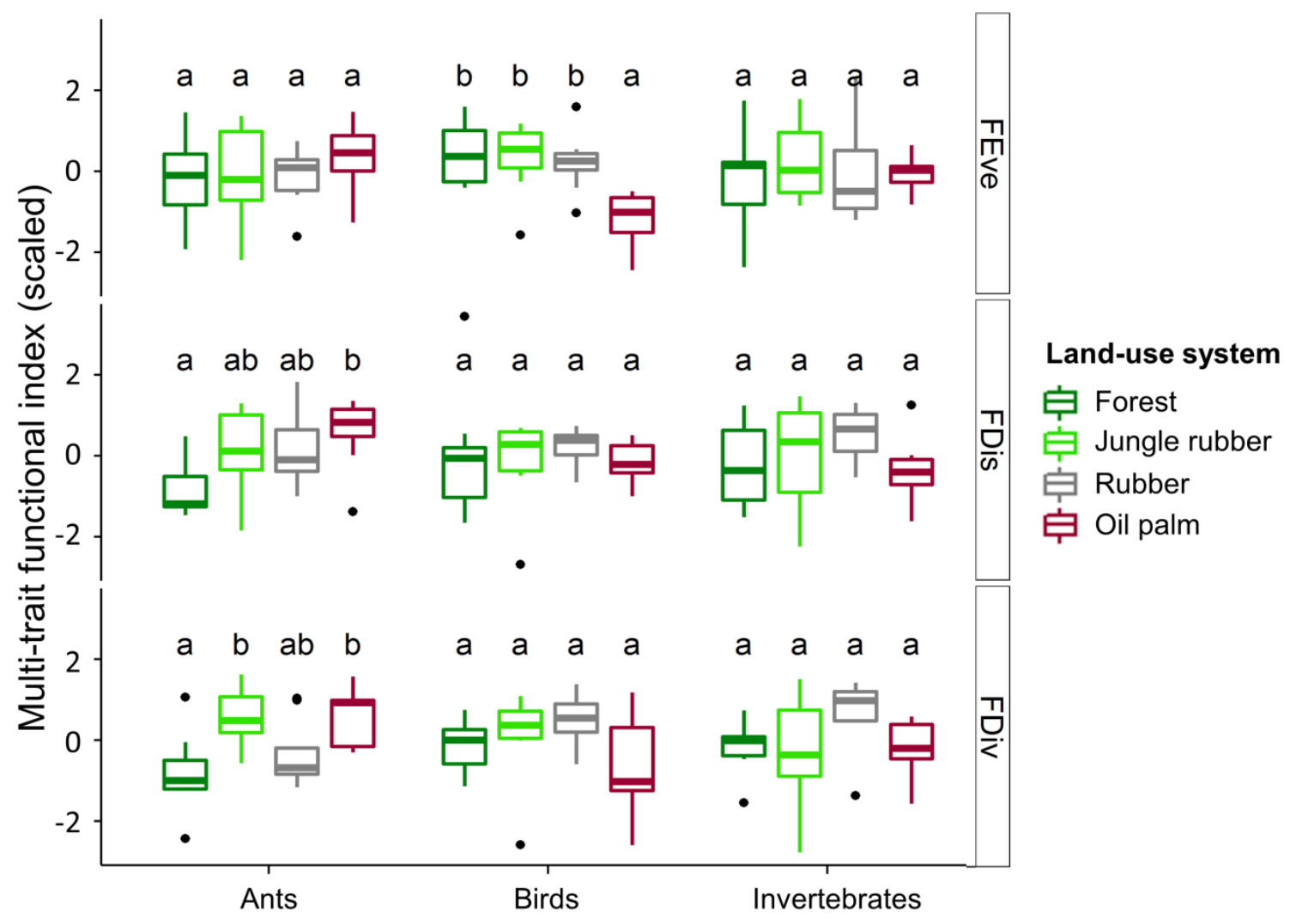

Figure 3.2. The response of ant, leaf-litter macro invertebrate and bird multi-trait (trait-space based) functional indices (functional evenness (FEve), functional dispersion (FDis) and functional divergence (FDiv)) to land-use system. Means with different letters within taxonomic group are significantly different (Tukey's HSD, $\mathrm{p} \leq 0.05$ ).

\section{Single-trait functional indices}

The CWM and CWV values for the animal biomass traits for each taxonomic group (ant head length, invertebrate body mass, bird body mass) showed a significant response to land-use change for invertebrates but not for ants or birds (Table S3.6). More specifically, CWM and CWV values for invertebrates were both significantly lower in oil palm than forest and rubber, with CWV values also significantly lower in jungle rubber than forest (Fig. 3.3, Table S3.7).

Ant, invertebrate and bird CWM values for trophic guild measures (ant protein/carbohydrate preference ratios and invertebrate and bird trophic guild) significantly decreased across the land-use gradient, with oil palm having significantly lower values than forest in all cases and the rubber systems having intermediate values (Fig. 3.3, Tables S3.8+S3.9). This indicates a decrease in the 
Chapter 4: Single- and multi-trait measures reveal widespread functional diversity loss in humanmodified tropical landscapes

presence of species at high trophic levels (i.e. predators) from forest to oil palm. Trophic guild CWV values did not differ significantly between land-uses for any of the taxonomic groups (Table S3.8).

The CWM and CWV values for the animal mobility traits (ant leg length, invertebrate mobility and bird relative wing length) showed a significant response to land-use change for ants and birds (only CWM), but not invertebrates (Table S3.10). Ant leg length CWM was significantly higher in oil palm than rubber, and higher in jungle rubber than forest. Also, bird relative wing length CWM was significantly lower in forest than in jungle rubber and rubber, with intermediate values for oil palm (Fig. 3.3, Table S3.11). The ant CWV values were significantly lower in forest than in any of the other land-use systems (Fig. 3.3, Table S3.11).

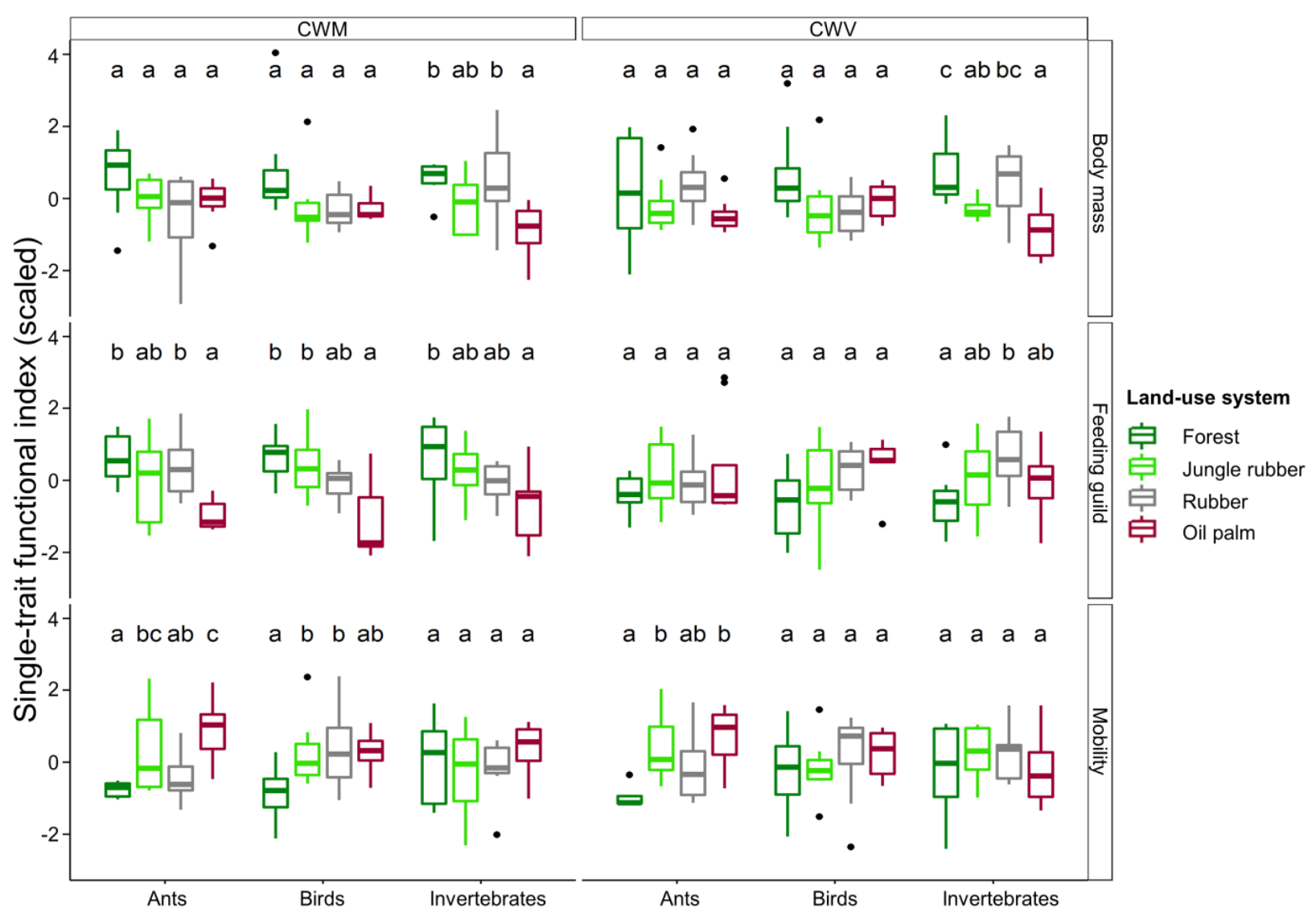

Figure. 3.3. The response of the community weighted mean (CWM) and community weighted variance (CWV) of ant, leaf-litter macro invertebrate and bird biomass, feeding guild and mobility traits to land-use system. Means with different letters within taxonomic group are significantly different (Tukey's HSD, $\mathrm{p} \leq 0.05$ ). 
Chapter 4: Single- and multi-trait measures reveal widespread functional diversity loss in humanmodified tropical landscapes

\section{Discussion}

We studied the relationship between taxonomic and functional diversity as well as the changes in functional diversity of multiple taxa with tropical rainforest transformation using several single and multi-trait indices of functional diversity. We found a linear relationship between species richness and functional diversity across all taxa, suggesting low functional redundancy in the land-use systems studied. The use of both dendrogram based and trait-space based multi-trait indices, along with single-trait indices, provided complementary results describing animal functional responses to landuse change and their implications. We found a general negative effect of land-use change on species richness and functional diversity, in particular for oil palm plantations. In addition, we established that higher trophic guilds were most vulnerable to land-use change; dispersal ability and to a lesser extent body mass were also important traits for determining animal responses to disturbance.

Our results showed a consistent linear relationship between species richness and functional diversity across three different taxonomic groups; ants, invertebrates and birds. The linear relationship implies low functional redundancy in the studied systems, which occurs when many of the species present in a community have a unique combination of traits (Flynn et al. 2009). Low functional redundancy has also been found in a number of other studies (e.g. Micheli and Halpern 2005; Petchey et al. 2007; Laliberte et al. 2010). For example, Petchey et al. (2007) found functional diversity changes were almost exactly proportional to species richness in British bird assemblages. In communities with low functional redundancy, even a relatively small decrease in species richness can decrease functional diversity which can have potential dramatic consequences for ecosystem functioning (Micheli and Halpern 2005). Due to this, redundancy is also linked with an ecosystem's resilience to disturbance and stability (Laliberte et al. 2010). Thus in our study, the low functional redundancy across a large number of different taxa points towards a much reduced resilience of the studied land-use systems towards future anthropogenic pressures.

As expected, due to the highly simplified habitat and intensive management of monoculture plantations, we also found a general decrease in functional diversity and species richness for birds and leaf-litter invertebrates from lowland rainforest towards monoculture production systems. The general decline, however, did not hold for arboreal ant species, which showed the highest biodiversity in the monoculture plantations, in particular oil palm. This could be due to a sampling bias because of the differences in vegetation density between the systems. However, a detailed study on the ant communities at the same sites also did not find a decline in species richness with land-use change (Rubiana et al. 2015), and similarly, Luke et al. (2014) found comparable occurrences of ants between oil palm and old growth forest in Malaysian Borneo. Nevertheless, both studies still concluded ant communities are changed from forest to oil palm due to the large differences in 
Chapter 4: Single- and multi-trait measures reveal widespread functional diversity loss in humanmodified tropical landscapes

community composition. The observed alteration of species richness with land-use change, along with the tightly coupled decreases in functional diversity and low functional redundancy, threatens long-term stability through potential consequences for ecosystem processes vital to the sustainability of agricultural systems such as biocontrol, decomposition and nutrient cycling.

We found that the majority of trait-space based functional indices showed no response to land-use change, with only three out of the nine measures used showing significant responses. The minimal response however, is in contrast to expectation as there are still large changes in the species richness and dendrogram based functional diversity of communities between these systems. However, using multi-trait indices may mask the underlying changes if different traits have varying responses; for example, if one trait responds positively to change and the other negatively then combining them could mask those responses entirely (Spasojevic and Suding 2012). By looking at each trait separately, we may gain more understanding about the specific changes in these communities.

Our investigation of each trait using single-trait functional indices yielded important results that would be masked by using multi-trait indices alone. In particular, we found a decline in the higher trophic guilds (predators) for all taxa from forest to oil palm plantations. Theory predicts losses of higher trophic guilds, in particular predators, with disturbances such as fragmentation and land-use change, and that these losses precede those of species at lower trophic levels (Holt 2009). However, empirical research demonstrating this is still uncommon and mostly restricted to a few specific taxa (in particular, parasitoid-host relationships) (van Nouhuys 2005; Cagnolo et al. 2009). In the land-use systems we investigated, however, there was a consistent loss of predators with land-use change, which threatens the long-term sustainability of the agricultural systems due to the potential decrease in important ecosystem services they provide; in particular, biocontrol. For example, it is established that birds and bats control arthropods in agroforestry systems and therefore impact herbivory and, often subsequently, yield (Maas, Karp, Bumrungsri, Darras, Gonthier, Huang, Lindell, Maine, Mestre, Michel, Morrison, Emily B., et al. 2015).

Interestingly, we also found unexpected results for ant and bird community-weighted mean biomass data, in that there were no significant differences between land-use systems. The results highlight that although species with large body sizes are often sensitive to disturbance, overall community biomass may not decrease with disturbance due to the persistence of large and/or very common generalist species. Ant communities in the plantations for example, are dominated by the mediumsized invasive species and generalists such as the very common Anoplolepis gracilipes. In contrast, comparatively larger forest specialists (e.g. Camponotus gigas and Polyrachis spp.) only occur in low numbers (Rubiana et al. 2015). Similarly, many of the birds that are able to persist in the plantations are large-bodied omnivores (e.g. Bulbuls and doves), which may better be able to use disturbed land- 
Chapter 4: Single- and multi-trait measures reveal widespread functional diversity loss in humanmodified tropical landscapes

use systems due to their less specialized resource use (Newbold et al. 2013; Grass, Berens, and Farwig 2014a).

Both ant and bird communities became dominated by more mobile species from forest to one or more of the agricultural systems. Also, ant leg length had higher variability in all agricultural systems compared with forest. Species with high mobility are often associated with disturbed or non-natural habitats (Driscoll and Weir 2005). For example, the highly invasive ant $A$. gracilipes has the largest relative leg length of any ant species in the study, a trait which positively relates to locomotion and foraging efficiency (Bihn, Gebauer, and Brandl 2010). Increased dispersal capability is a common trait in species that persist in disturbed habitats due to improved resource acquisition abilities where resources may be scarcer than in natural habitats (Barnes et al. 2014). In summary, we found that using single-trait functional indices allowed us to understand how species traits such as trophic guild position, biomass and dispersal capacity mediate species' responses to land-use change, shaping the trajectory of local community assembly and the taxonomic and functional diversity in different landuses.

\section{Conclusions}

The low functional redundancy seen here implies that even relatively small losses in biodiversity may impact ecosystem functioning. This finding suggests strong effects from biodiversity losses following rainforest transformation, particularly towards monoculture production systems. Ecosystem processes associated with higher trophic guilds are most vulnerable, indicating non-random simplification of food webs which may imperil ecosystem stability in the long-term. Single-trait functional indices provided information about important changes in the studied animal groups that were masked by most multi-trait indices. However, the comparison of multi-trait indices with species richness yields conclusions about the level of redundancy in a system. The few unexpected results along with the differing complementary applications of the different functional indices emphasize the need to investigate many aspects of taxonomic diversity, functional diversity and community composition if we want to fully understand the overall effects of land-use change on animal and plant communities.

\section{Acknowledgements}

We thank Winda Alasmari, Rico Fardiansah, Derly Hartika, Marisi Italiansia, Rizky Nazarreta, Ratna Rubiana, Alfianis Rumede, Leonarda Situmorang and other assistants for all their help in the lab and the field. We thank Martyna Kotowska and Katja Rembold for comments on earlier versions of the manuscript. We thank the following for granting us the use of their properties: village leaders, local plot owners, PT REKI and Bukit Duabelas National Park. This study was financed by the Deutsche 
Chapter 4: Single- and multi-trait measures reveal widespread functional diversity loss in humanmodified tropical landscapes

Forschungsgemeinschaft (DFG) in the framework of the collaborative German - Indonesian research project Collaborative Research Centre 990: Ecological and Socioeconomic Functions of Tropical Lowland Rainforest Transformation Systems (Sumatra, Indonesia). 


\section{Supplementary material}

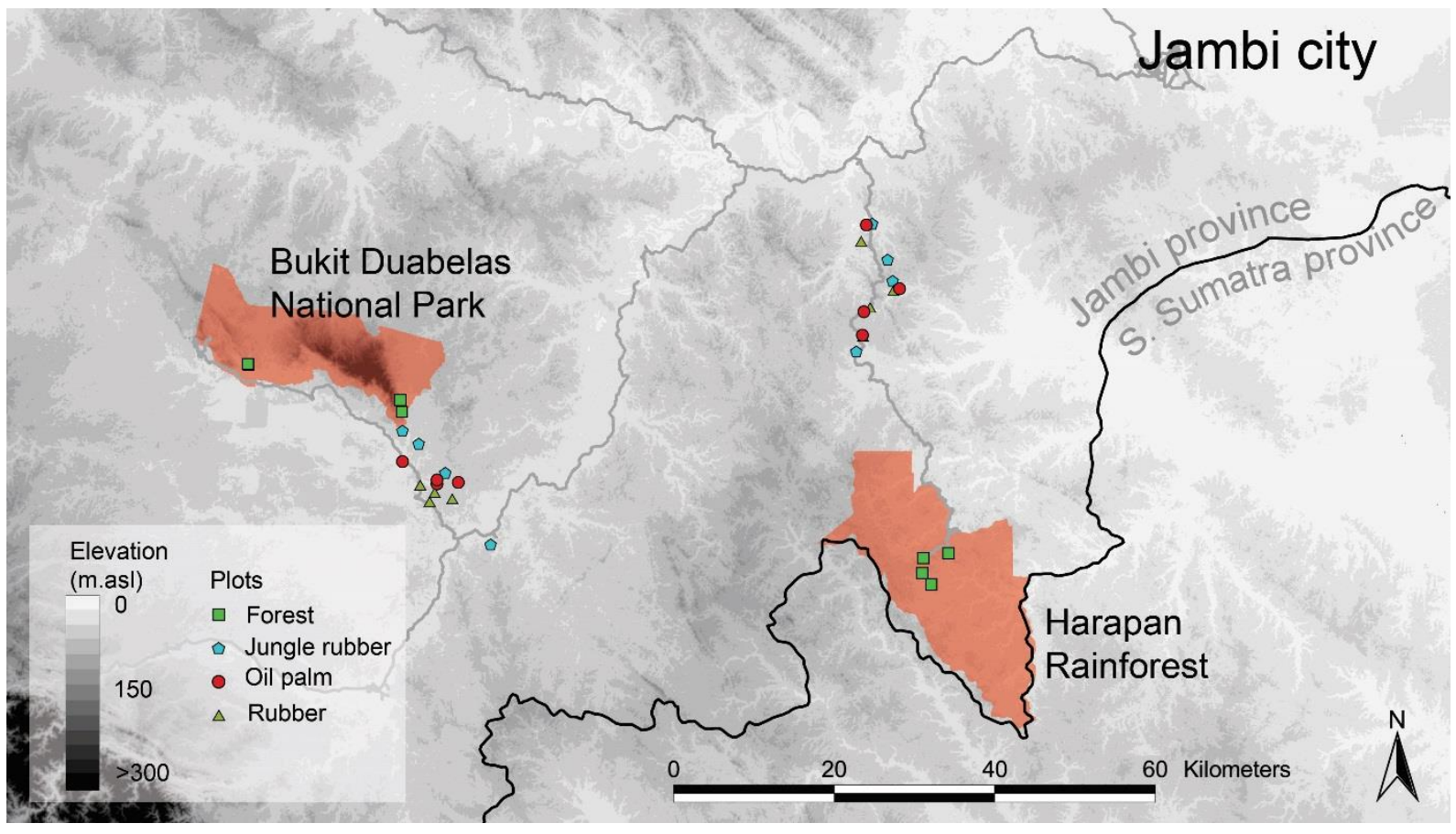

Figure S3.1. Map of study area located in Jambi, Sumatra, Indonesia. In the two study regions, each land-use system was replicated four times. The regions were adjacent to two protected areas, the Bukit Duabelas National Park and the Harapan rainforest (area shaded in orange). Figure modified from Allen et al (2015). 
Chapter 4: Single- and multi-trait measures reveal widespread functional diversity loss in humanmodified tropical landscapes

Table S3.1. AICc table for comparison of fits of linear mixed effects models testing the effect of land-use change on overall diversity (species richness and functional diversity/functional dispersion). The two models tested for (a) arboreal ant, (b) leaf-litter invertebrate and (c) bird overall diversity (both species richness and functional diversity or functional dispersion) are shown with K (number of parameters in the model), AICc (AIC adjusted for bias due to small sample size), $\triangle \mathrm{AICc}$ (change in AICc, models with $\triangle \mathrm{AICc}<2$ have an equal likelihood of being the model that best explains the response variable), and Akaike weight (relative probability of each model being the best model).The best supported models are indicated in bold. LUS is land-use system and DivType is diversity type.

Functional diversity

Functional dispersion

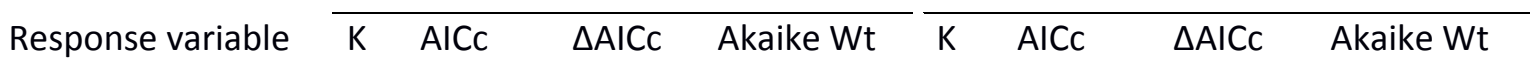

(a) Ant

$\begin{array}{lllllllll}\text { LUS } & \mathbf{7} & \mathbf{1 7 4 . 5 4} & \mathbf{0 . 0 0} & \mathbf{0 . 9 7} & \mathbf{7} & \mathbf{1 7 0 . 2 8} & \mathbf{0 . 0 0} & \mathbf{0 . 9 2} \\ \text { LUS*DivType } & 11 & 181.68 & 7.15 & 0.03 & 11 & 175.07 & 4.79 & 0.08\end{array}$

(b) Invertebrate

$\begin{array}{lllllllll}\text { LUS } & \mathbf{7} & \mathbf{1 7 0 . 5 8} & \mathbf{0 . 0 0} & \mathbf{0 . 9 9} & \mathbf{7} & \mathbf{1 8 4 . 5 8} & \mathbf{0 . 0 0} & \mathbf{0 . 7 8} \\ \text { LUS*DivType } & 11 & 179.13 & 8.56 & 0.01 & 11 & 184.06 & 2.48 & 0.22\end{array}$

(c) Bird

$\begin{array}{lllllllll}\text { LUS } & \mathbf{7} & \mathbf{1 6 9 . 3 7} & \mathbf{0 . 0 0} & \mathbf{1 . 0 0} & \mathbf{7} & \mathbf{1 8 0 . 6 4} & \mathbf{0 . 0 0} & \mathbf{0 . 9 4} \\ \text { LUS*DivType } & 11 & 180.13 & 10.76 & 0.00 & 11 & 186.12 & 5.47 & 0.06\end{array}$


Chapter 4: Single- and multi-trait measures reveal widespread functional diversity loss in humanmodified tropical landscapes

Table S3.2. Linear mixed effect model ANOVA outputs testing for a significant effect of land-use system on overall diversity (species richness and functional diversity). The best-fit linear mixed effects models which determined the effect of land-use change on (a) arboreal ant, (b) leaf-litter invertebrate and (c) bird overall diversity (both species richness and functional diversity) (Table S1). Significant $P$-values are indicated in bold $(P=\leq 0.05)$.

Response variable $\quad$ Effect $\quad$ df $\quad$ F-value P-value

\begin{tabular}{|c|c|c|c|c|c|}
\hline (a) & Ant diversity & Land-use system & 59 & 3.606 & 0.018 \\
\hline (b) & Invertebrate diversity & Land-use system & 59 & 9.565 & $<0.001$ \\
\hline (c) & Bird diversity & Land-use system & 57 & 7.333 & $<0.001$ \\
\hline
\end{tabular}


Chapter 4: Single- and multi-trait measures reveal widespread functional diversity loss in humanmodified tropical landscapes

Table S3.3. Summary statistics of Tukey post-hoc tests testing for significant differences in overall diversity (species richness and functional diversity) among land-use systems. Tukey post-host tests were performed on the best-fit linear mixed effects models which determined the effect of land-use change on (a) ant, (b) leaf-litter invertebrate and (c) bird overall diversity (both species richness and functional diversity) (Table S3.1). Significant P-values are indicated in bold (Tukey's HSD, $\mathrm{P}=\leq 0.05$ ). F=forest, J=jungle rubber, $\mathrm{R}=$ rubber, $\mathrm{O}=$ oil palm.

Response variable

(a) Ant diversity

$$
\begin{aligned}
& J-F \\
& O-F \\
& R-F \\
& O-J \\
& R-J \\
& R-O
\end{aligned}
$$

(b) Leaf-litter invertebrate diversity

$$
\begin{aligned}
& J-F \\
& O-F \\
& R-F \\
& O-J \\
& R-J \\
& R-O
\end{aligned}
$$

(c) Bird diversity

$$
\begin{aligned}
& J-F \\
& O-F \\
& R-F \\
& O-J \\
& R-J \\
& R-O
\end{aligned}
$$

Estimate

0.043

$0.132 \quad 1.000$

0.933

2.867

0.025

0.170

0.522

1.000

0.889

2.734

0.038

0.127

0.390

1.000

$-0.763$

$-2.344$

0.114

$-0.774$

$-2.619$

0.053

$-0.158$

$-5.345$

$<0.001$

$-0.702$

$-2.374$

0.106

$-0.806$

$-2.726$

0.038

0.072

0.245

1.000

0.878

2.971

0.018

$\begin{array}{rrr}-0.698 & -2.345 & 0.114 \\ -1.446 & -4.688 & <0.001 \\ -0.707 & -2.375 & 0.105 \\ -0.748 & -2.425 & 0.092 \\ -0.009 & -0.030 & 1.000 \\ 0.739 & 2.396 & 0.099\end{array}$


Table S3.4. Linear mixed effect model ANOVA outputs testing for a significant effect of land-use system on trait-space based functional indices. The linear mixed effects models determined the effect of land-use change on (a) arboreal ant, (b) leaf-litter invertebrate and (c) bird functional evenness, functional evenness and functional dispersion. Significant $P$-values are indicated in bold $(P=\leq 0.05)$.

\begin{tabular}{|c|c|c|c|c|c|c|c|c|c|c|}
\hline \multirow[b]{2}{*}{ Response variable } & \multirow[b]{2}{*}{ Effect } & \multicolumn{3}{|c|}{ functional evenness } & \multicolumn{3}{|c|}{ functional divergence } & \multicolumn{3}{|c|}{ functional dispersion } \\
\hline & & df & F-value & P-value & $\mathrm{df}$ & F-value & P-value & $\mathrm{df}$ & F-value & P-value \\
\hline (a) Ant & Land-use system & 27 & 0.504 & 0.683 & 27 & 5.433 & 0.005 & 27 & 3.882 & 0.020 \\
\hline (b) Invertebrate & Land-use system & 27 & 0.307 & 0.820 & 27 & 1.841 & 0.164 & 27 & 1.656 & 0.200 \\
\hline (c) Bird & Land-use system & 26 & 7.254 & 0.001 & 26 & 1.988 & 0.141 & 26 & 0.231 & 0.874 \\
\hline
\end{tabular}


Table S3.5. Summary statistics of Tukey post-hoc tests testing for significant differences in trait-space based functional indices among land-use systems. Tukey post-host tests were performed on linear mixed effects models determining the effect of land-use change on (a) arboreal ant and (b) bird functional evenness, functional evenness and functional dispersion. Only values from response variables with significant responses to land-use system (Table S3.4) are shown here. Significant $P$-values are indicated in bold (Tukey's HSD, $P=\leq 0.05$ ). $\mathrm{F}=$ forest, J= jungle rubber, R=rubber, $0=$ oil palm.

\begin{tabular}{|c|c|c|c|c|c|c|c|c|c|c|}
\hline \multirow{2}{*}{\multicolumn{2}{|c|}{ Response variable }} & \multicolumn{3}{|c|}{ functional evenness } & \multicolumn{3}{|c|}{ functional divergence } & \multicolumn{3}{|c|}{ functional dispersion } \\
\hline & & estimate & z-value & P-value & estimate & z-value & P-value & estimate & z-value & P-value \\
\hline \multicolumn{11}{|c|}{ (a) Ant } \\
\hline & $J-F$ & & & & 0.210 & 3.221 & 0.008 & 0.542 & 2.243 & 0.194 \\
\hline & $O-F$ & & & & 0.220 & 3.370 & 0.005 & 0.796 & 3.292 & 0.006 \\
\hline & $R-F$ & & & & 0.072 & 1.103 & 1.000 & 0.560 & 2.314 & 0.124 \\
\hline & $0-J$ & & & & 0.010 & 0.149 & 1.000 & 0.254 & 1.049 & 1.000 \\
\hline & $R-J$ & & & & -0.139 & -2.118 & 0.205 & 0.017 & 0.071 & 1.000 \\
\hline & $\mathrm{R}-\mathrm{O}$ & & & & -0.148 & -2.267 & 0.140 & -0.237 & -0.978 & 1.000 \\
\hline \multirow[t]{7}{*}{ (b) } & Bird & & & & & & & & & \\
\hline & $J-F$ & -0.010 & -0.368 & 1.000 & & & & & & \\
\hline & $O-F$ & -0.113 & -4.163 & $<0.001$ & & & & & & \\
\hline & $R-F$ & -0.017 & -0.647 & 1.000 & & & & & & \\
\hline & $0-J$ & -0.103 & -3.807 & $<0.001$ & & & & & & \\
\hline & $R-J$ & -0.007 & -0.279 & 1.000 & & & & & & \\
\hline & $R-O$ & 0.096 & 3.538 & 0.002 & & & & & & \\
\hline
\end{tabular}


Chapter 4: Single- and multi-trait measures reveal widespread functional diversity loss in human-modified tropical landscapes

Table S3.6. Linear mixed effect model ANOVA outputs testing for a significant effect of land-use system on single-trait (biomass) functional indices. The linear mixed effects models determined the effect of land-use change on the community weighted mean (CWM) and community weighted variance (CWV) (a) arboreal ant, (b) leaf-litter invertebrate and (c) bird biomass traits.

\begin{tabular}{|c|c|c|c|c|c|c|c|}
\hline \multirow[b]{2}{*}{ Response variable } & \multirow[b]{2}{*}{ Effect } & \multicolumn{3}{|c|}{ CWM } & \multicolumn{3}{|c|}{ CWV } \\
\hline & & $\mathrm{df}$ & F-value & P-value & $\mathrm{df}$ & F-value & P-value \\
\hline (a) Ant (head length) & Land-use system & 27 & 2.028 & 1.336 & 27 & 1.265 & 0.306 \\
\hline (b) Invertebrate (body mass) & Land-use system & 27 & 4.146 & 0.015 & 27 & 7.424 & $<0.001$ \\
\hline (c) Bird (body mass) & Land-use system & 26 & 2.333 & 0.097 & 26 & 2.031 & 0.134 \\
\hline
\end{tabular}


Table S3.7. Summary statistics of Tukey post-hoc tests testing for significant differences in single-trait (biomass) functional indices among land-use systems. Tukey post-host tests were performed on linear-mixed effect models testing the response of the community weighted mean (CWM) and community weighted variance (CWV) of leaf-litter invertebrate to land-use system. Only values from response variables with significant responses to land-use system (Table S3.6) are shown here. Significant $P$-values are indicated in bold (Tukey's HSD, $P=\leq 0.05$ ).

\begin{tabular}{|c|c|c|c|c|c|c|}
\hline \multirow[b]{2}{*}{ Response variable } & \multicolumn{3}{|c|}{ CWM-biomass } & \multicolumn{3}{|c|}{ CWV-biomass } \\
\hline & estimate & $z$-value & $p$-value & estimate & $z$-value & $p$-value \\
\hline \multicolumn{7}{|c|}{ Invertebrate (body mass) } \\
\hline$J-F$ & -0.780 & -1.477 & 0.838 & -1.371 & -2.667 & 0.046 \\
\hline$O-F$ & -1.428 & -2.706 & 0.041 & -2.211 & -4.301 & 0.001 \\
\hline$R-F$ & 0.237 & 0.448 & 1.000 & -0.418 & -0.813 & 1.000 \\
\hline $0-J$ & -0.649 & -1.229 & 1.000 & -0.840 & -1.634 & 0.614 \\
\hline$R-J$ & 1.016 & 1.925 & 0.325 & 0.953 & 1.854 & 0.382 \\
\hline $\mathrm{R}-\mathrm{O}$ & 1.665 & 3.154 & 0.010 & 1.793 & 3.488 & 0.003 \\
\hline
\end{tabular}


Chapter 4: Single- and multi-trait measures reveal widespread functional diversity loss in human-modified tropical landscapes

Table S3.8. Linear mixed effect model ANOVA outputs testing for a significant effect of land-use system on single-trait (feeding guild) functional indices. The linear mixed effects models determined the effect of land-use change on the community weighted mean (CWM) and community

weighted variance (CWV) (a) arboreal ant, (b) leaf-litter invertebrate and (c) bird feeding traits. Significant $P$-values are indicated in bold $(P=\leq 0.05$ ).

\begin{tabular}{|c|c|c|c|c|c|c|c|}
\hline \multirow[b]{2}{*}{ Response variable } & \multirow{3}{*}{$\begin{array}{l}\text { Effect } \\
\text { Land-use system }\end{array}$} & \multicolumn{3}{|c|}{ CWM } & \multicolumn{3}{|c|}{ CWV } \\
\hline & & df & F-value & P-value & $\mathrm{df}$ & F-value & P-value \\
\hline (a) Ant (protein/carbohydrate ratio) & & 27 & 5.437 & 0.005 & 27 & 0.669 & 0.578 \\
\hline (b) Invertebrate (feeding guild) & Land-use system & 27 & 3.047 & 0.046 & 27 & 2.401 & 0.090 \\
\hline (c) Bird (feeding guild) & Land-use system & 26 & 6.737 & 0.002 & 26 & 2.054 & 0.131 \\
\hline
\end{tabular}


Chapter 4: Single- and multi-trait measures reveal widespread functional diversity loss in humanmodified tropical landscapes

Table S3.9. Summary statistics of Tukey post-hoc tests testing for significant differences in single-trait (feeding guild) functional indices among land-use systems. Tukey post-host tests determined the response of the community weighted mean (CWM) of (a) arboreal ant, (b) leaflitter invertebrate and (c) bird feeding guild traits to land-use system. Only values from response variables with significant responses to land-use system (Table S3.8) are shown here. Significant $P$-values are indicated in bold (Tukey's HSD, $P=\leq 0.05$ ).

CWM-feeding guild

estimate $\quad z$-value $\quad P$-value

(a) Ant (protein/carbohydrate ratio)

$J-F$
$O-F$
$R-F$
$O-J$
$R-J$
$R-O$

(b) Invertebrate (feeding guild)

$$
\begin{aligned}
& J-F \\
& O-F \\
& R-F \\
& O-J \\
& R-J \\
& R-O
\end{aligned}
$$$$
-0.830
$$$$
1.000
$$

$-0.057$

$-1.494$

0.811

$-0.080$

$-2.090$

0.220

$-0.025$

$-0.664$

1.000

0.055

1.425

0.925

(c) Bird (feeding guild)

$$
\begin{aligned}
& J-F \\
& O-F \\
& R-F \\
& O-J \\
& R-J \\
& R-O
\end{aligned}
$$

$-0.043 \quad-0.599$

$-0.313$

$-4.185$

$<0.001$

$-0.124$

$-1.722$

0.510

$-0.270$

$-3.606$

0.002

$-0.081$

$-1.123$

1.000

0.189

2.521

0.070 
Table S3.10. Linear mixed effect model ANOVA outputs testing for a significant effect of land-use system on single-trait (mobility) functional indices. The linear mixed effects models determined the effect of land-use change on the community weighted mean (CWM) and community weighted variance (CWV) of (a) arboreal ant, (b) leaf-litter invertebrate, and (c) bird mobility traits. Significant $P$-values are indicated in bold $(P=\leq 0.05$ ).

\begin{tabular}{|c|c|c|c|c|c|c|c|}
\hline \multirow[b]{2}{*}{ Response variable } & \multirow[b]{2}{*}{ Effect } & \multicolumn{3}{|c|}{ CWM } & \multicolumn{3}{|c|}{ CWV } \\
\hline & & df & F-value & P-value & df & F-value & P-value \\
\hline (a) Ant (relative leg length) & Land-use system & 27 & 7.451 & $<0.001$ & 27 & 12.637 & $<0.001$ \\
\hline (b) Invertebrate (dispersal capacity) & Land-use system & 27 & 0.684 & 0.569 & 27 & 0.641 & 0.595 \\
\hline (c) Bird (relative wing length) & Land-use system & 26 & 3.417 & 0.032 & 26 & 0.425 & 0.736 \\
\hline
\end{tabular}


Table S3.11. Summary statistics of Tukey post-hoc tests testing for significant differences in single-trait (mobility) functional indices among land-use systems. Tukey post-host tests determined the response of the community weighted mean (CWM) and community weighted variance (CWV) of (a) arboreal ant and (b) bird dispersal traits to land-use system. Only values from response variables with significant responses to land-use system (Table S3.10) are shown here. Significant $P$-values are indicated in bold (Tukey's HSD, $P=\leq 0.05$ ).

CWM-mobility/dispersal

CWV- mobility/dispersal

\begin{tabular}{|c|c|c|c|c|c|c|c|}
\hline \multirow{2}{*}{\multicolumn{2}{|c|}{ Response variable }} & \multirow{3}{*}{ estimate } & \multirow{3}{*}{ z-value } & \multirow{3}{*}{ P-value } & \multirow{3}{*}{ estimate } & \multirow{3}{*}{ z-value } & \multirow{3}{*}{ P-value } \\
\hline & & & & & & & \\
\hline (a) & Ant (relative le & & & & & & \\
\hline & $J-F$ & 0.651 & 2.652 & 0.048 & 2.320 & 5.056 & $<0.001$ \\
\hline & $O-F$ & 1.053 & 4.289 & $<0.001$ & 2.546 & 5.550 & $<0.001$ \\
\hline & $R-F$ & 0.197 & 0.762 & 1.000 & 1.468 & 3.200 & 0.008 \\
\hline & $0-J$ & 0.402 & 1.637 & 0.610 & 0.227 & 0.494 & 1.000 \\
\hline & $R-J$ & -0.464 & -1.890 & 0.352 & -0.851 & -1.856 & 0.381 \\
\hline & $R-O$ & -0.866 & -3.527 & 0.003 & -1.078 & 2.350 & 0.113 \\
\hline \multirow[t]{4}{*}{ (b) } & Bird (relative w & & & & & & \\
\hline & $J-F$ & 0.863 & 2.570 & 0.061 & & & \\
\hline & $O-F$ & 0.870 & 2.501 & 0.074 & & & \\
\hline & $R-F$ & 0.912 & 2.713 & 0.040 & & & \\
\hline
\end{tabular}


Chapter 4: Single- and multi-trait measures reveal widespread functional diversity loss in human-modified tropical landscapes

$\begin{array}{llll}O-J & 0.007 & 0.019 & 1.000 \\ R-J & 0.048 & 0.143 & 1.000 \\ R-O & 0.042 & 0.120 & 1.000\end{array}$




\section{Chapter 5: Major predators do not influence ecosystem functions and yield in oil palm plantations}

Lisa H. Denmead ${ }^{1 \dagger}$, Kevin Darras ${ }^{1{ }^{* \dagger}}$, Yann Clough ${ }^{1,3}$, Patrick Diaz ${ }^{2}$, Ingo Grass ${ }^{1}$, Munir P. Hoffmann ${ }^{4}$, Fuad Nurdiansyah ${ }^{1,2}$, Teja Tscharntke ${ }^{1}$

${ }^{1}$ Agroecology, University of Göttingen, Göttingen, Germany

${ }^{2}$ University of Jambi, Jambi, Indonesia

${ }^{3}$ Centre for Environmental and Climate Research, Lund University, Lund, Sweden

${ }^{4}$ Crop Production Systems in the Tropics, University of Göttingen, Göttingen, Germany

Author email addresses: Idenmea@gwdg.de, kdarras@gwdg.de, yann.clough@cec.lu.se,

patrickdiaz@live.com, igrass@gwdg.de, mhoffma@gwdg.de, fuad.nurdiansyah@gmail.com,

ttschar@gwdg.de

*Corresponding author: Kevin Darras, Agroecology, Georg-August-University Göttingen,

Grisebachstr. 6, Göttingen 37077, Germany, kdarras@gwdg.de, Phone +49 (0) 551 3933734, Fax +49

(0) 551398806

${ }^{\dagger}$ These authors contributed equally to this work 
Chapter 5: Major predators do not influence ecosystem functions and yield in oil palm plantations

\begin{abstract}
One of the world's most important and rapidly expanding crops, oil palm, is associated with very low levels of biodiversity. Large changes in communities at higher trophic levels might alter ecosystem services and subsequently sustainable management but these links have received little attention to date. Here, for the first time, we manipulated ant and flying vertebrate (birds and bats) access, using six smallholder oil palm plantations in Sumatra (Indonesia), and measured effects on arthropod communities, related ecosystem functions (herbivory, predation, decomposition and pollination) and crop yield. Spiders increased in response to reductions in ant and bird access, but the overall effect of experimental manipulations on ecosystem functions was minimal. Similarly, effects on yield were not significant. We conclude that ecosystem functions and productivity in oil palm are, under current levels of low pest pressure and large pollinator populations, robust to large changes in the communities of major predator groups.
\end{abstract}


Chapter 5: Major predators do not influence ecosystem functions and yield in oil palm plantations

\section{Introduction}

Conversion of natural forests to agricultural systems results in considerable losses in biodiversity (Newbold et al. 2015), yet the remaining biodiversity can play an important role through supporting ecosystem functions and services, alongside inputs such as fertilisers and labour (Fischer, Lindenmayer, and Manning 2006). In tropical agricultural systems, species groups including ants, birds and bats contribute to a number of ecosystem services, in particular predation (biocontrol), soil aeration and nutrient cycling (Folgarait 1998; Vandermeer et al. 2002; Evans et al. 2011), and have been shown to positively affect yield (Evans et al. 2011; Wielgoss et al. 2014; Maas, Karp, Bumrungsri, Darras, Gonthier, Huang, Lindell, Maine, Mestre, Michel, Morrison, Emily B., et al. 2015; Maine and Boyles 2015). Currently the most rapidly expanding tropical perennial crop is oil palm, the world's most important oilseed commodity (Phalan et al. 2013). Despite the importance of oil palm, there have been few studies linking biodiversity and function (e.g. Dejean, Djieto-Lordon, and Durand 1997; Lian Pin Koh 2008; Slade et al. 2014) and the majority of these have looked at only one function or service (but see, Gray and Lewis 2014) and no studies as yet have analysed the relationship between biodiversity, functions and yield.

Almost all organisms studied thus far show a steep decrease in species diversity from forest to oil palm (Emily B Fitzherbert et al. 2008; Barnes et al. 2014; Foster et al. 2011). More importantly, this biodiversity loss is often non-random, endangering ecosystem functioning (Emily B Fitzherbert et al. 2008; Senior et al. 2013). However, certain management practices can promote biodiversity in oil palm plantations (Chung et al. 2000; Nájera and Simonetti 2010; Teuscher et al. 2015). Yet, plantation owners are unlikely to adopt new management practices to increase biodiversity alone. However, if there is any relationship between biodiversity and yield and/or any beneficial ecosystem service, this might alter a plantation owner's willingness to change.

While ant species richness and abundance in Indonesian oil palm can equal or exceed that in lowland rainforest, species and functional composition is drastically altered (Rubiana et al. 2015). Therefore, although ants remain dominant and likely play an important part in oil palm plantations, their influence on the community and certain ecosystem functions may be altered. Furthermore, birds and bats reduce the abundance of arthropod communities in agricultural systems, which results into lower herbivory and higher yields (Maas, Karp, Bumrungsri, Darras, Gonthier, Huang, Lindell, Maine, Mestre, Michel, Morrison, Emily B., et al. 2015). For instance, birds may lower leaf damage by pests in young, unproductive oil palms (Lian Pin Koh 2008). However, null and negative effects on herbivory and yield have also been reported for other systems (e.g. Gras et al. 2016). 
Chapter 5: Major predators do not influence ecosystem functions and yield in oil palm plantations

Exclusion studies including ants, birds and bats can exhibit important intra-guild interactions that lead to non-additive effects (Maas, Karp, Bumrungsri, Darras, Gonthier, Huang, Lindell, Maine, Mestre, Michel, Morrison, Emily B., et al. 2015), but such studies are scarce (Gras et al. 2016). In the present study, we established a one year long, large-scale full-factorial combination of flying vertebrate (birds and bats) and ant exclosures in young, productive oil palm plantations in Sumatra, Indonesia. We comprehensively assess the influence of ants, birds and bats on arthropod communities and associated ecosystem functions and services, investigating changes in arthropod communities and four key ecosystem functions: herbivory, predation, pollination (using pollinators as a proxy) and decomposition. This is the first study to assess the impact of predator exclusions on oil palm yield.

\section{Methods}

\section{Study area}

The experiment was carried out in the Batanghari Regency of Jambi Province, Sumatra, Indonesia. The climate of the region can be characterised as tropical humid, with more than $2000 \mathrm{~mm}$ rainfall per year (Allen et al. 2015) and a long sunshine duration of an average 6h/day. Thus, it is classified as suitable for oil palm production (R. Hereward V. Corley and Tinker 2003), and attainable yields are above $30,000 \mathrm{~kg} \mathrm{FFB} / \mathrm{ha} /$ year (FFB=fresh fruit bunch) during the most productive phase in the life cycle of the oil palm (Hoffmann et al. 2014). Over the past 20 years oil palm has become one of the most dominant crops in the Province, increasing almost 4-fold from 150,000 ha to 550,000 in the period from 1996 to 2011 (Gatto, Wollni, and Qaim 2014).

\section{Experimental design}

Six smallholder oil palm plantations were selected in the study area for inclusion in this study with a minimum distance between the sites of $1.0 \mathrm{~km}$ (mean distance to closest site: $2.4 \mathrm{~km}$; Figure S1). We selected oil palm sites with trees that were 2-3 years old (earliest age to begin harvesting) due to height limitations of establishing the bird and bat exclusion cages. The plantation management was consistent with plantations in the study area and site conditions were similar (Supplementary methods, Appendix 1). Within each plantation we created a full factorial combination of ant and flying vertebrate (bird and bat) exclusion plots, and each plot's location was randomly assigned (Figure 1). This resulted in four experimental plots per site: control, ant exclusion only, flying vertebrate exclusion only and both ant and flying vertebrate exclusion. Each plot was approximately $16 \mathrm{~m} \times 16 \mathrm{~m}$, encompassing four oil palm trees. 
a)

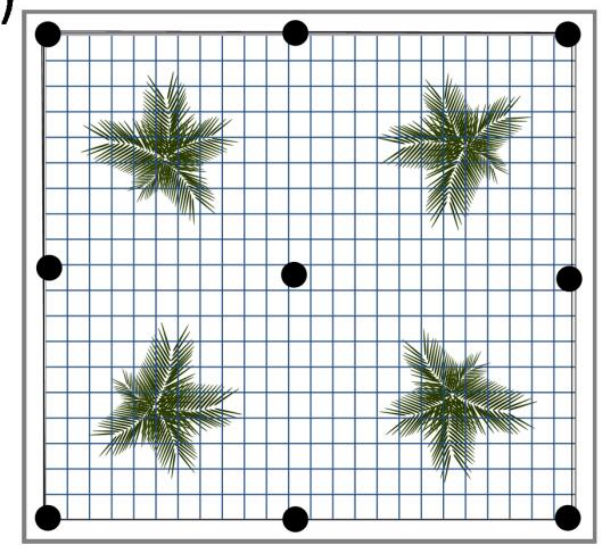

c)
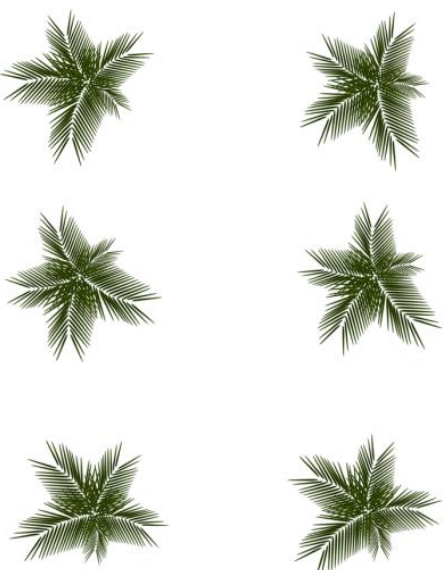
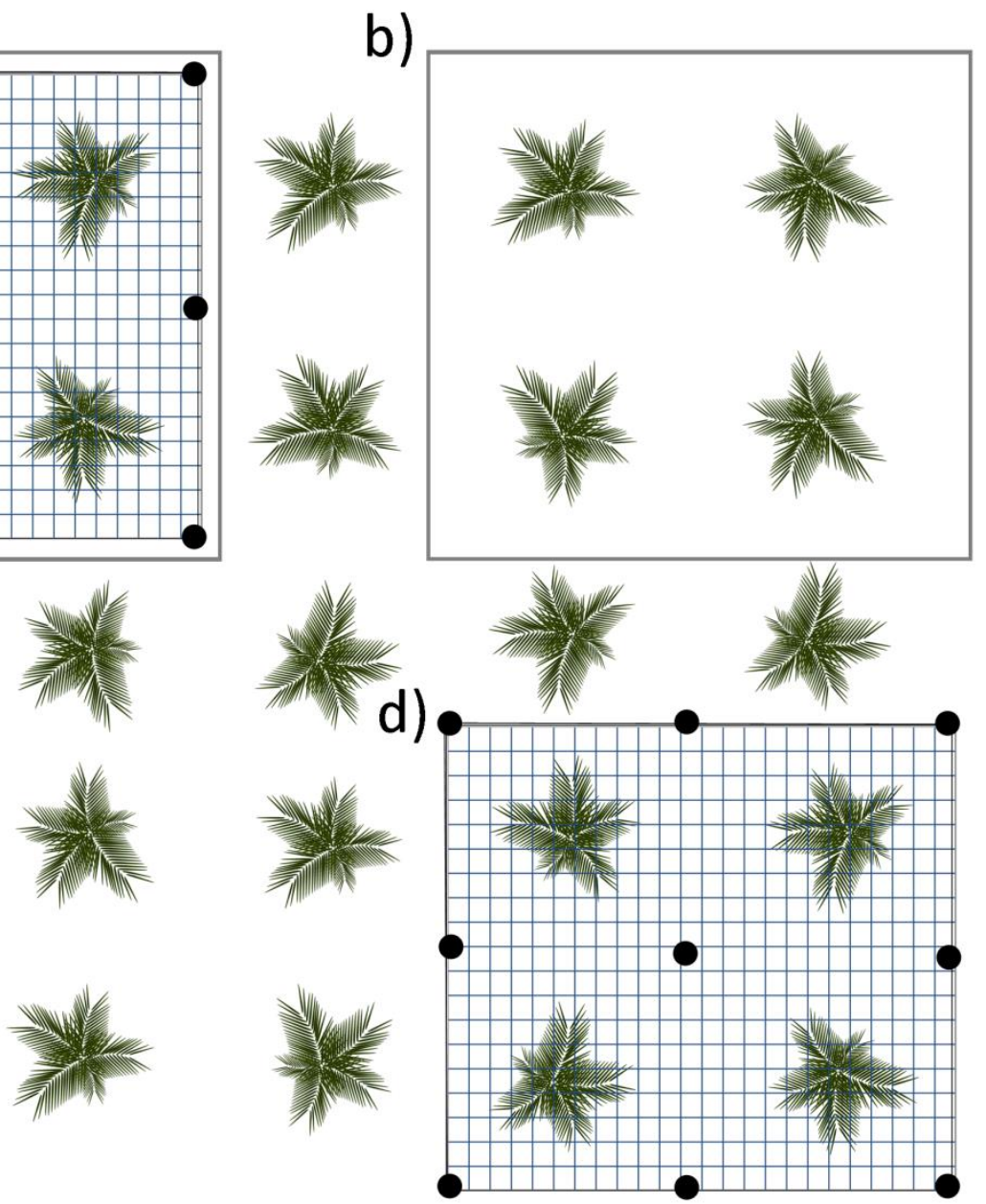

e)

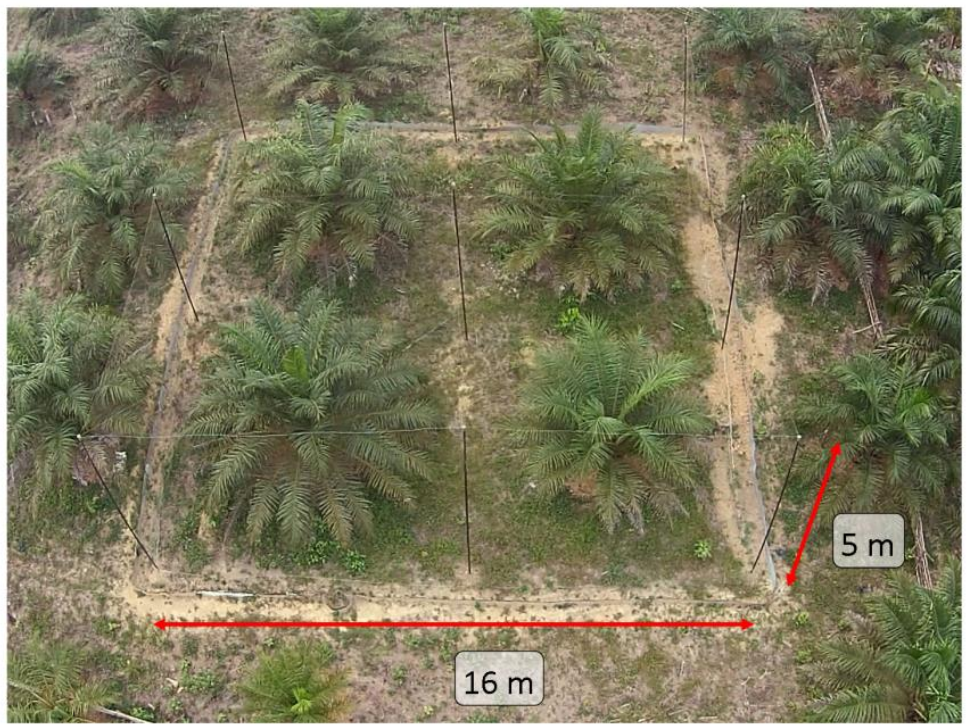

Figure 1. Experimental design. Full factorial combination of ant and bird and bat exclusion plots at each study site. (a) both bird, bat and ant exclusion, (b) ant exclusion only, (c) control (no exclusion), (d) bird and bat exclusion only. (e) example of a bird, bat and ant exclusion plot with approximate scales indicating the cage dimensions (Photo courtesy of Eulefilm (C). 
Chapter 5: Major predators do not influence ecosystem functions and yield in oil palm plantations

\section{Exclusion methodology}

Two methods were used to suppress ants in the exclusion plots. A $50 \mathrm{~cm}$ high aluminium barrier was established surrounding the plot, buried $20 \mathrm{~cm}$ beneath the soil and the top of the barrier was covered in insect glue (Tanglefoot, Contech Enterprises Inc., British Columbia). The glue was regularly checked and replaced when needed. We also carried out toxic baiting five days per week and targeted poisoning of ant nests during the first month of the experiment and then toxic baiting three times per week for the duration of the experiment. The toxic baiting consisted of placing sugar and tuna as attractants, mixed with the insecticide chlorpyrifos (Dursban ${ }^{\text {TM }}$ 200EC, Dow AgriSciences, Jakarta, Indonesia) in nine random locations (one in each tree, five on the ground) in each ant suppression plot for a minimum of one hour. Preliminary experiments determined these two attractants to be attractive to the majority of ant species present, but not to other arthropods.

Flying vertebrate (birds and bats) exclusion cages were constructed using a metal structure consisting of nine 5.0-5.5 $\mathrm{m}$ high iron poles ( 2.5 inches diameter). The poles were embedded in concrete foundations, lined with plastic bags to prevent leaching of carbonate to the soil. Fish nets (35 mm mesh size transparent, nylon) were pulled over the structure and fastened to the ground. Due to the size of the exclosure and the length of the experiment it was not possible to use removable nets that could be manipulated to differentiate between the effects of vertebrates with day or night activity (i.e., birds and bats; Maas et al., 2013). Ant suppression and bird and bat exclusion was continuous for one year, from August 2013 until August 2014 in four out of six plots, and from May 2014 to May 2015 for the other two.

\section{Ant abundance, bird and bat activity monitoring}

Ants were surveyed monthly in every plot to monitor the effectiveness of the ant suppression methods. We used two plastic observation plates per plot with two baits of $2 \mathrm{~cm}^{3}$ of tuna in oil and two sponges saturated with 70\% sugar solution attached (Wielgoss et al. 2010). At 15, 30, 45 and 60 minutes after placing the plates on the ground the abundance of each ant species present on the plate was recorded. Specimens were collected from each ant species present and were identified at species or morpho-species level (Fayle, Yusah, and Hashimoto 2014). Ant species abundance at a given plot each month was defined as the mean of the maximum number of each species on each plate used at an exclusion plot and the sum of all these values at each plot determined the total ant abundance each month (Denmead et al., in review). 
Chapter 5: Major predators do not influence ecosystem functions and yield in oil palm plantations

Bird and bat calls were recorded in January (4 sites) and July (6 sites) 2014, and January 2015 (remaining two sites) with automated sound recorders attached to the central oil palm, and fitted with one acoustic and one ultrasound microphone (SM2Bat+ recorder, SMX-II and SMX-US microphones, Wildlife Acoustics Inc., Massachusetts, USA). We recorded sound for 48 hours starting at sunset, and programmed a sampling rate of $44.1 \mathrm{kHz}$ during the day and a sampling rate of 192 $\mathrm{kHz}$ at night. Bird and bat recordings were processed on an online sound platform (http://soundefforts.uni-goettingen.de/). An ornithologist identified bird species in one morning recording per plot for each month (20 min starting after sunrise). We classified them into feeding guilds based on Thiollay et al. (1995b); missing data were retrieved from del Hoyo et al. (2015). The distance to bird calls (including songs) was estimated by ear by both the ornithologist and an additional listener. We computed the mean distance for each call and excluded calls beyond $35 \mathrm{~m}$. For bats, night recordings of 20 min per plot for each month (starting from 18:30) were timeexpanded by a factor of 4 (from 192 to $48 \mathrm{kHz}$ ) to make bat ultrasound calls audible. For insectivorous and omnivorous birds as well as insectivorous (echolocating) bats, we used the total duration of their calls in each plot to measure their activity in minutes. The activity of birds and bats inside cages was assumed to be null.

\section{Sampling methods}

\section{Soil and tree variables}

In each plot we measured four variables which could potentially vary between and within sites and influence our experiment's response variables to be included in our analysis: Soil pH $\left(\mathrm{H}_{2} \mathrm{O}\right)$, soil texture (clay content), initial oil palm height and oil palm red/green leaf colour ratios (Appendix 1). Soil pH and texture reflected soil conditions at our plots, initial oil palm height accounts for oil palm developmental stage and red/green leaf colour ratios were used to gauge the proportion of the leaves that had photosynthetic activity.

\section{Arthropod collection and identification}

The arthropod communities present in the oil palms were sampled intensively after one year of exclusion through three survey methods: insecticide spraying, beating and vacuuming. All methods were completed at one plot before moving to the next. First we laid four $0.9 \mathrm{~m} \times 2.9 \mathrm{~m}$ white sheets on the ground at right angles from four points at the base of the trunk of each oil palm. One person then walked around the palms twice spraying an insecticide with knock-down effect (deltamethrin, Decis ${ }^{\circledR}$ 2,5 EC, Bayer CropScience, Jakarta, Indonesia) over each palm using a knapsack sprayer. After 15 min all arthropods on the sheets were collected. Next, the beating method was completed by holding a $5 \mathrm{~m} \times 3 \mathrm{~m}$ sheet under four different fronds per palm and shaking the frond up and down 
Chapter 5: Major predators do not influence ecosystem functions and yield in oil palm plantations

so arthropods dropped onto the sheet. All arthropods that had dropped onto the sheet were collected. Finally, arthropods in the oil palm leaf axils and flowers were collected by vacuuming the axils for four minutes per palm using a modified vacuum cleaner.

Arthropods - other than ants and the introduced oil palm pollinator Elaeidobius kamerunicus, which were identified to species/morpho-species level - were identified to higher taxonomic groups, counted and assigned to four feeding guilds: herbivores, predators, detritivores and omnivores based on literature (Table S1).

\section{Ecosystem functions}

In each of the plots, data on four important ecosystem functions were collected: herbivory, decomposition, predation and pollination.

Herbivory was quantified using photos of two leaflets (pinnae) from four fronds per palm (eight leaflets per palm). Percentage leaf loss per photo was calculated using ImageJ software and converted to an average leaf loss per palm. These photos were taken at nine months after exclusion.

Leaf-litter decomposition was measured using litter bags (Falconer, Wright, and Beall 1933). Litter bags were $20 \mathrm{~cm} \times 20 \mathrm{~cm}$ and made from mesh with a $4 \mathrm{~mm} \times 4 \mathrm{~mm}$ mesh size. Each litter bag contained a known dry weight $(10.0 \mathrm{~g} \pm 0.05 \mathrm{~g})$ of oil palm leaves. Four litter bags were placed at random points within each plot. After approximately four and a half months the litter bags were collected and the remaining contents were air dried and weighed. Initial weight minus weight at collection divided by days exposed determined the decomposition rate.

Predation rates were estimated using three different prey sizes. To represent the large prey size we used dummy caterpillars modelled on (similar size and colour) a common species of nettle caterpillar that is known to attack oil palm (Setothosea asigna). Four dummy caterpillars were glued to a leaflet on four different fronds on each oil palm (four caterpillars/palm) and collected 48 hours later. Each caterpillar was defined as predated (visible marks present in the clay) or not (no marks present) and missing caterpillars were excluded from analysis. This method was carried out four and eight months after exclusion start. To represent a medium and small prey size we used dead crickets (Acheta domesticus) and aphids (Aphidoidea sp.) respectively. Four individuals were glued onto a piece of card and then one card was glued to four different fronds on each oil palm (16 individuals/palm for both prey). Cards were checked after two hours for crickets and four hours for aphids, and each individual was defined as predated (visible marks present, or individual missing) or not (no marks present). The cricket predation method was carried out at eight (last two sites) and 12 
Chapter 5: Major predators do not influence ecosystem functions and yield in oil palm plantations

months (first four sites), and the aphids at five and eight (last two sites), and 11 and 12 months (first four sites) after exclusion.

We used the abundance of Elaeidobius kamerunicus collected at final arthropod sampling as a proxy for pollination in our ecosystem functions analysis. Elaeidobius kamerunicus was introduced to South East Asia in the 1980s and is now the main pollinator of oil palm in the area (Foster et al. 2011). The introduction resulted in an approximate $20 \%$ increase in yield and removed the need for hand pollination (Greathead 1983; Foster et al. 2011).

\section{Yield}

Yield measurements continued throughout the experiment and six months after exclusion ended (total = 18 months), except for one plot where the manager decided to terminate their partnership with the experiment at exclusion end (site two, Figure S2). Plantation owners harvested fruit bunches following their normal schedule (twice per month). Yield as fresh fruit bunch weight was recorded as kg/palm. In oil palm, pollinated flowers take 5-6 months until they reach bunch maturity (Verheye 2010), therefore we discarded the first six months of data and used the following 12 months' data in order to reduce carry-over effects from the pre-study period. Also, a few palms had not developed mature bunches by the experiment start, therefore, we computed yield by time by dividing yield by the number of days since the first harvest (FFB $(\mathrm{kg} / \mathrm{palm}) /$ day) (Figure S2). Two palms (out of 96) that were never harvested were excluded from the overall analysis. Analysis of all 18 months of yield data (FFB $(\mathrm{kg} / \mathrm{palm}) /$ day) was also included in the supporting information.

\section{Statistical analysis}

Treatment effects on arthropods, ecological functions, growth and yield

We used linear-mixed effect models (LMEs) to determine the effect of experimental treatment on the arthropod feeding guild abundances (predator, herbivore, detritivore and omnivore), weevil abundances, oil palm herbivory (\% leaf loss), decomposition rate, predation rates and oil palm yield (FFB $(\mathrm{kg} /$ palm)/day). In the LMEs a Poisson distribution was specified for modelling arthropod abundances and a binomial distribution was specified for modelling predation rates, where we used the counts of predated and unpredated prey items (aphids, crickets and dummy caterpillars). An observation-level random effect was included in the case of over-dispersion with the Poisson distributions (Harrison 2014). Experimental treatment consisted of three variables: average ant abundance, bird activity and bat activity (measured in minutes; bird and bat activity in caged plots was set to zero). To account for the different combinations of exclusion we included an interaction term for ants and birds and ants and bats. We used these three continuous variables instead of the factorial treatment to account for the variation in the effectiveness of ant suppression and the 
Chapter 5: Major predators do not influence ecosystem functions and yield in oil palm plantations

known variation in bird and bat activity between sites (Appendix 1, Table S2, Figure S3+S4). In each model all other theoretically possible measured predictors were also included (Table S3) and treatment was nested within site (plantation) as a random effect. Oil palm initial height, soil pH and soil clay content were included as predictors in all the models where is was theoretically relevant due to preliminary analyses determining there were significant differences between treatments within sites (Appendix 1, Table S4). Due to highly skewed distributions, we log-transformed bat activity and weevil abundance when they were included in models as predictors. All numeric predictors were z-transformed to facilitate comparisons of effect sizes.

We then used a model selection approach to assess which of the variables included were most important in explaining each response variable (i.e., maximized the likelihood of the model). For each response, we constructed a model set based on the initial full model -which included all possible combinations of predictors up to a model including only the intercept - and ranked models within each set using Akaike's Information Criterion for small sample sizes (AICC) (dredge() function in R-package MuMIn (Bartoń 2013)). We then identified the best models as those with $\triangle \mathrm{AICC}<2$ (Burnham and Anderson 2002). We used model averaging to combine the best models, which were equivalently likely (Grueber et al. 2011), and derived relative variable importance by summing up the predicted variables weights (model.avg() function in package MuMIn) (Burnham and Anderson 2002). We also determined conditional $R^{2}$ values for all of the best models (Table S5). All analyses were conducted in R 3.2.2 (R Core Team 2015b). 
Chapter 5: Major predators do not influence ecosystem functions and yield in oil palm plantations

\section{Results}

The following results from LMEs are displayed in Fig. 2, 3 and 4 and listed in detail in the supplement (see Table S6 (arthropods), S7 (functions) and S8 (yield)). If not specified, discussed relationships are significant at least at a $P$-value of $<0.05$.

\section{Arthropod responses to ant, bird and bat treatments.}

Average ant abundance and bird activity had negative effects on arthropod predator abundance, however, bat activity did not significantly influence predators (Fig. 2). Predator abundance decreased by $53 \%$ and $42 \%$ from the lowest to the highest ant abundance and bird activity respectively. Ant abundance also had negative effects on omnivore abundance and a marginally significant negative relationship with herbivore $(P=0.078)$ abundance but not bird or bat activity (Fig 2.). Omnivore abundance decreased by only $18 \%$ (eight individuals) from the lowest to the highest ant abundance. Detritivore abundance was not affected by ant abundance or bird and bat activity. Soil clay content had a positive relationship with predator, herbivore and detritivore abundance. 


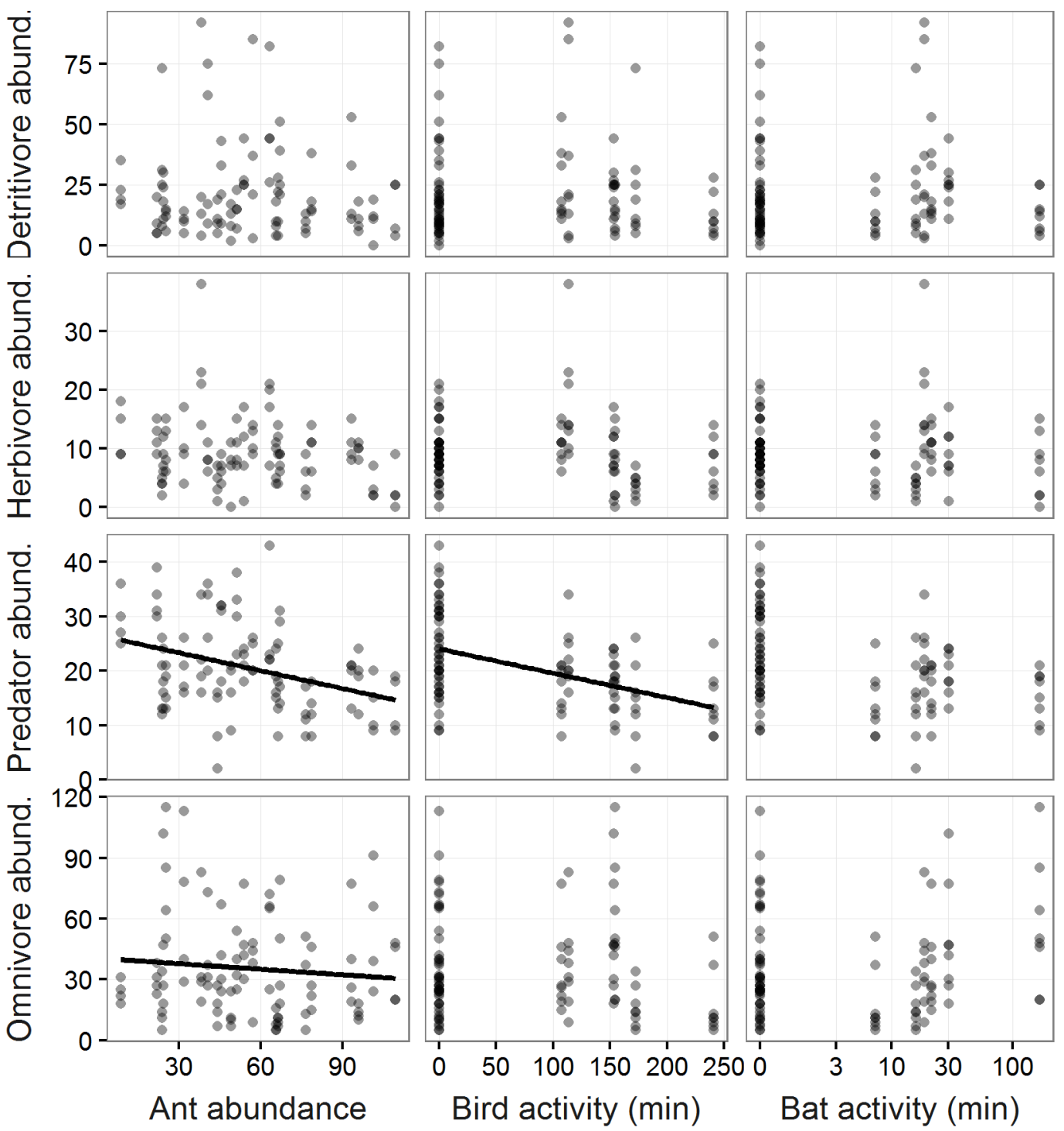

Figure 2. The response of arthropod feeding guilds to average ant abundance, bird activity and bat activity. Significant $(P<0.05)$ relationships are indicated with a solid line. Darker shading of points indicates multiple overlapping points.

\section{Ecosystem function responses to ant, bird and bat treatments and arthropod communities}

Our ant, bird and bat manipulations had no effects on herbivory, rather only oil palm initial height and soil pH had (marginally significant for height) positive and negative effects respectively (Fig. 3). Decomposition was not affected by any of our treatments (Fig. 3) or measured variables. Bird and bat activity respectively had a negative and positive marginally significant relationship $(P=0.070$ and 0.081 ) with predation rate for crickets, but were not related to the predation rate for aphids and dummy caterpillars (Fig. 3). Ant abundance did not affect predation rate for any of the prey types. 
Arthropod predator abundance ( $99 \%$ of which were spiders) however had a positive effect on predation rate of all three prey types (though only marginally significant for dummy caterpillars, $P=$ 0.090). Furthermore, herbivore abundance had a positive relationship with aphid predation and omnivore abundance had a negative relationship with cricket predation. Pollinator weevil abundance was not affected by ant abundance and bird and bat activity (Fig. 2). However, weevil abundance was positively related to omnivore abundance and soil clay content and negatively to oil palm initial height.
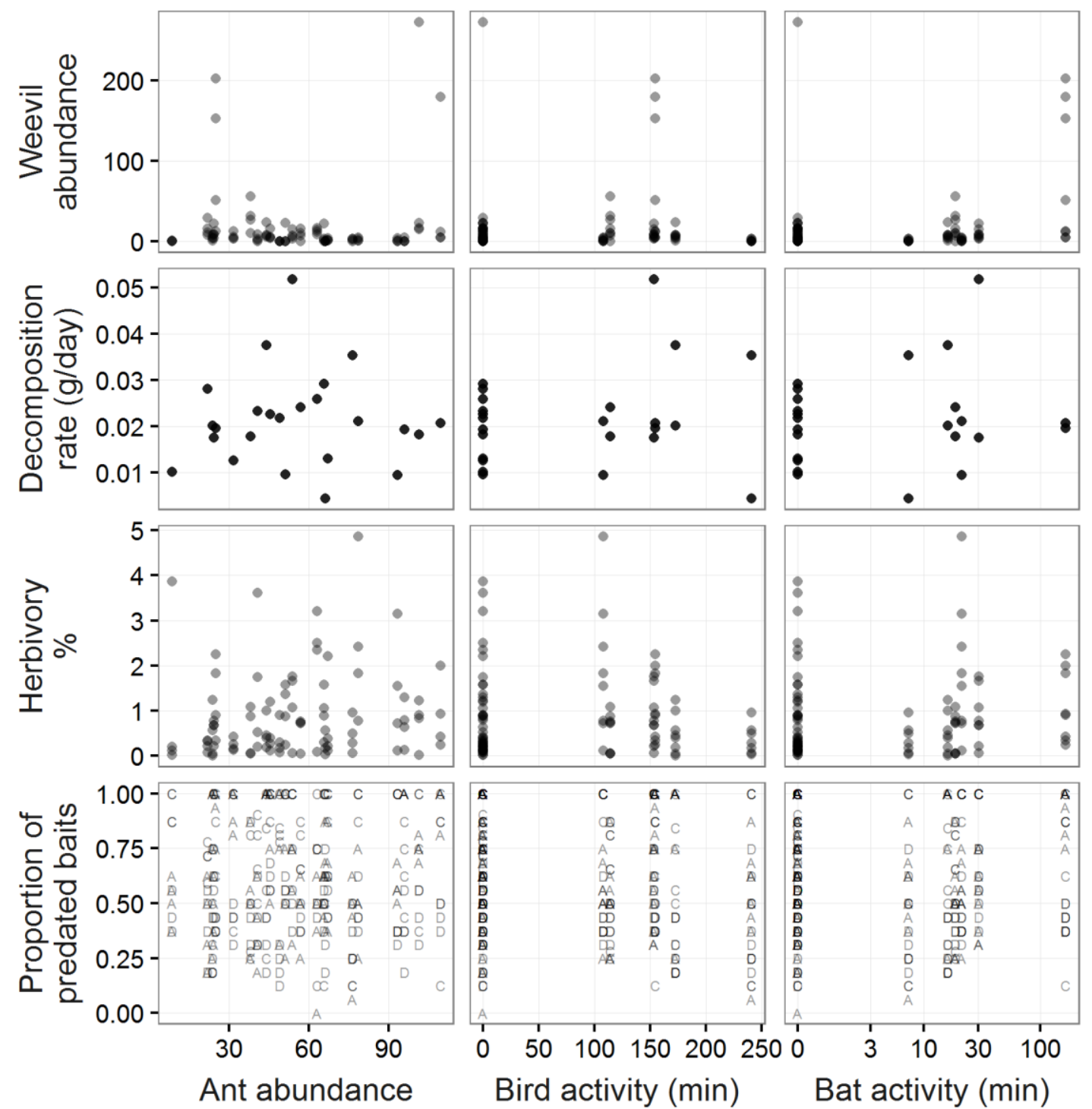

Figure 3. The response of measured ecosystem functions to average ant abundance, bird activity and bat activity. For proportion predation aphids are indicated by " $A$ ", crickets by " $C$ " and dummy caterpillars by "D". Significant $(P<0.05)$ relationships are indicated with a solid line. Darker shading of points indicates multiple overlapping points. 
Chapter 5: Major predators do not influence ecosystem functions and yield in oil palm plantations

\section{Oil palm yield responses to ant, bird and bat treatments and ecosystem functions}

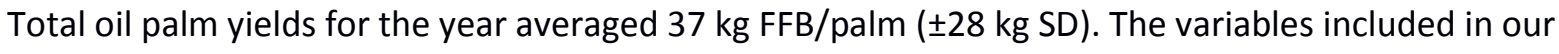
models had no effects on yield (FFB(kg/palm)/day) (Fig. 4) and the three supplementary yield measurements showed similar results (Table S9).
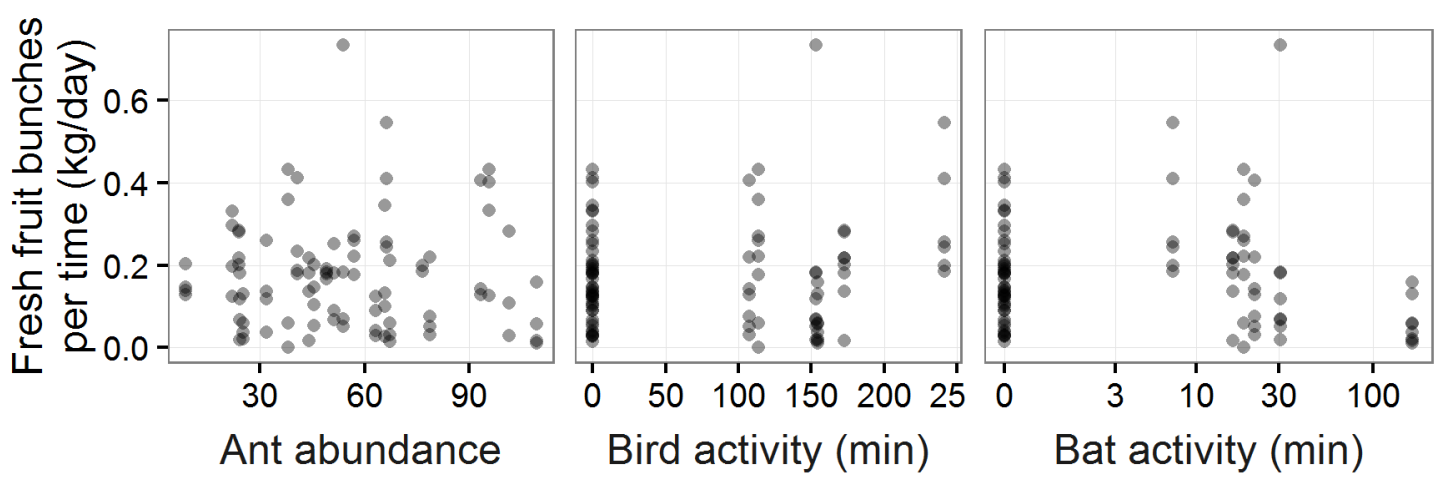

Figure 4. The response of yield (FFB (kg/palm)/day) to average ant abundance, bird activity and bat activity. Significant $(P<0.05)$ relationships are indicated with a solid line. Darker shading of points indicates multiple overlapping points. 
Chapter 5: Major predators do not influence ecosystem functions and yield in oil palm plantations

\section{Discussion}

This is the first exclusion experiment in productive oil palm plantations covering considerable temporal and spatial scales. Our results detail the role of ants, birds and bats for arthropod communities, ecosystem functions and yield in oil palm. We found a strong negative effect of manipulated ant abundance and bird activity on arthropod predators, but only minimal effects if any on the other arthropod feeding guilds. The measured ecosystem functions, including herbivory, predation, decomposition and pollination, did not respond to variation in ant, bird and bat abundance. Rather, local soil variables, tree height and arthropod abundances (other than ants) were, although generally weakly related, the most important predictors for ecosystem functions in our oil palm plantations. The economically most important ecosystem service, yield, however, did not respond to our measured predictors.

\section{Birds and ants have strong effects on arthropod predators but not on other arthropods groups}

Our study showed that ants and birds both have a strong negative influence on arthropod predators. However, except for a weak negative influence of ants on herbivores, all other feeding guilds were not influenced by our experimental exclusion. It is likely that the predators (ants, birds, and other arthropod predators) of our disturbed sites are generalists (Emily B Fitzherbert et al. 2008) and therefore can exert similar predation pressures on the other arthropod communities. The predators would be complementary through processes such as mesopredator release or similar in the sense that the absence of one predator group is compensated by the increase of the other, resulting in a constant predation pressure. Indeed, the most active birds (see Table S9) all consume arthropods to some degree, and all but one were omnivores and small insectivores who glean arthropods. The lack of bat effects on arthropods could be due to bats mostly feeding on aerial nocturnal insects, which would not have been optimally sampled with our methods and can disperse freely between experimental cages, diluting the effect of bat predation.

\section{No net effects of ants, birds and bats on ecosystem functions in oil palm plantations}

Our manipulations of ants, birds and bats had no significant effects on any of the ecosystem functions measured. Local environmental variables and arthropods other than ants were generally more important.

Although ants, birds and bats manipulation did not influence predation rates, we found a positive correlation between arthropod predator abundance and predation rate for all three prey types. This suggests that ants, birds and bats may not successfully suppress phytophagous insects, or 
Chapter 5: Major predators do not influence ecosystem functions and yield in oil palm plantations

at least the species we investigated, in oil palm plantations. Also, other predators could play an important role (e.g. spiders and Orthoptera (Nurdiansyah et al., unpublished data).

Contrary to previous research (Lian Pin Koh 2008), exclusion of birds and bats did not affect oil palm herbivory. However, the previous research looked at very young (one year old) palms, which are likely more susceptible to damage (Coley 1980). Furthermore, these plants were situated in a relatively old (more than one crop generation) and large oil palm complex (pers. comm. Lian Pin Koh), where pest pressure may be higher. Our sites were smallholder plantations all bordered by other vegetation types, including forest and jungle rubber. The herbivory we measured on our palms was overall low (0-4.8\%, mean \pm standard error of $0.9 \pm 0.1 \%$, versus $0-21 \%$ herbivory in Koh (2008)). Overall, our findings suggest that defoliating pests are not a major problem in the smallholder oil palm plantations of Jambi Province, where the crop has been introduced only one crop cycle ago. In particular, two of the most important defoliating pests of oil palm, the nettle caterpillar (Setothosea asigna) and bagworm (Metisa plana) are relatively uncommon in the study area (Nurdiansyah et al. unpublished data) and tend to have non-cyclic outbreaks. We only observed a single pest outbreak in our experimental sites, which subsided without control, and insecticide application throughout the entire experiment was null. However with time, if pest numbers increase and outbreaks become cyclic the role of predators for pest control may become more important.

Ant, bird and bat manipulation did not affect decomposition rates directly or indirectly through changes in detritivore abundance. This could suggest that other unmeasured variables are more important for the decomposition rate of oil palm leaves than the variables we measured. Many other factors can contribute to decomposition and are often more important than the variables we measured, such as local climatic variables, microbial activity and soil nutrients (Vossbrinck, Coleman, and Woolley 1979; Dyer, Meentemeyer, and Berg 1990).

The pollination of oil palm in Indonesia relies to a large extent on the weevil E. kamerunicus (Foster et al. 2011). While birds can consume E. kamerunicus in oil palm plantations (Amit et al. 2015), the lack of predator effects on E. kamerunicus found in our study is reassuring, and suggests that measures taken to increase the abundance and diversity of predators of arthropods are unlikely to be accompanied by reduced pollination. However, in the long-term the reliance on a single pollinator species may be a risky strategy given the significant fluctuations of wild and managed pollinators in other agricultural systems (Potts et al. 2010).

\section{Ants, birds and bats and other measured variables do not influence oil palm yield}

Oil palm yield was not affected by the variables studied in this research, indicating that our comprehensive manipulations of biodiversity or even variation in arthropods and ecosystem 
Chapter 5: Major predators do not influence ecosystem functions and yield in oil palm plantations

functions do not affect oil palm productivity. Most interestingly we found no link between herbivory and yield. However, as mentioned, herbivory was low at the sites, and in the past other studies have shown leaf herbivory is not always important for yield, rather other types of herbivory can be more important (e.g. flower herbivory (Maas, Clough, and Tscharntke 2013a)). Also, yield responses to herbivory may only be observed in the case of pest outbreaks (Kamarudin and Wahid 2010), which are rare in oil palm in Indonesia. However, there is evidence from other crops that as the area cultivated increases there is an increase in pest and disease problems (Clough, Faust, and Tscharntke 2009). Lack of any effects on yield at these sites suggests that other limiting factors play a more important role in yield variation, such as nutrient availability, rainfall and efficiency of light uptake from the canopy (Breure 2010; Rafflegeau et al. 2010). For example, the very low soil pH across sites could indicate a potential phosphorous deficiency. Furthermore, the absence of a biodiversity and yield relationship suggests there is an opportunity for a win-win situation for high biodiversity and yield in oil palm plantations (Clough et al. 2011; Teuscher et al. 2015).

\section{Conclusions}

We conclude that ecosystem functions and productivity in oil palm are, under current levels of pest pressure and pollinator populations, robust to large changes in the communities of major predator groups. Although it is widely presumed that biocontrol plays a major role in crop production everywhere, the lack of relationship we observed between predators and yield proves that expectation to be wrong. However biodiversity conservation should not be compromised if it is not coupled with economically meaningful services (Silvertown 2015); its intrinsic value alone is important.

\section{Acknowledgements}

We thank Rico Fardiansah, Derly Hartika, Marisi Italiansia, Leonarda Situmorang, Ilham, Fahrurozi and Arie Perdana for all their help in the lab and the field. We thank local plot owners and village leaders for granting us the use of the study sites. This study was financed by the Deutsche Forschungsgemeinschaft (DFG) in the framework of the German - Indonesian Collaborative Research Centre 990: Ecological and Socioeconomic Functions of Tropical Lowland Rainforest Transformation Systems (Sumatra, Indonesia) (CRC 990 EFForTS) 
Chapter 5: Major predators do not influence ecosystem functions and yield in oil palm plantations

\section{Supplementary Material}

\section{Appendix 1. Supplementary Methods}

\section{Site conditions}

The plantation management was consistent with plantations in the study area: herbicides were used at least twice during the experiment (depending on the owner's financial situation) and both chemical and organic fertilisers were used, however exact quantification of nutrient input was not possible. Soils of the region are fine textured but there was some variation between sites (Table A1.1). The $\mathrm{pH}\left(\mathrm{H}_{2} \mathrm{O}\right)$ ranged from 4.03 (site four) to 4.45 (site five) (Table A1.1). Plantation area was between 2 and 10 ha and planting density was between 25 and 47 palms/ha (Table A1.1).Tree density at each site was determined by measuring the area of a block containing 49 oil palms (a $7 x 7$ block) with a GPS device (Garmin GPSmap 64s), centred around the experiment.

Table A1.1. Conditions for each plantation.

\begin{tabular}{|c|c|c|c|c|c|c|}
\hline Site & Plant source & Size (ha) & $\begin{array}{l}\text { Planting } \\
\text { density } \\
\text { (palms/ha) }\end{array}$ & Planting date & $\begin{array}{l}\text { Average } \mathrm{pH} \\
\left(\mathrm{H}_{2} \mathrm{O}\right)^{1}\end{array}$ & Soil type ${ }^{1}$ \\
\hline 1 & Marihat & 7 & 188 & January 2011 & 4.15 & Clay \\
\hline 2 & Supindo & 2 & 170 & August 2010 & 4.17 & Sandy clay \\
\hline 3 & Marihat & 10 & 100 & August 2010 & 4.12 & Sandy clay \\
\hline 4 & Marihat & 4 & 116 & September 2009 & 4.03 & Clay \\
\hline 5 & Private nursery & 2.5 & 153 & March 2008 & 4.45 & Sandy clay loam \\
\hline 6 & AHOK & 4 & 150 & August 2011 & 4.37 & Clay \\
\hline
\end{tabular}


Chapter 5: Major predators do not influence ecosystem functions and yield in oil palm plantations

\section{Soil and tree variable measurements and analysis}

We took soil cores in each experimental plot at a depth of $50 \mathrm{~cm}$ eight months after experiment start. Eight samples were taken in caged plots, and four samples in plots without cage. All soil samples were taken between bordering oil palms $200 \mathrm{~cm}$ away from the foundation at the border middle. The additional four samples were taken at $20 \mathrm{~cm}$ from the foundation concrete border to test for possible effects of carbonate leaching into the soil from the concrete foundations of the bird/bat cages. The soil samples were air dried and sieved $(2 \mathrm{~mm})$ then analysed for $\mathrm{pH}$ and texture at the University of Jambi, Indonesia. Soil pH $\left(\mathrm{H}_{2} \mathrm{O}\right)$ was analysed in a 1:2.5 soil-to-water ratio and soil texture (clay content) was measured using the pipette method (Gee and Bauder 1986).

The height of each oil palm included in the experimental plots was recorded at the beginning (initial height) and the end of the experiment (final height). We measured height from the palm base to the tip of the meristem (Kotowska et al. 2015a). We used linear mixed effects models (LMEs) to determine the differences in initial palm height, soil $\mathrm{pH}$ and soil texture between treatments with plantation (experiment site) included as a random effect. We used Wilcoxon rank sum tests to compare mean $\mathrm{pH}$ values between samples collected near $(20 \mathrm{~cm})$ and far $(200 \mathrm{~cm})$ from the concrete foundation border $(n=48)$. Mean $\mathrm{pH}$ values far from the concrete foundation (mean=4.27 \pm $0.21 \mathrm{sd}$ ) were higher than $\mathrm{pH}$ values near to it (mean=4.20 \pm 0.17 ), confirming that the concrete foundations were not leaking carbonates into the soil (Wilcoxon mean comparison: $P=0.288$ ).

The occurrence of red and brown spots on the oil palm leaves was determined by analysis of the red and green components of leaf JPEG photographs taken for herbivory measurements to estimate a $\mathrm{red} / \mathrm{green}$ leaf area ratio. Brownish spots on oil palm leaflets, typical of wet conditions, are due to algal infestation, and orange-coloured spots are caused by K-deficiency (Turner 1981). One photograph from each of four fronds was chosen randomly per tree and the white balance was adjusted with the underlying white cardboard. The crops were twice longer than wide and taken from the greatest leaf portion without holes. The mean of its scaled red and green values were used to compute the red/green leaf area ratio, indicating the proportion of the leaf surface that is red and thus photosynthetically not active.

\section{Effectiveness of ant suppression}

We used linear mixed effects models (LMEs) to determine the effect of ant suppression (independent of bird/bat exclusion) on ant abundance and species richness in the experimental plots with plantation (experiment site) included as a random effect. To meet assumptions of normality ant abundance was log-transformed prior to analysis. LMEs were conducted using the nlme (Pinheiro et al. 2015) package in R 3.2.0 (R Core Team 2015). 
Chapter 5: Major predators do not influence ecosystem functions and yield in oil palm plantations

Table S1. Invertebrate higher taxonomic groups, assigned to feeding guilds.

\begin{tabular}{|c|c|}
\hline Higher taxonomic group & Feeding guild \\
\hline Acari & omnivore \\
\hline Annelida & detritivore \\
\hline Araneae & predator \\
\hline Blattodea & detritivore \\
\hline Chilopoda & predator \\
\hline Coleoptera & omnivore \\
\hline Collembola & omnivore \\
\hline Dermaptera & omnivore \\
\hline Diplopoda & detritivore \\
\hline Diptera & omnivore \\
\hline Gastropoda & detritivore \\
\hline Haplotaxida & detritivore \\
\hline Hemiptera & omnivore \\
\hline Hymenoptera: Formicidae & omnivore \\
\hline Hymenoptera: other & omnivore \\
\hline Isopoda & detritivore \\
\hline Isoptera & detritivore \\
\hline Lepidoptera & herbivore \\
\hline Mantodea & predator \\
\hline Neuroptera & predator \\
\hline Opiliones & omnivore \\
\hline Orthoptera & herbivore \\
\hline Pseudoscorpionida & predator \\
\hline Psocoptera & detritivore \\
\hline Symphyla & detritivore \\
\hline Thysanoptera & herbivore \\
\hline Thysanura & omnivore \\
\hline
\end{tabular}

Table S2. Linear mixed effects model ANOVA outputs testing for a significant effect of ant suppression on ant abundance and richness. The linear mixed effects models which determined the effect of the ant suppression treatment on (a) average ant abundance and (b) average ant species richness. Significant $\mathrm{p}$-values are indicated in bold $(P<0.05)$. 
Chapter 5: Major predators do not influence ecosystem functions and yield in oil palm plantations

\begin{tabular}{llllr}
\hline Response variable & Effect & df & F-value & p-value \\
\hline (a) Ant abundance & Ant suppression treatment & 17 & 8.003 & $\mathbf{0 . 0 1 2}$ \\
(b) Ant species richness & Ant suppression treatment & 17 & 0.395 & 0.538 \\
\hline
\end{tabular}


Table S3. Variables included in full models for each response variable. PredA = predator abundance, HerbA = herbivore abundance, DetA = detritivore abundance, $0 \mathrm{mni} A=$ omnivore abundance, herb $=$ herbivory, Decomp $=$ decomposition rate, Pred $=$ predation rate (proportion of predated baits), WvilA = weevil abundance, AntA = average ant abundance, BirdA = bird activity, BatA = bat activity, Height = initial oil palm height and $\mathrm{RG}=$ leaf red/green ratio.

\begin{tabular}{|c|c|c|c|c|c|c|c|c|c|c|c|c|c|c|c|}
\hline Response & & & & & & & & & & & & & & & \\
\hline variable & AntA & BirdA & BatA & $\mathrm{pH}$ & Clay & Height & RG & PredA & HerbA & $\operatorname{Det} A$ & OmniA & Herb & Decomp & Pred & WvilA \\
\hline PredA & $x$ & $x$ & $x$ & $x$ & $x$ & $x$ & & & & & & & & & \\
\hline HerbA & $x$ & $x$ & $x$ & $x$ & $x$ & $x$ & $x$ & & & & & & & & \\
\hline DetA & $x$ & $x$ & $x$ & $x$ & $x$ & $x$ & & & & & & & & & \\
\hline OmniA & $x$ & $x$ & $x$ & $x$ & $x$ & $x$ & $x$ & & & & & & & & \\
\hline Herb & $x$ & $x$ & $x$ & $x$ & $x$ & $x$ & $x$ & & $x$ & & $x$ & & & & \\
\hline Decomp & $x$ & $x$ & $x$ & $x$ & $x$ & $x$ & & & $x$ & $x$ & $x$ & & & & \\
\hline Predation & $x$ & $x$ & $x$ & & & $x$ & & $x$ & $x$ & & $x$ & & & & \\
\hline WvilA & $x$ & $x$ & $x$ & $x$ & $x$ & $x$ & & $x$ & & & $x$ & & & & \\
\hline Yield & $x$ & $x$ & $x$ & $x$ & $x$ & $x$ & $x$ & & & & & $x$ & $x$ & $x$ & $x$ \\
\hline
\end{tabular}


Chapter 5: Major predators do not influence ecosystem functions and yield in oil palm plantations

Table S4. Linear mixed effects model ANOVA outputs testing for significant difference in environmental variables between treatments. The linear mixed effects models which determined the effect of treatment on (a) soil $\mathrm{pH}$, (b) soil texture and (c) initial palm height. Significant p-values are indicated in bold $(\mathrm{p}<0.05)$.

\begin{tabular}{|c|c|c|c|c|c|}
\hline \multicolumn{2}{|c|}{ Response variable } & \multirow{2}{*}{$\begin{array}{l}\text { Effect } \\
\text { Treatment }\end{array}$} & \multirow{2}{*}{$\begin{array}{l}\mathrm{df} \\
85\end{array}$} & \multirow{2}{*}{$\begin{array}{r}\text { F-value } \\
7.395\end{array}$} & \multirow{2}{*}{$\begin{array}{c}\text { p-value } \\
<0.001\end{array}$} \\
\hline (a) & Soil pH & & & & \\
\hline (b) & Soil texture & Treatment & 81 & 9.525 & $<0.001$ \\
\hline (c) & Initial palm height & Treatment & 85 & 4.995 & 0.003 \\
\hline
\end{tabular}


Chapter 5: Major predators do not influence ecosystem functions and yield in oil palm plantations

Table S5. The range of conditional $\mathrm{R}^{2}$ values for all best models $(\Delta \mathrm{AICc}<2)$ for each response variable.

\begin{tabular}{lr}
\hline Response variable & $\mathbf{R}^{2}$ range \\
\hline Predator abundance & $0.466-0.472$ \\
Herbivore abundance & $0.451-0.458$ \\
Detritivore abundance & $0.216-0.257$ \\
Omnivore abundance & $0.415-0.491$ \\
Decomposition & $<0.001$ \\
Herbivory & $0.150-0.153$ \\
Predation: aphids & $0.293-0.377$ \\
Predation: crickets & $0.225-0.233$ \\
Predation: dummy caterpillars & $0.026-0.029$ \\
Weevil abundance & $0.631-0.652$ \\
Yield by time (12 months) & 0.214 \\
\hline
\end{tabular}


Table S6. Linear mixed effects model ANOVA outputs and relative variable importance (RVI) for the average of the best models $(\Delta$ AICc $<2)$ for arthropod feeding guild abundances. Pred $\mathrm{A}=$ predator abundance, $\mathrm{Herb} \mathrm{A}=$ herbivore abundance, Det $\mathrm{A}=\operatorname{detritivore}$ abundance, $0 \mathrm{mni} \mathrm{A}=$ omnivore abundance, AntA = average ant abundance, BirdA = bird activity, BatA = bat activity, Height = initial oil palm height and RG = leaf red/green ratio.

Predictors marked with an "X" were not included in the full model, predictors marked with a "---" were included in the full but not in the average best model. Significant $(P<0.05)$ predictors are indicated in bold.

\begin{tabular}{|c|c|c|c|c|c|c|c|c|c|c|c|c|}
\hline & & HerbA & & & DetA & & & PredA & & & OmniA & \\
\hline Predictor & coeff & P-val & RVI & coeff & P-val & RVI & coeff & $p$-val & RVI & coeff & P-val & RVI \\
\hline AntA & -0.13 & 0.078 & 1.00 & -0.10 & 0.275 & 0.23 & -0.11 & 0.005 & 1.00 & -0.13 & 0.043 & 0.84 \\
\hline BirdA & --- & --- & --- & 0.06 & 0.516 & 0.10 & -0.16 & $<0.001$ & 1.00 & --- & --- & -- \\
\hline BatA & --- & --- & --- & 0.08 & 0.354 & 0.12 & --- & --- & --- & --- & --- & -- \\
\hline AntA:BirdA & --- & --- & --- & --- & --- & --- & 0.06 & 0.106 & 0.52 & --- & --- & -- \\
\hline AntA:BatA & --- & --- & --- & --- & --- & --- & --- & --- & --- & --- & --- & -- \\
\hline Clay & 0.29 & $<0.001$ & 0.71 & 0.26 & 0.004 & 1.00 & 0.12 & 0.004 & 1.00 & 0.10 & 0.426 & 0.14 \\
\hline $\mathrm{pH}$ & -0.06 & 0.378 & 0.18 & -0.11 & 0.225 & 0.25 & --- & --- & --- & -0.22 & 0.111 & 0.41 \\
\hline Height & --- & --- & --- & 0.17 & 0.058 & 0.86 & --- & --- & --- & --- & --- & -- \\
\hline RG & -0.04 & 0.545 & 0.14 & $x$ & $x$ & --- & $x$ & $\mathrm{x}$ & --- & -0.06 & 0.495 & 0.13 \\
\hline
\end{tabular}




\begin{tabular}{|c|c|c|c|c|c|c|c|c|c|c|c|c|c|c|c|c|c|c|}
\hline \multirow[b]{2}{*}{ Predictor } & \multicolumn{3}{|c|}{ Decomposition } & \multicolumn{3}{|c|}{ Herbivory } & \multicolumn{3}{|c|}{ Predation:aphids } & \multicolumn{3}{|c|}{ Predation:crickets } & \multicolumn{3}{|c|}{ Predation:Dcat } & \multicolumn{3}{|c|}{ Weevil abund } \\
\hline & coeff & P-val & RVI & coeff & P-val & RVI & coeff & P-val & RVI & coeff & P-val & RVI & coeff & P-val & RVI & coeff & P-val & RVI \\
\hline AntA & --- & --- & --- & --- & --- & --- & 0.26 & 0.151 & 0.83 & --- & --- & --- & 0.05 & 0.403 & 0.19 & -0.07 & 0.735 & 0.08 \\
\hline BirdA & --- & --- & --- & --- & --- & --- & --- & --- & --- & --- & --- & --- & -0.05 & 0.348 & 0.09 & -0.86 & 0.045 & 1.00 \\
\hline BatA & --- & --- & --- & --- & --- & --- & 0.15 & 0.374 & 0.16 & --- & --- & --- & --- & --- & --- & 1.00 & 0.026 & 1.00 \\
\hline AntA:BirdA & --- & --- & --- & --- & --- & --- & --- & --- & --- & --- & --- & --- & --- & --- & --- & -0.41 & 0.067 & 0.08 \\
\hline AntA:BatA & --- & --- & --- & --- & --- & --- & --- & --- & --- & --- & --- & --- & --- & --- & --- & --- & --- & --- \\
\hline Clay & --- & --- & --- & --- & --- & --- & --- & --- & --- & --- & --- & --- & --- & --- & --- & 0.29 & 0.206 & 0.37 \\
\hline $\mathrm{pH}$ & --- & --- & --- & -0.24 & 0.044 & 0.31 & $x$ & $x$ & $x$ & $x$ & $x$ & $x$ & $x$ & $x$ & $x$ & 0.41 & 0.061 & 0.51 \\
\hline Height & --- & --- & --- & --- & --- & --- & 0.24 & 0.111 & 0.55 & 0.11 & 0.441 & 0.30 & --- & --- & --- & -0.61 & 0.002 & 1.00 \\
\hline RG & $x$ & $x$ & $x$ & --- & --- & --- & $x$ & $x$ & $x$ & $x$ & $x$ & $x$ & $x$ & $x$ & $x$ & $x$ & $x$ & $x$ \\
\hline PredA & --- & --- & --- & --- & --- & --- & 0.18 & 0.058 & 0.45 & 0.32 & 0.002 & 1.00 & 0.11 & 0.093 & 0.60 & -0.20 & 0.242 & 0.19 \\
\hline HerbA & --- & --- & --- & --- & --- & --- & 0.17 & 0.058 & 0.82 & -0.13 & 0.154 & 0.47 & 0.09 & 0.156 & 0.52 & --- & --- & --- \\
\hline
\end{tabular}


DetA

Table S7. Linear mixed effects model ANOVA outputs and relative variable importance (RVI) for the average of the best models $(\Delta$ AICc $<2)$ for ecosystem functions. Abbreviations are as in Table 1, except for, Dcat = dummy caterpillar. Predictors marked with an "X" were not included in the full model, predictors marked with a "---" were included in the full but not in the average best model. Significant $(P<0.05)$ predictors are indicated in bold. 
Chapter 5: Major predators do not influence ecosystem functions and yield in oil palm plantations

Table S9. The ten most active bird species heard in all recordings across all sites. Six sites were recorded twice for twenty minutes. Diet was extracted from del Hoyo et al.(2015)

\begin{tabular}{lcc}
\hline Bird Species & calling activity (minutes) & Diet \\
\hline Pycnonotus goiavier & 324 & omnivore \\
Dicaeum trigonostigma & 224 & omnivore \\
Pycnonotus aurigaster & 175 & omnivore \\
Orthotomus ruficeps & 69 & insectivore \\
Geopelia striata & 42 & omnivore \\
Orthotomus sericeus & 34 & insectivore \\
Acridotheres javanicus & 26 & omnivore \\
Todiramphus chloris & 19 & carnivore \\
Prinia familiaris & 17 & insectivore \\
Pycnonotus plumosus & 16 & omnivore \\
\hline
\end{tabular}




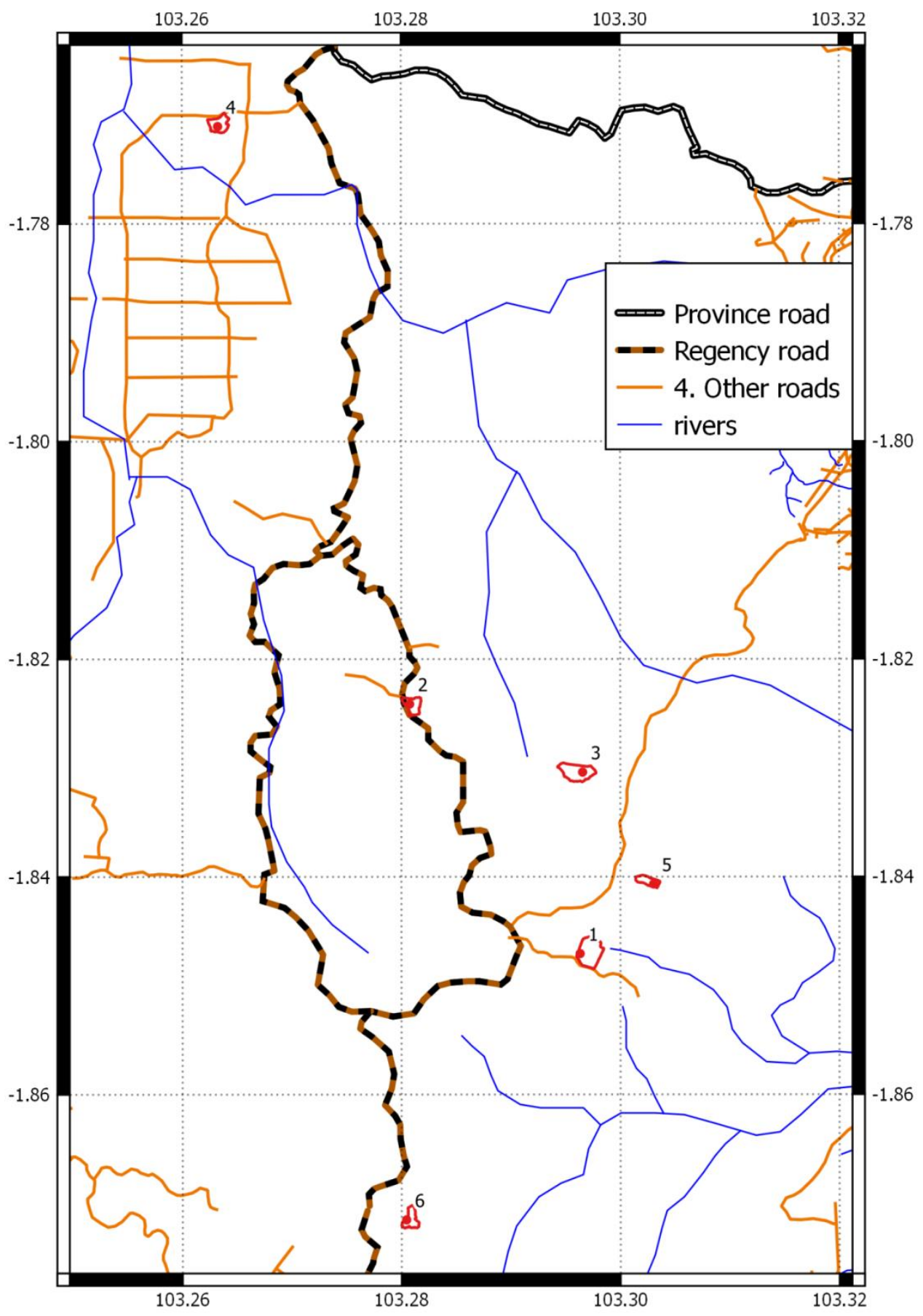

Figure S1. Study site location. Map of study area located in Batanghari Regency, Jambi Province, Sumatra, Indonesia. Experimental sites were located in six oil palm plantations. Plantation borders are indicated in red, Site centres marked with red dots, rivers in blue. 
Chapter 5: Major predators do not influence ecosystem functions and yield in oil palm plantations

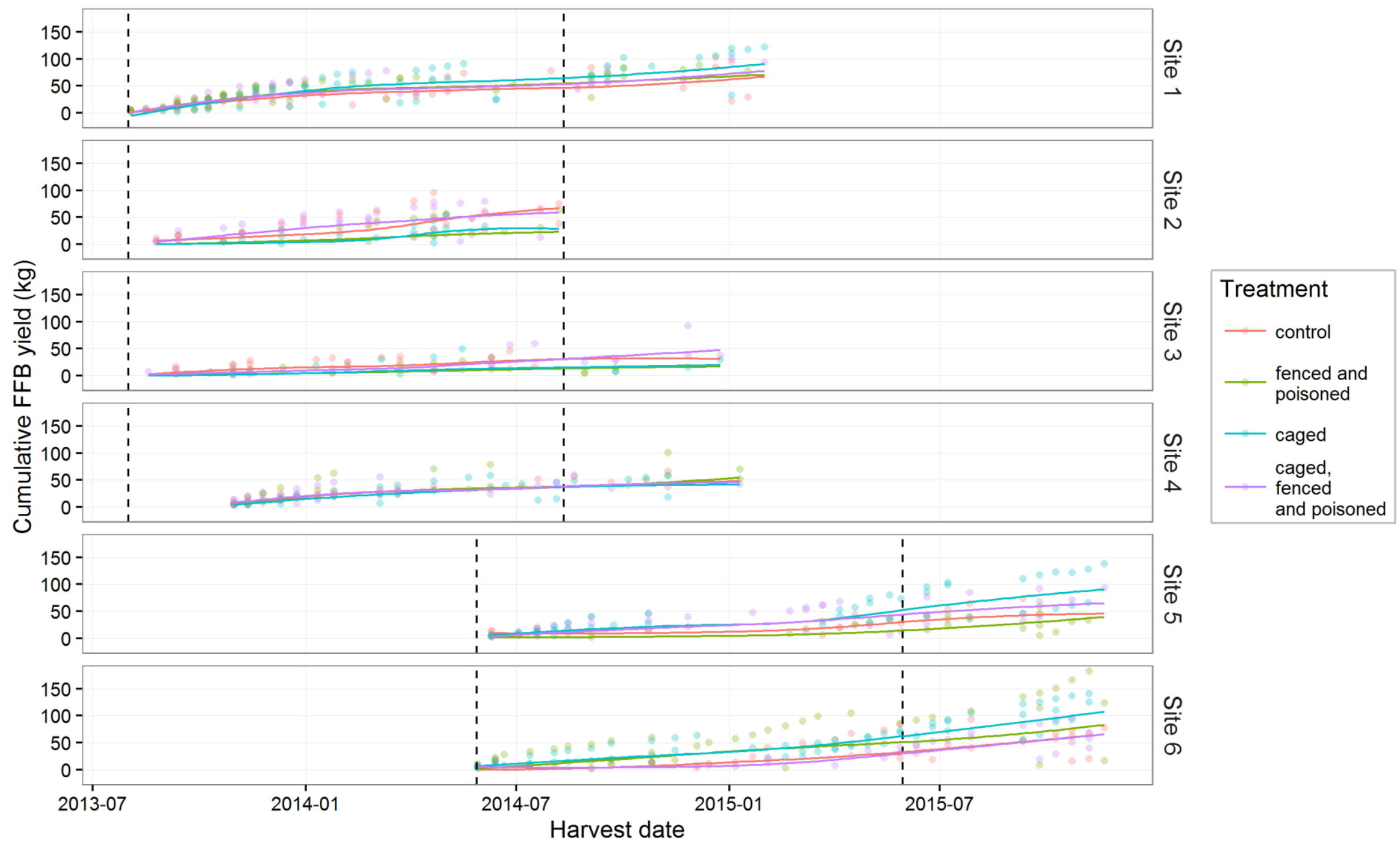

Figure S2. Cumulative oil palm yield (FFB (kg)) across sites and treatments. Dashed lines indicate the beginning and end of the experiment. 


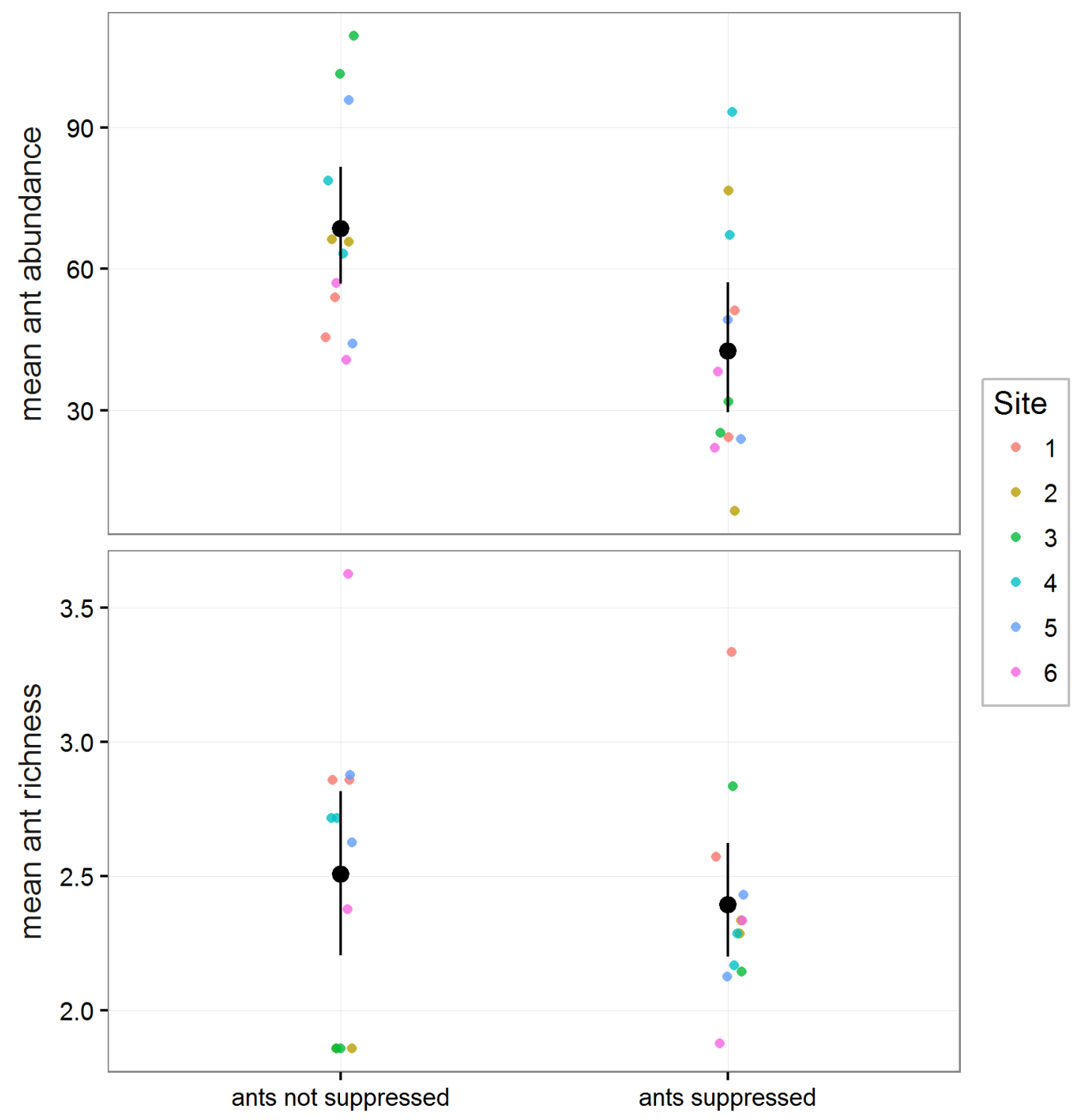

Figure S3. Ant suppression effectiveness. Means indicated by black dots, error bars represent standard error of the mean. 


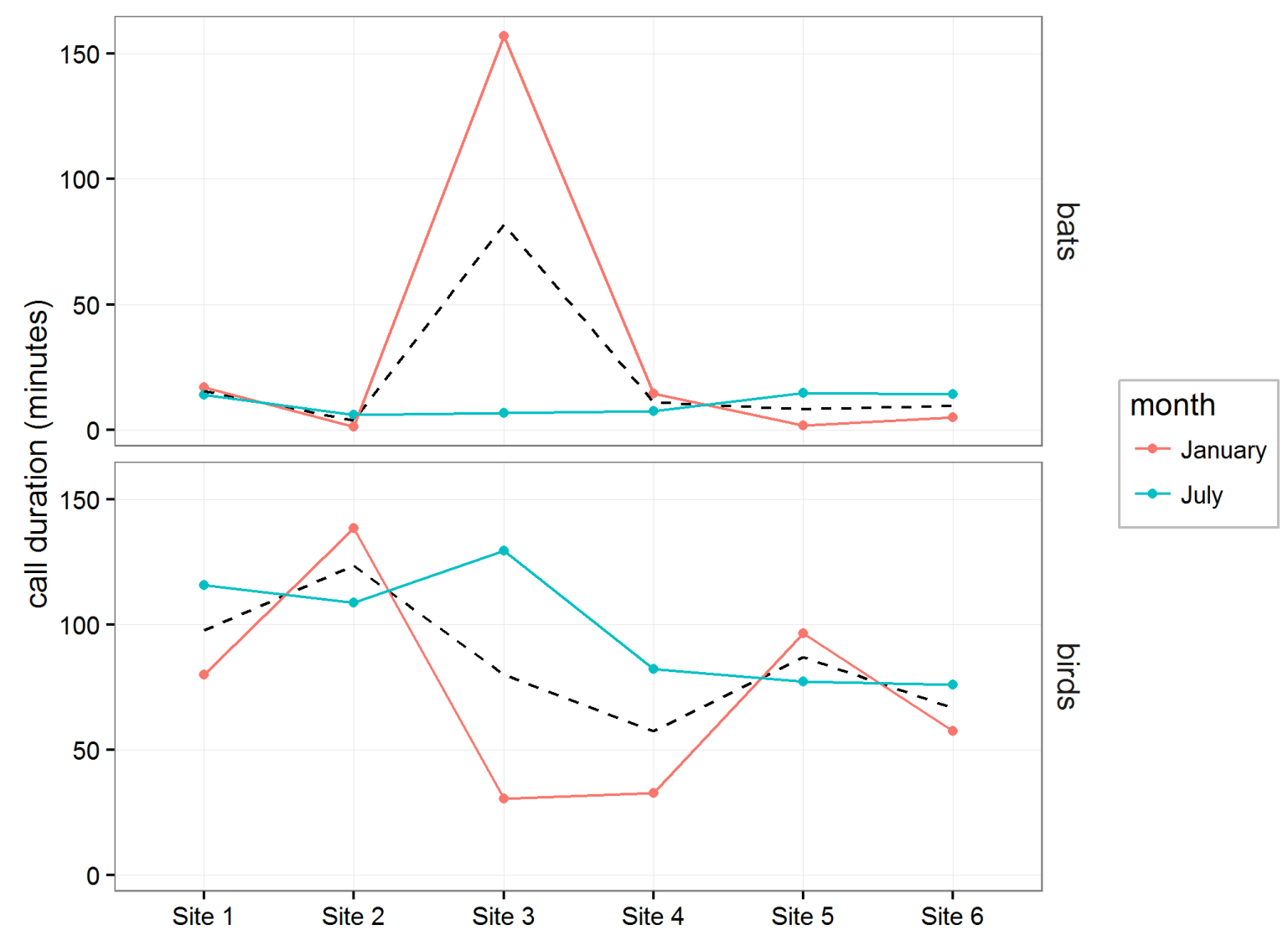

Figure S4. Variation in bat and bird calling activity between sites. The mean between the two values is indicated by the dashed line. 


\section{Discussion}

\section{Summary}

In chapter 1, I provided arguments to promote autonomous acoustic recordings as the method of choice for monitoring birds. Such recorders should be adopted more widely throughout the world, in a first step to standardise bird survey methods and foster exchanges across an international community of ornithologists.

We saw in chapter $\mathbf{2}$ that acoustically sampled sites may only be objectively compared when the detection space area is known. Previous studies did not take that into account but since sound detection spaces of sound recorders can now be measured, we can close the gap between acoustic monitoring methods and standard point counts.

Using traditional survey methods in chapter 3, we saw that bird species richness clearly responds negatively to agricultural expansion in our region. We observed that frugivores declined from natural systems to monoculture plantations. However, we also expected insectivores to decline and omnivores to increase but this was not observed in each landscape. In line with my acoustic monitoring recommendations, we also carried out acoustic surveys with a single 20 minute recording in the same plots during the same season, starting at sunrise. The results are not included in the manuscript that forms the basis of chapter three, but we display them in Figure 1. Thus, sound recordings appear to have sampled the bird community very effectively since they surpass the point count richness count with only one third of the sampling time.

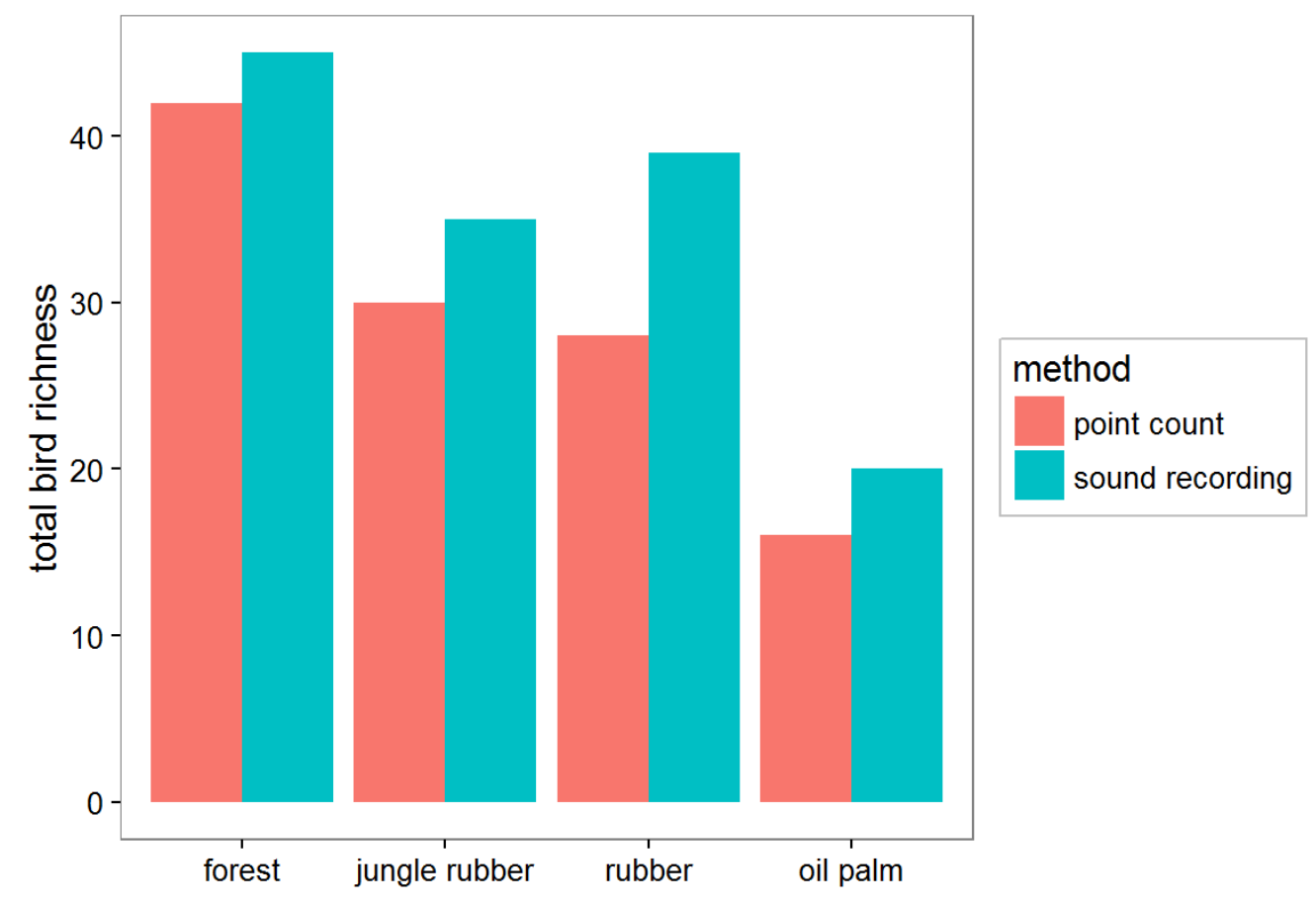


Figure 1. Total bird richness recorded during a 20-minute sound recording starting at sunset, and after three 20-minute point counts in the CRC990 core plots during May-July 2013, using birds detected within $35 \mathrm{~m}$.

We took a closer look at functional changes in bird and invertebrate communities in chapter

4. Here we used data from both the point counts as well as the sound recordings, and so the functional changes emerge more clearly: we see a significant decline in trophic level from forest to oil palm, due to a sharp drop in insectivores and a relative increase in omnivorous birds.

Furthermore, the bird community in rubber habitats comprises more mobile species, which indicates that more vagile birds can cope with the disturbance in their habitat. Overall, the loss of functional diversity along the transformation gradient, due to the low functional redundancy, presages future losses in ecosystem functioning.

Contrary to our expectations, experimental evidence in chapter 5 suggests that in our region, birds and ants may not play an important role in ecosystem functioning for oil palm yet. Ecosystem functions were unaffected by our pervasive treatments, which could be explained by the fact that all predator groups are complementary: since we could not exclude spiders, there was always a constant predation pressure. Furthermore, as pest populations are extremely low in our region, and leaf damage was consequently minimal, we could not ultimately demonstrate treatment effects on oil palm yield. However, similar exclusion experiments are under way in other regions (Costa Rica: Bea Maas, Riau province: BEFTA project) which are experiencing considerably higher pest pressure and it is likely they will yield different results. 


\section{Outlook}

\section{Direct measurement of bird functions}

While acoustic monitoring methods are needed to deliver baseline biodiversity data, bird function is best analysed on an individual basis. Species-level information about diets, habitat use, or even morphological indicator traits, can still be used as a proxy to hint at general trends in ecological function, but it is not sufficient as they are prone to a large variation. For example, habitat use of Chalcophaps indica, which was classified as a forest bird in early surveys (Thiollay 1995b) has changed, as we currently observe it most often in oil palm plantations and almost never in forest. However, especially bird diets vary considerably, even more so for omnivorous birds, or birds with a large distribution range across different regions and land-use types. For example, the diet of Pycnonotus goiavier, common in our region, varies tremendously (Fishpool, L., Tobias, J. \& de Juana, E 2016). Consequently, birds fulfil a variety of functions in different places, habitats, and times, and the usefulness of species-specific data may be questioned as they are too coarse for detailed analyses.

For that very reason, we sampled birds with mist-nets to retrieve their droppings as a means to investigate their diets. Preliminary analysis of consumer-resource networks suggests that networks become more specialised in the plantations, presumably due to resource limitation, which is at odds with the observed trend of increasing omnivores in plantations (Figure 2). Our results also suggest that not only do individual birds' diets within species vary in different habitats, but the whole community is also adaptable in its trophic structure. As a consequence, simple bird feeding guilds do not convey nearly as much information as detailed individual-based diet analyses do, which also allow for a wide range of more precise analyses to understand the tremendous variation observed in bird diets. 

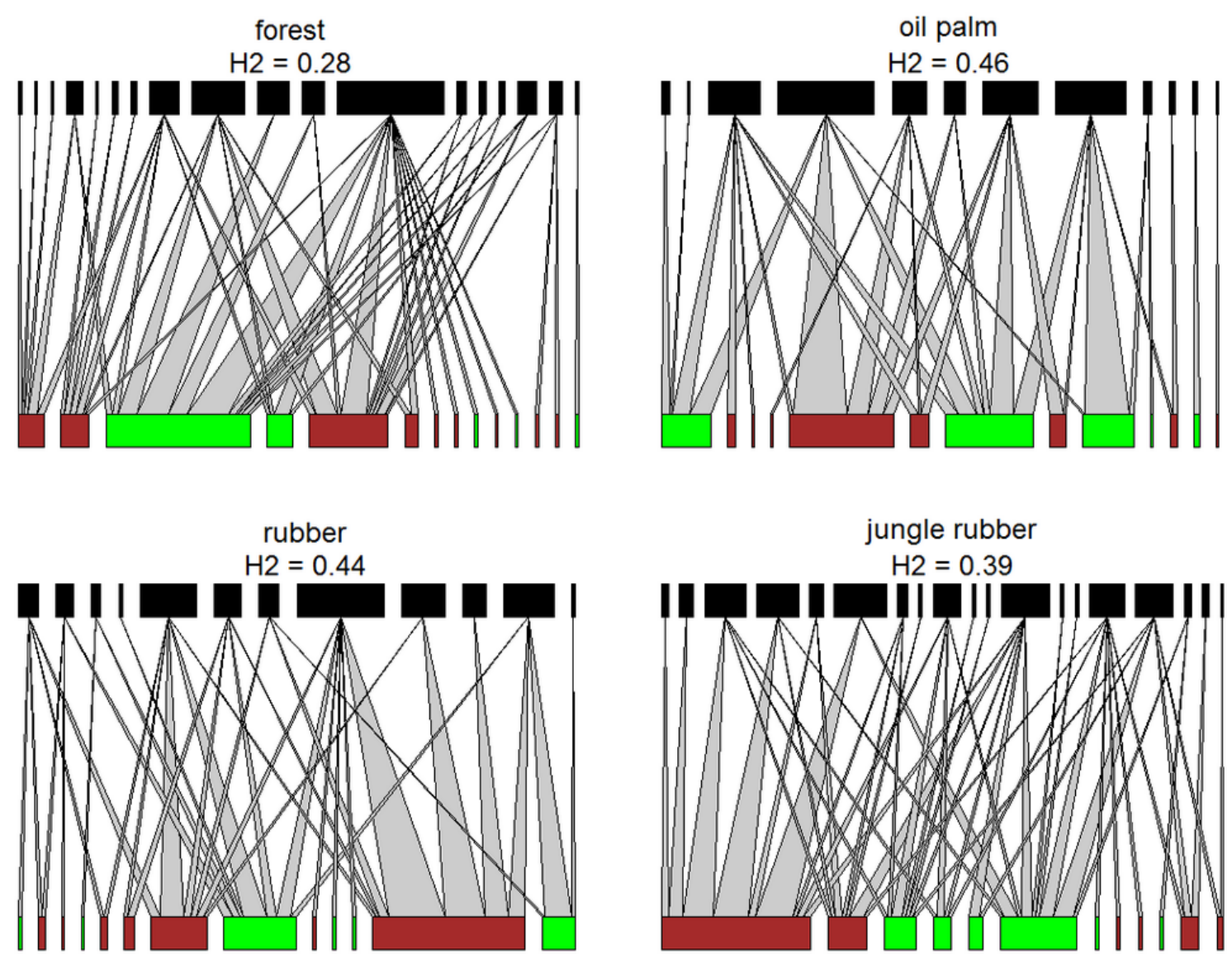

Figure 2. Consumer-resource networks of bird communities sampled in 4 different land-use types. black boxes represent bird species, brown and green boxes respectively represent arthropod and plant orders. $\mathrm{H} 2$ is an index of network specialisation, with higher values corresponding to more specialized networks (Blüthgen, Menzel, and Blüthgen 2006).

While bird diets are an excellent indication of the birds' functions, direct evidence still needs to be acquired by measuring the ecosystem functions themselves. Frugivory can be measured with dummy and real fruits, coupled with camera traps, and seed removal can be rapidly assessed (Boissier et al. 2014). The seed rain from bird droppings can be intercepted by seed-collecting traps, indicating seed dispersal level (Herrera et al. 1994), and predation pressure can be measured with dummy caterpillars (A. Howe, Lövei, and Nachman 2009), which enable to distinguish between different predator types by their characteristic marks, as well as natural baits, if they are coupled with camera traps for identifying the predator. These direct functional measurements are already planned in the second phase of the CRC 990. 


\section{Ecosystem services and trade-offs}

Bird function is readily measured by catching them and assessing their diet; however whether their impact trickles down to affect ecosystem functions relevant to humans (ecosystem services) is an entirely different matter. Theoretically, insectivorous birds are predators that can exert some biological control (De Chenon and Susanto 2006), frugivores can be seed dispersers or seed predators (H. F. Howe 1986), and nectarivores can be important plant pollinators (Anderson et al. 2011). However in our agricultural systems, most of these functions are not directly relevant: humans themselves arrange crop planting, thus making seed dispersal redundant; insects take over oil palm pollination, and rubber pollination is irrelevant since the crop's product is the latex and not the fruit; pest control can be achieved with pesticides, although the cost of biological control versus chemical control has not been assessed; finally, decomposition is generally assured by litter detritivores (microbial and invertebrate). However, birds have been shown to affect crops through control of herbivores in previous exclusion experiments (Maas, Karp, Bumrungsri, Darras, Gonthier, Huang, Lindell, Maine, Mestre, Michel, Morrison, Emily B., et al. 2015). Pollination is also possibly negatively affected by birds through pollinator depredation (Amit et al. 2015), or inversely, positively through arthropod predator suppression like shown in chapter 5 . Finally, detritivores could be controlled by top-down trophic cascades of birds through arthropod mesopredators. Despite all these theoretical links of birds to ecosystem services, we could not establish a functional link between birds and oil palm in our exclusion experiment.

We may still ask however, whether there is a trade-off between biodiversity and oil palm or rubber productivity. Even if birds are currently unlikely to affect oil palm productivity, the same cannot be said for rubber, which has not been studied yet. Independently of crop productivity considerations, birds have a great socio-economic value in Indonesia: Bird keeping is an integral part of Indonesian culture and their trade represents a large monetary value (Jepson and Ladle 2005). Furthermore, birds are generally appreciated for purely esthetical reasons. Therefore, we might ask whether avian biodiversity and crop productivity are negatively related to another: do we have to choose one over the other? First elements of response were provided by Teuscher et al. (2015), who showed that there is a negative relationship between the number of remnant trees and crop yield in oil palm plantations. However we already saw that there is great variation in avian biodiversity between sampling sites, even in monoculture plantations without any remnant trees, so we may ask whether there generally is a negative relationship between biodiversity and crop yield in rubber and monoculture oil palm plantations?

Crop productivity per se does not affect the animals living in plantations. Rather, it is the management, which is determining yield through pruning, harvesting, fertilizing, weeding, and 
pesticide application, and at the same time affecting the biodiversity within plantations. There is observational evidence that understory management affects birds (Aratrakorn, Thunhikorn, and Donald 2006; Azhar et al. 2014 ; Asrulsani Jambari et al. 2012), but no further aspects of management have been studied. Ideally, we should demonstrate the impact of management on animal communities experimentally. In the second phase of the CRC 990, we will implement a fullfactorial management experiment in a company-owned oil palm plantation precisely to study tradeoffs between productivity and biodiversity. Different levels of fertilizer and weeding will be applied to disentangle the effects of these management actions on productivity and biodiversity.

Furthermore, the effect of native tree species in oil palm plantations will also be studied on a large scale with a tree enrichment experiment (subproject B11), allowing further insights in biodiversityproductivity trade-offs.

\section{The landscape's influence}

As previously mentioned, the point-count study revealed striking differences between landscapes. This suggests that the habitats surrounding our sampling sites affect bird communities on-site, as the Bukit Duabelas landscape, where we observed a non-significant decline of bird richness with habitat transformation, contains more forest fragments and crop plantations are generally younger (pers. obs.). There is conflicting information about the effect of forest proximity on birds (Azhar et al. 2013 ; Edwards et al. 2010), which further stresses that we should explicitly take the landscape context into account when trying to explain variation in bird presence. We already carried out a field survey specifically for addressing such questions, spanning a larger area with 112 plots located in diverse landscape contexts with contrasting forest cover. With such a large number of plots, we are also able to address biodiversity-productivity trade-offs by using the crop yield data of the plantations.

It is crucial to elucidate whether the birds that we observe in-situ were observed simply because they were passing through the site or because they can utilize the sampled habitat for foraging and breeding. Certainly, passage, breeding and foraging sites need not be the same (Cody 1985), so that a bird observed in a plantation plot might just be passing through it. It is plausible that breeding and foraging sites are both indispensable for bird populations, while passage habitats (like wooded habitat for forest birds) are not indispensable in the short term but might support bird populations by increasing connectivity, dependent on the landscape composition and configuration (Villard, Trzcinski, and Merriam 1999). Anyhow, foraging and breeding sites are more important, and we need to ascertain whether plantations can provide such critical habitat for birds. 
Different methods are available for examining the movement of birds across the landscape. While radio-tagging methods are currently the only available solutions for tracking bird movement precisely, these methods are cost- and time-intensive, and susceptible to pitfalls (Harris et al. 1990). As an alternative, we planned to use pollen grains collected from the birds' beaks and plumage as an indicator of where the birds have been dwelling before their capture. Most flowering plants and ferns produce species-specific pollen grains and spores, and plantation plant communities differ substantially from these found in forest (eg. epiphytic plants, MSc thesis by Arne Wenzel, subproject B06). The vascular plant communities have previously been documented in detail (CRC 990, subgroup B06, Katja Rembold) and reference collections for spore and pollen material have been established (CRC 990, subgroup A01, Siria Biaggioni). Therefore it is technically possible to prove whether some birds have been dwelling in different habitats from the one they were caught in and therefore infer that they might depend on these.

A further indication of habitat use can be obtained from the sound recordings. While calls are usually emitted when birds are on the way or foraging, songs are emitted to defend territories and attract mates, therefore indicating that the bird is in its breeding habitat (Catchpole and Slater 2008). Indeed, our acoustic data indicate that forest habitats harbour a considerably greater proportion of singing birds - in contrast to calling birds, with oil palm sites harboring distinctly few singing birds (Figure 3). Clearly, Forest habitats are of great importance for conserving bird populations and their associated functions in the long run.

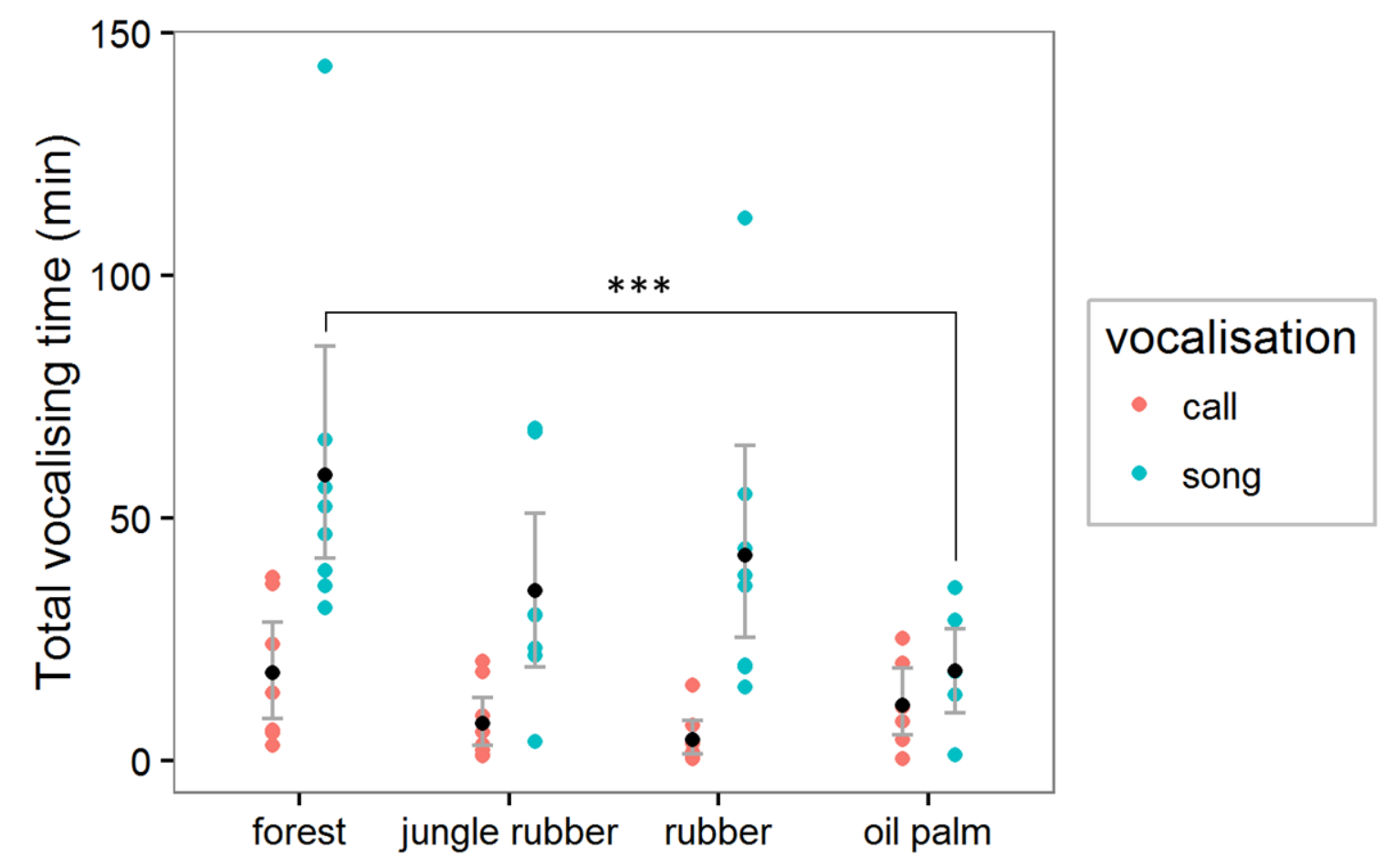


Figure 3. Boxplots showing the total duration of bird vocalizations for songs and calls in the different land-use types. Singinficant differences shown with asterisks. Post-hoc based on generalised linear mixed-effects model with poisson family

\section{Conclusion}

The negative taxonomic and functional diversity trends we observed in the current study are essentially mirrored in a wide range of taxa in tropical regions. Our findings are symptomatic of a global biodiversity crisis in which ecosystem functions may not be unharmed. It is likely that the functioning of these ecosystems will be impaired with biodiversity loss due to their low functional redundancy.

Acoustic sampling methods may replace some of the bird sampling methods that were traditionally used. With this in mind, they can become a jack of all trades for all organisms that use sound to communicate (birds, mammals, frogs, cicadas and orthopterans) or for orientation (bats). This encourages the testing and application of acoustic recording systems to survey a wide range of organisms.

In finding ways to explore the functions of birds and other animals in the ecosystem, it is desirable, but not imperative, to demonstrate how biodiversity can benefit agriculture. Despite the fact that we could not find such a link, we also showed that there were no downsides to the presence of birds in oil palm plantations. Our further research will explore the functional links in greater depth, but we should keep in mind that biodiversity should be preserved for its own sake. 


\section{References}

Abrahamczyk, Stefan, Michael Kessler, Dadang Dwi Putra, Matthias Waltert, and Teja Tscharntke. 2008. "The Value of Differently Managed Cacao Plantations for Forest Bird Conservation in Sulawesi, Indonesia." Bird Conservation International 18 (04): 349. doi:10.1017/S0959270908007570.

Acevedo, Miguel A., and Luis J. Villanueva-Rivera. 2006. "Using Automated Digital Recording Systems as Effective Tools for the Monitoring of Birds and Amphibians." Wildlife Society Bulletin 34 (1): 211-14. doi:10.2193/00917648(2006)34[211:UADRSA]2.0.CO;2.

Adams, Amanda M., Meredith K. Jantzen, Rachel M. Hamilton, and Melville Brockett Fenton. 2012. "Do You Hear What I Hear? Implications of Detector Selection for Acoustic Monitoring of Bats." Edited by Robert Freckleton. Methods in Ecology and Evolution 3 (6): 992-98. doi:10.1111/j.2041-210X.2012.00244.x.

Aide, T. Mitchell, Carlos Corrada-Bravo, Marconi Campos-Cerqueira, Carlos Milan, Giovany Vega, and Rafael Alvarez. 2013. "Real-Time Bioacoustics Monitoring and Automated Species Identification.” PeerJ 1 (July): e103. doi:10.7717/peerj.103.

Alldredge, Mathew W., Theodore R. Simons, and Kenneth H. Pollock. 2007. "A Field Evaluation of Distance Measurement Error in Auditory Avian Point Count Surveys." The Journal of Wildlife Management 71 (8): 2759-66. doi:10.2193/2006-161.

Allen, Kara, Marife D. Corre, Aiyen Tjoa, and Edzo Veldkamp. 2015. "Soil NitrogenCycling Responses to Conversion of Lowland Forests to Oil Palm and Rubber Plantations in Sumatra, Indonesia." PLoS ONE 10 (7): e0133325.

Alquezar, Renata D., and Ricardo B. Machado. 2015. "Comparisons between Autonomous Acoustic Recordings and Avian Point Counts in Open Woodland Savanna." Wilson Journal of Ornithology 127 (4): 712-23.

Amit, Bettycopa, Andrew Alek Tuen, Khalid Haron, Mohd Haniff Harun, and Norman Kamarudin. 2015. "The Diet of Yellow-Vented Bulbul (Pycnonotus Goiavier) in Oil Palm Agroecosystems." Journal of Oil Palm Research 27 (4): 417-24.

Amoah, F. M., B. N. Nuertey, K. Baidoo-Addo, F. K. Oppong, K. Osei-Bonsu, and T. E. O. Asamoah. 1995. "Underplanting Oil Palm with Cocoa in Ghana." Agroforestry Systems 30 (3): 289-99.

Anderson, Sandra H., Dave Kelly, Jenny J. Ladley, Sue Molloy, and Jon Terry. 2011. "Cascading Effects of Bird Functional Extinction Reduce Pollination and Plant Density." Science 331 (6020): 1068-71. doi:10.1126/science.1199092.

Aratrakorn, Sirirak, Somying Thunhikorn, and Paul F. Donald. 2006. "Changes in Bird Communities Following Conversion of Lowland Forest to Oil Palm and Rubber Plantations in Southern Thailand." Bird Conservation International 16 (01): 71. doi:10.1017/S0959270906000062.

Asrulsani Jambari, Badrul Azhar, Nor Laili Ibrahim, Syari Jamian, Arnina Hussin, Puan ChongLeong, Hafidzi Mohd Noor, Ebil Yusof, and Mohamed Zakaria. 2012. "Avian Biodiversity and Conservation in Malaysian Oil Palm Production Areas." Journal of Oil Palm Research 24 (April): 1277-86.

Aylor, Donald. 1972. "Noise Reduction by Vegetation and Ground." The Journal of the Acoustical Society of America 51 (1B): 197-205. doi:10.1121/1.1912830.

Azhar, Badrul, David B. Lindenmayer, Jeff Wood, Joern Fischer, Adrian Manning, Chris McElhinny, and Mohamed Zakaria. 2011. "The Conservation Value of Oil Palm Plantation Estates, Smallholdings and Logged Peat Swamp Forest for Birds." Forest Ecology and Management 262 (12): 2306-15. doi:10.1016/j.foreco.2011.08.026. 
Azhar, Badrul, David B. Lindenmayer, Jeff Wood, Joern Fischer, Adrian Manning, Chris Mcelhinny, and Mohamed Zakaria. 2013. "The Influence of Agricultural System, Stand Structural Complexity and Landscape Context on Foraging Birds in Oil Palm Landscapes." Ibis 155 (2): 297-312.

Azhar, Badrul, Chong Leong Puan, Najjib Aziz, Muhammad Sainuddin, Nurfatin Adila, Sohaimi Samsuddin, Siti Asmah, et al. 2015. "Effects of in Situ Habitat Quality and Landscape Characteristics in the Oil Palm Agricultural Matrix on Tropical Understory Birds, Fruit Bats and Butterflies." Biodiversity and Conservation 24 (12): 3125-44. doi:10.1007/s10531-015-1005-6.

Azhar, Badrul, Chong Leong Puan, Mohamed Zakaria, Nuraishah Hassan, and Mohd Arif. 2014. "Effects of Monoculture and Polyculture Practices in Oil Palm Smallholdings on Tropical Farmland Birds." Basic and Applied Ecology 15 (4): 336-46. doi:10.1016/j.baae.2014.06.001.

Bader, Elias, Kirsten Jung, Elisabeth K.V. Kalko, Rachel A. Page, Raul Rodriguez, and Thomas Sattler. 2015. "Mobility Explains the Response of Aerial Insectivorous Bats to Anthropogenic Habitat Change in the Neotropics." Biological Conservation 186 (June): 97-106. doi:10.1016/j.biocon.2015.02.028.

Barnes, Andrew D., Malte Jochum, Steffen Mumme, Noor Farikhah Haneda, Achmad Farajallah, Tri Heru Widarto, and Ulrich Brose. 2014. "Consequences of Tropical Land Use for Multitrophic Biodiversity and Ecosystem Functioning." Nature Communications 5 (October). doi:10.1038/ncomms6351.

Bart, Jonathan, and James D. Schoultz. 1984. "Reliability of Singing Bird Surveys: Changes in Observer Efficiency with Avian Density." The Auk 101 (2): 307-18.

Bartoń, Kamil. 2013. MuMIn: Multi-Model Inference (version R package version 1.9.5). R package version 1.9.5. http://CRAN.R-project.org/package=MuMIn.

Bas, Yves, Vincent Devictor, Jean-Pierre Moussus, and Frédéric Jiguet. 2008. “Accounting for Weather and Time-of-Day Parameters When Analysing Count Data from Monitoring Programs." Biodiversity and Conservation 17 (14): 3403-16. doi:10.1007/s10531-008-9420-6.

Beukema, Hendrien, Finn Danielsen, Grégoire Vincent, Suryo Hardiwinoto, and Jelte Andel. 2007. "Plant and Bird Diversity in Rubber Agroforests in the Lowlands of Sumatra, Indonesia." Agroforestry Systems 70 (3): 217-42. doi:10.1007/s10457-007-9037-x.

Bihn, Jochen H., Gerhard Gebauer, and Roland Brandl. 2010. "Loss of Functional Diversity of Ant Assemblages in Secondary Tropical Forests." Ecology 91 (3): 782-92.

BirdLife International. 2015. "Birdlife Data Zone." October 2. http://www.birdlife.org/datazone/home. . 2015. "Birdlife Data Zone." Accessed October 2. http://www.birdlife.org/datazone/home.

Blumstein, Daniel T., Daniel J. Mennill, Patrick Clemins, Lewis Girod, Kung Yao, Gail Patricelli, Jill L. Deppe, et al. 2011. "Acoustic Monitoring in Terrestrial Environments Using Microphone Arrays: Applications, Technological Considerations and Prospectus: Acoustic Monitoring." Journal of Applied Ecology 48 (3): 758-67. doi:10.1111/j.1365-2664.2011.01993.x.

Blüthgen, Nico, Florian Menzel, and Nils Blüthgen. 2006. "Measuring Specialization in Species Interaction Networks.” BMC Ecology 6: 9. doi:10.1186/1472-6785-6-9.

Boer, E., ed. 2000. Plants Producing Exudates. Plant Resources of South-East Asia, No. 18. Leiden: Backhuys.

Boissier, Olivier, Axelle Bouiges, Irene Mendoza, François Feer, and Pierre-Michel Forget. 2014. "Rapid Assessment of Seed Removal and Frugivore Activity as a Tool for 
Monitoring the Health Status of Tropical Forests.” Biotropica 46 (5): 633-41. doi:10.1111/btp.12134.

Brandes, T. Scott. 2008. "Automated Sound Recording and Analysis Techniques for Bird Surveys and Conservation." Bird Conservation International 18 (S1). doi:10.1017/S0959270908000415.

Breure, C. J. 2010. "Rate of Leaf Expansion: A Criterion for Identifying Oil Palm (Elaeis Guineensis Jacq.) Types Suitable for Planting at High Densities." NJAS - Wageningen Journal of Life Sciences 57 (2): 141-47. doi:10.1016/j.njas.2010.03.001.

Brooks, Thomas M., Stuart L. Pimm, Valerie Kapos, and Corinna Ravilious. 1999. "Threat from Deforestation to Montane and Lowland Birds and Mammals in Insular SouthEast Asia." Journal of Animal Ecology 68 (6): 1061-78.

Brown, Kerry A., Dan FB Flynn, Nicola K. Abram, J. Carter Ingram, Steig E. Johnson, and Patricia Wright. 2011. “Assessing Natural Resource Use by Forest-Reliant Communities in Madagascar Using Functional Diversity and Functional Redundancy Metrics." PLoS ONE 6 (9): e24107.

Buckland, Stephen T., David R. Anderson, Kenneth P. Burnham, and Jeffrey L. Laake. 2005. "Distance Sampling." In Encyclopedia of Biostatistics. John Wiley \& Sons, Ltd. http://onlinelibrary.wiley.com/doi/10.1002/0470011815.b2a16019/abstract.

Burnham, Kenneth P., and David R. Anderson. 2002. Model Selection and Multimodel Inference: A Practical Information-Theoretic Approach. New York, New York: Springer Science \& Business Media. https://books.google.de/books?hl=en\&lr=\&id=fT1Iu-h6EoC\&oi=fnd\&pg=PR7\&dq=Model+selection+and+multimodel+inference:+a+practical +information-theoretic+approach\&ots=tevr3-TFq6\&sig=157tIwIxiew23Qd2GIARJIGYTY. ., eds. 2004. Model Selection and Multimodel Inference. New York, NY: Springer New York. http://link.springer.com/10.1007/b97636.

Butchart, Stuart H. M., Matt Walpole, Ben Collen, Arco van Strien, Jörn P. W. Scharlemann, Rosamunde E. A. Almond, Jonathan E. M. Baillie, et al. 2010. "Global Biodiversity: Indicators of Recent Declines." Science 328 (5982): 1164-68. doi:10.1126/science.1187512.

Butterfield, Bradley J., and Katharine N. Suding. 2013. "Single-Trait Functional Indices Outperform Multi-Trait Indices in Linking Environmental Gradients and Ecosystem Services in a Complex Landscape." Journal of Ecology 101 (1): 9-17.

Cagnolo, Luciano, Graciela Valladares, Adriana Salvo, Marcelo Cabido, and Marcelo Zak. 2009. "Habitat Fragmentation and Species Loss across Three Interacting Trophic Levels: Effects of Life-History and Food-Web Traits." Conservation Biology 23 (5): 1167-75.

Catchpole, Clive, and P. J. B. Slater. 2008. Bird Song: Biological Themes and Variations. 2nd ed. Cambridge [England]; New York: Cambridge University Press.

Celis-Murillo, Antonio, Jill L. Deppe, and Michael F. Allen. 2009. "Using Soundscape Recordings to Estimate Bird Species Abundance, Richness, and Composition." Journal of Field Ornithology 80 (1): 64-78. doi:10.1111/j.1557-9263.2009.00206.x.

Celis-Murillo, Antonio, Jill L. Deppe, and Michael P. Ward. 2012. "Effectiveness and Utility of Acoustic Recordings for Surveying Tropical Birds.” Journal of Field Ornithology 83 (2): 166-79. doi:10.1111/j.1557-9263.2012.00366.x.

Cheke, R, and C Mann. 2016. "Orange-Bellied Flowerpecker (Dicaeum Trigonostigma)." In Del Hoyo, J., Elliott, A., Sargatal, J., Christie, D.A. \& de Juana, E. (eds.). Handbook of the Birds of the World Alive. Lynx Edicions, Barcelona. Accessed June 3. http://www.hbw.com/node/60133. 
Chung, A. Y. C., P. Eggleton, M. R. Speight, P. M. Hammond, and V. K. Chey. 2000. "The Diversity of Beetle Assemblages in Different Habitat Types in Sabah, Malaysia." Bulletin of Entomological Research 90 (06): 475-96.

Clough, Yann. (in revision). "Land-Use Choices, Profitability, and Consequences for Biodiversity and Ecological Functions in Indonesian Smallholder Landscapes." Nature Communications

Clough, Yann, Jan Barkmann, Jana Juhrbandt, Michael Kessler, Thomas Cherico Wanger, Alam Anshary, Damayanti Buchori, et al. 2011. "Combining High Biodiversity with High Yields in Tropical Agroforests." Proceedings of the National Academy of Sciences 108 (20): 8311-16.

Clough, Yann, Heiko Faust, and Teja Tscharntke. 2009. "Cacao Boom and Bust: Sustainability of Agroforests and Opportunities for Biodiversity Conservation." Conservation Letters 2 (5): 197-205. doi:10.1111/j.1755-263X.2009.00072.x.

Cody, Martin L. 1985. Habitat Selection in Birds. Academic Press.

Coley, Phyllis D. 1980. "Effects of Leaf Age and Plant Life History Patterns on Herbivory." Nature 284: 545-46.

Collen, Ben, Mala Ram, Tara Zamin, and Louise McRae. 2008. "The Tropical Biodiversity Data Gap: Addressing Disparity in Global Monitoring." Tropical Conservation Science 1 (2): 75-88.

Corley, R. Hereward V., and P. B. H. Tinker. 2003. The Oil Palm. Oxford, UK: Blackwell Publishing Ltd.

https://books.google.de/books?hl=en\&lr=\&id=NtCo1TdXuQkC\&oi=fnd\&pg=PR5\&d $\mathrm{q}=\mathrm{The}+\mathrm{Oil}+\mathrm{Palm}+$ corly\&ots=CByIhGZkR1\&sig=UxhL05WiW2bqkfwY8huIM1zTw g0.

Corley, R. H. V., and P. B. H. Tinker. 2008. The Oil Palm. John Wiley \& Sons.

Daily, Gretchen C. 1997. Nature's Services: Societal Dependence on Natural Ecosystems. Island Press.

Darras, Kevin. 2015. "Sound Detection Spaces.” Sound Detection Spaces. March 29. http://wwwuser.gwdg.de/ ecosound/index.html.

Davies, Neil, and David Spencer Smith. 1998. "Munroe Revisited: A Survey of West Indian Butterfly Faunas and Their Species-Area Relationship." Global Ecology \& Biogeography Letters 7 (4): 285-94.

Dawson, Deanna K., and Murray G. Efford. 2009. "Bird Population Density Estimated from Acoustic Signals: Population Density from Acoustic Signals." Journal of Applied Ecology 46 (6): 1201-9. doi:10.1111/j.1365-2664.2009.01731.x.

De Chenon, R. DESMIER, and AGUS Susanto. 2006. "Ecological Observations on Diurnal Birds in Indonesian Oil Palm Plantations." J. Oil Palm Res., 122-43.

Dejean, Aa, C. Djieto-Lordon, and J. La Durand. 1997. “Ant Mosaic in Oil Palm Plantations of the Southwest Province of Cameroon: Impact on Leaf Miner Beetle (Coleoptera: Chrysomelidae)." Journal of Economic Entomology 90 (5): 1092-96.

del Hoyo, J, A Elliot, J Sargatal, DA Christie, and E de Juana. 2015. Handbook of the Birds of the World Alive. Barcelona, Spain: Lynx Edicions.

del Hoyo, J, A Elliott, J Sargatal, DA Christie, and E de Juana. 2015. "Handbook of the Birds of the World Alive." Lynx Edicions, Barcelona. http://www.hbw.com/.

Depraetere, M., S. Pavoine, F. Jiguet, A. Gasc, S. Duvail, and J. Sueur. 2012. "Monitoring Animal Diversity Using Acoustic Indices: Implementation in a Temperate Woodland." Ecological Indicators 13 (1): 46.

de Solla, Shane R., Leonard J. Shirose, Kim J. Fernie, Glenn C. Barrett, Chris S. Brousseau, and Christine A. Bishop. 2005. "Effect of Sampling Effort and Species Detectability 
on Volunteer Based Anuran Monitoring Programs." Biological Conservation 121 (4): 585-94. doi:10.1016/j.biocon.2004.06.018.

Diefenbach, Duane R., Daniel W. Brauning, and Jennifer A. Mattice. 2003. "Variability in Grassland Bird Counts Related to Observer Differences and Species Detection Rates." The Auk 120 (4): 1168-79. doi:10.1642/0004-

8038(2003)120[1168:VIGBCR]2.0.CO;2.

Dinas Komunikasi dan Informatika Prov. Jambi. 2013. "Official Website Provinsi Jambi Profil: Letak Wilayah Dalam Provinsi Jambi." http://jambiprov.go.id/index.php?letluaswil.

Drakare, Stina, Jack J. Lennon, and Helmut Hillebrand. 2006. "The Imprint of the Geographical, Evolutionary and Ecological Context on Species-Area Relationships: Imprint on Species-Area Relationships." Ecology Letters 9 (2): 215-27. doi:10.1111/j.1461-0248.2005.00848.x.

Drescher, Jochen, and et al. n.d. "Ecological and Socioeconomic Functions across Tropical Land-Use Systems after Rainforest Conversion.” Philosophical Transactions B.

Drescher, Jochen, Katja Rembold, Kara Allen, Philip Beckschäfer, Damayanti Buchori, Yann Clough, Heiko Faust, et al. 2016. "Ecological and Socio-Economic Functions across Tropical Land Use Systems after Rainforest Conversion.” Phil. Trans. R. Soc. B 371 (1694): 20150275. doi:10.1098/rstb.2015.0275.

Driscoll, Don A., and T. O. M. Weir. 2005. "Beetle Responses to Habitat Fragmentation Depend on Ecological Traits, Habitat Condition, and Remnant Size." Conservation Biology 19 (1): 182-94.

Dyer, Mary L., Vernon Meentemeyer, and Björn Berg. 1990. "Apparent Controls of Mass Loss Rate of Leaf Litter on a Regional Scale: Litter Quality vs. Climate." Scandinavian Journal of Forest Research 5 (1-4): 311-23.

Edwards, David P., Jenny A. Hodgson, Keith C. Hamer, Simon L. Mitchell, Abdul H. Ahmad, Stephen J. Cornell, and David S. Wilcove. 2010. "Wildlife-Friendly Oil Palm Plantations Fail to Protect Biodiversity Effectively: Farming and the Fate of Tropical Biodiversity." Conservation Letters 3 (4): 236-42. doi:10.1111/j.1755263X.2010.00107.x.

Ellinger, Norbert, and Walter Hödl. 2003. "Habitat Acoustics of a Neotropical Lowland Rainforest." Bioacoustics 13 (3): 297-321. doi:10.1080/09524622.2003.9753503.

Embleton, T. F. W. 1963. "Sound Propagation in Homogeneous Deciduous and Evergreen Woods." The Journal of the Acoustical Society of America 35 (8): 1119. doi:10.1121/1.1918662.

Evans, Theodore A., Tracy Z. Dawes, Philip R. Ward, and Nathan Lo. 2011. "Ants and Termites Increase Crop Yield in a Dry Climate." Nature Communications 2 (March): 262. doi:10.1038/ncomms1257.

Falconer, Joseph G., J. W. Wright, and H. W. Beall. 1933. "The Decomposition of Certain Types of Forest Litter under Field Conditions." American Journal of Botany 20 (3): 196-203.

Fayle, T. M., K. M. Yusah, and Y. Hashimoto. 2014. "Key to the Ant Genera of Borneo in English and Malay." http://www.tomfayle.com/Ant\%20key.htm.

Feintrenie, Laurène, and Patrice Levang. 2009. "Sumatra's Rubber Agroforests: Advent, Rise and Fall of a Sustainable Cropping System.” Small-Scale Forestry 8 (3): 323-35. doi:10.1007/s11842-009-9086-2.

Ficetola, Gentile F., Johan Pansu, Aurélie Bonin, Eric Coissac, Charline Giguet-Covex, Marta De Barba, Ludovic Gielly, et al. 2015. "Replication Levels, False Presences and the Estimation of the Presence/absence from eDNA Metabarcoding Data." Molecular Ecology Resources 15 (3): 543-56. doi:10.1111/1755-0998.12338. 
Fischer, Joern, David B. Lindenmayer, and Adrian D. Manning. 2006. "Biodiversity, Ecosystem Function, and Resilience: Ten Guiding Principles for Commodity Production Landscapes." Frontiers in Ecology and the Environment 4 (2): 80-86.

Fishpool, L., Tobias, J. \& de Juana, E. 2016. "Yellow-Vented Bulbul (Pycnonotus Goiavier).” Accessed March 7. http://www.hbw.com/species/yellow-vented-bulbulpycnonotus-goiavier.

Fitzherbert, E.B., M.J. Struebig, A. Morel, F. Danielsen, C.A. Brühl, P.F. Donald, and B. Phalan. 2008. "How Will Oil Palm Expansion Affect Biodiversity?" Trends in Ecology \& Evolution 23 (10): 538-45.

Fitzherbert, Emily B., Matthew J. Struebig, Alexandra Morel, Finn Danielsen, Carsten A. Brühl, Paul F. Donald, and Ben Phalan. 2008. "How Will Oil Palm Expansion Affect Biodiversity?" Trends in Ecology \& Evolution 23 (10): 538-45.

Fitzherbert, Emily B, Matthew J Struebig, Alexandra Morel, Finn Danielsen, Carsten a Brühl, Paul F Donald, and Ben Phalan. 2008. "How Will Oil Palm Expansion Affect Biodiversity?" Trends in Ecology \& Evolution 23 (10): 538-45. doi:10.1016/j.tree.2008.06.012.

Fitzpatrick, Matthew C., Evan L. Preisser, Aaron M. Ellison, and Joseph S. Elkinton. 2009. "Observer Bias and the Detection of Low-Density Populations." Ecological Applications 19 (7): 1673-79. doi:10.1890/09-0265.1.

Fletcher, Neville. 2007. “Animal Bioacoustics.” In Springer Handbook of Acoustics, edited by Thomas D. Rossing Prof, 785-804. Springer New York. http://link.springer.com/referenceworkentry/10.1007/978-0-387-30425-0_19.

Flynn, Dan FB, Melanie Gogol-Prokurat, Theresa Nogeire, Nicole Molinari, Bárbara Trautman Richers, Brenda B. Lin, Nicholas Simpson, Margaret M. Mayfield, and Fabrice DeClerck. 2009. "Loss of Functional Diversity under Land Use Intensification across Multiple Taxa." Ecology Letters 12 (1): 22-33.

Foley, J. A. 2005. “Global Consequences of Land Use.” Science 309 (July): 570-74. doi:10.1126/science.1111772.

Foley, Jonathan A., Ruth DeFries, Gregory P. Asner, Carol Barford, Gordon Bonan, Stephen R. Carpenter, F. Stuart Chapin, et al. 2005a. "Global Consequences of Land Use." Science 309 (5734): 570-74. doi:10.1126/science.1111772. . 2005b. "Global Consequences of Land Use." Science 309 (5734): 570-74. doi:10.1126/science.1111772.

Folgarait, Patricia J. 1998. "Ant Biodiversity and Its Relationship to Ecosystem Functioning: A Review." Biodiversity and Conservation 7 (9): 1221-44.

Food and Agriculture Organization. 2013. "FAOSTAT." http://faostat.fao.org/site/339/default.aspx.

Ford, W. Mark, Michael A. Menzel, Jane L. Rodrigue, Jennifer M. Menzel, and Joshua B. Johnson. 2005. "Relating Bat Species Presence to Simple Habitat Measures in a Central Appalachian Forest." Biological Conservation 126 (4): 528-39. doi:10.1016/j.biocon.2005.07.003.

Forrest, T. G. 1994. "From Sender to Receiver: Propagation and Environmental Effects on Acoustic Signals." American Zoologist 34 (6): 644-54.

Foster, William A., Jake L. Snaddon, Edgar C. Turner, Tom M. Fayle, Timothy D. Cockerill, M. D. Farnon Ellwood, Gavin R. Broad, et al. 2011. "Establishing the Evidence Base for Maintaining Biodiversity and Ecosystem Function in the Oil Palm Landscapes of South East Asia." Philosophical Transactions of the Royal Society of London B: Biological Sciences 366 (1582): 3277-91. doi:10.1098/rstb.2011.0041.

Frey-Ehrenbold, Annie, Fabio Bontadina, Raphaël Arlettaz, and Martin K. Obrist. 2013. "Landscape Connectivity, Habitat Structure and Activity of Bat Guilds in Farmland- 
Dominated Matrices." Journal of Applied Ecology 50 (1): 252-61. doi:10.1111/13652664.12034.

Fristrup, Kurt. 2009. "The Acoustical Status of U. S. National Parks." The Journal of the Acoustical Society of America 125 (4): 2716-2716. doi:10.1121/1.4784418.

Furnas, Brett J., and Richard L. Callas. 2015. "Using Automated Recorders and Occupancy Models to Monitor Common Forest Birds across a Large Geographic Region." The Journal of Wildlife Management 79 (2): 325-37. doi:10.1002/jwmg.821.

Gagic, Vesna, Ignasi Bartomeus, Tomas Jonsson, Astrid Taylor, Camilla Winqvist, Christina Fischer, Eleanor M. Slade, et al. 2015. "Functional Identity and Diversity of Animals Predict Ecosystem Functioning Better than Species-Based Indices." Proceedings of the Royal Society of London B: Biological Sciences 282 (1801): 20142620. doi:10.1098/rspb.2014.2620.

Gardner, Toby A., Jos Barlow, Ivanei S. Araujo, Teresa Cristina Ávila-Pires, Alexandre B. Bonaldo, Joana E. Costa, Maria Cristina Esposito, et al. 2008. "The CostEffectiveness of Biodiversity Surveys in Tropical Forests.” Ecology Letters 11 (2): 139-50. doi:10.1111/j.1461-0248.2007.01133.x.

Gatto, Marcel, Meike Wollni, and Matin Qaim. 2014. "Oil Palm Boom and Land-Use Dynamics in Indonesia : The Role of Policies and Socioeconomic Factors." Working Paper Series 6. EFForTS Discussion Paper Series. Göttingen: Georg-AugustUniversität Göttingen. http://resolver.sub.uni-goettingen.de/purl/?webdoc-3938. . 2015. "Oil Palm Boom and Land-Use Dynamics in Indonesia: The Role of Policies and Socioeconomic Factors." Land Use Policy 46: 292-303.

Gee, Glendon W., and James W. Bauder. 1986. "Particle-Size Analysis." In Methods of Soil Analysis. Part 1. Physical and Mineralogical Methods, 383-411. Madison, Wisconsin: American Society of Agronomy, Inc. http://www.cabdirect.org/abstracts/19881917517.html.

Geist, Helmut J., and Eric F. Lambin. 2002. "Proximate Causes and Underlying Driving Forces of Tropical Deforestation." BioScience 52 (2): 143-50. doi:10.1641/00063568(2002)052[0143:PCAUDF]2.0.CO;2.

Gibbs, Holly K., A. S. Ruesch, F. Achard, M. K. Clayton, P. Holmgren, N. Ramankutty, and J. A. Foley. 2010. "Tropical Forests Were the Primary Sources of New Agricultural Land in the 1980s and 1990s." Proceedings of the National Academy of Sciences 107 (38): 16732-37.

Gibbs, James P., Malcolm L. Hunter, and Scott M. Melvin. 1993. "Snag Availability and Communities of Cavity Nesting Birds in Tropical Versus Temperate Forests." Biotropica 25 (2): 236. doi:10.2307/2389188.

Goulart, Fernando Figueiredo, John Vandermeer, Ivette Perfecto, and Rodrigo Pinto da Matta-Machado. 2011. "Frugivory by Five Bird Species in Agroforest Home Gardens of Pontal Do Paranapanema, Brazil." Agroforestry Systems 82 (3): 239-46. doi:10.1007/s10457-011-9398-z.

Gouyon, Anne. 2003. "Eco-Certification as an Incentive to Conserve Biodiversity in Rubber Smallholder Agroforestry Systems : A Preliminary Study." ICRAF Southeast Asia Working Paper No 2003_1.

http://regions/southeast_asia/publicationsdo=view_pub_detail\&pub_no=WP0003-0410.

Gouyon, Anne, Hubert de Foresta, and Patrice Levang. 1993. "Does ‘jungle Rubber'deserve Its Name? An Analysis of Rubber Agroforestry Systems in Southeast Sumatra." Agroforestry Systems 22 (3): 181-206. 
Gras, Pierre, Teja Tscharntke, Bea Maas, Aiyen Tjoa, Awal Hafsah, and Yann Clough. 2016. "How Ants, Birds and Bats Affect Crop Yield along Shade Gradients in Tropical Cacao Agroforestry." Journal of Applied Ecology, In press.

Grass, Ingo, Dana G. Berens, and Nina Farwig. 2014a. "Guild-Specific Shifts in Visitation Rates of Frugivores with Habitat Loss and Plant Invasion." Oikos 123 (5): 575-82. . 2014b. "Natural Habitat Loss and Exotic Plants Reduce the Functional Diversity of Flower Visitors in a Heterogeneous Subtropical Landscape." Functional Ecology 28 (5): 1117-26.

Gray, Claudia L., and Owen T. Lewis. 2014. "Do Riparian Forest Fragments Provide Ecosystem Services or Disservices in Surrounding Oil Palm Plantations?" Basic and Applied Ecology 15 (8): 693-700.

Greathead, D. J. 1983. "The Multi-Million Dollar Weevil That Pollinates Oil Palms." Antenna 7 (3): 105-7.

Greenfield, Michael D. 1994. "Synchronous and Alternating Choruses in Insects and Anurans: Common Mechanisms and Diverse Functions." Integrative and Comparative Biology 34 (6): 605-15. doi:10.1093/icb/34.6.605.

Grueber, C. E., S. Nakagawa, R. J. Laws, and I. G. Jamieson. 2011. "Multimodel Inference in Ecology and Evolution: Challenges and Solutions." Journal of Evolutionary Biology 24 (4): 699-711.

Harrison, Xavier A. 2014. "Using Observation-Level Random Effects to Model Overdispersion in Count Data in Ecology and Evolution." PeerJ 2: e616.

Harris, S., W. J. Cresswell, P. G. Forde, W. J. Trewhella, T. Woollard, and S. Wray. 1990. "Home-Range Analysis Using Radio-Tracking Data-a Review of Problems and Techniques Particularly as Applied to the Study of Mammals." Mammal Review 20 (2-3): 97-123. doi:10.1111/j.1365-2907.1990.tb00106.x.

Harvey, C. A., and W. A. Haber. 1998. "Remnant Trees and the Conservation of Biodiversity in Costa Rican Pastures." Agroforestry Systems 44 (1): 37-68. doi:10.1023/A:1006122211692.

Heaney, LR. 1991. "An Analysis of Patterns of Distribution and Species Richness among Philippine Fruit Bats Pteropodidae." Bull. Am. Mus. Nat. Hist. 206: 145-67.

Hedges, Larry V., Jessica Gurevitch, and Peter S. Curtis. 1999. "The Meta-Analysis of Response Ratios in Experimental Ecology." Ecology 80 (4): 1150-56. doi:10.2307/177062.

Henle, Klaus, Kendi F. Davies, Michael Kleyer, Chris Margules, and Josef Settele. 2004. "Predictors of Species Sensitivity to Fragmentation." Biodiversity and Conservation 13 (1): 207-51.

Herrera, Carlos M., Pedro Jordano, Luis Lopez-Soria, and Juan A. Amat. 1994. "Recruitment of a Mast-Fruiting, Bird-Dispersed Tree: Bridging Frugivore Activity and Seedling Establishment." Ecological Monographs 64 (3): 315-44. doi:10.2307/2937165.

Hobson, Keith A., Robert S. Rempel, Hamilton Greenwood, Brian Turnbull, and Steven L. Van Wilgenburg. 2002. "Acoustic Surveys of Birds Using Electronic Recordings: New Potential from an Omnidirectional Microphone System." Wildlife Society Bulletin (1973-2006) 30 (3): 709-20.

Hoffmann, M. P., A. Castaneda Vera, M. T. Van Wijk, K. E. Giller, T. Oberthür, C. Donough, and A. M. Whitbread. 2014. "Simulating Potential Growth and Yield of Oil Palm (Elaeis Guineensis) with PALMSIM: Model Description, Evaluation and Application." Agricultural Systems 131: 1-10.

Holt, Robert D. 2009. “Toward a Trophic Island Biogeography.” In The Theory of Island Biogeography Revisted, 143-85. Princeton, USA: Princeton University Press. 
https://books.google.de/books?hl=en\&lr=\&id=slwedU4I4JMC\&oi=fnd\&pg=PA143\& $\mathrm{dq}=$ trophic+island + holt\&ots=CL6IF9Btil\&sig=lUvMe9-aUyQh2eUSiH23r6-ndDA.

Hothorn, Torsten, Frank Bretz, and Peter Westfall. 2008a. "Simultaneous Inference in General Parametric Models." http://epub.ub.uni-muenchen.de/2120.

. 2008b. "Simultaneous Inference in General Parametric Models." Biometrical Journal 50 (3): 346-63.

Howe, Andrew, Gabor L. Lövei, and Gösta Nachman. 2009. "Dummy Caterpillars as a Simple Method to Assess Predation Rates on Invertebrates in a Tropical Agroecosystem." Entomologia Experimentalis et Applicata 131 (3): 325-29. doi:10.1111/j.1570-7458.2009.00860.x.

Howe, HENRY F. 1986. "Seed Dispersal by Fruit-Eating Birds and Mammals." Seed Dispersal 123: 189.

Huveneers, Charlie, Colin A. Simpfendorfer, Susan Kim, Jayson Semmens, Alistair J. Hobday, Hugh Pederson, Thomas Stieglitz, et al. 2015. "The Influence of Environmental Parameters on the Performance and Detection Range of Acoustic Receivers." Methods in Ecology and Evolution, December, n/a - n/a. doi:10.1111/2041-210X.12520.

Ingård, Uno. 1953. "A Review of the Influence of Meteorological Conditions on Sound Propagation." The Journal of the Acoustical Society of America 25 (3): 405. doi:10.1121/1.1907055.

Jepson, Paul, and Richard J. Ladle. 2005. "Bird-Keeping in Indonesia: Conservation Impacts and the Potential for Substitution-Based Conservation Responses." Oryx 39 (04): 442. doi:10.1017/S0030605305001110.

Jetz, W., G. H. Thomas, J. B. Joy, K. Hartmann, and A. O. Mooers. 2012. "The Global Diversity of Birds in Space and Time." Nature 491 (7424): 444-48. doi:10.1038/nature11631.

Ji, Yinqiu, Louise Ashton, Scott M. Pedley, David P. Edwards, Yong Tang, Akihiro Nakamura, Roger Kitching, et al. 2013. "Reliable, Verifiable and Efficient Monitoring of Biodiversity via Metabarcoding." Ecology Letters 16 (10): 1245-57. doi:10.1111/ele.12162.

Jung, Kirsten, Sonja Kaiser, Stefan Böhm, Jens Nieschulze, and Elisabeth K. V. Kalko. 2012. "Moving in Three Dimensions: Effects of Structural Complexity on Occurrence and Activity of Insectivorous Bats in Managed Forest Stands." Journal of Applied Ecology 49 (2): 523-31. doi:10.1111/j.1365-2664.2012.02116.x.

Kalcounis, M. C., K. A. Hobson, R. M. Brigham, and K. R. Hecker. 1999. "Bat Activity in the Boreal Forest: Importance of Stand Type and Vertical Strata." Journal of Mammalogy 80 (2): 673-82. doi:10.2307/1383311.

Kamarudin, Norman, and Mohd Basri Wahid. 2010. "Interactions of the Bagworm, Pteroma Pendula (Lepidoptera: Psychidae), and Its Natural Enemies in an Oil Palm Plantation in Perak." Journal of Oil Palm Research 22: 758-64.

Kehlenbeck, K., and B. L. Maass. 2004. "Crop Diversity and Classification of Homegardens in Central Sulawesi, Indonesia." Agroforestry Systems 63 (1): 53-62. doi:10.1023/B:AGFO.0000049433.95038.25.

Koh, Lian Pin. 2008. "Birds Defend Oil Palms from Herbivorous Insects." Ecological Applications 18 (4): 821-25.

Koh, Lian Pin, and Jaboury Ghazoul. 2010. "Spatially Explicit Scenario Analysis for Reconciling Agricultural Expansion, Forest Protection, and Carbon Conservation in Indonesia." Proceedings of the National Academy of Sciences 107 (24): 11140-44.

Koh, L.P. 2008. "Birds Defend Oil Palms from Herbivorous Insects." Ecological Applications 18 (4): 821-25. 
Koh, L. P., and J. Ghazoul. 2010. "Spatially Explicit Scenario Analysis for Reconciling Agricultural Expansion, Forest Protection, and Carbon Conservation in Indonesia." Proceedings of the National Academy of Sciences 107 (24): 11140-44. doi:10.1073/pnas.1000530107.

Konishi, Sadanori, and G. Kitagawa. 2008. Information Criteria and Statistical Modeling. Springer Series in Statistics. New York: Springer.

Kopp, Thomas, and Bernhard Brümmer. 2015. "Moving Rubber to a Better Place - and Extracting Rents from Credit Constrained Farmers along the Way." GOEDOC, Dokumenten - Und Publikationsserver Der Georg - August - Universität, EFForTS discussion paper series, , no. 9. http://resolver.sub.uni-goettingen.de/purl/?webdoc3948.

Kotowska, Martyna M., Christoph Leuschner, Triadiati Triadiati, Selis Meriem, and Dietrich Hertel. 2015a. "Quantifying above-and Belowground Biomass Carbon Loss with Forest Conversion in Tropical Lowlands of Sumatra (Indonesia)." Global Change Biology, doi: 10.1111/gcb.12979.

- 2015b. "Quantifying above- and Belowground Biomass Carbon Loss with Forest Conversion in Tropical Lowlands of Sumatra (Indonesia)." Global Change Biology, May, n/a - n/a. doi:10.1111/gcb.12979.

Krzywinski, Martin, and Naomi Altman. 2013. "Points of Significance: Error Bars." Nature Methods 10 (10): 921-22.

Kumar, B. M., and P. K. R. Nair, eds. 2006. Tropical Homegardens: A Time-Tested Example of Sustainable Agroforestry. Advances in Agroforestry, v. 3. Dordrecht: Springer.

Kumar, B. Mohan, and PK Ramachandran Nair. 2004. "The Enigma of Tropical Homegardens." Agroforestry Systems 61 (1-3): 135-52.

Laliberté, E., and B. Shipley. 2014. FD: Measuring Functional Diversity from Multiple Traits, and Other Tools for Functional Ecology. R package version 1.0-11.

Laliberté, Etienne, and Pierre Legendre. 2010. "A Distance-Based Framework for Measuring Functional Diversity from Multiple Traits." Ecology 91 (1): 299-305.

Laliberte, Etienne, Jessie A. Wells, Fabrice DeClerck, Daniel J. Metcalfe, Carla P. Catterall, Cibele Queiroz, Isabelle Aubin, et al. 2010. "Land-Use Intensification Reduces Functional Redundancy and Response Diversity in Plant Communities." Ecology Letters 13 (1): 76-86.

Lambert, F. R. 1992. "The Consequences of Selective Logging for Bornean Lowland Forest Birds." Philosophical Transactions of the Royal Society B: Biological Sciences 335 (1275): 443-57. doi:10.1098/rstb.1992.0036.

Lambert, Kathryn T. A., and Paul G. McDonald. 2014. "A Low-Cost, yet Simple and Highly Repeatable System for Acoustically Surveying Cryptic Species.” Austral Ecology 39 (7): 779-85. doi:10.1111/aec.12143.

Larsen, Trond H., Neal M. Williams, and Claire Kremen. 2005. "Extinction Order and Altered Community Structure Rapidly Disrupt Ecosystem Functioning.” Ecology Letters 8 (5): 538-47.

Laumonier, Yves, Yumiko Uryu, Michael Stüwe, Arif Budiman, Budi Setiabudi, and Oki Hadian. 2010. "Eco-Floristic Sectors and Deforestation Threats in Sumatra: Identifying New Conservation Area Network Priorities for Ecosystem-Based Land Use Planning." Biodiversity and Conservation 19 (4): 1153-74.

Lee, Janice Ser Huay, Sinan Abood, Jaboury Ghazoul, Baba Barus, Krystof Obidzinski, and Lian Pin Koh. 2014. "Environmental Impacts of Large-Scale Oil Palm Enterprises Exceed that of Smallholdings in Indonesia: Forest Loss from Sumatra's Oil Palm Industry." Conservation Letters 7 (1): 25-33. doi:10.1111/conl.12039. 
Lefcheck, Jonathan S., and J. Emmett Duffy. 2015. "Multitrophic Functional Diversity Predicts Ecosystem Functioning in Experimental Assemblages of Estuarine Consumers." Ecology 96 (11): 2973-83.

Lehmann, Gerlind U. C., Karl-Heinz Frommolt, Arne W. Lehmann, and Klaus Riede. 2014. "Baseline Data for Automated Acoustic Monitoring of Orthoptera in a Mediterranean Landscape, the Hymettos, Greece." Journal of Insect Conservation 18 (5): 909-25. doi:10.1007/s10841-014-9700-2.

Leimona, Beria, Meine van Noordwijk, Rudolf de Groot, and Rik Leemans. 2015. "Fairly Efficient, Efficiently Fair: Lessons from Designing and Testing Payment Schemes for Ecosystem Services in Asia." Ecosystem Services 12 (April): 16-28. doi:10.1016/j.ecoser.2014.12.012.

Li, Shining, Fasheng Zou, Qiang Zhang, and Frederick H. Sheldon. 2013. "Species Richness and Guild Composition in Rubber Plantations Compared to Secondary Forest on Hainan Island, China." Agroforestry Systems 87 (5): 1117-28. doi:10.1007/s10457013-9624-y.

Llusia, Diego, Rafael Márquez, and Richard Bowker. 2011. "Terrestrial Sound Monitoring Systems, a Methodology for Quantitative Calibration.” Bioacoustics 20 (3): 277-86.

Luck, Gary W., Andrew Carter, and Lisa Smallbone. 2013. "Changes in Bird Functional Diversity across Multiple Land Uses: Interpretations of Functional Redundancy Depend on Functional Group Identity.” PLoS ONE 8 (5): e63671. doi:10.1371/journal.pone.0063671.

Luke, Sarah H., Tom M. Fayle, Paul Eggleton, Edgar C. Turner, and Richard G. Davies. 2014. "Functional Structure of Ant and Termite Assemblages in Old Growth Forest, Logged Forest and Oil Palm Plantation in Malaysian Borneo." Biodiversity and Conservation 23 (11): 2817-32.

Maas, Bea, Yann Clough, and Teja Tscharntke. 2013a. "Bats and Birds Increase Crop Yield in Tropical Agroforestry Landscapes." Ecology Letters 16 (12): 1480-87. - 2013b. "Bats and Birds Increase Crop Yield in Tropical Agroforestry Landscapes." Ecology Letters 16 (12): 1480-87. doi:10.1111/ele.12194.

Maas, Bea, Daniel S. Karp, Sara Bumrungsri, Kevin Darras, David Gonthier, Joe C.-C. Huang, Catherine A. Lindell, Josiah J. Maine, Laia Mestre, Nicole L. Michel, Morrison, Emily B., et al. 2015. "Bird and Bat Predation Services in Tropical Forests and Agroforestry Landscapes." Biological Reviews, doi: 10.1111/brv.12211.

Maas, Bea, Daniel S. Karp, Sara Bumrungsri, Kevin Darras, David Gonthier, Joe C.-C. Huang, Catherine A. Lindell, Josiah J. Maine, Laia Mestre, Nicole L. Michel, Emily B. Morrison, et al. 2015. "Bird and Bat Predation Services in Tropical Forests and Agroforestry Landscapes: Ecosystem Services Provided by Tropical Birds and Bats." Biological Reviews, July, n/a - n/a. doi:10.1111/brv.12211.

MacKinnon, John, and Karen Phillipps. 1993. A Field Guide to the Birds of Borneo, Sumatra, Java, and Bali: The Greater Sunda Islands. Oxford University Press.

MacLean, WP, R Kellner, and H Dennis. 1977. "Island Lists of West Indian Amphibians and Reptiles." Smithsonian Herpetol. Info. Serv. 40.

Magurran, Anne E., Stephen R. Baillie, Stephen T. Buckland, Jan McP. Dick, David A. Elston, E. Marian Scott, Rognvald I. Smith, Paul J. Somerfield, and Allan D. Watt. 2010. "Long-Term Datasets in Biodiversity Research and Monitoring: Assessing Change in Ecological Communities through Time." Trends in Ecology \& Evolution, Special Issue: Long-term ecological research, 25 (10): 574-82. doi:10.1016/j.tree.2010.06.016.

Maine, Josiah J., and Justin G. Boyles. 2015. "Bats Initiate Vital Agroecological Interactions in Corn." Proceedings of the National Academy of Sciences 112 (40): 12438-43. 
Margono, Belinda Arunarwati, Peter V. Potapov, Svetlana Turubanova, Fred Stolle, and Matthew C. Hansen. 2014. "Primary Forest Cover Loss in Indonesia over 20002012." Nature Climate Change, June. doi:10.1038/nclimate2277.

Margono, Belinda Arunarwati, Svetlana Turubanova, Ilona Zhuravleva, Peter Potapov, Alexandra Tyukavina, Alessandro Baccini, Scott Goetz, and Matthew C Hansen. 2012. "Mapping and Monitoring Deforestation and Forest Degradation in Sumatra (Indonesia) Using Landsat Time Series Data Sets from 1990 to 2010.” Environmental Research Letters 7 (3): 034010. doi:10.1088/1748-9326/7/3/034010.

Marques, Tiago A., Len Thomas, Stephen W. Martin, David K. Mellinger, Jessica A. Ward, David J. Moretti, Danielle Harris, and Peter L. Tyack. 2013. "Estimating Animal Population Density Using Passive Acoustics.” Biological Reviews 88 (2): 287-309. doi:10.1111/brv.12001.

Marsh, Robin. 1998. "Building on Traditional Gardening to Improve Household Food Security." Food Nutrition and Agriculture, 4-14.

Marten, Ken, and Peter Marler. 1977. "Sound Transmission and Its Significance for Animal Vocalization I. Temperate Habitats." Behavioral Ecology and Sociobiology 2 (3): 271-90.

Marten, Ken, Douglas Quine, and Peter Marler. 1977. "Sound Transmission and Its Significance for Animal Vocalization II. Tropical Habitats." Behavioral Ecology and Sociobiology 2 (3): 291-302. doi:10.1007/BF00299741.

Martens, M.J.M., P.P.J. Severens, H.A.W.M. Van Wissen, and L.A.M. Van Der Heijden. 1985. "Acoustic Reflection Characteristics of Deciduous Plant Leaves." Environmental and Experimental Botany 25 (3): 285-92. doi:10.1016/00988472(85)90013-9.

Mazerolle, M. J. 2015. AICcmodavg: Model Selection and Multimodel Inference Based on $(Q) A I C(c)$ (version 2.0-3). R package version 2.0-3. http://CRAN.Rproject.org/package $=$ AICcmodavg.

Melati, Dian, I Nengah Surati Jaya, César Pérez-Cruzado, Paul Magdon, Muhammad Zuhdi, Lutz Fehrmann, and Christoph Kleinn. (in prep.). "Spatio-Temporal Analysis on Land Transformation in a Forested Tropical Landscape in Jambi Province, Sumatra"

Merchant, Nathan D., Kurt M. Fristrup, Mark P. Johnson, Peter L. Tyack, Matthew J. Witt, Philippe Blondel, and Susan E. Parks. 2015. "Measuring Acoustic Habitats." Edited by David Hodgson. Methods in Ecology and Evolution, January, n/a - n/a. doi:10.1111/2041-210X.12330.

Micheli, Fiorenza, and Benjamin S. Halpern. 2005. "Low Functional Redundancy in Coastal Marine Assemblages." Ecology Letters 8 (4): 391-400.

Mielke, Alexander, and Klaus Zuberbühler. 2013. "A Method for Automated Individual, Species and Call Type Recognition in Free-Ranging Animals." Animal Behaviour 86 (2): 475-82. doi:10.1016/j.anbehav.2013.04.017.

Mohri, Hideyuki, Shruti Lahoti, Osamu Saito, Anparasan Mahalingam, Nimal Gunatilleke, Irham, Van Thang Hoang, Gamini Hitinayake, Kazuhiko Takeuchi, and Srikantha Herath. 2013. "Assessment of Ecosystem Services in Homegarden Systems in Indonesia, Sri Lanka, and Vietnam.” Ecosystem Services 5 (September): 124-36. doi:10.1016/j.ecoser.2013.07.006.

Morton, E. S. 1975. "Ecological Sources of Selection on Avian Sounds." Am Nat 109: 17. Mouillot, David, Sébastien Villéger, Michael Scherer-Lorenzen, and Norman WH Mason. 2011. "Functional Structure of Biological Communities Predicts Ecosystem Multifunctionality." PLOS ONE 6 (3): e17476. 
Mumme, Steffen. 2014. "Alteration of Functional Diversity along a Land-Use Intensification Gradient in Sumatra, Indonesia.” MSc Thesis, Göttingen, Germany: Georg-AugustUniversität Göttingen.

Myers, N., R. A Mittermeier, C. G Mittermeier, G. A.B da Fonseca, and J. Kent. 2000. "Biodiversity Hotspots for Conservation Priorities." Nature 403 (6772): 853-58.

Nájera, Andrea, and Javier A. Simonetti. 2010. "Can Oil Palm Plantations Become Bird Friendly?" Agroforestry Systems 80 (2): 203-9.

Newbold, Tim, Lawrence N. Hudson, Samantha LL Hill, Sara Contu, Igor Lysenko, Rebecca A. Senior, Luca Börger, et al. 2015. "Global Effects of Land Use on Local Terrestrial Biodiversity.” Nature 520 (7545): 45-50.

Newbold, Tim, Jörn PW Scharlemann, Stuart HM Butchart, Çağan H. Şekercioğlu, Rob Alkemade, Hollie Booth, and Drew W. Purves. 2013. "Ecological Traits Affect the Response of Tropical Forest Bird Species to Land-Use Intensity." Proceedings of the Royal Society of London B: Biological Sciences 280 (1750): 20122131.

Newson, Stuart E., Hazel E. Evans, and Simon Gillings. 2015. “A Novel Citizen Science Approach for Large-Scale Standardised Monitoring of Bat Activity and Distribution, Evaluated in Eastern England." Biological Conservation 191 (November): 38-49. doi:10.1016/j.biocon.2015.06.009.

Oksanen, Jari, F. Guillaume Blanchet, Roeland Kindt, Pierre Legendre, Peter R. Minchin, R. B. O’Hara, Gavin L. Simpson, Peter Solymos, M. Henry H. Stevens, and Helene Wagner. 2015. Vegan: Community Ecology Package. http://CRAN.Rproject.org/package=vegan.

Oliver, Ian, and Andrew J. Beattie. 1996. "Designing a Cost-Effective Invertebrate Survey: A Test of Methods for Rapid Assessment of Biodiversity.” Ecological Applications 6 (2): 594-607. doi:10.2307/2269394.

Patricelli, Gail L., Marc S. Dantzker, and Jack W. Bradbury. 2007. "Differences in Acoustic Directionality among Vocalizations of the Male Red-Winged Blackbird (Agelaius Pheoniceus) Are Related to Function in Communication." Behavioral Ecology and Sociobiology 61 (7): 1099-1110. doi:10.1007/s00265-006-0343-5.

Patriquin, Krista J., Laureen K. Hogberg, Bryan J. Chruszcz, and Robert MR Barclay. 2003. "The Influence of Habitat Structure on the Ability to Detect Ultrasound Using Bat Detectors." Wildlife Society Bulletin, 475-81.

Pekin, Burak K., Jinha Jung, Luis J. Villanueva-Rivera, Bryan C. Pijanowski, and Jorge A. Ahumada. 2012. "Modeling Acoustic Diversity Using Soundscape Recordings and LIDAR-Derived Metrics of Vertical Forest Structure in a Neotropical Rainforest." Landscape Ecology 27 (10): 1513-22. doi:10.1007/s10980-012-9806-4.

Penna, Mario, and Rigoberto Solís. 1998. "Frog Call Intensities and Sound Propagation in the South American Temperate Forest Region." Behavioral Ecology and Sociobiology 42 (6): 371-81.

Petchey, Owen L., Karl L. Evans, Isla S. Fishburn, and Kevin J. Gaston. 2007. "Low Functional Diversity and No Redundancy in British Avian Assemblages." Journal of Animal Ecology 76 (5): 977-85.

Petchey, Owen L., and Kevin J. Gaston. 2002. "Functional Diversity (FD), Species Richness and Community Composition." Ecology Letters 5 (3): 402-11.

. 2006. "Functional Diversity: Back to Basics and Looking Forward." Ecology Letters 9 (6): 741-58.

Phalan, Ben, Monika Bertzky, Stuart HM Butchart, Paul F. Donald, Jörn PW Scharlemann, Alison J. Stattersfield, Andrew Balmford, and others. 2013. "Crop Expansion and Conservation Priorities in Tropical Countries.” PLoS ONE 8 (1): e51759. 
Phommexay, Phansamai, Chutamas Satasook, Paul Bates, Malcolm Pearch, and Sara Bumrungsri. 2011. "The Impact of Rubber Plantations on the Diversity and Activity of Understorey Insectivorous Bats in Southern Thailand." Biodiversity and Conservation 20 (7): 1441-56. doi:10.1007/s10531-011-0036-x.

Pijanowski, Bryan C., Luis J. Villanueva-Rivera, Sarah L. Dumyahn, Almo Farina, Bernie L. Krause, Brian M. Napoletano, Stuart H. Gage, and Nadia Pieretti. 2011. "Soundscape Ecology: The Science of Sound in the Landscape." BioScience 61 (3): 203-16. doi:10.1525/bio.2011.61.3.6.

Pinheiro, Jose, Douglas Bates, Saikat DebRoy, Deepayan Sarkar, and R Core Team. 2015. Nlme: Linear and Nonlinear Mixed Effects Models (version 3.1-120). R package version 3.1-120. R Package Version 3.1-120. R package version 3.1-120. ttp://CRAN.R-project.org/package=nlme.

Potts, Simon G., Jacobus C. Biesmeijer, Claire Kremen, Peter Neumann, Oliver Schweiger, and William E. Kunin. 2010. "Global Pollinator Declines: Trends, Impacts and Drivers." Trends in Ecology \& Evolution 25 (6): 345-53.

Powell, Luke L., Norbert J. Cordeiro, and Jeffrey A. Stratford. 2015. "Ecology and Conservation of Avian Insectivores of the Rainforest Understory: A Pantropical Perspective." Biological Conservation 188 (August): 1-10. doi:10.1016/j.biocon.2015.03.025.

Rafflegeau, Sylvain, Isabelle Michel-Dounias, Bertrand Tailliez, Benjamin Ndigui, and François Papy. 2010. "Unexpected N and K Nutrition Diagnosis in Oil Palm Smallholdings Using References of High-Yielding Industrial Plantations." Agronomy for Sustainable Development 30 (4): 777-87.

Ralph, C. John, Sam Droege, and John R. ; Sauer. 1995. "Managing and Monitoring Birds Using Point Counts: Standards and Applications." In , 161-68. http://www.treesearch.fs.fed.us/pubs/31755.

Rao, C. Radhakrishna. 1995. "A Review of Canonical Coordinates and an Alternative to Correspondence Analysis Using Hellinger Distance.” Qüestiió 19 (1-2-3): 23-63.

R Core Team. 2015a. R: A Language and Environment for Statistical Computing. Vienna, Austria: R Foundation for Statistical Computing. http://www.R-project.org/. . 2015b. R: A Language and Environment for Statistical Computing. Vienna, Austria: $\mathrm{R}$ Foundation for Statistical Computing.

Rempel, Robert S., Charles M. Francis, Jeffrey N. Robinson, and Margaret Campbell. 2013. "Comparison of Audio Recording System Performance for Detecting and Monitoring Songbirds.” Journal of Field Ornithology 84 (1): 86-97. doi:10.1111/jofo.12008.

R Foundation for Statistical Computing. 2014. R: A Language and Environment for Statistical Computing. Vienna, Austria. http://www.R-project.org/.

Robbins, C. S. 1981. "Bird Activity Levels Related to Weather," 301-10.

Robinson, Herbert Christopher, and Frederick Nutter Chasen. 1927. The Birds of the Malay Peninsula: A General Account of the Birds Inhabiting the Region from the Isthmus of Kra to Singapore with the Adjacent Islands. Vol. 1-4. London, UK: H. F. and G. Witherby. http://lkcnhm.nus.edu.sg/biblio/robinson_chasen/\#voll.

Romer, Heiner, and Jörg Lewald. 1992. "High-Frequency Sound Transmission in Natural Habitats: Implications for the Evolution of Insect Acoustic Communication." Behavioral Ecology and Sociobiology 29 (6): 437-44.

Rowcliffe, J. M., and C. Carbone. 2008. "Surveys Using Camera Traps: Are We Looking to a Brighter Future?" Animal Conservation 11 (3): 185-86. doi:10.1111/j.14691795.2008.00180.x.

Rubiana, Ratna, Akhmad Rizali, Lisa Helen Denmead, Winda Alamsari, Pudjianto Hidayat, Dadan Hindayana, Yann Clough, Teja Tscharntke, and Damayanti Buchori. 2015. 
“Agricultural Land Use Alters Species Composition but Not Species Richness of Ant Communities." Asian Myrmecology 7: 73-85.

Sanborn, A. F., and P. K. Phillips. 1995. "Scaling of Sound Pressure Level and Body Size in Cicadas (Homoptera: Cicadidae; Tibicinidae)." Annals of the Entomological Society of America 88 (4): 479-84. doi:10.1093/aesa/88.4.479.

Sauer, John R., Bruce G. Peterjohn, and William A. Link. 1994. "Observer Differences in the North American Breeding Bird Survey." The Auk 111 (1): 50-62. doi: $10.2307 / 4088504$.

Savilaakso, Sini, Claude Garcia, John Garcia-Ulloa, Jaboury Ghazoul, Martha Groom, Manuel R Guariguata, Yves Laumonier, et al. 2014. "Systematic Review of Effects on Biodiversity from Oil Palm Production." Environmental Evidence 3 (1): 4. doi:10.1186/2047-2382-3-4.

Schroth, G., G.A.B. da Fonseca, C.A. Harvey, C. Gascon, H.L. Vasconcelos, and A.M.N. Izac. 2013. Agroforestry and Biodiversity Conservation in Tropical Landscapes. Island Press. https://books.google.de/books?id=lfmBO4XpfyUC.

Sebastián-González, Esther, Joshua Pang-Ching, Jomar M. Barbosa, and Patrick Hart. 2015. "Bioacoustics for Species Management: Two Case Studies with a Hawaiian Forest Bird." Ecology and Evolution 5 (20): 4696-4705. doi:10.1002/ece3.1743.

Sekercioglu, Cagan H. 2012. "Bird Functional Diversity and Ecosystem Services in Tropical Forests, Agroforests and Agricultural Areas." Journal of Ornithology 153 (S1): 15361. doi:10.1007/s10336-012-0869-4.

Sekercioglu, C. H., G. C Daily, and P. R Ehrlich. 2004. "Ecosystem Consequences of Bird Declines." Proceedings of the National Academy of Sciences 101 (52): 18042-47.

Senior, Michael JM, Keith C. Hamer, Simon Bottrell, David P. Edwards, Tom M. Fayle, Jennifer M. Lucey, Peter J. Mayhew, et al. 2013. "Trait-Dependent Declines of Species Following Conversion of Rain Forest to Oil Palm Plantations." Biodiversity and Conservation 22 (1): 253-68.

Silvertown, Jonathan. 2015. "Have Ecosystem Services Been Oversold?" Trends in Ecology \& Evolution 30 (11): 641-48. doi:10.1016/j.tree.2015.08.007.

Slade, Eleanor M., M. I. Burhanuddin, J. P. Caliman, W. A. Foster, M. Naim, S. Prawirosukarto, J. L. Snaddon, E. C. Turner, and Darren J. Mann. 2014. "Can Cattle Grazing in Mature Oil Palm Increase Biodiversity and Ecosystem Service Provision?" The Planter 90 (1062): 655-65.

Sliwinski, Maggi, Larkin Powell, Nicola Koper, Matthew Giovanni, and Walter Schacht. 2015. "Research Design Considerations to Ensure Detection of All Species in an Avian Community." Methods in Ecology and Evolution, November, n/a - n/a. doi:10.1111/2041-210X.12506.

Snoeck, Didier, Régis Lacote, Jules Kéli, Amadou Doumbia, Thierry Chapuset, Patrick Jagoret, and Éric Gohet. 2013. "Association of Hevea with Other Tree Crops Can Be More Profitable than Hevea Monocrop during First 12 Years." Industrial Crops and Products 43 (May): 578-86. doi:10.1016/j.indcrop.2012.07.053.

Soberón, Jorge, and Townsend Peterson. 2004. "Biodiversity Informatics: Managing and Applying Primary Biodiversity Data." Philosophical Transactions of the Royal Society of London B: Biological Sciences 359 (1444): 689-98. doi:10.1098/rstb.2003.1439.

Sodhi, Navjot S., Lian Pin Koh, Barry W. Brook, and Peter K.L. Ng. 2004. "Southeast Asian Biodiversity: An Impending Disaster." Trends in Ecology \& Evolution 19 (12): 65460. doi:10.1016/j.tree.2004.09.006.

Sodhi, Navjot S., Lian Pin Koh, Reuben Clements, Thomas C. Wanger, Jane K. Hill, Keith C. Hamer, Yann Clough, Teja Tscharntke, Mary Rose C. Posa, and Tien Ming Lee. 
2010. "Conserving Southeast Asian Forest Biodiversity in Human-Modified Landscapes." Biological Conservation 143 (10): 2375-84.

doi:10.1016/j.biocon.2009.12.029.

Sonnier, Grégory, Bill Shipley, and Marie-Laure Navas. 2010. "Quantifying Relationships between Traits and Explicitly Measured Gradients of Stress and Disturbance in Early Successional Plant Communities.” Journal of Vegetation Science 21 (6): 1014-24.

Sousa-Lima, Renata S., Thomas F. Norris, Julie N. Oswald, and Deborah P. Fernandes. 2013. "A Review and Inventory of Fixed Autonomous Recorders for Passive Acoustic Monitoring of Marine Mammals." Aquatic Mammals 39 (1): 23.

Spasojevic, Marko J., and Katharine N. Suding. 2012. "Inferring Community Assembly Mechanisms from Functional Diversity Patterns: The Importance of Multiple Assembly Processes.” Journal of Ecology 100 (3): 652-61.

Stermin, Alexandru Nicolae, Alin David, and Eliana Sevianu. 2013. "An Evaluation of Acoustic Monitoring Methods for a Water Rail (Rallus Aquaticus) Population in a Large Reed Bed." Waterbirds 36 (4): 463-69. doi:10.1675/063.036.0403.

Sueur, J., T. Aubin, and C. Simonis. 2008. "Equipment Review-Seewave, A Free Modular Tool for Sound Analysis and Synthesis." Bioacoustics 18 (2): 213.

Sueur, Jérôme, Almo Farina, Amandine Gasc, Nadia Pieretti, and Sandrine Pavoine. 2014. "Acoustic Indices for Biodiversity Assessment and Landscape Investigation." Acta Acustica United with Acustica 100 (4): 772-81. doi:10.3813/AAA.918757.

Sueur, Jérôme, Sandrine Pavoine, Olivier Hamerlynck, and Stéphanie Duvail. 2008. "Rapid Acoustic Survey for Biodiversity Appraisal." PLoS ONE 3 (12): e4065. doi:10.1371/journal.pone.0004065.

Sutherland, William J., Ian Newton, and Rhys Green. 2004. Bird Ecology and Conservation: A Handbook of Techniques. OUP Oxford.

Swift, M. J., A. -M. N. Izac, and M. van Noordwijk. 2004. "Biodiversity and Ecosystem Services in Agricultural Landscapes—are We Asking the Right Questions?" Agriculture, Ecosystems \& Environment, Environmental Services and Land Use Change: Bridging the Gap between Policy and Research in Southeast Asia, 104 (1): 113-34. doi:10.1016/j.agee.2004.01.013.

Swiston, Kyle A., and Daniel J. Mennill. 2009. "Comparison of Manual and Automated Methods for Identifying Target Sounds in Audio Recordings of Pileated, Pale-Billed, and Putative Ivory-Billed Woodpeckers." Journal of Field Ornithology 80 (1): 42-50. doi:10.1111/j.1557-9263.2009.00204.x.

Terborgh, John. 1986. "Community Aspects of Frugivory in Tropical Forests.” In Frugivores and Seed Dispersal, edited by Alejandro Estrada and TheodoreH. Fleming, 15:37184. Tasks for Vegetation Science. Springer Netherlands. http://dx.doi.org/10.1007/978-94-009-4812-9_32.

Teuscher, Miriam, Miriam Vorlaufer, Meike Wollni, Ulrich Brose, Yeni Mulyani, and Yann Clough. 2015. "Trade-Offs between Bird Diversity and Abundance, Yields and Revenue in Smallholder Oil Palm Plantations in Sumatra, Indonesia." Biological Conservation 186: 306-18.

The IUCN Species Survival Commission. 2004. IUCN Red List of Threatened Species: A Global Species Assessment.

Thiollay, Jean-Marc. 1995a. "The Role of Traditional Agroforests in the Conservation of Rain Forest Bird Diversity in Sumatra." Conservation Biology 9 (2): 335-53. doi:10.1046/j.1523-1739.1995.9020335.x. 1995b. "The Role of Traditional Agroforests in the Conservation of Rain Forest Bird Diversity in Sumatra." Conservation Biology 9 (2): 335-53. doi:10.1046/j.15231739.1995.9020335.x. 
Tilman, David, Johannes Knops, David Wedin, Peter Reich, Mark Ritchie, and Evan Siemann. 1997. "The Influence of Functional Diversity and Composition on Ecosystem Processes.” Science 277 (5330): 1300-1302.

Tscharntke, T., C.H. Sekercioglu, T.V. Dietsch, N.S. Sodhi, P. Hoehn, and J.M. Tylianakis. 2008. "Landscape Constraints on Functional Diversity of Birds and Insects in Tropical Agroecosystems." Ecology 89 (4): 944-51.

Turner, Peter D. 1981. Oil Palm Diseases and Disorders. Kuala Lumpur, Malaysia: Oxford University Press. http://www.cabdirect.org/abstracts/19811378355.html.

USDA. 2007. "Indonesia Palm Oil Production.” December. http://www.pecad.fas.usda.gov/highlights/2007/12/Indonesia_palmoil/.

Vandermeer, John, Ivette Perfecto, Guillermo Ibarra Nuñez, Stacy Phillpott, and Alvaro Garcia Ballinas. 2002. "Ants (Azteca Sp.) as Potential Biological Control Agents in Shade Coffee Production in Chiapas, Mexico." Agroforestry Systems 56 (3): 271-76.

van Nouhuys, Saskya. 2005. "Effects of Habitat Fragmentation at Different Trophic Levels in Insect Communities.” Annales Zoologici Fennici 42: 433-47.

Verheye, Willy. 2010. "Growth and Production of Oil Palm." In Land Use, Land Cover and Soil Sciences. Encyclopedia of Life Support Systems (EOLSS). Oxford, UK: UNESCO-EOLSS Publishers. http://www.eolss.net/Sample-Chapters/C10/E1-05A27-00.pdf.

Villanueva-Rivera, Luis J., and Bryan C. Pijanowski. 2012. "Pumilio: A Web-Based Management System for Ecological Recordings." Bulletin of the Ecological Society of America 93 (1): 71-81.

Villard, Marc-André, M. Kurtis Trzcinski, and Gray Merriam. 1999. "Fragmentation Effects on Forest Birds: Relative Influence of Woodland Cover and Configuration on Landscape Occupancy." Conservation Biology 13 (4): 774-83. doi:10.1046/j.15231739.1999.98059.x.

Villéger, Sébastien, Norman WH Mason, and David Mouillot. 2008. "New Multidimensional Functional Diversity Indices for a Multifaceted Framework in Functional Ecology." Ecology 89 (8): 2290-2301.

Vitousek, Peter M., Harold A. Mooney, Jane Lubchenco, and Jerry M. Melillo. 1997. "Human Domination of Earth's Ecosystems.” Science 277 (5325): 494-99. doi:10.1126/science.277.5325.494.

Vossbrinck, C. R., D. C. Coleman, and T. A. Woolley. 1979. "Abiotic and Biotic Factors in Litter Decomposition in a Sermiarid Grassland.” Ecology 60 (2): 265-71. doi: $10.2307 / 1937654$.

Watson, R. T., and United Nations Environment Programme, eds. 1995. Global Biodiversity Assessment: Summary for Policy-Makers. Cambridge [England] ; New York, NY, USA: Cambridge University Press.

Whelan, Christopher J., Daniel G. Wenny, and Robert J. Marquis. 2008. "Ecosystem Services Provided by Birds." Annals of the New York Academy of Sciences 1134 (1): 25-60. doi:10.1196/annals.1439.003.

Wickham, Hadley. 2009. Ggplot2: Elegant Graphics for Data Analysis. Use R! New York: Springer.

Wielgoss, Arno, Teja Tscharntke, Damayanti Buchori, Brigitte Fiala, and Yann Clough. 2010. "Temperature and a Dominant Dolichoderine Ant Species Affect Ant Diversity in Indonesian Cacao Plantations." Agriculture, Ecosystems \& Environment 135 (4): 253-59.

Wielgoss, Arno, Teja Tscharntke, Alfianus Rumede, Brigitte Fiala, Hannes Seidel, Saleh Shahabuddin, and Yann Clough. 2014. "Interaction Complexity Matters: Disentangling Services and Disservices of Ant Communities Driving Yield in 
Tropical Agroecosystems." Proceedings of the Royal Society of London B: Biological Sciences 281 (1775): 20132144.

Wiggins, Sean M, and John A Hildebrand. 2007. "High-Frequency Acoustic Recording Package (HARP) for Broad-Band, Long-Term Marine Mammal Monitoring." UC San Diego, International Symposium on Underwater Technology 2007 and International Workshop on Scientific Use of Submarine Cables \& Related Technologies 2007, UT07 (January): 551-57.

Wilcove, David S., and Lian Pin Koh. 2010. "Addressing the Threats to Biodiversity from Oil-Palm Agriculture." Biodiversity and Conservation 19 (4): 999-1007. doi:10.1007/s10531-009-9760-x.

Wiley, R. Haven, and Douglas G. Richards. 1978. "Physical Constraints on Acoustic Communication in the Atmosphere: Implications for the Evolution of Animal Vocalizations." Behavioral Ecology and Sociobiology 3 (1): 69-94.

Wilman, Hamish, Jonathan Belmaker, Jennifer Simpson, Carolina de la Rosa, Marcelo M. Rivadeneira, and Walter Jetz. 2014a. "EltonTraits 1.0: Species-Level Foraging Attributes of the World's Birds and Mammals.” Ecology 95 (7): 2027-2027. doi:10.1890/13-1917.1.

2014b. "EltonTraits 1.0: Species-Level Foraging Attributes of the World's Birds and Mammals.” Ecology 95 (7): 2027-2027. doi:10.1890/13-1917.1.

Wimmer, Jason, Michael Towsey, Paul Roe, and Ian Williamson. 2013. "Sampling Environmental Acoustic Recordings to Determine Bird Species Richness." Ecological Applications 23 (6): 1419-28. doi:10.1890/12-2088.1.

Xeno-canto Foundation. 2012. Xeno-Canto: Sharing Bird Sounds from around the World. Xeno-canto Foundation Amsterdam.

Yamamoto, Yoshinori, Naohiro Kubota, Tatso Ogo, and Priyono. 1991. "Changes in the Structure of Homegardens under Different Climatic Conditions in Java Island." Japanese Journal of Tropical Agriculture 35 (2): 104-17.

Zwart, Mieke C., Andrew Baker, Philip J. K. McGowan, and Mark J. Whittingham. 2014. "The Use of Automated Bioacoustic Recorders to Replace Human Wildlife Surveys: An Example Using Nightjars." PLOS ONE 9 (7): e102770. doi:10.1371/journal.pone.0102770. 


\section{Publications}

Publication / Manuscript

Maas, B., Karp, D.S., Bumrungsri, S., Darras, K., Gonthier, D., Huang, J.C.-C., Lindell, C.A., Maine, J.J., Mestre, L., Michel, N.L., Morrison, E.B., Perfecto, I., Philpott, S.M., Şekercioğlu, Ç.H., Silva, R.M., Taylor, P.J., Tscharntke, T., Van Bael, S.A., Whelan, C.J., Williams-Guillén, K., 2015. Bird and bat predation services in tropical forests and agroforestry landscapes. Biol Rev.

doi:10.1111/brv.12211

Clough, Y., Abrahamczyk, S., Adams, M.-O., Anshary, A., Ariyanti, N., Betz, L., Buchori, D., Cicuzza, D., Darras, K., Putra, D.D., Fiala, B., Gradstein, S.R., Kessler, M., Klein, A.-M., Pitopang, R., Sahari, B., Scherber, C., Schulze, C.H., Shahabuddin, Sporn, S., Stenchly, K., Tjitrosoedirdjo, S.S., Wanger, T.C., Weist, M., Wielgoss, A., Tscharntke, T., 2010. Biodiversity patterns and trophic interactions in human-dominated tropical landscapes in Sulawesi (Indonesia): plants, arthropods and vertebrates, in: Tscharntke, T., Leuschner, C., Veldkamp, E., Faust, H., Guhardja, E., Bidin, A. (Eds.), Tropical Rainforests and Agroforests under Global Change. Springer Berlin Heidelberg, Berlin, Heidelberg, pp. 15-71.

*Wanger, T.C., *Darras, K., Bumrungsri, S., Tscharntke, T., Klein, A.-M., 2014. Bat pest control contributes to food security in Thailand. Biological Conservation 171, 220-223.

doi:10.1016/j.biocon.2014.01.030

\begin{tabular}{|l|l} 
Contribution & status \\
Wrote the bat section in & published \\
figures. & \\
Wrote the sub-chapter about & published \\
butterflies, collected data and & \\
performed analysis & \\
Collected, modelled and & published \\
analysed results, co-wrote &
\end{tabular}


Clough, Y., Barkmann, J., Juhrbandt, J., Kessler, M., Wanger, T.C., Anshary, A., Buchori, D.,

Cicuzza, D., Darras, K., Putra, D.D., Erasmi, S., Pitopang, R., Schmidt, C., Schulze, C.H., Seidel, D., Steffan-Dewenter, I., Stenchly, K., Vidal, S., Weist, M., Wielgoss, A.C., Tscharntke, T., 2011. Combining high biodiversity with high yields in tropical agroforests. Proceedings of the National Academy of Sciences. doi:10.1073/pnas.1016799108

*Walesa Edho Prabowo, *Kevin Darras, Yann Clough, Manuel Toledo-Hernandez, Raphael Arlettaz, Teja Tscharntke. Bird Responses to Lowland Rainforest Conversion in Sumatran Smallholder Landscapes, Indonesia.

Clough, Y., Krishna, V.V., Corre, MD., Darras, K., Denmead, L.H., Meijide, A., Moser, S., Musshoff, O., Steinebach, S., Veldkamp, E., Allen, K., Barnes, A.D., Breidenbach, N., Brose, U., Buchori, D., Daniel, R., Finkeldey, R., Harahap, I., Hertel, D.A. Holtkamp, M., Hörandl, E., I Nengah Surati Jaya, Jochum, J., Klarner, B., Knohl, A., Kotowska, M.M., Krashevska, V., Kreft, H., Kurniawan, S., Leuschner, L., Maraun, M., Melati, D.N., Opfermann, N., Pérez-Cruzado, C., Prabowo, W.E., Rembold, K., Rizali, A., Rubiana, R., Schneider, D., Tjitrosoedirdjo, S.S., Tjoa, A., Tscharntke, T., Scheu, S. Land-use choices, profitability, and consequences for biodiversity and ecological functions in Indonesian smallholder landscapes.

Claudia Dislich, Alexander C. Keyel, Jan Salecker, Yael Kisel, Katrin M. Meyer, Mark Auliya, Andrew D. Barnes, Marife D. Corre, Kevin Darras, Heiko Faust, Bastian Hess, Stephan Klasen, Alexander Knohl, Holger Kreft, Ana Meijide, Fuad Nurdiansyah, Fenna Otteng, Guy Pe'erc, Stefanie Steinebach, Suria Tarigan, Merja H. Tölle, Teja Tscharntke, and Kerstin Wiegand.

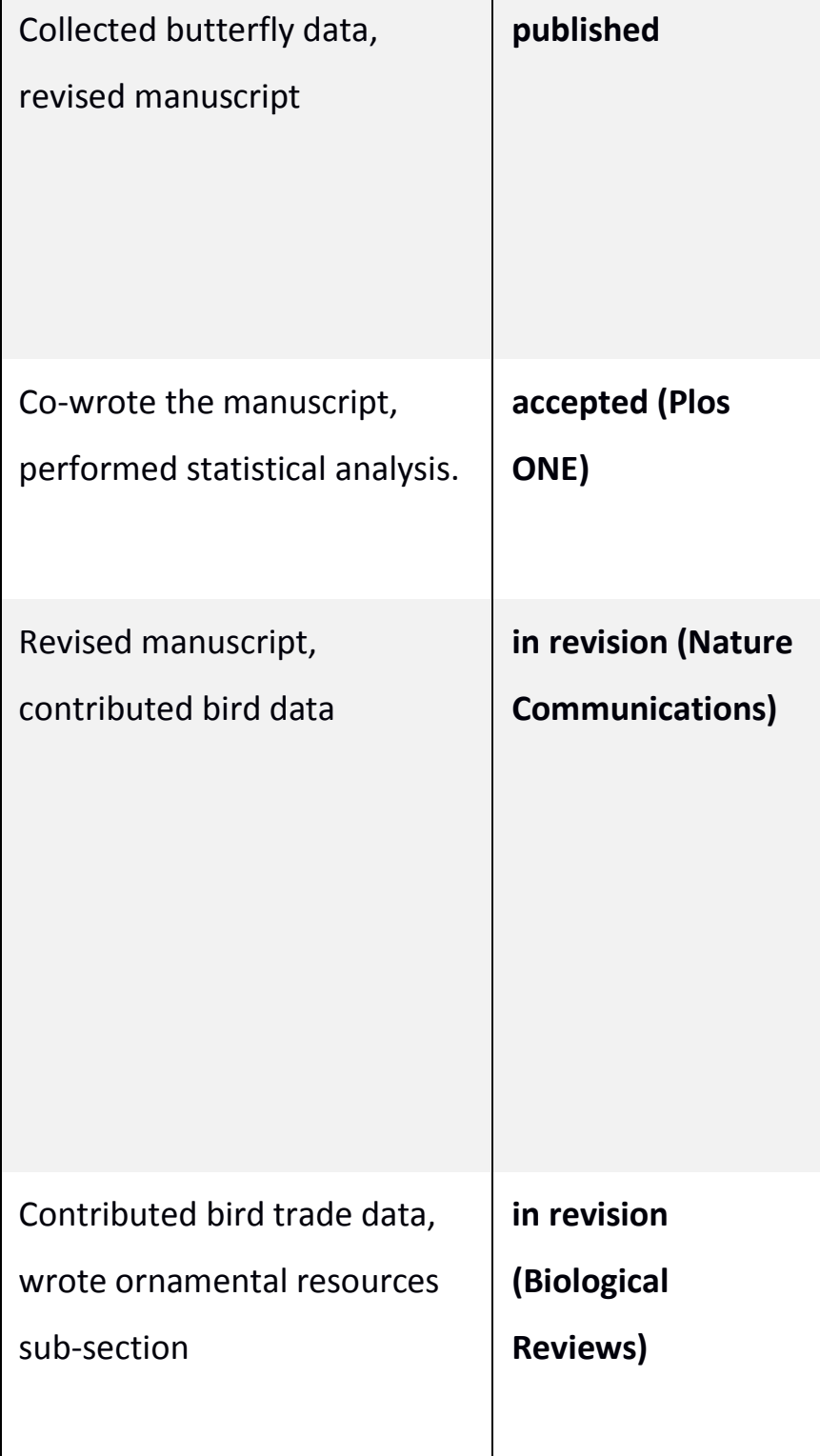




\begin{abstract}
Ecosystem functions of oil palm plantations compared to forests: a review. Biological reviews
Kevin Darras, Peter Pütz, Fahrurrozi, Katja Rembold, Teja Tscharntke. Measuring sound detection spaces for acoustic animal sampling and monitoring.

Lisa H. Denmead, Kevin Darras, Yann Clough, Ingo Grass, Andrew D. Barnes, Ulrich Brose,

Damayanti Buchori, Malte Jochum, Martyna M. Kotowska, Holger Kreft, Christoph Leuschner, Steffen Mumme, Walesa Edho Prabowo, Katja Rembold, Akhmad Rizali, Teja Tscharntke. Singleand multi-trait measures reveal widespread functional diversity loss in human-modified tropical landscapes.
\end{abstract}

*Lisa H. Denmead, *Kevin Darras, Yann Clough, Patrick Diaz, Ingo Grass, Munir P. Hoffmann, Fuad Nurdiansyah,Teja Tscharntke: Major predators do not influence ecosystem functions and yield in oil palm plantations.

Kara E. Allen, Andrew D. Barnes, Marife D. Corre, Yann Clough, Holger Kreft, Malte Jochum, Edzo Veldkamp, Rolf Daniel, Kevin Darras, Lisa H. Denmead, Noor Farikhah Haneda, Dietrich Hertel, Malte Jochum, Alexander Knohl, Martyna M. Kotowska, Syahrul Kurniawan, Ana Meijide, Walesa Edho Prabowo, Katja Rembold, Dominik Schneider, Teja Tscharntke, and Ulrich Brose: Direct and cascading impacts of tropical land-use intensification

\begin{tabular}{|c|c|}
\hline $\begin{array}{l}\text { Wrote the manuscript, } \\
\text { collected and analysed data }\end{array}$ & $\begin{array}{l}\text { in revision (Biol. } \\
\text { Conservation) }\end{array}$ \\
\hline $\begin{array}{l}\text { Collected bird data, co- } \\
\text { analysed data }\end{array}$ & $\begin{array}{l}\text { in review } \\
\text { (Ecosphere) }\end{array}$ \\
\hline $\begin{array}{l}\text { Collected data, designed } \\
\text { experiment, performed } \\
\text { statistics, co-wrote the } \\
\text { manuscript }\end{array}$ & in review (Ecology) \\
\hline $\begin{array}{l}\text { Contributed bird data and } \\
\text { manuscript revision }\end{array}$ & to be re-submitted \\
\hline $\begin{array}{l}\text { Wrote manuscript, collected } \\
\text { meta-analysis data, designed }\end{array}$ & in preparation \\
\hline
\end{tabular}




\section{outperforms direct human observation in bird surveys: Synthesis and new evidence.}

Kevin Darras, Vijesh Krishna, Berton Harris, Peter Pütz, Dewi Prawiradilaga, Teja Tscharntke: Testing the Anthropogenic Allee Effect in the Indonesian bird trade

Kevin Darras, Arite Hildebrandt, Fransisca Noni, Yeni Mulyani, Ingo Grass, Teja Tscharntke: Functional responses and trophic networks of birds in rainforest transformation systems of Jambi, Indonesia

Kevin Darras, Dedi Rahman, Waluyo Sugito, Wich'yanan Limparungpatthanakij: Bird communities of shrub bush, secondary and primary swamp forest of Berbak National Park, Indonesia

Kevin Darras, Irfan Fitriawan, Edho Walesa Prabowo, Christoph Kubitza, Yeni Mulyani, Yann Clough, Teja Tscharntke: Landscape and socio-economic drivers of bird diversity in rainforest transformation systems of Jambi, Indonesia

Kevin Darras, Iwan, Low Bing Wen, Noemi Perez, Teja Tscharntke: SoundEFForTS: Internet Audio Platform for Soundscape Biodiversity Identification study, analysed all data

Wrote the draft, performed

statistical analysis and data

collection

Wrote the draft, performed

statistical analysis and data

collection

Wrote the draft, performed

statistical analysis and data

collection

Wrote the draft, performed statistical analysis and data

collection

wrote the draft, performed

statistical analysis in preparation

in preparation

in preparation

in preparation

in preparation

\footnotetext{
*: these authors contributed equally to this work.
} 


\section{Curriculum Vitae}

\section{General Information}

\begin{tabular}{l|l}
\hline Name & Kevin DARRAS \\
Address & Albrecht Thaer Weg 22C-01, 37075 Göttingen, Germany \\
Contact & $(+49) 1757157517, \underline{\text { kdarras@gwdg.de }}$ \\
Birth & December 21, 1986, Ambilly, France \\
\hline
\end{tabular}

\section{Diplomas}

\begin{tabular}{l|l}
\hline 2011 & Diplôme de l’Ecole Normale Supérieure de Paris, France
\end{tabular}

$2010 \quad$ Master degree in Ecology, Biodiversity and Evolution, Université Pierre et Marie Curie, Paris, France

2007 Bachelor in Biology, Swiss Federal Institute of Technology Zurich, Switzerland

\section{Professional Experience}

\begin{tabular}{|c|c|}
\hline 2016-present & PostDoc researcher in Agroecology, Georg-August University of Göttingen, Germany \\
\hline $2012-2015$ & PhD student in Agroecology, Georg-August University of Göttingen, Germany, 4 years \\
\hline 2011 & Sales employee at Jardiland (pet and plant shop), director Franck Berzinger, 6 months \\
\hline $2010-2011$ & Research assistant for Mammals and EcoSystem Services (MESS) project, Georg- \\
\hline & August University of Göttingen, Germany, 5 months \\
\hline 2009 & $\begin{array}{l}\text { Teaching and management at Easy English School, Palu, Sulawesi, Indonesia, director } \\
\text { Jimmy Antolis, } 6 \text { months }\end{array}$ \\
\hline
\end{tabular}




\section{Languages}

\begin{tabular}{l|l}
\hline Native & French, German \\
Fluent & English and Indonesian \\
Basic & Spanish, Italian and Russian \\
\hline
\end{tabular}

\section{Computer Skills}

\begin{tabular}{l|l}
\hline Office & Microsoft Office: Word, Excel, Access, Powerpoint, Publisher \\
Scientific & Scientific software: R, ArcGIS ESRI, Quantum GIS \\
Other & miscellaneous graphic software, basic HTML publishing, macro programming \\
\hline
\end{tabular}

\section{Miscellaneous}

\begin{tabular}{l|l}
\hline Licenses & $\begin{array}{l}\text { International car driving license, Indonesian motorbike driving license, first aid } \\
\text { certificate }\end{array}$ \\
Website & http://kevindarras.weebly.com \\
\hline
\end{tabular}

References available upon request

Last updated: January 11, 2016 


\section{Acknowledgements}

Many people are to thank for supporting me and my work. My warmest thanks go to my wife and two (no, wait, it's three now!) children who endured living with a PhD student for 4 years. Of course, I would also like to thank Teja enormously for the unwavering support and advice he has given me all these years, and I certainly intend to continue making good use of it. Patrick and all other field assistants and staff in Indonesia, also have a special place here, as good friends and people with whom work also became fun. Lisa in particular, but also all friends and colleagues from the CRC 990, made these four years enjoyable, thank you for the constant update stream, I did not need to sign up for an RSS feed.

My supervisors, mentors, colleagues and co-authors obviously also need a place here, but since they are already named in the manuscript author list, I will refrain from writing names in a particular, unfair order. Last but not least, let us mention the DFG for its generous provision of ample financial resources, and the German taxpayer, for unconsciously allowing making use of their money in this exciting research. 